\title{
WestVirginiaUniversity
}

THE RESEARCH REPOSITORY @ WVU

Graduate Theses, Dissertations, and Problem Reports

2003

\section{Mesomechanics of fabric reinforced composites}

Thomas Miles Damiani

West Virginia University

Follow this and additional works at: https://researchrepository.wvu.edu/etd

\section{Recommended Citation}

Damiani, Thomas Miles, "Mesomechanics of fabric reinforced composites" (2003). Graduate Theses, Dissertations, and Problem Reports. 2491.

https://researchrepository.wvu.edu/etd/2491

This Dissertation is protected by copyright and/or related rights. It has been brought to you by the The Research Repository @ WVU with permission from the rights-holder(s). You are free to use this Dissertation in any way that is permitted by the copyright and related rights legislation that applies to your use. For other uses you must obtain permission from the rights-holder(s) directly, unless additional rights are indicated by a Creative Commons license in the record and/ or on the work itself. This Dissertation has been accepted for inclusion in WVU Graduate Theses, Dissertations, and Problem Reports collection by an authorized administrator of The Research Repository @ WVU.

For more information, please contact researchrepository@mail.wvu.edu. 


\title{
Mesomechanics of Fabric Reinforced Composites
}

\author{
Thomas Miles Damiani
}

Dissertation submitted to the College of Engineering and Mineral

Resources at West Virginia University, in partial fulfillment of the requirements for the degree of

\author{
Doctor of Philosophy \\ in \\ Engineering
}

\author{
Ever J. Barbero, Ph. D., Chair \\ Jacky Prucz, Ph. D. \\ Julio Davalos, Ph. D. \\ Ian Christie, Ph. D. \\ Charles Stanley, Ph. D.
}

Department of Mechanical and Aerospace Engineering

Morgantown, WV

2003

Keywords: Homogenization, Periodic Microstructure, Fourier Expansion

Copyright 2003 Thomas M. Damiani 


\section{ABSTRACT}

\section{Mesomechanics of Fabric Reinforced Composites}

\section{Thomas Miles Damiani}

Fiber reinforced plastic composites are an attractive alternative to traditional materials because of, among other things, the ability to concurrently design the materials and ratios to fit a specific need. One method of fiber reinforcement is through the used of woven fabrics, which provide more balanced overall strengths and durability during fabrication. The weaving and interlacing of the fibers, however, adds a level of complexity when predicting material properties and strengths using micromechanical models. Traditional models have mostly been based on classical thin lamination theory, and this method is limited in its scope and applicability for woven fabric composites. This research sought to develop a novel procedure for predicting the overall material properties (a complete set) and internal stresses for a plain weave fabric composite. The new model is based on periodic microstructure, taking advantage of the sinusoidal weaving nature of the plain weave geometry. The new application of periodic microstructure combines the power and comprehensiveness of the finite element method with the ease of use and speed of a micromechanical model based in classical lamination theory. All of the relevant equations and relationships pertaining to the application of periodic microstructure to a plain weave fabric composite were developed. The analytical weave geometry of Ito and Chou and the experimentally determined geometry developed by the Construction Engineering Research Laboratory (Army Corps of Engineers), along with the derived equations, were inputs into a Mathcad program that calculates the effective stiffness matrix of the representative volume element (RVE) as well as the point wise stresses at any location within the RVE volume. Results were compared with existing experimental and finite element data, with excellent correlation in both cases. 


\section{DEDICATION}

I would like to dedicate this dissertation to my family. To my wife Candice, we finally did it! It has been a long road for us, but we have reached the goals that we set for ourselves more than five years ago. Through all of the trials and tribulations of this experience, I am so thankful that we were able to bear each other's burdens, frustrations, and fears together. God has truly blessed us. Thank you for your unconditional support, and for allowing me to continue with my passion for track and field. I love you more and more everyday. To my daughter Alexis, I'm so proud of you. You are growing up so fast! I'll never forget the times when you would wake up in the middle of the night crying while I was still awake doing my homework. Now you're a first grader who can read, spell, do math (sometimes better than me!), and beat me in Bible quizzing. You have been a wonderous blessing to mommy and me, and I thank God for giving you to us. Thank you for being patient with my while I had to get my work done. There were many times when you wanted me to play with you, but I couldn't. You were so understanding, and that made it just a little bit easier for me. I love you millions. To my Mom and Dad, I'm finally getting out of school! I know there were many times that you wondered if I would ever finish, but I finally did. I would not be in this position today were it not for your sacrifices and support. You were always there, behind me in all of my endeavors, even when you didn't understand or agree. As a parent, I now understand what it means to live through your children. I know that you are proud of me, and this accomplishment is just as much a reflection of your character and sacrifice as it is of my academic success. I love you both very much. To the rest of my family, my brother Adam and sister Lisa, my grandparents Modest and Virginia, my aunts, uncles and cousins, you have all been a blessing to me in your own individual way. You were always there to help me in any way that you could, whether it was helping me fix my car, move into a new home, or just giving me an encouraging word. I will always be grateful.

I would like especially thank the parishioners of Pierpont Church of the Nazarene. You have been the backbone that has supported and nurtured me through my spiritual infancy, both with continued prayers and discipleship. There were many times that I would bring requests and burdens to the senior high small group at LIFE, or a men's prayer breakfast, or to church elders prior to an important step in my academic career. In every instance, I could feel the peace and rest found only through faith in Christ Jesus descending upon me before, during, and after the event. I thank God for the church, and hope that I can provide the comfort and insights that were provided to me. Finally, I have to give praise and glory to God through Jesus Christ. It is only by the grace of God, and the benevolence of his giving that I am able to complete this task. My hope and prayer is that through our career and family decisions, I will be able to lead my family in the task of using all of our talents and abilities to accomplish God's will for our lives. 


\section{Acknowledgements}

I would like to thank my advisor and mentor, Dr. Ever J. Barbero, for all of his guidance and expertise throughout my graduate career. His dedication to academic excellence, both through research and in the classroom, has been a shining example of what means to attain the rank of professor at a research university. Your commitment to my success and your willingness to mentor me in all aspects of faculty life has inspired and motivated me to pursue a career in academics. I will always be grateful to you for giving me opportunities outside of the normal coursework and research, such as grant writing, course instruction, and presentations at technical conferences so that I could have a more complete understanding of what it means to be a university professor. I would also like to thank the other members of my doctoral committee, Drs. Charles Stanley, Ian Christie, Julio Davalos, and Jacky Prucz. Your guidance and wisdom from your respective areas of expertise have helped me to see my work from different perspectives.

It has been a goal of mine since my freshman year at West Virginia Wesleyan College to obtain a Ph.D. This dissertation and subsequent oral defense represent the completion of nine years of undergraduate and graduate education. I would like to thank all of the teachers, professors, and coaches that have inspired me throughout my tenure as a student and athlete. These accomplishments were possible because you were able to get more out of me than I thought I could give. That is the mark of a great teacher. 


\section{Table of Contents}

Chapter 1 Introduction and Objectives .......................................................... 1

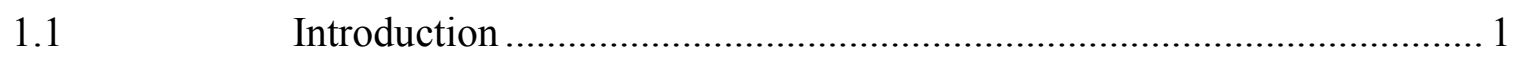

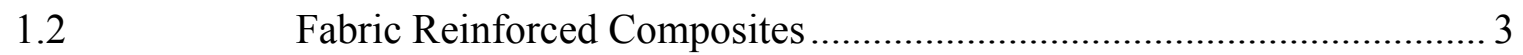

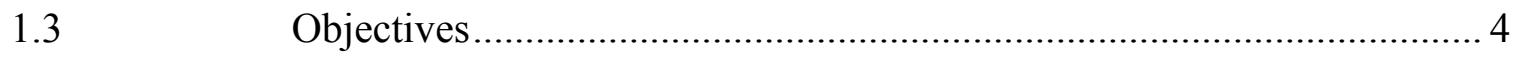

Chapter 2 Review of Literature ......................................................................... 6

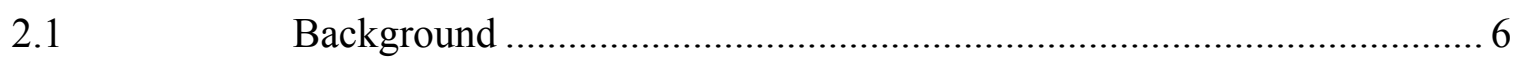

2.2 Classical Lamination Theory …………......................................... 7

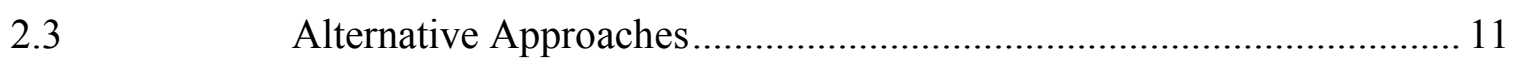

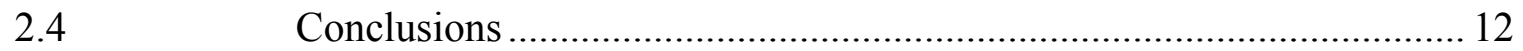

Chapter $3 \quad$ Periodic Microstructure.................................................................. 13

Eigenstress and Eigenstrain........................................................ 14

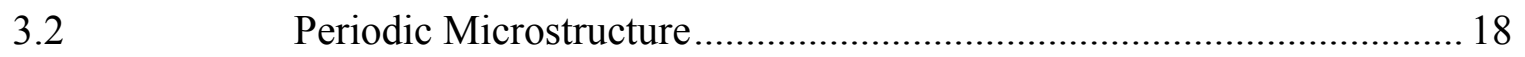

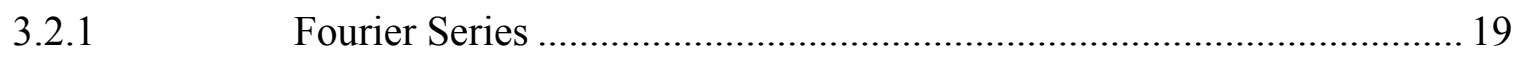

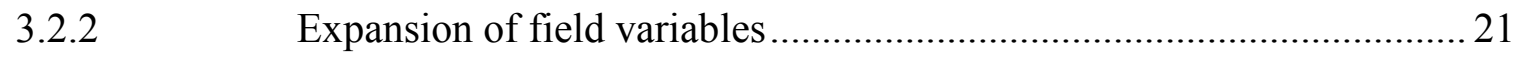

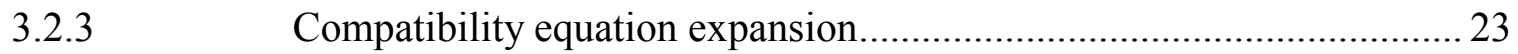

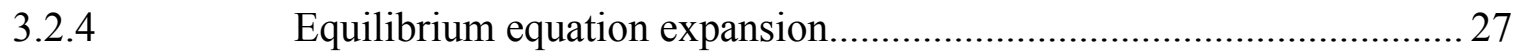

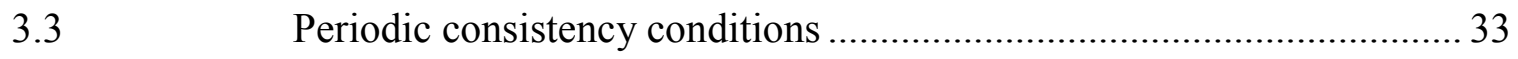

3.4 Average eigenstrain approximation ……........................................... 35

Chapter $4 \quad$ Average Eigenstrain Approximation.................................................... 46

4.1 Geometric characterization procedures ................................................ 47

4.1.1 Ito and Chou geometry ................................................................... 49

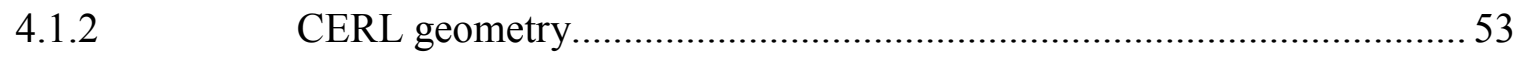

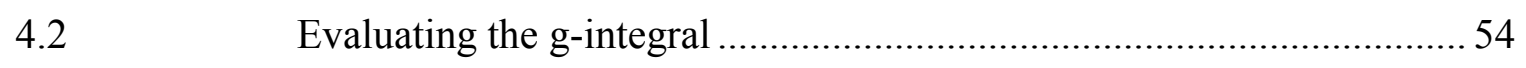

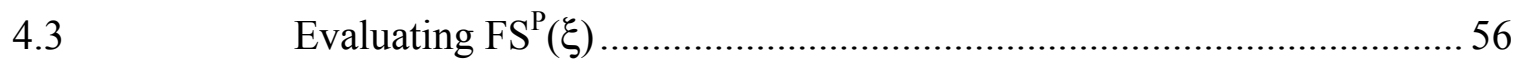

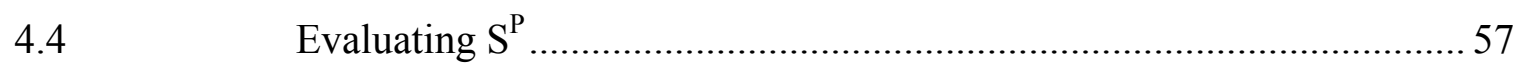

$4.5 \quad$ Determination of material and global tow properties............................5 59

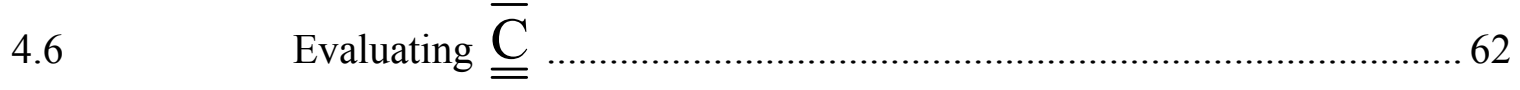

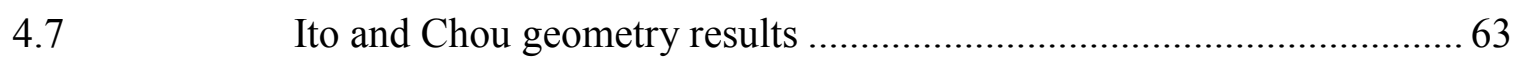

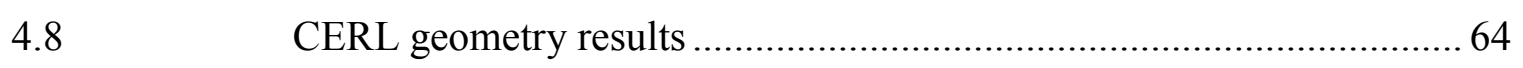




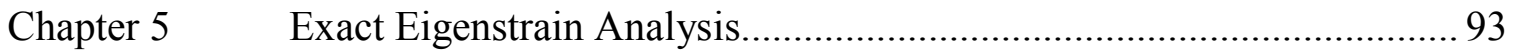

5.1 Evaluation procedures for point-wise RVE stresses ............................. 93

5.1.1 Solution of the Linear System of Equation (3.57) ………................... 93

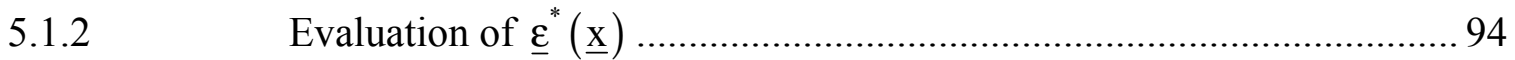

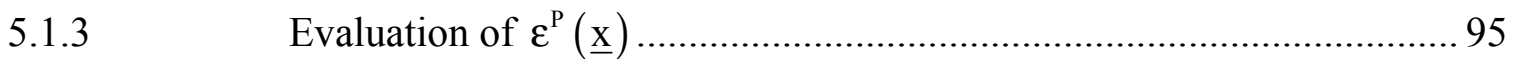

5.2 Selection of the consistency conditions for stress

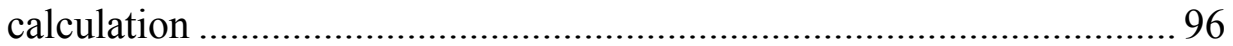

5.3 Comparison of Ito and Chou geometry with Finite

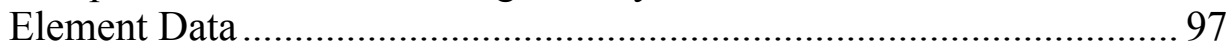

Chapter $6 \quad$ Summary and Conclusions............................................................. 99

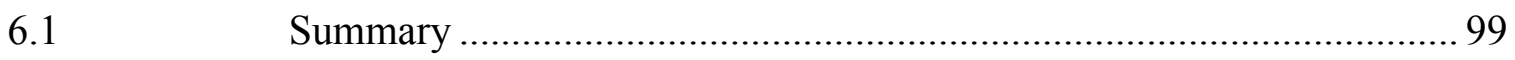

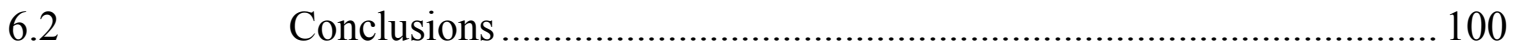

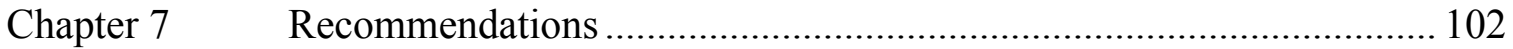

Appendix A Matrix Representation of $4^{\text {th }}$ Order Symmetric Tensors and Coordinate Transformations......................................................... 107

Appendix B Computation of the Effective Material Properties of a

Plain Weave Woven Fabric Composite ................................................ 112

Appendix C Computation of Point-wise Stresses in the RVE of a

Plain Weave Fabric Composite 133 


\section{List of Tables}

Table 3.1: $\quad$ Listing of the Fourier expansions and coefficients for some pertinent field variables........................................................................... 41

Table 4.1: $\quad 0$ degree face parameters for the CERL geometry..................................82

Table 4.2: Averaged values of the 90 degree face parameters for the CERL geometry.

Table 4.3: Micro-scale properties of the fiber matrix tow system for the geometry of Ito and Chou.

Table 4.4: Meso-scale averaged properties over the undulations for the fiber/matrix tow system for the geometry of Ito and Chou.

Table 4.5: Effective material property comparison for the AS4/vinyl ester composite from [13].

Table 4.6: Micro-scale properties of the fiber matrix tow system for the geometry of Ito and Chou and the material properties of Scida et al. [17]

Table 4.7: Meso-scale properties over the undulations for the fiber/matrix tow system for the geometry of Ito and Chou and material properties of Scida et al. [17].

Table 4.8: Comparison of periodic microstructure vs. the experimental results from Scida et al. [17] for an E glass/vinyl ester plain weave fabric composite.

Table 4.9: Micro-scale properties of the fiber matrix tow system for the CERL geometry and the material properties of [25].

Table 4.10: Meso-scale properties over the undulations for the fiber/matrix tow system for the geometry of CERL and material properties of [25]

Table 4.11: Comparison of periodic microstructure vs. the experimental results from Kollegal and Sridharan [25] for an E glass/epoxy plain weave fabric composite.

Table 5.1: Comparison of point wise stress calculations with finite element analysis of the geometry of Ito and Chou. 


\section{List of Figures}

Figure 1.1: Schematics of some woven fabric geometries ...................................... 3

Figure 2.1: Mosaic model [11] idealization of a plain woven fabric

RVE

Figure 2.2: Idealization of the fiber undulation model [11] (top) with

the discretization of the cross section (bottom) ……………...................... 8

Figure 3.1: Illustration of the homogenization of an RVE using eigenstrains

Figure 3.2: Cross section of a plain weave fabric, illustrating an example of geometric periodicity with the sinusoidal shape of the warp tows.

Figure 3.3: An example of periodic spacing in a material cross-section or RVE.

Figure 3.4: An illustration showing that if the material is periodic at an interval $\mathrm{d}$, the material properties are equivalent at a spacing that are multiples of $\mathrm{d}$.

Figure 4.1: Illustration of the plain weave fabric representative volume element.

Figure 4.2: Two dimensional plot of the 0 degree front and rear faces of a plain weave fabric RVE. 66

Figure 4.3: Two dimensional plot of the 90 degree front and rear faces of a plain weave fabric RVE.

Figure 4.4: Plot of the 0 degree front face of the RVE of Ito and Chou [13]

Figure 4.5: Plot of the 0 degree rear face of the RVE of Ito and Chou [13].

Figure 4.6: 90 degree front face of the RVE of Ito and Chou [13]............................ 70

Figure 4.7: Plot of the 90 degree rear face for the RVE of Ito and Chou [13]

Figure 4.8: Plot of the top fill boundary that exists for the front and rear faces of the 0 degree direction in [13].

Figure 4.9: $\quad$ Plot of the surface function generated by Equation (4.10) for the upper portion of the top fill yarn in [13]....................................... 73

Figure 4.10: 0 degree front face for the fabric geometry of CERL............................. 74 
Figure 4.11: 0 degree rear face for the fabric geometry of CERL............................. 75

Figure 4.12: 90 degree front face of the fabric geometry of CERL.............................. 76

Figure 4.13: 90 degree rear face of the fabric geometry of CERL ….......................... 77

Figure 4.14: 0 degree front face for the CERL geometry ....................................... 78

Figure 4.15: 0 degree rear face for the CERL geometry ............................................. 79

Figure 4.16: 90 degree front face for the CERL geometry ........................................ 80

Figure 4.17: 90 degree rear face for the CERL geometry. ......................................... 81 


\section{List of Symbols and Nomenclature}

$\mathrm{M}$

$\Omega$

$\underline{\sigma}(\underline{\mathrm{x}})$

$\underline{\varepsilon}^{0}$

$\underline{\varepsilon}^{\mathrm{d}}(\underline{\mathrm{x}})$

$\underline{\underline{\mathrm{C}}}$

$\underline{\underline{C}}^{\Omega}(\underline{x})$

$\underline{\varepsilon}^{*}(\underline{\mathrm{x}})$

$\underline{\sigma}^{*}(\underline{x})$

$\underline{\underline{\mathrm{S}}}\left(\underline{\mathrm{x}} ; \underline{\varepsilon}^{*}\right)$

$\underline{\underline{T}}\left(\underline{\mathrm{x}} ; \underline{\varepsilon}^{*}\right)$

$\underline{\xi}$

$\mathrm{a}_{\mathrm{i}}$

$\mathrm{U}$

$\underline{\mathrm{u}}(\underline{\mathrm{x}})$

$\mathrm{F} \underline{\mathrm{u}}(\underline{\xi})$

$\underline{\varepsilon}(\underline{\mathrm{x}})$

$\mathrm{F} \underline{\varepsilon}(\underline{\xi})$

$\mathrm{Fe}^{*}(\underline{\xi})$

$\sqcup$

$\otimes$

$\underline{\nabla}$

$=$

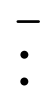

sym

$\underline{\varepsilon}^{\mathrm{P}}(\underline{\mathrm{x}})$
Designation of the matrix region

Inclusion region

Stress induced by an applied strain as a function of position

Externally applied strain

Disturbance strain induced due to the presence of the inclusion

Stiffness of the isotropic matrix expressed in matrix notation $(6 \times 6$ matrix)

Stiffness of a given inclusion as a function of position

Eigenstrain term used to homogenize the matrix to the inclusion

Eigenstress term used for homogenization

Integral operator that relates $\underline{\varepsilon}^{\mathrm{d}}(\underline{\mathrm{x}})$ to $\underline{\varepsilon}^{*}(\underline{\mathrm{x}})$

Integral operator that relates $\underline{\sigma}^{\mathrm{d}}(\underline{\mathrm{x}})$ to $\underline{\sigma}^{*}(\underline{\mathrm{x}})$

Index term for the three dimensional Fourier series expansion

$1 / 2$ of the length of a given RVE dimension $\left(2 a_{1} \times 2 a_{2} \times 2 a_{3}\right)$

Volume of the RVE

Displacement as a function of position

Fourier coefficient of the displacement

Strain as a function of position

Fourier coefficient of the strain

Fourier coefficient of the eigenstrain

Inner product of two $2^{\text {nd }}$ order tensors

Outer product of two $2^{\text {nd }}$ order tensors

del operator

Matrix notation for a $4^{\text {th }}$ order tensor that has been double contracted

Column vector notation for a $2^{\text {nd }}$ order tensor

Double dot product of two dyads

The symmetric part of a given term

Periodic disturbance strain 


\begin{tabular}{|c|c|}
\hline $\mathrm{F} \underline{\varepsilon}^{\mathrm{P}}(\underline{\mathrm{x}})$ & Fourier coefficient of the periodic disturbance strain \\
\hline$\underline{\underline{S}}^{\mathrm{P}}(\underline{\mathrm{x}})$ & Periodic integral operator as a function of position \\
\hline $\mathrm{FS}^{\mathrm{P}}(\underline{\xi})$ & Fourier coefficient of the periodic integral operator \\
\hline$\underline{\underline{D}}$ & Compliance of the matrix region \\
\hline$\underline{\underline{D}}^{\Omega}(\underline{\mathrm{x}})$ & Compliance of the inclusion region \\
\hline $\mathrm{FC}^{\Omega}(\underline{\xi})$ & Fourier coefficient of the inclusion stiffness \\
\hline $\mathrm{f}$ & Volume fraction of the inclusion to the RVE \\
\hline $\mathrm{g}(\underline{\xi})$ & $\mathrm{g}$ integral as a function of $\underline{\xi}$ \\
\hline$\underline{\underline{\underline{C}}}$ & Effective stiffness in matrix notation \\
\hline$\underline{I}^{(4 \mathrm{~s})}$ & $4^{\text {th }}$ order symmetric identity tensor \\
\hline $\mathrm{F}_{\mathrm{tfu} 0}(\mathrm{x}, \mathrm{y})$ & $\begin{array}{l}\text { Surface function designation for the top boundary of the top fill } \\
\text { tow that starts from the } 0 \text { degree front face, also designated tow } 1\end{array}$ \\
\hline $\mathrm{F}_{\mathrm{tf10}}(\mathrm{x}, \mathrm{y})$ & $\begin{array}{l}\text { Surface function designation for the bottom boundary of the top fill } \\
\text { tow that starts from the } 0 \text { degree front face }\end{array}$ \\
\hline $\mathrm{V}_{\mathrm{tf} 0}$ & Volume of the top fill tow that starts from the 0 degree front face \\
\hline$\delta_{\mathrm{il}}$ & Dirac delta function used to calculate $\mathrm{FS}^{\mathrm{P}}(\underline{\xi})$ \\
\hline$\underline{\bar{\xi}}$ & Unit vector of $\underline{\xi}$ \\
\hline [a] & matrix representation of the direction cosines \\
\hline$[\mathrm{T}]$ & Transformation matrix \\
\hline$\underline{\underline{\mathrm{W}}}$ & $\begin{array}{l}\text { Reuter matrix used for evaluating the double dot product of a } 4^{\text {th }} \\
\text { and } 2^{\text {nd }} \text { order tensor written in matrix notation }\end{array}$ \\
\hline $\mathrm{E}_{\mathrm{f}}$ & Longitudinal modulus of the constituent fibers \\
\hline $\mathrm{E}_{\mathrm{m}}$ & Longitudinal modulus of the matrix \\
\hline $\mathrm{E}_{\mathrm{x}}$ & Longitudinal modulus of a given fiber tow \\
\hline $\mathrm{E}_{\mathrm{y}}$ & Transverse modulus of a fiber tow \\
\hline $\mathrm{G}_{\mathrm{xy}}$ & In plane shear modulus of the fiber tow \\
\hline$v_{\mathrm{xy}}$ & In plane Poisson's ratio of the fiber tow \\
\hline $\mathrm{E}_{1}$ & $\mathrm{x}$ direction modulus of the effective RVE \\
\hline $\mathrm{E}_{2}$ & $y$ direction modulus of the effective RVE \\
\hline $\mathrm{E}_{3}$ & $z$ direction modulus of the effective RVE \\
\hline $\mathrm{G}_{23}$ & yz plane shear modulus of the effective RVE \\
\hline $\mathrm{G}_{13}$ & xz plane shear modulus of the effective RVE \\
\hline $\mathrm{G}_{12}$ & xy plane shear modulus of the effective RVE \\
\hline$v_{23}$ & yz plane Poisson's ratio of the effective RVE \\
\hline
\end{tabular}


$v_{13}$

$v_{12}$

xz plane Poisson's ratio of the effective RVE

xy plane Poisson's ratio of the effective RVE 


\section{Chapter 1}

\section{Introduction and Objectives}

\subsection{Introduction}

Composite materials, specifically fiber reinforced plastic (FRP) composites, are being researched and marketed as an alternative to traditional load-carrying materials (steel, aluminum, etc.) because of their enhanced properties, some of which are an increased strength to weight ratio, corrosion resistance, and the ability to concurrently design both the constituent materials and orientations necessary to meet the specifications required for a given structural member. However, these advantageous properties are offset, in some instances dramatically offset, by the uncertainty that comes with the implementing an FRP member. There is a sense of security that is associated with the use of traditional materials because their properties are well known and their effectiveness has been proven over time. Materials such as steel and aluminum have been extensively tested and their properties and characteristics have been well documented over the last century. Compared with the variety and property variations in traditional materials, FRP composites have an infinite number of combinations of types, ratios, and orientations of the FRP constituents. This leads to a unique set of material properties for each specific FRP configuration. Because of this, a comprehensive testing program that encompasses all possible configurations is not possible. 
There are many different material characteristics pertaining to FRP composites that are in doubt. Steel and aluminum, for example, are isotropic materials. Only two material parameters (E, G, or $v$ ) are required to fully describe the properties of an isotropic material, and those properties are independent of the orientation of the loading. Taking the fiber and matrix constituent materials (of which their properties are also well known) and processing them forms a single heterogeneous material. It is significantly more complicated to determine the "effective" material properties of the composite based on the known material properties of the constituents. A simple unidirectional composite is generally orthotropic in nature, meaning that instead of only two parameters describing the material, there are now nine. This ability to predict the properties of the composite material based on the properties of the constituents is an area of great interest to both the research community and design engineers alike.

One method for property prediction is through micromechanical modeling. This method establishes the overall material properties of the FRP composite as a function of the properties and ratios of the constituent materials (fiber and matrix) as well as the geometry of the system. For a unidirectional composite, the overall properties of the FRP can be accurately determined through micromechanics because the geometry is simple. This method becomes complex when the constituent properties and/or geometry are more complex. Another tool for property prediction is through finite element modeling. By taking the material and geometrically discretizing it into many smaller sections, the properties of the material can be ascertained through simple micromechanical procedures. This method is very powerful, but it can also be very complex and computationally expensive to implement. 


\subsection{Fabric Reinforced Composites}

A fabric reinforced composite material can be made by taking constituent fiber tows and weaving them together into a desired pattern, which results in a fabric of interlacing fiber tows. The fabric is then infused with a resin to form a fabric reinforced composite material. There are a variety of commercially available fabric materials and weave patterns. Some of the most common fabric weaving patterns are the plain weave, twill weave, and satin weave, as seen in Figure 1.1.

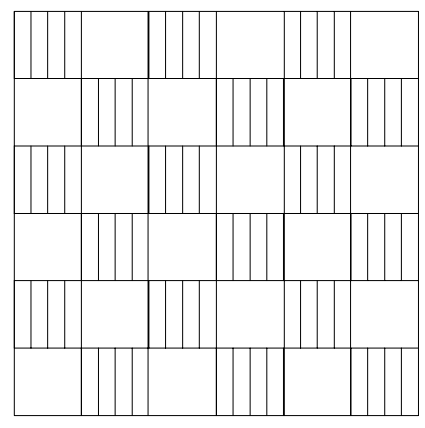

Plain Weave

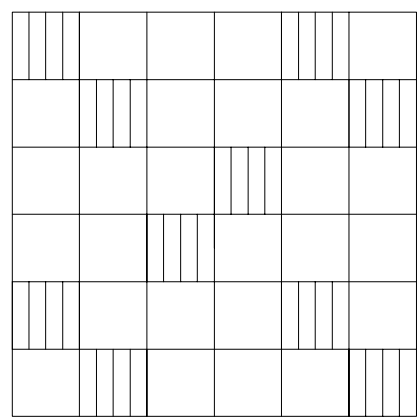

4 Harness Satin Weave

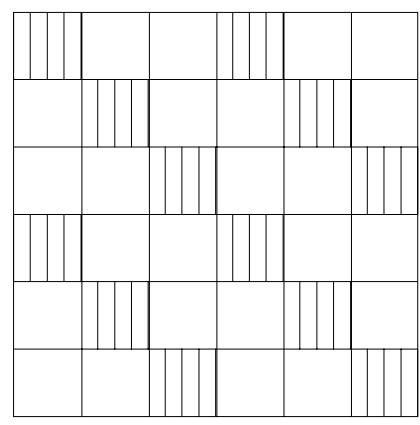

Twill Weave

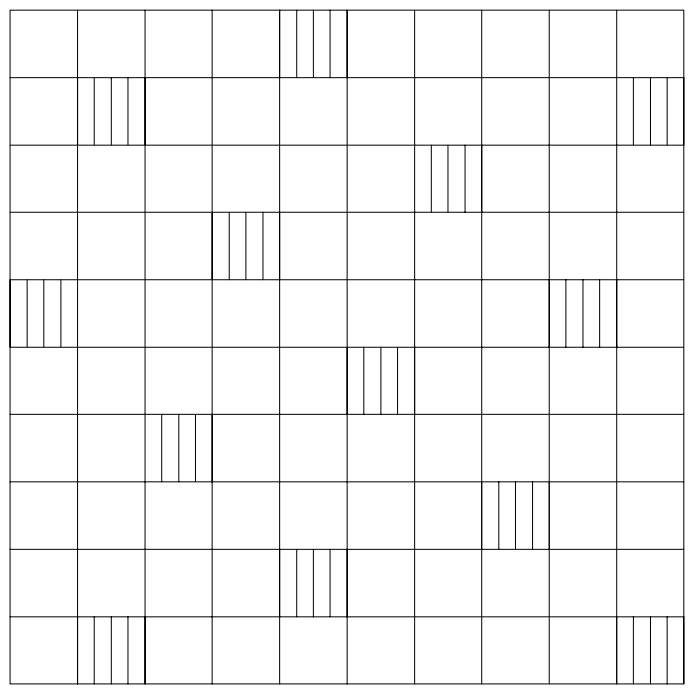

8 Harness Satin Weave

Figure 1.1: Schematics of some woven fabric geometries 
In Figure 1.1, the blank boxes represent the fiber tows that are running in the leftto-right direction on the page, also known as the warp direction when looking at the fabric cross section. The boxes with the vertical lines inside represent the fiber tows that run from top to bottom on the page, and that direction is known as the fill direction. These materials possess some additional advantages to using directional fiber tows. Through the interlacing of the fiber tows to form a fabric, the fiber material becomes more of a self-supporting system. Fabrics can be draped and manipulated to form more complex shapes. In addition to the fabrication advantages, the interlacing of the tows provides both bi-directional rigidity in the plane of loading $\left(E_{1}, E_{2}, G_{12}\right)$ and increased interlaminar strength out of the plane of loading $\left(E_{3}, G_{23}, G_{13}\right)$. For these and other reasons, fabric reinforced composites are an attractive alternative to traditional materials, as well as ordinary directional tow FRP composites.

\subsection{Objectives}

In Sections 1.1 and 1.2, the methods of FRP composite material property prediction were outlined, and fabric reinforced composites were introduced. The objective of this research is to develop a novel mathematical model, using the principle of periodic microstructure, to determine the material properties and internal stresses of a woven fabric composite material. In Chapter 2 of this dissertation, a literature review of the current available micromechanical models is presented, and from that review a need will be established for a novel method of determining the material properties. Chapter 3 
consists of a full derivation and explanation of all equations and relationships required to justify and implement periodic microstructure. Chapters 4 and 5 detail the construction of the mathematical models for a plain weave fabric composite using Mathcad 2001 and the comparison of the results with experimental and similar micromechanical modeling data. The research is culminated in Chapter 6 and Chapter 7 with a summary of the current work and recommendations for future extension and/or expansions. 


\section{Chapter 2}

\section{Review of Literature}

\subsection{Background}

Research pertaining to the modeling of woven fabrics for use in the textile industry began in the 1930's. Pan [1] provides an excellent review of the origin of the analysis of woven fabrics for use in the textile industry, which are summarized in references [2] through [10]. The paper by Pierce [2] is acknowledged to be the first model to describe the behavior of a woven fabric under loading. Subsequent papers that were published in the following years sought to build new and/or refine existing models that could provide more accurate representations, or to predict properties that had yet to be accurately determined. The approach in these references was to idealize the geometry and material characteristics in such a way that would make the analysis as simple as possible and that would still maintain the integrity of the system. In light of the fact that computers were either non-existent or not readily accessible, these approaches had to be idealized to the point to where their application was limited. The research that was done on textile fabrics, though idealized, provided a foundation for the research that developed in the 1980 's when the woven fabric geometry was used in the formation of woven fiber tow systems that could be fabricated into FRP composites. 


\subsection{Classical Lamination Theory}

The first significant paper dealing with the analysis of woven fabric composites was authored by Ishikawa and Chou [11] in 1982. This research produced three analytical models to predict the linear elastic properties of woven fabric composites: the mosaic model, the fiber undulation model, and the bridging model. The mosaic model idealizes the woven fabric geometry as an assemblage of asymmetrical cross-ply laminates, as seen in Figure 2.1. This assumption enables the mechanics of the system to be solved by classical thin lamination theory, as would be the case for a ply laminate composite material. The mosaic model completely neglects the undulation and interlacing of the fiber tows, and is not capable of completely describing all of the material properties (CLT cannot predict out of plane properties, i.e. $E_{3}, G_{13}$, etc.).
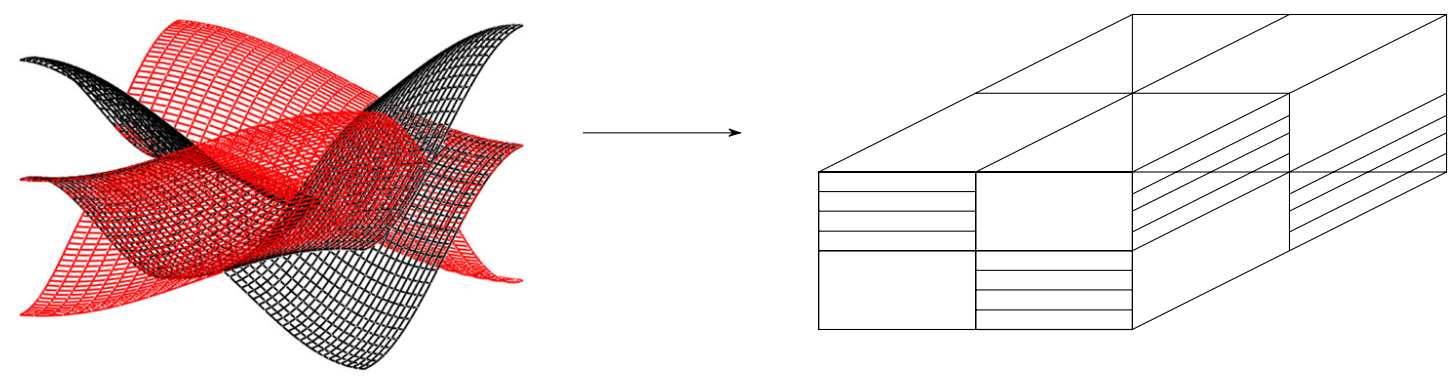

Figure 2.1: Mosaic model [11] idealization of a plain woven fabric RVE 
The fiber undulation model takes the undulation of the fiber into partial account by looking at the undulation of the fabric in either the warp or the fill direction, and assuming no undulation in the opposite direction. In Figure 2.2, the formation of the fiber undulation model is presented. The cross section that contains the undulation is segregated into three sections. The outer sections are analyzed by traditional classical lamination theory.
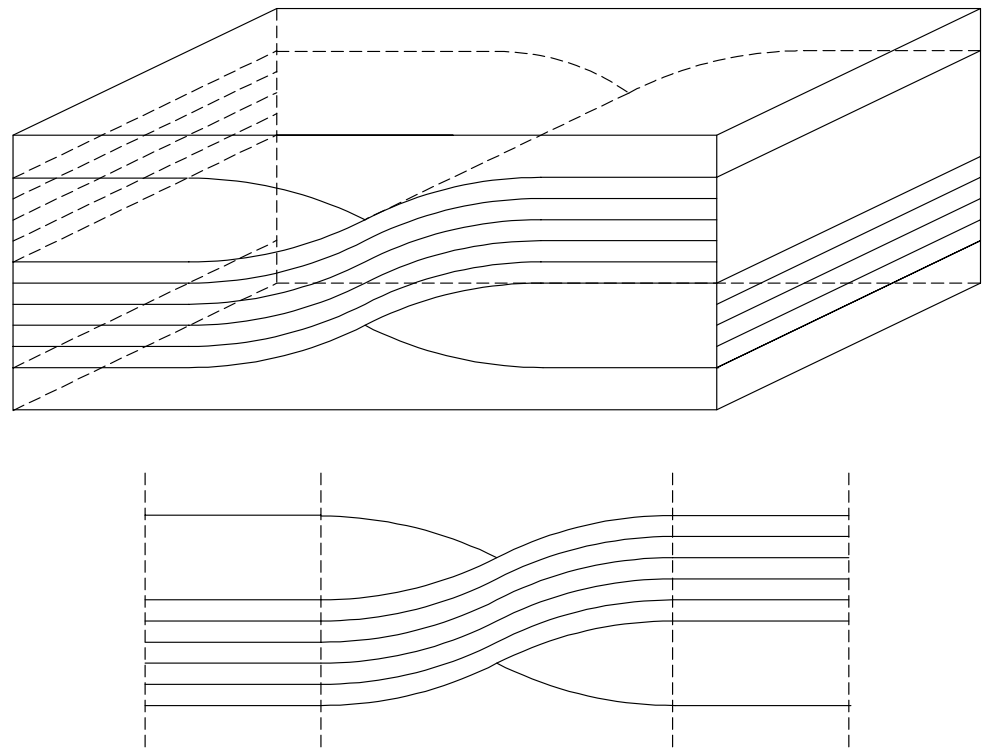

Figure 2.2: Idealization of the fiber undulation model [11] (top) with the discretization of the cross section (bottom).

The same can be done for the middle section, but it must be discretized into smaller sections. Each small section of laminate is assumed to be a linear, but set at an angle to the outer section. The properties are solved for in the local or material coordinates of the discretized section and then transformed to the global coordinates of the representative volume element. The bridging model is a combination of the mosaic and the fiber undulation models, and was developed for the analysis of satin weave fabric composites. 
Many authors have taken the general approach of Ishikawa and Chou and developed a wide variety of models for both material property characterization as well as strength and failure prediction. Hahn and Pandey [12] developed a relationship for the effective stiffness $\mathrm{C}^{*}$ of a plain woven fabric composite simply by taking the volume average of all of the constituents in the fabric RVE in conjunction with the assumption that the strain in the RVE is uniform (iso-strain). The volume averaging was presented in the form of classical lamination theory and equations were derived to predict both the mechanical and thermal material properties, namely the longitudinal and transverse thermal expansion coefficients. The results they attempted to correlate with experimental data were limited to only the in-plane modulus of elasticity and shear modulus $\left(\mathrm{E}_{11}\right.$ and $\left.\mathrm{G}_{12}\right)$. Ito and Chou [13], [14] researched the effect of the laminate stacking sequence through the modeling of the representative volume element (RVE) as being either in phase, out of phase, or a random phase. Their analysis used the iso-strain assumption along with classical lamination theory to describe the stiffness and strength of a plain weave fabric composite. Naik and Ganesh [15] applied the method of cells approach of Aboudi [16] to the idealized cross ply laminates and assumed material nonlinearity in order to predict material failure for plain weave fabric laminates. They took into account the undulations in both the warp and the fill direction by discretizing along the fill direction and using the geometric shape functions to determine the idealized laminate size and material properties. Scida et al. [16] used a technique similar to that used in [15] by discretizing each infinitesimal section of the fabric through its depth and calculating the material coordinate stiffness of each of the composite constituents (warp strand, fill strand, or matrix). These incremental stiffnesses are then averaged over volume of the 
infinitesimal slice. The calculated stiffness terms are then transformed into the global coordinate system and averaged over all of the discretized sections in order to determine an average effective stiffness term, denoted as $\left[\mathrm{A}_{\text {global }}\right]$ in the paper. This method was programmed using computer software called MESOTEX (MEchanical Simulation Of TEXtile), providing users a general method to predict properties of a wide variety of fabric dimensions and loadings. It was tested on a-glass composites with epoxy and vinyl ester resins and plain, 8 harness satin, and 2/2 twill weave fabrics. Vandeurzen et al. [18], [19] developed a similar program called TEXCOMP using Microsoft Excel. The program was built in order to analyze complex unit cells that have the capability to depict complex fabric reinforced composite RVE's. These complex unit cells are constructed by means of a bank of rectangular macro cells that have been developed and programmed. This program incorporates a variation in the methods of discretizing the cross sections, either through mixing, not mixing, or combining the different constituent properties in each section. The contrast of the traditional classical lamination theory approach (fabric geometry model) and their combi-cell model expose the limitation of CLT for computing the out-of-plane properties. The combi-cell model is evaluated through the use of the complementary variational principle. The discretization procedures of references [16] and [19] allow for the calculation of a complete set of stiffness terms, which is a significant improvement of the mosaic and fiber undulation models of [11]. 


\subsection{Alternative Approaches}

Some novel approaches exist that derive from a theory other than classical lamination theory. Zhang and Harding [20] used an energy equivalence method that combines a finite element analysis with the 1D fiber undulation model of [11] to ascertain the mechanical properties of a one ply plain weave fabric composite. This method was also used to obtain values for all of the material properties except the out of plane shear terms $\left(\mathrm{G}_{13}, \mathrm{G}_{23}\right)$. The values, however, were not effectively compared with experimental results. Sheng and Van Hoa [21] developed a 3D model and used variational principles, namely the variational potential energy method and the variational complementary energy method, along with an iso-strain assumption. This method predicted a full set of material properties for Carbon/Epoxy and E-Glass/Epoxy plain weave fabric composites as well as an S2-Glass/C-50 Resin twill weave specimen. Experimental verification through testing was not complete for these specimens, either.

A vast number of researchers have done finite element analyses on a variety of fabric geometries. These methods vary in, among other things, geometric modeling, mesh generation, element type, and the material properties of the constituents. Dasgupta et al, [22], [23] developed a finite element model that uses a two-scale asymptotic homogenization theory. This model also includes the effect of matrix nonlinearity and damage. The research of Kollegal and Sridharan [24]-[26] produced a series of papers dealing with the modeling of plain weave fabrics for the prediction of both tensile and compressive strength. These are just a few examples of the finite element analysis 
research that has been published, and more research can be investigated concerning the use of finite element analysis in woven fabric composite modeling in the following references: [22]-[31].

\subsection{Conclusions}

The method of finite elements can be a very powerful method of solution, and one can include a variety and combination of material and geometric complexities simultaneously. However, this method can be very complex to implement and is often only applicable to a specific design. So on one hand there are the generalizations and assumptions of classical lamination theory that provide ease of use with limited results. On the other hand, there is the finite element method that can provide complete material characterizations, but is very complex and time consuming to construct and to solve. From the review of the literature, it is evident that there is a need to be able to meld the two extremes together with a new constituitive approach that maximizes the accuracy and completeness of the material property characterization at a minimum of preliminary setup and computer expense. 


\section{Chapter 3}

\section{Periodic Microstructure}

The literature review of Chapter 2 outlined the need for a method of analysis in the area of woven fabric composite materials that takes the best attributes of finite element analysis (ability to handle complex parameters) and classical lamination theory (ease of solution) and, through a new analytical method, combines them so as to produce a simple, efficient, and accurate way to determine a complete set of composite material properties.

There are essentially two aspects of a woven fabric composite that result in a more complex situation: The undulation and interlacing of the warp and fill fiber tows. The idealization of classical lamination theory can take into account the undulation of the fiber tows through the discretization of the representative volume element (RVE) and subsequent transformation of the local material properties to the global coordinate system (i.e. the fiber undulation model). However, it does not take into account the effect that the warp tow has to the fill tow, and vice versa. Each set of material properties is determined for that specific discretized section and the contributions of each part are averaged to determine the overall RVE properties. The finite element method can 
account for these two complexities, but the disadvantages of using this method have already been outlined in Chapter 2 .

From a careful analysis of the existing literature on both woven fabrics, as well as existing micromechanical models for unidirectional composites, it was determined that a woven fabric composite could be modeled using periodic microstructure because the undulation of the fiber tows in a fabric reinforced composite are generally periodic in the weaving between the warp and the fill tows. The book authored by Nemat-Nasser and Hori [32] outlines the theory behind periodic microstructure and its application to materials with micro-cracks or micro voids. This chapter deals with the derivation of all the equations and relationships necessary to extend this technique to the analysis of woven fabric composites.

\subsection{Eigenstress and Eigenstrain}

Periodic microstructure is applied through the homogenization of a heterogeneous woven fabric representative volume element. The RVE section consists of the warp fibers, the fill fibers, and the matrix material that impregnates and surrounds the fiber tows. The new material is effectively homogeneous, with a unified set of material properties. Homogenization is the basis for some existing micromechanical models that are available in composite textbooks and literature. For a simple unidirectional composite, the determination of the modulus of elasticity is found simply by using the rule of mixtures: 


$$
\mathrm{E}_{1}=\mathrm{E}_{\mathrm{f}} \mathrm{V}_{\mathrm{f}}+\mathrm{E}_{\mathrm{m}} \mathrm{V}_{\mathrm{m}}
$$

where $\mathrm{E}$ is the modulus of elasticity, $\mathrm{V}$ is the volume fraction of the material, and the " $\mathrm{f}$ " and " $\mathrm{m}$ " subscripts represent the property of the fiber and matrix, respectively. This is a simple example of homogenization, which produces a single material property $\left(E_{1}\right)$ from a combination of the geometric $\left(\mathrm{V}_{\mathrm{f}}, \mathrm{V}_{\mathrm{m}}\right)$ and material $\left(\mathrm{E}_{\mathrm{f}}, \mathrm{E}_{\mathrm{m}}\right)$ properties. Even with the simple case of a unidirectional FRP composite, however, there are five independent material constants (If the material is assumed to be transversely isotropic) that need to be determined, and the rule of mixtures is only accurate in the determination of the "effective" modulus of elasticity in the direction of the fibers. Therefore, four other relationships are needed in order to fully describe the effective material properties of a unidirectional composite (The balance of these properties can be found in Barbero [33]).

The homogenization approach that was used in this research, and is outlined in [32] by Nemat-Nasser and Hori, utilizes the concepts of eigenstrain and eigenstress. Consider a heterogeneous material (total volume of $\mathrm{V}$ ) that consists of a matrix material (M) that surrounds an inclusion $(\Omega)$. Assume further that each of constituent materials is linear elastic and homogenous (the materials need not be isotropic). Each constituent has an independent set of material properties, which are summarized by stiffness matrices and denoted as $\mathbf{C}$ for the matrix material and $\mathrm{C}^{\Omega}(\mathrm{x})$ for the inclusion. The stiffness matrix fully describes the material properties of the constituents and in the most general form is a $6 \times 6$ matrix consisting of 36 terms (for a fully anisotropic material). In order to homogenize the material, it is assumed that both of the constituents have the same stiffness matrix. For the purposes of this research, the inclusion is homogenized to the 
surrounding matrix material because the surrounding matrix is usually isotropic, which is much simpler to represent.

Figure 3.1 depicts the process of homogenizing the inclusion to the matrix in terms of the total strain on the system, in which $\varepsilon^{0}$ is the applied external strain on the system and $\varepsilon^{\mathrm{d}}(\mathrm{x})$ is the disturbance strain induced due to the presence of the inclusion. To account for this assumption, an eigenstrain term $\varepsilon^{*}(\mathrm{x})$ is added to the total strain term so as to "correct" the constitutive equation such that the consistency condition holds. The entire process is represented in the following equations

$$
\begin{aligned}
& \underline{\sigma}(\underline{\mathrm{x}})=\underline{\underline{\mathrm{C}}}:\left(\underline{\varepsilon}^{\mathrm{o}}+\underline{\varepsilon}^{\mathrm{d}}(\underline{\mathrm{x}})\right) \quad \text { in } \mathrm{M} \\
& \underline{\sigma}(\underline{\mathrm{x}})=\underline{\underline{C}}^{\Omega}(\underline{\mathrm{x}}):\left(\underline{\varepsilon}^{\mathrm{o}}+\underline{\varepsilon}^{\mathrm{d}}(\underline{\mathrm{x}})\right) \quad \text { in } \Omega
\end{aligned}
$$

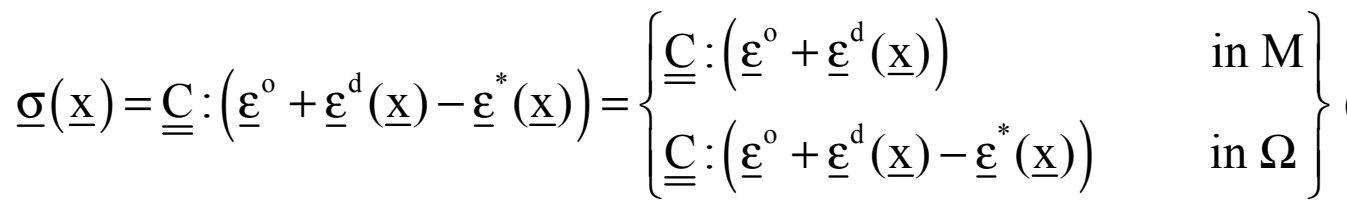

where Equations (3.2) and (3.3) represent the heterogeneous constitutive equations for the matrix and the inclusion, and Equation (3.4) is the homogenized relationship with the addition of the eigenstrain term $\varepsilon^{*}(\mathrm{x})$. A similar relationship can be developed through the use of an eigenstress $\sigma^{*}(\mathrm{x})$ 


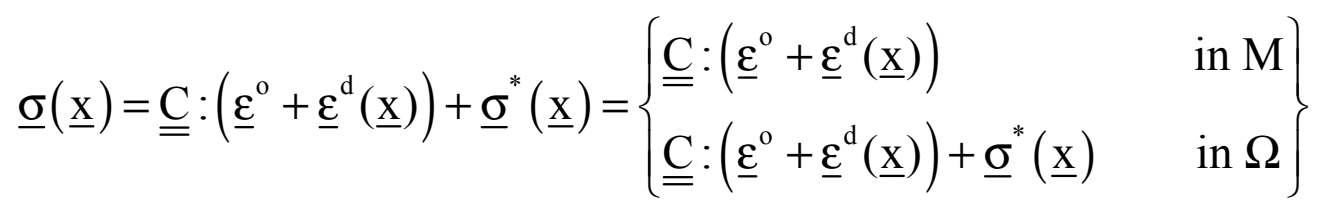

in which the disturbance stress $\sigma^{\mathrm{d}}(\mathrm{x})$ can be written as

$$
\underline{\sigma}^{\mathrm{d}}(\underline{\mathrm{x}})=\underline{\mathrm{C}}: \underline{\varepsilon}^{\mathrm{d}}(\underline{\mathrm{x}})+\underline{\sigma}^{*}(\underline{\mathrm{x}})
$$

There are several complexities that have to be resolved in order to apply the relationships derived from the homogenization of the material using eigenstrains. In the most general form, the terms in Equations (3.2)-(3.4) are functions of position. The stiffness of the matrix $\mathbf{C}$ is independent of position if we assume an isotropic matrix, which is more than valid. The stiffness of the inclusion, $C^{\Omega}(x)$, cannot be assumed to be isotropic, and therefore remains a function of position. However, the material properties can be determined using a variety of other methods, depending on the specifics of the inclusion. The terms that are difficult to determine are the disturbance strain $\varepsilon^{\mathrm{d}}(\mathrm{x})$ and the eigenstrain $\varepsilon^{*}(\mathrm{x})$. Since both of the strain fields are induced due to the presence of the inclusion, the disturbance strain can be written as an integral operator acting on the corresponding eigenstrain [32]. This relationship can be written as follows

$$
\underline{\varepsilon}^{\mathrm{d}}(\underline{\mathrm{x}})=\underline{\underline{S}}\left(\underline{\mathrm{x}} ; \underline{\varepsilon}^{*}\right)
$$

where $\mathrm{S}$ is the integral operator. The same form of an integral operator is written for the solution of the eigenstress, and is written as 


$$
\underline{\sigma}^{\mathrm{d}}(\underline{\mathrm{x}})=\underline{\underline{T}}\left(\underline{\mathrm{x}} ; \underline{\sigma}^{*}\right) \text {. }
$$

A unique relationship will be derived in subsequent sections that will be specific to the periodicity of the woven fabric system.

\subsection{Periodic Microstructure}

The technique of homogenizing an inherently heterogeneous material, as outlined in Section 3.1, can be a useful step in the process of determining a unified or "effective" set of material properties. One of those processes utilizes the periodic nature of the material, either through the geometric shape of the constituents, or the placement and spacing of the heterogeneities throughout the RVE.

Figure 3.2 and Figure 3.3 illustrate geometric and spacing periodicity, respectively. In Figure 3.2 it is clear that both the warp and fill tows exhibit periodicity. The warp tow is an example of geometric periodicity, since its pattern of undulation is sinusoidal, which is inherently periodic. The fill tow is likewise sinusoidal in nature, and if another cross-section were illustrated it would have similar shape. Figure 3.3 is an example of periodic spacing. The figure could be representative of a variety of material views. It could be an idealized cross-section of a unidirectional composite with cylindrical fibers. Also, it could be a view of the top of a material with spherical inclusions spaced throughout. In either case, the spacing of the heterogeneities is uniform, and thus periodic. This technique has been used by Luciano and Barbero [34] to 
develop micromechanical models to predict material properties for directional ply laminates.

\subsection{1 $\quad$ Fourier Series}

Fourier series expansion is a useful mathematical tool for representing generally discontinuous functions with a summation of a series of sine and cosine functions (such as square waves or saw tooth waves). In a one dimensional case, the Fourier series expansion is as follows

$$
\begin{gathered}
f(x)=\sum_{n=-\infty}^{\infty} c_{n} \cdot e^{i\left(\frac{n \pi x}{L}\right)} \\
c_{n}=\frac{1}{2 L} \int_{-L}^{L} g(x) \cdot e^{i\left(\frac{n \pi x}{L}\right)} d x
\end{gathered}
$$

where $\mathbf{g}(\mathbf{x})$ is the local function definition in the range of $L$ and $\mathbf{f}(\mathbf{x})$ is the resulting function from the summation. This procedure can be extended into three dimensions, and Nemat-Nasser and Hori [32] stated the Fourier series in this manner

$$
\underline{f}_{3 D}(\underline{x})=\sum_{\underline{\xi}} F \underline{f}_{3 D}(\underline{x}) \cdot e^{i(\underline{x} \cdot \underline{\xi})}
$$




$$
\mathrm{Ff}_{3 \mathrm{D}}(\underline{\xi})=\frac{1}{\mathrm{U}} \int_{\mathrm{U}} \underline{\mathrm{g}}_{3 \mathrm{D}}(\underline{\mathrm{x}}) \cdot \mathrm{e}^{-\mathrm{i}(\underline{\mathrm{x}} \cdot \underline{\xi})} \mathrm{dV}
$$

where $\mathbf{F f}_{3 \mathrm{D}}(\underline{\mathbf{x}})$ is the three dimensional Fourier coefficient, and the vector $\boldsymbol{\xi}$ is represented in the following way

$$
\underline{\xi}=\xi_{\mathrm{i}}=\xi_{\mathrm{i}}\left(\mathrm{n}_{\mathrm{i}}\right)=\frac{\mathrm{n}_{\mathrm{i}} \pi}{\mathrm{a}_{\mathrm{i}}}
$$

in which $a_{i}$ is the vector that represents the domain of the RVE in question. For the formulation in this dissertation, the volume of the RVE, denoted as $\mathrm{U}$, is defined as

$$
\mathrm{U}=\prod_{\mathrm{i}=1}^{3}\left(2 \cdot \mathrm{a}_{\mathrm{i}}\right) \quad\left[\mathrm{U} \text { is }\left(2 \mathrm{a}_{1}\right) \times\left(2 \mathrm{a}_{2}\right) \times\left(2 \mathrm{a}_{3}\right)\right]
$$

When there exists a level of periodicity in the material (either geometric or spacing), the Fourier expansion can be applied to all of the relevant field variables, some of which being the strain $(\varepsilon)$, stress $(\sigma)$, displacements $(\underline{u})$, etc. This leads to an approximation of the exact field variable that is as accurate as the number of terms considered.

In addition to the Fourier expansion being a tool to represent the field variables, the field variables themselves exhibit periodic behavior. Consider the illustration inFigure 3.4, where the material is periodic at a spacing of $\mathbf{d}$ in the $\mathrm{x}$ direction. In this simple case, the effective stiffness tensor is only a function of $\mathrm{x}$. Due to the repeating 
nature of the material at an $\mathrm{x}$ coordinate spacing of $\mathrm{d}$, the effective stiffness tensors $\overline{\mathrm{C}}\left(\mathrm{x}_{1}\right)$ and $\overline{\mathrm{C}}\left(\mathrm{x}_{2}\right)$ are equal and can be expressed as follows

$$
\begin{gathered}
\mathrm{x}_{2}=\mathrm{x}_{1}+\mathrm{d} \\
\underline{\overline{\mathrm{C}}}\left(\mathrm{x}_{1}\right)=\underline{\overline{\mathrm{C}}}\left(\mathrm{x}_{2}\right)=\underline{\overline{\mathrm{C}}}\left(\mathrm{x}_{1}+\mathrm{d}\right)
\end{gathered}
$$

This simple illustration shows that the field variables in addition to the physical geometry repeat as multiple of the dimensions of the RVE.

\subsubsection{Expansion of field variables}

Recall from Section 3.1 that the homogenization resulted in there being two terms, $\varepsilon^{\mathrm{d}}(\underline{\mathrm{x}})$ and $\varepsilon^{*}(\underline{\mathbf{x}})$ that are unknown, and that the disturbance strain $\varepsilon^{\mathrm{d}}(\underline{\mathrm{x}})$ is written as an integral operator acting on the eigenstrain $\varepsilon^{*}(\underline{x})$, as described in Equation (3.7). In general, these terms are not able to be resolved, except in the case where the inclusion is ellipsoidal in shape. Eshelby [35] presented a solution for this case, and it turns out that the eigenstrain is uniform throughout the inclusion $\boldsymbol{\Omega}$. The expansion of the field variables through the use of a Fourier series produces a solution for these terms, and therefore provides a method of resolving the effective properties of the material. In this section, the relevant field variables are expanded in a Fourier series due to the application of either a macro-strain $\underline{\varepsilon}^{0}$ or macro-stress $\underline{\sigma}^{0}$. 
The Fourier expansion of the displacement and strain fields are addressed first, and are written as follows

$$
\begin{aligned}
\underline{u}(\underline{x}) & =\sum_{\xi}^{\prime}[F \underline{u}(\underline{\xi}) \cdot \exp (\underline{i} \underline{x} \cdot \underline{\xi})] \\
F \underline{u}(\underline{\xi}) & =\frac{1}{U} \int_{U} \underline{u}(\underline{x}) \cdot \exp (-i \underline{x} \cdot \underline{\xi}) d V \\
\underline{\varepsilon}(\underline{x}) & =\sum_{\xi}^{\prime}[F \underline{\varepsilon}(\underline{\xi}) \cdot \exp (\underline{i} \underline{\underline{x}} \cdot \underline{\xi})] \\
F \underline{\varepsilon}(\underline{\xi}) & =\frac{1}{U} \int_{U} \underline{\varepsilon}(\underline{x}) \cdot \exp (-i \underline{x} \cdot \underline{\xi}) d V
\end{aligned}
$$

where $\mathrm{Fu}(\xi)$ and $\mathrm{F \varepsilon}(\xi)$ are the Fourier coefficients and the prime "in front of the summation term in Equations (3.16) and (3.18) represent an exclusion of the term that corresponds to $\underline{\xi}=0$. This term is omitted because it corresponds to rigid body translation. The Fourier expansions for some pertinent field variables are listed in Table 3.1 .

Along with the terms that have been listed and outlined above, the utilization of the Fourier expansion in the context of periodic microstructure provides a method of solving for the eigenstrain $\varepsilon^{*}(\underline{x})$ and the eigenstress $\sigma^{*}(\underline{x})$, and thus determining the effective properties of the material. This is perhaps the most important transformation, and the variable with which the entire method hinges. The expansion of the eigenstrain is as follows 


$$
\underline{\varepsilon}^{*}(\underline{\mathrm{x}})=\sum_{\xi} \mathrm{F \varepsilon}^{*}(\underline{\xi}) \exp (\underline{\mathrm{ix}} \cdot \underline{\xi})
$$

with the Fourier coefficient being

$$
\mathrm{F} \underline{\varepsilon}^{*}(\underline{\xi})=\frac{1}{U} \int_{U} \underline{\varepsilon}^{*}(\underline{x}) \cdot \exp (-\mathrm{i} \underline{x} \cdot \underline{\xi}) \mathrm{dV} .
$$

Similarly, the eigenstress expansion is

$$
\underline{\sigma}^{*}(\underline{x})=\sum_{\xi}{ }^{\prime} F \underline{\sigma}^{*}(\underline{\xi}) \exp (\underline{i x} \cdot \underline{\xi})
$$

with the Fourier coefficient being

$$
\mathrm{F} \underline{\sigma}^{*}(\underline{\xi})=\frac{1}{U} \int_{U} \underline{\sigma}^{*}(\underline{x}) \cdot \exp (-i \underline{x} \cdot \underline{\xi}) d V .
$$

In addition to being able to functionally represent a system that is locally continuous, the Fourier series expansion produces continuum relationships that can be resolved in terms of the Fourier coefficients, which are not dependant on the position $\underline{x}$. The constitutive equations have already been discussed in Section 3.1. The compatibility and equilibrium equations and their resulting relationships will be discussed in subsequent sections.

\subsubsection{Compatibility equation expansion}

The compatibility equation is the relationship between the strain and the displacement for a given RVE. The assumptions in these derivations, along with all of 
the work in this dissertation, work within the bound of a compatibility relationship in which the following conditions exist:

1. The real body forces and inertia terms are zero

2. Surface tractions must be self-equilibrating

3. Surface displacements must be such that they do not produce rigid body translations or rotations.

With these conditions in mind, the strain-displacement, or compatibility, equation is as follows

$$
\underline{\varepsilon}(\underline{\mathrm{x}})=\frac{1}{2}\left[\underline{\nabla} \otimes \underline{\mathrm{u}}(\underline{\mathrm{x}})+(\underline{\nabla} \otimes \underline{\mathrm{u}}(\underline{\mathrm{x}}))^{\mathrm{T}}\right]
$$

where the term $\underline{\nabla} \otimes \underline{u}(\underline{\mathrm{x}})$ denotes the vector gradient of the displacement. When the gradient of $\underline{u}(\underline{x})$ and its transpose are equal, then the Equation (3.24) simplifies to

$$
\underline{\varepsilon}(\underline{\mathrm{x}})=\underline{\nabla} \otimes \underline{\mathrm{u}}(\underline{\mathrm{x}})
$$

The vector gradient of $\mathrm{u}(\mathrm{x})$ can be expanded in a Fourier series, just as the displacement field $u(x)$ was in Equation (3.16). The expansion is as follows:

$$
\underline{\nabla} \otimes \underline{\mathrm{u}}(\underline{\mathrm{x}})=\sum_{\xi}{ }^{\prime}[\mathrm{F}(\underline{\nabla} \otimes \underline{\mathrm{u}}(\underline{\mathrm{x}}))(\underline{\xi}) \cdot \exp (\underline{\mathrm{i}} \underline{\mathrm{\xi}} \cdot \underline{\xi})]
$$


where the Fourier coefficient is expressed as

$$
\mathrm{F}(\underline{\nabla} \otimes \underline{\mathrm{u}}(\underline{\mathrm{x}}))(\underline{\xi})=\frac{1}{\mathrm{U}} \int_{\mathrm{U}} \underline{\nabla} \otimes \underline{\mathrm{u}}(\underline{\mathrm{x}}) \cdot \exp (-\mathrm{i} \underline{\mathrm{x}} \cdot \underline{\xi}) \mathrm{dV} .
$$

Equation (3.27) can be rewritten through the use of the divergence theorem of Gauss to be

$$
\begin{aligned}
\mathrm{F}(\underline{\nabla} \otimes \underline{\mathrm{u}}(\underline{\mathrm{x}}))(\underline{\xi})= & \frac{1}{\mathrm{U}} \int_{\partial \mathrm{U}} \underline{\mathrm{v}}(\underline{\mathrm{x}}) \otimes \underline{\mathrm{u}}(\underline{\mathrm{x}}) \cdot \exp (-\mathrm{i} \underline{\mathrm{x}} \cdot \underline{\xi}) \mathrm{dS}- \\
& \frac{1}{\mathrm{U}} \int_{\mathrm{U}} \nabla\{\exp (-\mathrm{i} \underline{\mathrm{x}} \cdot \underline{\xi})\} \otimes \underline{\mathrm{u}}(\underline{\mathrm{x}}) \mathrm{dV}
\end{aligned} .
$$

Because of the periodicity that exists, the surface integral in Equation (3.27) equates to zero. The second term can be simplified through the resultant scalar gradient $\nabla\{\exp (-\mathrm{i} \underline{x} \cdot \underline{\xi})\}$ in the following manner

$$
\nabla[\exp (-\mathrm{ix} \cdot \underline{\xi})]=-\mathrm{i} \underline{\xi} \exp (-\mathrm{ix} \cdot \underline{\xi})
$$

From the simplifications that have been made, Equation (3.28) can be rewritten as follows

$$
\mathrm{F}(\underline{\nabla} \otimes \underline{\mathrm{u}}(\underline{\mathrm{x}}))(\underline{\xi})=-\frac{1}{\mathrm{U}} \int_{\mathrm{U}}[-\mathrm{i} \underline{\xi} \exp (-\mathrm{i} \underline{\mathrm{x}} \cdot \underline{\xi})] \otimes \underline{\mathrm{u}}(\underline{\mathrm{x}}) \mathrm{dV} .
$$


From this equation, it can be seen that the negative signs cancel, and since the integral is over the volume, the isolated vector $\xi$ as well and the imaginary term i can be taken out of the integral. This further modification results in

$$
\mathrm{F}(\underline{\nabla} \otimes \underline{\mathrm{u}}(\underline{\mathrm{x}}))(\underline{\xi})=\mathrm{i} \underline{\xi} \otimes \frac{1}{\mathrm{U}} \int_{\mathrm{U}} \underline{\mathrm{u}}(\underline{\mathrm{x}}) \exp (-\mathrm{i} \underline{\mathrm{x}} \cdot \underline{\xi}) \mathrm{dV}
$$

which further reduces to

$$
\mathrm{F}(\underline{\nabla} \otimes \underline{\mathrm{u}}(\underline{\mathrm{x}}))(\underline{\xi})=\mathrm{i} \underline{\xi} \otimes \mathrm{F} \underline{\mathrm{u}}(\underline{\xi}) .
$$

Equations (3.26) and (3.32) make up the Fourier expansion of the vector gradient of the displacement. These relationships, along with the expansion of the strain term in Equation (3.24) yields a modified compatibility equation that relates only the Fourier coefficients of the field variables, which in case are the strain and displacement. The expansion is as follows:

$$
\sum_{\xi}{ }^{\prime}[\mathrm{F} \underline{\varepsilon}(\underline{\xi}) \cdot \exp (\underline{i} \underline{x} \cdot \underline{\xi})]=\frac{1}{2}\left[\begin{array}{l}
\sum_{\xi}{ }^{\prime}[\mathrm{i} \underline{\xi} \otimes F \underline{u}(\underline{\xi}) \cdot \exp (i \underline{x} \cdot \underline{\xi})]+ \\
\left(\sum_{\xi}[i \underline{\xi} \otimes F \underline{u}(\underline{\xi}) \cdot \exp (i \underline{x} \cdot \underline{\xi})]\right)^{T}
\end{array}\right]
$$

which further reduces to 


$$
\mathrm{F} \underline{\varepsilon}(\underline{\xi})=\frac{i}{2}[\underline{\xi} \otimes \mathrm{F} \underline{u}(\underline{\xi})+\mathrm{F} \underline{u}(\underline{\xi}) \otimes \underline{\xi}] .
$$

\subsubsection{Equilibrium equation expansion}

The equilibrium equation, in light of the assumptions made in Sub-section 3.2.3, is free of real body forces. This means that, in general, the equilibrium equation can be written as

$$
\underline{\nabla} \cdot \underline{\sigma}(\underline{\mathrm{x}})=0 \text {. }
$$

The stress term $\underline{\sigma}(\underline{\mathrm{x}})$ can be expanded in terms of both the constitutive equation (Equations (3.2) and (3.3)) and the homogenization using eigenstrains (Equation (3.4)). If we homogenize through an applied eigenstress, then the stress distribution follows the form of Equation (3.6). Substituting that equation into Equation (3.35) yields the following

$$
\underline{\nabla} \cdot[\underline{\mathrm{C}}: \underline{\varepsilon}(\underline{\mathrm{x}})]+\underline{\nabla} \cdot\left[\underline{\sigma}^{*}(\underline{\mathrm{x}})\right]=0 .
$$


It can be seen from Equation (3.36) that the modification of the constitutive equation results in the "corrective" eigenstress that can be thought of through the equilibrium equation as a distribution of body forces.

From Equation (3.36), a relationship can be established that relates the Fourier coefficients of the strain $\varepsilon(\underline{x})$ to the eigenstrain $\varepsilon^{*}(\underline{x})$. First, the strain term is replaced by Equation (3.25), creating a relationship between the displacement $u(x)$ and the eigenstress. The substitution is a follows:

$$
\underline{\nabla} \cdot[\underline{\underline{C}}:(\underline{\nabla} \otimes \underline{\mathrm{u}}(\underline{\mathrm{x}}))]+\underline{\nabla} \cdot\left[\underline{\sigma}^{*}(\underline{\mathrm{x}})\right]=0
$$

The field variables $\underline{\nabla} \otimes \underline{\mathrm{u}}(\underline{\mathrm{x}})$ and $\sigma^{*}(\mathrm{x})$ can be expanded as a Fourier series from Equations (3.26) and (3.22), and then substituted into Equation (3.37). The substitution results in

$$
\underline{\nabla} \cdot\left[\underline{\underline{C}}:\left(\sum_{\xi}[[\underline{i} \underline{\xi} \otimes F \underline{u}(\underline{\xi}) \exp (\underline{i x} \cdot \underline{\xi})])\right]+\underline{\nabla} \cdot\left[\sum_{\xi}^{\prime} F \underline{\sigma}^{*}(\underline{\xi}) \exp (\underline{i x} \cdot \underline{\xi})\right]=0 .\right.
$$

The divergence term only operates on the exponential term, because that is the only term that is a function of position. Distributing the del operator through each term and evaluating $\underline{\nabla} \cdot \exp (\underline{i x} \cdot \underline{\xi})$ simplifies Equation (3.38) to

$$
\underline{\underline{\mathrm{C}}}:\left(\sum_{\xi}{ }^{\prime}[\mathrm{i} \underline{\xi} \otimes \mathrm{F} \underline{\mathrm{u}}(\underline{\xi})(\underline{\mathrm{i}} \underline{\xi} \cdot \exp (\underline{\mathrm{i}} \underline{\mathrm{x}} \cdot \underline{\xi}))]\right)+\sum_{\xi}{ }^{\prime} \underline{\mathrm{\sigma}}^{*}(\underline{\xi})(\mathrm{i} \underline{\xi} \cdot \exp (\underline{\mathrm{i}} \underline{\mathrm{z}} \cdot \underline{\xi}))=0
$$


Because both terms are summations over $\xi$, the summations can be removed, realizing that the equilibrium exist for a summation of all of the terms inside the summation evaluated for all values of $\xi$, except for $\xi=0$. This simplification yields the following relationship

$$
\underline{\underline{C}}: i \underline{\xi} \otimes \mathrm{F} \underline{u}(\underline{\xi}) \cdot i \underline{\xi}+F \underline{\sigma}^{*}(\underline{\xi}) \cdot i \underline{\xi}=0
$$

which can be further rearranged to be

$$
-\underline{\xi} \cdot \underline{\underline{C}}:[\underline{\xi} \otimes F \underline{u}(\underline{\xi})]+F \underline{\sigma}^{*}(\underline{\xi}) \cdot i \underline{\xi}=0
$$

which is valid for all $\xi \neq 0$. If the term $\underline{\xi} \cdot \underline{\underline{C}} \cdot \underline{\xi}$ in Equation (3.41) has a defined inverse, then the Fourier coefficient of the displacement, $\mathrm{F} \underline{u}(\underline{\xi})$, can be resolved as a function of $\mathrm{F} \underline{\sigma}^{*}(\underline{\xi})$ to be

$$
\mathrm{F} \underline{\mathrm{u}}(\underline{\xi})=\mathrm{i}(\underline{\xi} \cdot \underline{\mathrm{C}} \cdot \underline{\xi})^{-1} \cdot\left[\underline{\xi} \cdot \mathrm{F} \underline{\sigma}^{*}(\underline{\xi})\right] .
$$

The results from Equation (3.42) can be substituted into Equation (3.34), which relates the Fourier coefficients of the strain to the displacement, in order to obtain the following 


$$
\mathrm{F} \underline{\varepsilon}(\underline{\xi})=\frac{\mathrm{i}}{2}\left\{\begin{array}{l}
\underline{\xi} \otimes\left[\mathrm{i}(\underline{\xi} \cdot \underline{\mathrm{C}} \cdot \underline{\xi})^{-1} \cdot\left[\underline{\xi} \cdot \mathrm{F} \underline{\sigma}^{*}(\underline{\xi})\right]\right]+ \\
{\left[\mathrm{i}(\underline{\xi} \cdot \underline{\mathrm{C}} \cdot \underline{\xi})^{-1} \cdot\left[\underline{\xi} \cdot \mathrm{F} \underline{\sigma}^{*}(\underline{\xi})\right]\right] \otimes \underline{\xi}}
\end{array}\right\}
$$

which can be rewritten as

$$
\mathrm{F} \underline{\varepsilon}(\underline{\xi})=-\operatorname{sym}\left[\underline{\xi} \otimes(\underline{\xi} \cdot \underline{\mathrm{C}} \cdot \underline{\xi})^{-1} \otimes \underline{\xi}\right]: \underline{F}^{*}(\underline{\xi})
$$

where "sym" stands for the symmetric part of the bracketed term $\underline{\xi} \otimes(\underline{\xi} \cdot \underline{\underline{C}} \cdot \underline{\xi})^{-1} \otimes \underline{\xi}$. Equation (3.44) represents the relationship between the Fourier coefficients of the strain and the eigenstress. In order to equate the strain and eigenstrain coefficients, the equilibrium equation (Equation (3.35)) can be rewritten, using the eigenstrain constitutive equation (Equation (3.4)), as

$$
\underline{\nabla} \cdot[\underline{\underline{C}}: \underline{\varepsilon}(\underline{\mathrm{x}})]-\underline{\nabla} \cdot[\underline{\mathrm{C}}: \underline{\varepsilon} * \underline{\mathrm{x}})]=0
$$

The subsequent Fourier expansions and simplifications are done in the same order as in Equations (3.38) through (3.44). The result of those steps, for a prescribed eigenstrain, is as follows for the displacement-eigenstrain relationship:

$$
\mathrm{Fu}(\underline{\xi})=-\mathrm{i}(\underline{\xi} \cdot \underline{\underline{\mathrm{C}}} \cdot \underline{\xi})^{-1} \cdot[\underline{\xi} \cdot(\underline{\underline{C}}: \mathrm{F} \underline{\underline{\varepsilon}}(\underline{\xi}))] .
$$


The strain-eigenstrain relationship follows the form of Equation (3.44) and is presented as

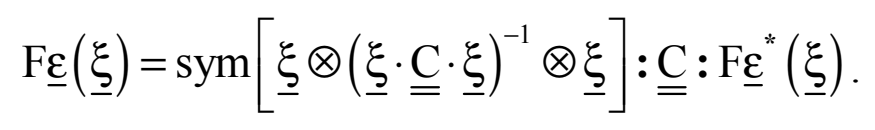

Equation (3.47) represents the integral operator expression of Equation (3.7) in terms of the Fourier coefficients of the field variables. The expression can be rewritten as follows

$$
\mathrm{F} \underline{\varepsilon}(\underline{\xi})=\mathrm{FS}^{\mathrm{P}}(\underline{\xi}): \mathrm{F} \underline{\varepsilon}^{*}(\underline{\xi})
$$

in which

$$
\operatorname{FS}^{\mathrm{P}}(\underline{\xi})=\operatorname{sym}\left[\underline{\xi} \otimes(\underline{\xi} \cdot \underline{\underline{C}} \cdot \underline{\xi})^{-1} \otimes \underline{\xi}\right]: \underline{C} .
$$

Recall from Equation (3.7) that the disturbance strain is written as $S\left(x ; \varepsilon^{*}\right)$, which relates the disturbance strain to the eigenstrain. Equation (3.48) provides that relationship through the respective Fourier coefficients. $\mathrm{S}^{\mathrm{P}}$, the periodic integral operator, can be written as follows by substituting Equation (3.48) into Equation (3.18)

$$
\underline{\mathrm{S}}^{\mathrm{P}}(\underline{\mathrm{x}})=\sum_{\xi} \mathrm{FS}^{\mathrm{P}}(\underline{\xi}): \mathrm{F} \underline{\varepsilon}^{*}(\underline{\xi}) \exp (\underline{\mathrm{i}} \underline{\underline{\xi}} \cdot \underline{\xi})
$$


The FE* term can be replaced by Equation (3.21), realizing that the position term contained in the Fourier coefficient is different from the position term for $\mathrm{S}^{\mathrm{P}}$ because the term is integrated over the volume $\mathrm{U}$. The expression can be rearranged in the following manner

$$
\underline{S}^{\mathrm{P}}(\underline{\mathrm{x}})=\sum_{\xi} \mathrm{FS}_{\underline{\underline{\mathrm{P}}}}^{\mathrm{P}}(\underline{\xi}):\left[\frac{1}{\mathrm{U}} \int_{\mathrm{U}} \underline{\varepsilon}^{*}(\underline{\mathrm{y}}) \cdot \exp (-\mathrm{i} \underline{\mathrm{y}} \cdot \underline{\xi}) \mathrm{dV} \mathrm{y}_{\mathrm{y}}\right] \exp (\underline{\mathrm{i}} \underline{\mathrm{x}} \cdot \underline{\xi})
$$

and Equation (3.51) can be further simplified by condensing the exponential term as

$$
\underline{\underline{S}}^{\mathrm{P}}(\underline{\mathrm{x}})=\sum_{\xi}{ }^{\prime} \underline{\underline{S}}^{\mathrm{P}}(\underline{\xi}):\left[\frac{1}{\mathrm{U}} \int_{\mathrm{U}} \underline{\varepsilon}^{*}(\underline{\mathrm{y}}) \cdot \exp (\underline{\mathrm{i}} \underline{\xi} \cdot(\underline{\mathrm{x}}-\underline{\mathrm{y}})) \mathrm{dV} \mathrm{y}_{\mathrm{y}}\right] .
$$

Equation (3.52) represents the periodic integral operator that acts on the eigenstrain $\varepsilon^{*}(\mathrm{x})$.

The equations developed in this and previous sections, though complicated, underscore the power of the periodic microstructure method. Through the use of the Fourier expansion, the relationships that were all generally functions of position have been replaced by functions of $\xi$, which is the additive term of the expansion and is independent of position. From this foundation, the constitutive, consistency, and equilibrium equations can be applied to a heterogeneous representative volume element (RVE) in order to ascertain its effective material properties. 


\subsection{Periodic consistency conditions}

The consistency condition for the homogenized inclusion relates the stiffness or compliance of the inclusion to that of the homogenized reference term and corresponding eigenstrain/eigenstress. For the case of periodic microstructure, the relationship can be written as follows

$$
\underline{\underline{C}}^{\Omega}(\underline{\mathrm{x}}):\left(\varepsilon^{\mathrm{o}}+\varepsilon^{\mathrm{p}}(\underline{\mathrm{x}})\right)=\underline{\underline{\mathrm{C}}}:\left(\varepsilon^{\mathrm{o}}+\varepsilon^{\mathrm{p}}(\underline{\mathrm{x}})-\varepsilon^{*}(\underline{\mathrm{x}})\right)
$$

for an applied strain and

$$
\underline{\underline{D}}^{\Omega}(\underline{\mathrm{x}}):\left(\sigma^{\mathrm{o}}+\sigma^{\mathrm{p}}(\underline{\mathrm{x}})\right)=\underline{\underline{\mathrm{D}}}:\left(\sigma^{\mathrm{o}}+\sigma^{\mathrm{p}}(\underline{\mathrm{x}})-\sigma^{*}(\underline{\mathrm{x}})\right)
$$

for an applied stress. The periodic disturbance strain $\varepsilon^{\mathrm{P}}(\mathrm{x})$ is determined according to Equation (3.52), because Equation (3.7) equates the disturbance strain, $\mathrm{S}^{\mathrm{P}}$, to the periodic integral operator. It is written as

$$
\underline{\varepsilon}^{\mathrm{P}}(\underline{\mathrm{x}})=\sum_{\xi} \mathrm{FS}^{\mathrm{P}}(\underline{\xi}):\left[\frac{1}{\mathrm{U}} \int_{\mathrm{U}} \underline{\varepsilon}^{*}(\underline{\mathrm{y}}) \cdot \exp (\underline{\mathrm{i}} \underline{\xi} \cdot(\underline{\mathrm{x}}-\underline{\mathrm{y}})) \mathrm{dV} \mathrm{y}\right]
$$


An equation of the same form could be written for the disturbance stress, $\sigma^{\mathrm{P}}(\mathrm{x})$. For purposes of this research, only an applied strain $\varepsilon^{\mathrm{o}}$ was considered. Replacing the $\varepsilon^{\mathrm{P}}(\mathrm{x})$ term in Equation (3.53) with Equation (3.55) and rearranging yields the following equation

$$
\begin{aligned}
& {\left[\underline{\underline{C}}^{\Omega}(\underline{x})-\underline{\underline{C}}\right]:\left(\varepsilon^{0}+\sum_{\xi}{ }^{\prime} \underline{\underline{S}}^{\mathrm{P}}(\underline{\xi}):\left[\frac{1}{\mathrm{U}} \int_{\mathrm{U}} \underline{\varepsilon}^{*}(\underline{\mathrm{y}}) \cdot \exp (\underline{\mathrm{i}} \underline{\xi} \cdot(\underline{\mathrm{x}}-\underline{\mathrm{y}})) \mathrm{dV} \mathrm{y}_{\mathrm{y}}\right]\right) .} \\
& +\underline{\underline{\mathrm{C}}}: \varepsilon^{*}(\underline{\mathrm{x}})=0
\end{aligned}
$$

Through expansion of the eigenstrain and inclusion stiffness terms into their respective Fourier series, Equation (3.56) can be rewritten in terms of only the Fourier coefficients:

$$
\begin{aligned}
& \underline{F C}^{\Omega}(\underline{\xi}): \underline{\varepsilon}^{0}+\left[\sum_{\zeta} \mathrm{FC}^{\Omega}(\underline{\xi}-\underline{\zeta}): \underline{F S}^{\mathrm{P}}(\underline{\zeta}): F \underline{\varepsilon}^{*}(\underline{\zeta})\right] \\
& =\mathrm{C}:\left[\varepsilon^{0}+\mathrm{FS}^{\mathrm{P}}(\underline{\xi}): \mathrm{F} \underline{\varepsilon}^{*}(\underline{\xi})-\mathrm{F} \underline{\varepsilon}^{*}(\underline{\xi})\right]
\end{aligned}
$$

where the $\zeta$ term is an identical vector of the form of $\xi$ that is needed because the summation term must be done for every value of $\xi$. Equation (3.57) represents a linear system of equations for all values of $\xi$. This equation can be solved for any degree of accuracy in $\xi$ required to determine the Fourier coefficients of the eigenstrain $\mathrm{F}^{*}(\mathrm{x})$. Once the Fourier coefficients of the eigenstrain are known, the expanded eigenstrain is known according to Equation (3.20) as a function of the number of $\xi$ terms that are considered. 


\subsection{Average eigenstrain approximation}

The resolution of the linear system of equations prescribed by Equation (3.57) is an involved process, and one that will be outlined in the subsequent chapters in this dissertation. A simplification of the analysis is to assume that the eigenstrain is equal to some average value, which is denoted as $\bar{\varepsilon}^{*}$. This assumption has the effect of simplifying the periodic disturbance strain term $\varepsilon^{\mathrm{P}}(\mathrm{x})$ given by Equation (3.55), which results in the following

$$
\underline{\varepsilon}^{\mathrm{P}}(\underline{\mathrm{x}})=\sum_{\xi} \mathrm{FS}^{\mathrm{P}}(\underline{\xi}):\left[\frac{1}{\mathrm{U}} \int_{\mathrm{U}}^{\boldsymbol{E}^{*}} \cdot \exp (\underline{\mathrm{i}} \underline{\underline{\xi}} \cdot(\underline{\mathrm{x}}-\underline{\mathrm{y}})) \mathrm{dV} \mathrm{y}\right]
$$

Since the eigenstrain exists only in the domain of the inclusion, which was previously defined as $\Omega$, Equation (3.58) can be rewritten in the following form

$$
\underline{\varepsilon}^{\mathrm{P}}(\underline{\mathrm{x}})=\sum_{\xi} \mathrm{FS}_{\underline{\underline{S}}}^{\mathrm{P}}(\underline{\xi})\left[\frac{1}{\mathrm{U}} \int_{\Omega} \exp (-\mathrm{i} \underline{\xi} \cdot \underline{\mathrm{y}}) \mathrm{dV} \mathrm{y}\right] \exp (\underline{\mathrm{i}} \underline{\underline{\xi}} \cdot \underline{\mathrm{x}}): \bar{\varepsilon}^{*}
$$


in which the domain of the volume integral has been modified from $U$ to $\Omega$. If the algebraic term $\frac{\Omega}{\Omega}$ is multiplied to the right side of Equation (3.59), then it can be simplified further to be

$$
\underline{\varepsilon}^{\mathrm{P}}(\underline{\mathrm{x}})=\sum_{\xi} \mathrm{f} \cdot \mathrm{g}(-\underline{\xi}) \mathrm{FS}_{\underline{\underline{S}}}^{\mathrm{P}}(\underline{\xi}) \exp (i \underline{\mathrm{i}} \cdot \underline{\mathrm{x}}): \bar{\varepsilon}^{*}
$$

in which $\mathrm{f}=\frac{\Omega}{\mathrm{U}}$ and

$$
\mathrm{g}(-\underline{\xi})=\frac{1}{\Omega} \int_{\Omega} \exp (-\underline{\mathrm{i}} \underline{\underline{y}} \cdot \underline{\mathrm{y}}) \mathrm{dV}_{\mathrm{y}} .
$$

Given that the eigenstrain has been assumed to be an average (uniform) value, then the subsequent volume average of the periodic disturbance strain can be written as

$$
\frac{1}{\Omega} \int_{\Omega} \underline{\varepsilon}^{\mathrm{P}}(\underline{\mathrm{x}}) \mathrm{dV}=\mathrm{S}^{\mathrm{P}}: \bar{\varepsilon}^{*}
$$

where $\mathrm{S}^{\mathrm{P}}$ is found according to

$$
\mathrm{S}^{\mathrm{P}}=\sum_{\xi} \mathrm{f} \cdot \mathrm{g}(-\underline{\xi}) \mathrm{g}(\underline{\xi}) \mathrm{FS}^{\mathrm{P}}(\underline{\xi})
$$


and the g-integral values are determined according to Equation (3.61). The modified consistency condition in light of the average eigenstrain can be expressed as

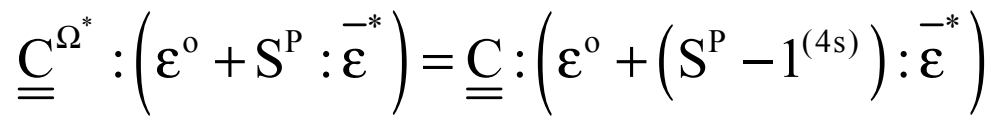

in which $\underline{\underline{C}}^{\Omega^{*}}$ is a defined here as the average value of the general inclusion stiffness matrix $\underline{\underline{C}}^{\Omega}(\underline{\mathrm{x}})$ and $1^{(4 \mathrm{~s})}$ is a fourth order identity tensor. Similarly, the effective stiffness consistency condition can be expressed according to

$$
\overline{\underline{C}}: \varepsilon^{o}=\underline{\underline{C}}:\left(\varepsilon^{o}-f \bar{\varepsilon}^{*}\right)
$$

By solving Equation (3.64) for $\bar{\varepsilon}^{-*}$ and substituting into Equation (3.65), the following expression can be written for the effective stiffness matrix

$$
\underline{\underline{C}}=\mathrm{C}:\left\{1^{(4 \mathrm{~s})}-\mathrm{f}\left[\left(\left(\underline{\left.\left.\left.\left.\underline{C}-\underline{\mathrm{C}}^{\Omega}\right)^{-1}: \underline{\mathrm{C}}-\underline{\underline{S}}^{\mathrm{P}}\right)^{-1}\right]\right\}}\right.\right.\right.\right.
$$

This equation is valid for a heterogeneous RVE consisting of a single inclusion surrounding an isotropic matrix region. In the case of multiple inclusions, the analysis is the same with the exception that there will be "n" number of consistency equations 
corresponding to the number of inclusion present in the RVE. This is represented as follows:

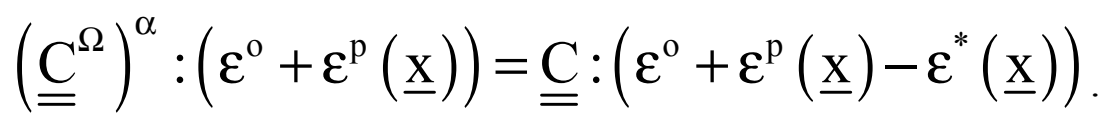

In addition, the term SP is written as

$$
\mathrm{S}^{\mathrm{P}}\left(\Omega_{\alpha}, \Omega_{\beta}\right)=\sum_{\xi} \mathrm{f} \cdot \mathrm{g}_{\alpha}(-\underline{\xi}) \mathrm{g}_{\beta}(\underline{\xi}) \mathrm{FS}^{\mathrm{P}}(\underline{\xi})
$$

in which the $\alpha$ and $\beta$ terms correspond to the considered inclusion. For multiple inclusions, there are $S^{P}$ terms that correspond to the effects that inclusion $\alpha(1 \ldots n)$ has on inclusion $\beta(1 \ldots \mathrm{n})$. Equation (3.68) takes into account the interaction between the various inclusions present in the RVE. Subsequently, the $\mathrm{g}$ integral is now represented as

$$
g_{\alpha}(-\underline{\xi})=\frac{1}{\Omega_{\alpha}} \int_{\Omega_{\alpha}} \exp (-\underline{i} \underline{\xi} \cdot \underline{y}) d V_{y}
$$

Replacing the periodic disturbance strain term in Equation (3.67) with the summation of $S^{P}$ terms for all of the interactions transforms the consistency equation to the following form 


$$
\begin{aligned}
& \left(\underline{\underline{C}}^{\Omega}\right)^{\alpha}:\left(\varepsilon^{o}+\sum_{\beta=1}^{\mathrm{n}} \mathrm{S}^{\mathrm{P}}\left(\Omega_{\alpha}, \Omega_{\beta}\right): \bar{\varepsilon}^{* \beta}\right)= \\
& \underline{\underline{C}}:\left(\varepsilon^{\mathrm{o}}+\sum_{\beta=1}^{\mathrm{n}}\left[\mathrm{S}^{\mathrm{P}}\left(\Omega_{\alpha}, \Omega_{\beta}\right)-\delta_{\alpha \beta} 1^{(4 \mathrm{~s})}\right]: \bar{\varepsilon}^{* \beta}\right)
\end{aligned}
$$

This equation is valid for every $\alpha^{\text {th }}$ inclusion. The effective stiffness matrix can also be rewritten to account for multiple inclusions. The procedure for deriving the effective stiffness term is similar to that of the single inclusion outlined in Equations (3.64) through (3.66). Solving Equation (3.70) for the eigenstrain results in a linear system of equations of the form of

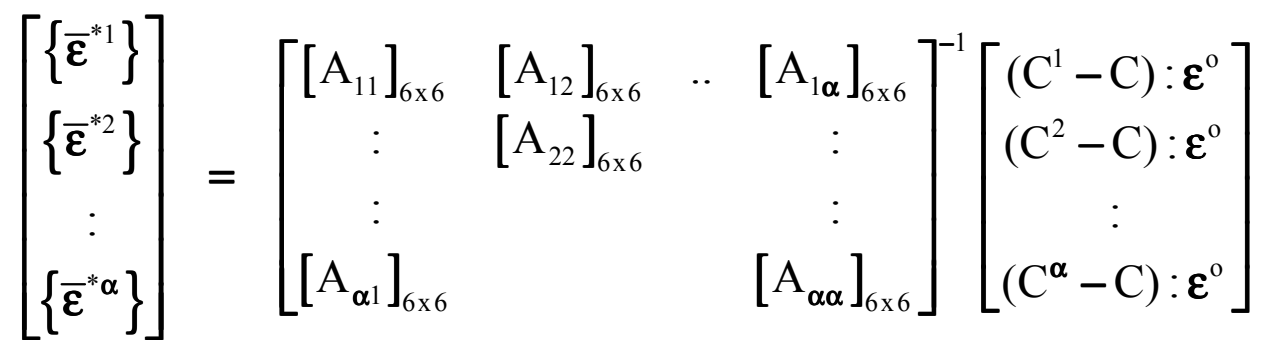

in which the $\left[\mathrm{A}_{\mathrm{ij}}\right]$ sub matrices are all $6 \times 6$, and each of the eigenstrain terms are all $6 \times 1$, which completely describes all of the components of the eigenstrain. Subsequently, the entire matrix that encompasses all of the $\left[\mathrm{A}_{\mathrm{ij}}\right]$ sub matrices is $6 \alpha \times 6 \alpha$. The $\left[\mathrm{A}_{\mathrm{ij}}\right]$ sub matrices are written as

$$
\underline{\underline{\mathrm{A}}}=\underline{\underline{\mathrm{C}}}:\left(\underline{\underline{\mathrm{S}}}^{\mathrm{P}}\left(\Omega_{\alpha}, \Omega_{\beta}\right)-\delta_{\alpha \beta} 1^{(4 \mathrm{~s})}\right)-\underline{\underline{\mathrm{C}}}^{\Omega^{\alpha}}: \underline{\underline{\mathrm{S}}}^{\mathrm{P}}\left(\Omega_{\alpha}, \Omega_{\beta}\right)
$$


The effective stiffness consistency equation for a multiple inclusion case is written as

$$
\overline{\underline{C}}: \varepsilon^{o}=\underline{\underline{C}}:\left(\varepsilon^{o}-\sum_{\beta=1}^{\mathrm{n}} \mathrm{f}_{\beta} \bar{\varepsilon}^{* \beta}\right)
$$

and the effective stiffness matrix is resolved by substituting the eigenstrain terms found in Equation (3.71) and simplifying, which results in the following:

$$
\underline{\underline{\mathrm{C}}}=\underline{\underline{C}}:\left\{\mathrm{I}^{(4 \mathrm{~s})}-\sum_{\alpha=1}^{\mathrm{n}} \mathrm{f}_{\alpha}\left[\sum_{\beta=1}^{\mathrm{n}} \mathrm{A}_{\alpha \beta}^{-1}:\left(\underline{\underline{C}}^{\alpha}-\underline{\underline{C}}\right): \mathrm{I}^{(4 \mathrm{~s})}\right]\right\}
$$

The equations that have been derived and expounded upon in this Chapter detail the mechanical and mathematical foundations that were used in developing the mesoscale models for the material property prediction of fabric reinforced composite materials. In the next two chapters, the procedures that were taken to apply these equations to the woven fabric geometry for both the average eigenstrain assumption and the exact eigenstrain term will be presented, along with the analysis and comparison of the results with experimental data. 


\begin{tabular}{|c|c|c|}
\hline Field Variable & Fourier Expansion & Fourier Coefficient \\
\hline Displacement & $\underline{\mathrm{u}}(\underline{\mathrm{x}})=\sum_{\xi}[\underline{\mathrm{Fu}}(\underline{\xi}) \cdot \exp (\underline{\operatorname{ix}} \cdot \underline{\xi})]$ & $\underline{\mathrm{Fu}}(\underline{\xi})=\frac{1}{U} \int_{U} \underline{u}(\underline{x}) \cdot \exp (-i \underline{x} \cdot \underline{\xi}) d V$ \\
\hline Strain & $\underline{\varepsilon}(\underline{x})=\sum_{\xi}^{\prime}\left[\underline{F \varepsilon}{ }^{*}(\underline{\xi}) \cdot \exp (\underline{i x} \cdot \underline{\xi})\right]$ & $\underline{F \varepsilon}(\underline{\xi})=\frac{1}{U} \int_{U} \underline{\varepsilon}(\underline{x}) \cdot \exp (-i \underline{x} \cdot \underline{\xi}) d V$ \\
\hline $\begin{array}{l}\text { Inclusion } \\
\text { Stiffness }\end{array}$ & $\underline{\underline{C}}^{\Omega}(\underline{\mathrm{x}})=\sum_{\xi}\left[\underline{\underline{F C}}^{\Omega}(\underline{\xi}) \cdot \exp (\underline{i x} \cdot \underline{\xi})\right]$ & $\underline{\underline{F C}}(\underline{\xi})=\frac{1}{U} \int_{U} \underline{C}^{\Omega}(\underline{x}) \cdot \exp (-i \underline{x} \cdot \underline{\xi}) d V$ \\
\hline $\begin{array}{l}\text { Matrix } \\
\text { Stiffness }\end{array}$ & $\underline{\underline{C}}(\underline{\mathrm{x}})=\sum_{\xi}[\underline{\underline{\mathrm{FC}}}(\underline{\xi}) \cdot \exp (\underline{\mathrm{ix}} \cdot \underline{\xi})]$ & $\underline{\underline{\mathrm{FC}}}(\underline{\xi})=\frac{1}{\mathrm{U}} \int_{\mathrm{U}} \underline{\underline{\mathrm{C}}}(\underline{\mathrm{x}}) \cdot \exp (-\mathrm{ix} \cdot \underline{\xi}) \mathrm{dV}$ \\
\hline
\end{tabular}

Table 3.1: Listing of the Fourier expansions and coefficients for some pertinent field variables 


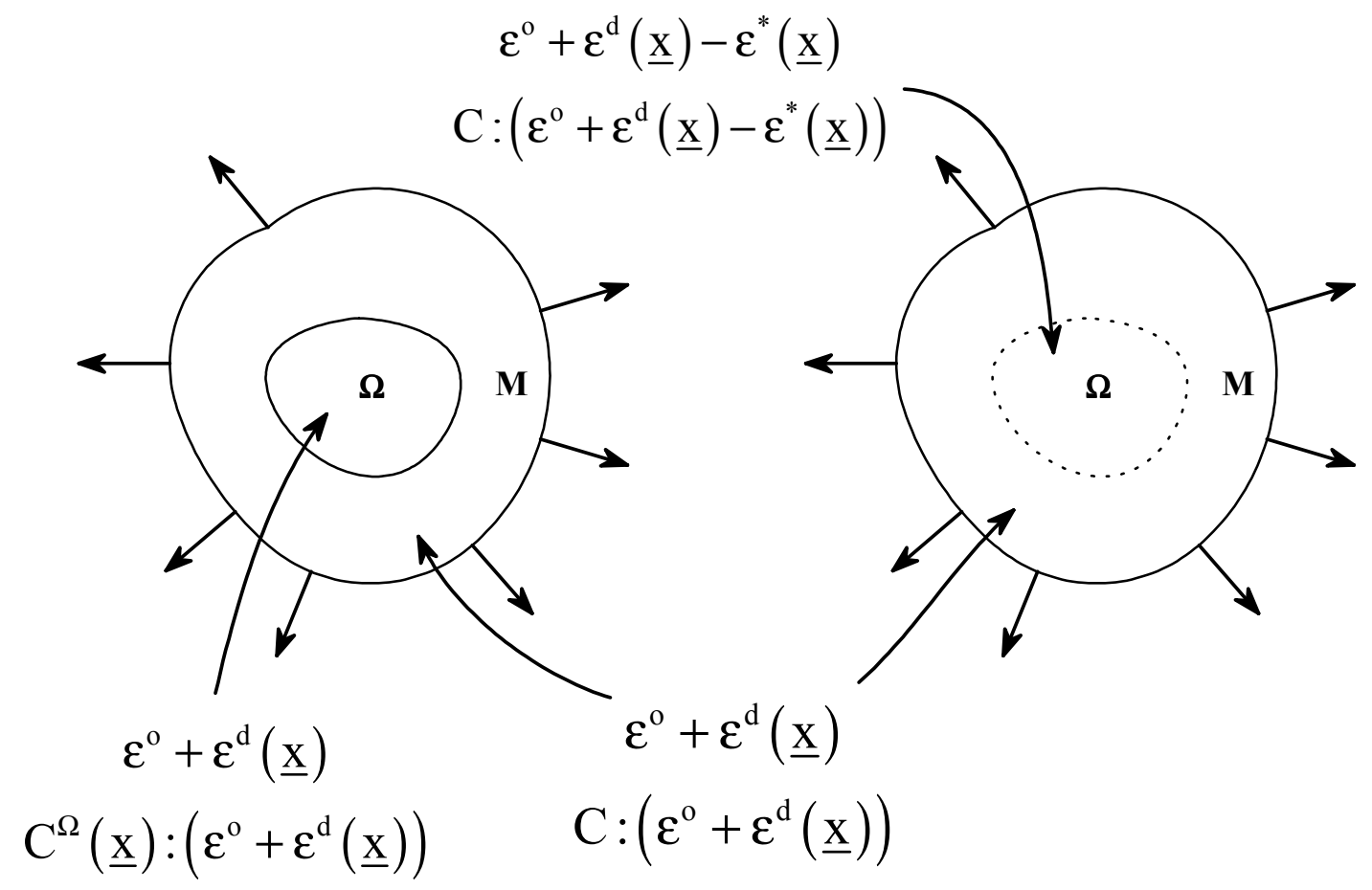

a) Heterogeneous Material

b) Equivalent Homogeneous Material

Figure 3.1: Illustration of the homogenization of an RVE using eigenstrains. 


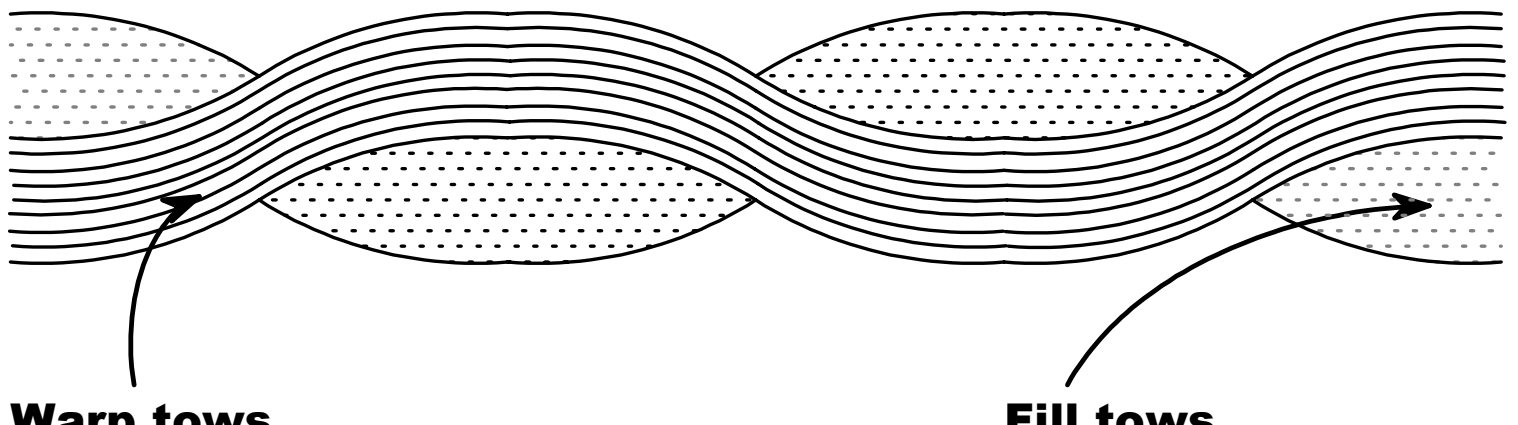

Warp tows

Fill tows

Figure 3.2: Cross section of a plain weave fabric, illustrating an example of geometric periodicity with the sinusoidal shape of the warp tows. 


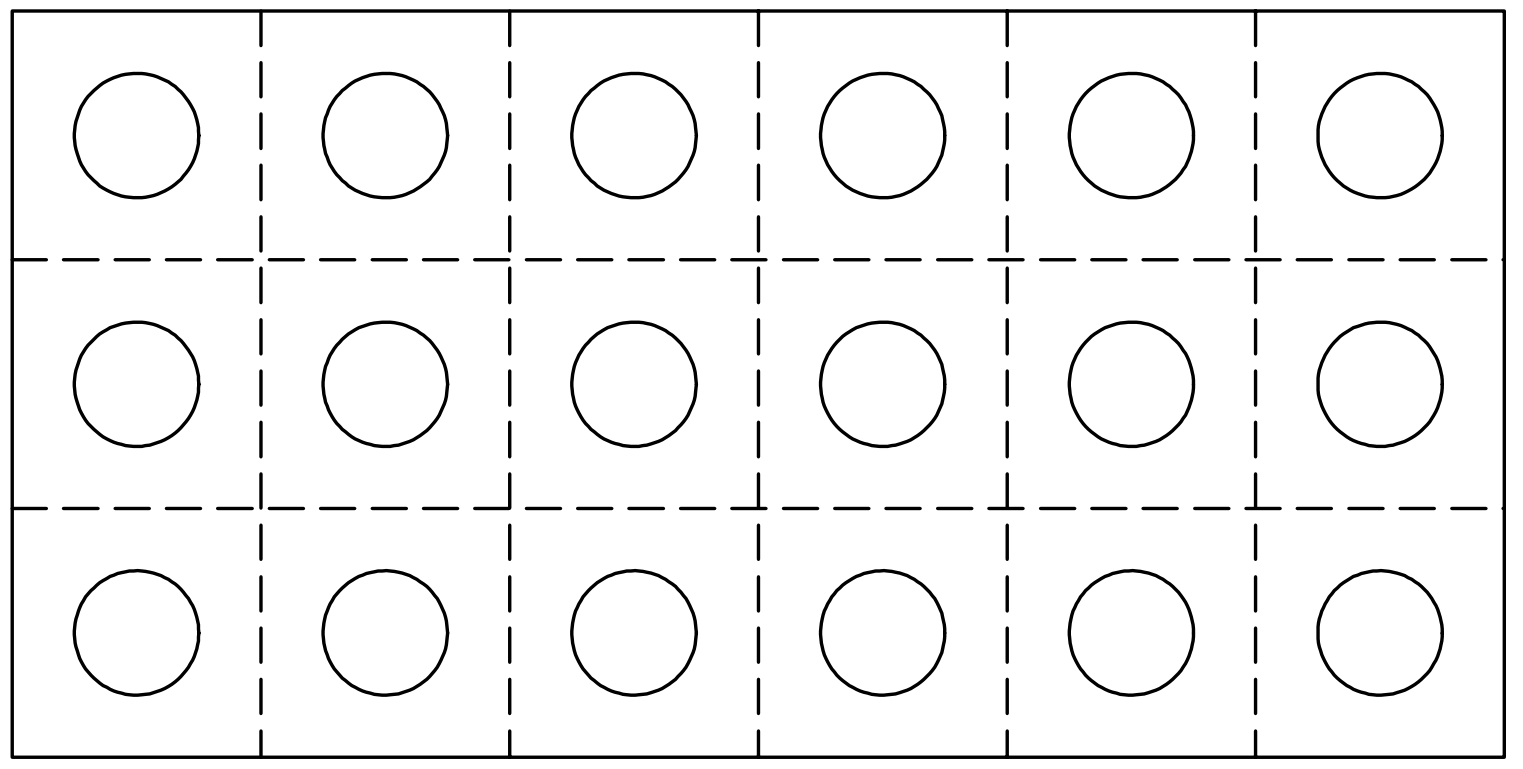

Figure 3.3: An example of periodic spacing in a material cross-section or RVE. 


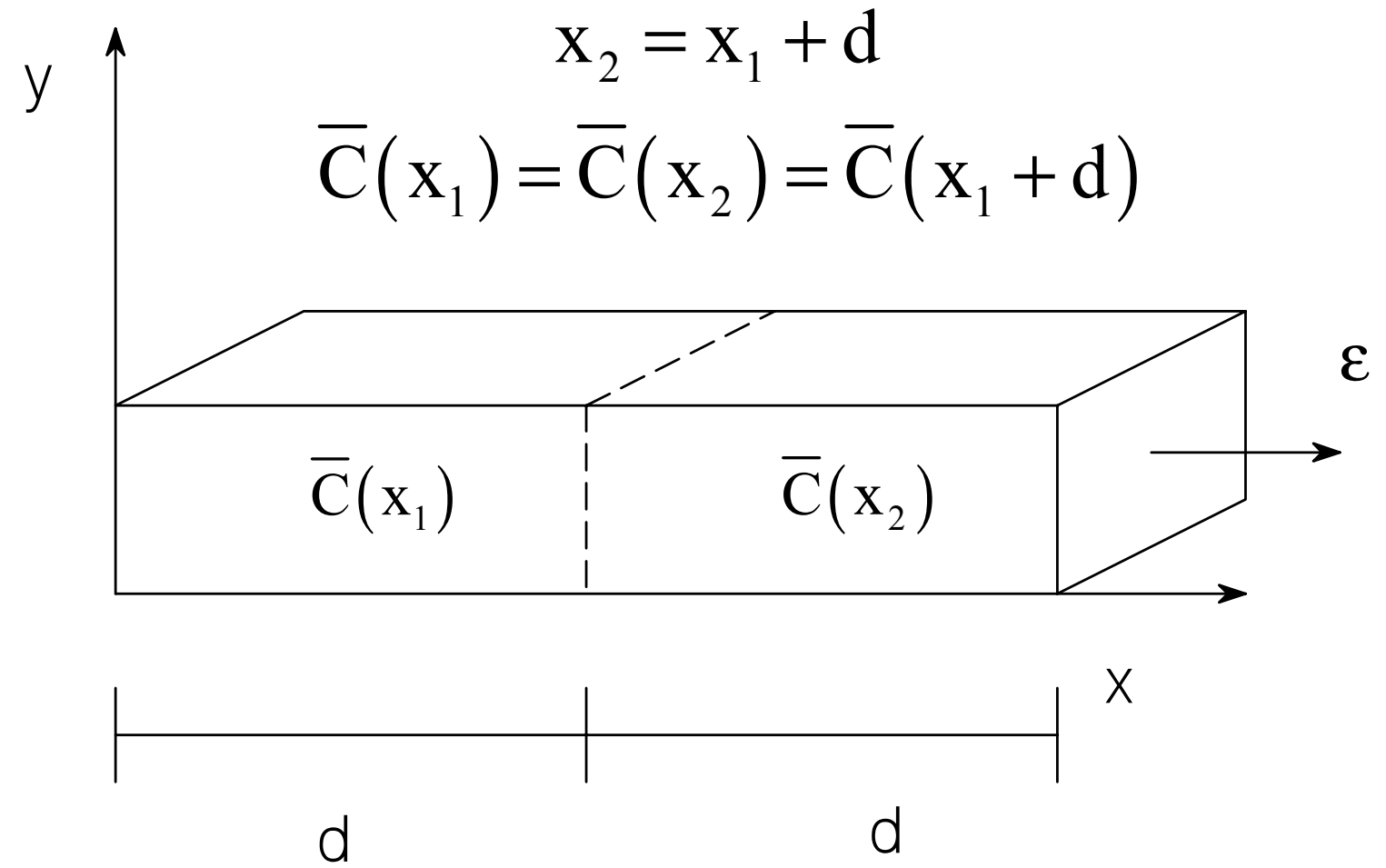

Figure 3.4: An illustration showing that if the material is periodic at an interval $d$, the material properties are equivalent at a spacing that are multiples of $\mathrm{d}$. 


\section{Chapter 4}

\section{Average Eigenstrain Approximation}

The application of periodic microstructure set forth by Nemat-Nasser and Hori in [32] was applied to heterogeneous representative volume elements containing microvoids and micro-inclusions in which the fraction of the total void volume to the RVE volume is small $(\sim 0.10)$. The contribution of this dissertation is to apply these techniques of homogenization and effective material property determination in order to ascertain the effective material properties of a plain weave fabric composite material. The inclusions are defined as the system of fiber tows and the matrix that impregnates the tow during fabrication. For the woven fabric architectures analyzed, the void/RVE volume fraction is on the order of 0.5 for a given RVE, meaning that the inclusions exist in the meso scale, instead of the micro scale.

This chapter details the geometric representation of the boundaries of each yarn through three dimensional surface functions, and even though the inclusions consist of a sub-level of fiber and matrix (micro scale), the model assumes that the tows are locally unidirectional and the material properties are already known (the properties of a unidirectional composite can be accurately determined from existing micromechanical models). Once the inclusion geometry has been completely described, the equations 
derived in Chapter 2 can be evaluated and the effective material properties of the RVE can be determined. Those subsequent equation evaluations will be described herein.

Two plain weave fabric geometries were investigated: AS4 Carbon/Vinyl Ester fabric composite analyzed by Ito and Chou [13] and an E-glass/Epoxy fabric composite for use by the Construction Engineering Research Laboratory (CERL) of the US Army Corps of Engineers. The geometry of Ito and Chou is derived solely from sinusoidal functions that were reported in their investigation. For the CERL geometry, the sinusoidal functions were fit from photomicrographs of the composite cross section. The objective of the geometric characterization is to describe with surface functions the volume boundaries of the tows, i.e. where the pure matrix and the fiber/matrix regions meet. From the functional representations of the faces of the RVE, three dimensional surface functions were generated.

\subsection{Geometric characterization procedures}

This section details the procedures for obtaining the surface functions that define the boundaries of the fiber/matrix tow system. For a plain weave fabric composite, the representative volume element is represented according to Figure 4.1. From this illustration, it is evident that the weaving and interlacing of the tows in the 0 and 90 degree directions are sinusoidal in nature. The general weaving shape of the fiber/matrix tow can be represented according to the following function 


$$
f(x)=A \sin (B \cdot x+C)+D
$$

in which the variables $\mathrm{A}, \mathrm{B}, \mathrm{C}$, and $\mathrm{D}$ are all curve fitting parameters. This equation holds not only for the general shape of the tow, but also for the shape of the tow crosssection as well. From photomicrographs of the four faces of the RVE, the warp (tow running across the face) and fill (the two tows that come out of the page) tows can be plotted and curves can be fitted in accordance with Equation (4.1). This concept is portrayed in Figures 4.2 and 4.3. From these two dimensional plots, two things can be determined for a given cross-section: The shape of the fill tow cross-sections, and the nature of the warp tow undulation through the RVE. For the cross-section modeled in [13], only one face is defined. Because the authors used classical lamination theory to analyze the system, there was no need to define or model the other three faces of the RVE. It was assumed in this work that the 0 and 90 degree front faces were identical, and the corresponding rear faces were mirror images. This was done for the simplicity of the equations. For each tow, there exists boundaries on each of the four faces of the RVE that define the top and the bottom of the tow, respectively. The top fill tow on the front face in, say, the 0 degree direction is aligned with the bottom fill tow on the rear face, and so on. Therefore, from Figures 4.2 and 4.3 the outermost boundaries and the crosssections are defined, with there being two equations to describe each fill cross section, respectively. The shape of the warp tows in the 0 degree direction defines the sinusoidal path that the fill tows in the 90 degree direction take, and vice versa. By resolving the two dimensional representations of all four RVE faces, the three dimensional surface functions corresponding to the boundaries of the fiber/matrix tow system can be derived. 


\subsubsection{Ito and Chou geometry}

The graphs in Figures 4.4 through 4.7 depict the cross sections that are defined in [13]. The equations that describes that warp tow for the front faces are (the function defined with $\mathrm{f}$ denotes the 0 degree direction and $\mathrm{g}$ described the 90 degree direction).

$$
\begin{gathered}
\mathrm{f}_{\text {front }}(\mathrm{x})=\frac{\mathrm{a}_{3}}{2} \sin \left(\frac{\pi}{2 \cdot \mathrm{a}_{1}} \mathrm{x}\right) \\
\mathrm{g}_{\text {front }}(\mathrm{y})=\frac{\mathrm{a}_{3}}{2} \sin \left(\frac{\pi}{2 \cdot \mathrm{a}_{2}} \mathrm{y}\right)
\end{gathered}
$$

in which $\mathrm{a}_{1}, \mathrm{a}_{2}$, and $\mathrm{a}_{3}$ are the dimensions of the RVE that describe the total volume $(\mathrm{V}=$ $\left.2 a_{1} \times 2 a_{2} \times 2 a_{3}\right)$. The outermost warp boundaries correspond to lines which are displaced a distance equal to $1 / 2$ the vertical RVE dimension, $\mathrm{a}_{3}$. Therefore, the warp boundaries on each cross section have the following form:

$$
\begin{gathered}
\mathrm{f}, \mathrm{g}_{\text {front }, \text { top }}(\mathrm{x}, \mathrm{y})=\mathrm{f}_{\text {front }}(\mathrm{x}, \mathrm{y})+\frac{\mathrm{a}_{3}}{2} \\
\mathrm{f}, \mathrm{g}_{\text {front bottom }}(\mathrm{x}, \mathrm{y})=\mathrm{f}_{\text {front }}(\mathrm{x}, \mathrm{y})-\frac{\mathrm{a}_{3}}{2}
\end{gathered}
$$


The equations for the top and bottom fill boundaries for the 0 degree front face are

$$
\begin{gathered}
\mathrm{f}_{\text {fill, top }}(\mathrm{x})=\left(-\frac{1}{2} \mathrm{a}_{3} \sin \left(\frac{\pi \cdot \mathrm{a}_{\mathrm{g}}}{4 \cdot \mathrm{a}_{1}}\right)-\frac{1}{2} \mathrm{a}_{3}\right) \cdot \sin \left(\frac{\pi}{\mathrm{ag}_{\mathrm{g}}-2 \mathrm{a}_{1}} \cdot \mathrm{x}-\frac{\pi\left(\mathrm{a}_{\mathrm{g}}-4 \mathrm{a}_{1}\right)}{2\left(\mathrm{a}_{\mathrm{g}}-2 \mathrm{a}_{1}\right)}\right)- \\
\frac{1}{2} \mathrm{a}_{3} \sin \left(\frac{\pi \mathrm{a}_{\mathrm{g}}}{4 \mathrm{a}_{1}}\right)+\frac{1}{2} \mathrm{a}_{3} \\
\mathrm{f}_{\text {fill, bottom }}(\mathrm{x})=\left(-\frac{1}{2} \mathrm{a}_{3} \sin \left(\frac{\pi \cdot \mathrm{a}_{\mathrm{g}}}{4 \cdot \mathrm{a}_{1}}\right)-\frac{1}{2} \mathrm{a}_{3}\right) \cdot \sin \left(\frac{\pi}{\mathrm{ag}_{\mathrm{g}}-2 \mathrm{a}_{1}} \cdot \mathrm{x}+\frac{\pi\left(\mathrm{a}_{\mathrm{g}}-4 \mathrm{a}_{1}\right)}{2\left(\mathrm{a}_{\mathrm{g}}-2 \mathrm{a}_{1}\right)}\right)+ \\
\frac{1}{2} \mathrm{a}_{3} \sin \left(\frac{\pi \mathrm{a}_{\mathrm{g}}}{4 \mathrm{a}_{1}}\right)-\frac{1}{2} \mathrm{a}_{3}
\end{gathered}
$$

in which the term $a_{\mathrm{g}}$ is the measured distance between the innermost fill points, as they intersect with the warp tow boundaries. The equations that describe the top and bottom fill tows in the 90 degree direction are:

$$
\begin{gathered}
g_{\text {fill, top }}(y)=\left(\frac{1}{2} a_{3} \sin \left(\frac{\pi \cdot a_{g}}{4 \cdot a_{2}}\right)+\frac{1}{2} a_{3}\right) \cdot \sin \left(\frac{\pi}{a_{g}-2 a_{2}} \cdot y+\frac{\pi\left(a_{g}-4 a_{2}\right)}{2\left(a_{g}-2 a_{2}\right)}\right)- \\
\frac{1}{2} a_{3} \sin \left(\frac{\pi a_{g}}{4 a_{2}}\right)+\frac{1}{2} a_{3} \\
g_{\text {fill, bottom }}(y)=\left(\frac{1}{2} a_{3} \sin \left(\frac{\pi \cdot a_{g}}{4 \cdot a_{2}}\right)+\frac{1}{2} a_{3}\right) \cdot \sin \left(\frac{\pi}{a_{g}-2 a_{2}} \cdot y-\frac{\pi\left(a_{g}-4 a_{2}\right)}{2\left(a_{g}-2 a_{2}\right)}\right)+ \\
\frac{1}{2} a_{3} \sin \left(\frac{\pi a_{g}}{4 a_{2}}\right)-\frac{1}{2} a_{3}
\end{gathered}
$$


The lines described by Equations (4.6) to (4.9) are for the top or bottom cross section boundary for each respective fill yarn. The other boundary is described by the equation for the top or bottom warp tow boundary, signified by Equations (4.4) and (4.5). In order to account for the rear faces, the equations for the front face need only to be multiplied by -1 , given the simplifications of the geometry. For the photomicrographs from CERL, this will not be the case.

Now that the equations for all of the boundaries are taken into account, the next step is to combine the boundary values of the front and rear fill cross sections along with the corresponding warp shape on the adjacent face to develop a surface function that blends the two faces together. Consider first the 0 degree front face. In Figure 4.8, only the top boundary of the top fill is plotted with respect to the RVE on the front face. On the rear face, the top portion of the top warp tow boundary is plotted along the same distance in $\mathrm{a}_{\mathrm{x}}$. These two extremum are going to be the "points" that are used to fit a surface function to the two lines. Recalling the general form of a sinusoidal function in Equation (4.1), this term can be rewritten for the surface function purposes to be

$$
\mathrm{F}_{\text {fill, top }, 0}(\mathrm{x}, \mathrm{y})=\mathrm{A}(\mathrm{x}) \sin [\mathrm{B}(\mathrm{x}) \cdot \mathrm{y}+\mathrm{C}(\mathrm{x})]+\mathrm{D}(\mathrm{x})
$$

in which the terms A through D are now functions of the position in $\mathrm{x}$, and the surfaces is swept in the y, or 90 degree, direction. In Mathcad 2001, there is a tool called a symbolic solve block, in which linear systems of equations can be solved simultaneously. Four conditions exist at the boundaries that enable the unknowns $\mathrm{A}$ through $\mathrm{D}$ to be determined as functions of the position in $\mathrm{x}$. The equations of the lines on the front and 
rear face are known from Equations (4.4) and (4.6). The other two conditions come from the shape of the RVE. Looking at the shape of the warp tow in the 90 degree direction, the slope of that line at the end points $-a_{2}$ and $a_{2}$ are zero. From this, four conditions exist with which to symbolically determine the values of A, B, C, and D. The results of that calculation for the upper portion of the top fill yarn in the 0 degree direction are summarized below

$$
\begin{aligned}
& \mathrm{A}_{\text {fill, top }, 0}(\mathrm{x})=-\frac{1}{4} \mathrm{a}_{3} \sin \left(\frac{\pi \mathrm{x}}{2 \mathrm{a}_{1}}\right)-\frac{1}{2} \mathrm{a}_{3} \\
&+\frac{\mathrm{a}_{3}}{4} \sin \left[\frac{\pi\left(2 \mathrm{x}-\mathrm{a}_{\mathrm{g}}+4 \mathrm{a}_{1}\right)}{2\left(\mathrm{a}_{\mathrm{g}}-2 \mathrm{a}_{1}\right)}\right] \sin \left(\frac{\pi \mathrm{a}_{\mathrm{g}}}{4 \mathrm{a}_{1}}\right) \\
&+\frac{\mathrm{a}_{3}}{4} \sin \left[\frac{\pi\left(2 \mathrm{x}-\mathrm{a}_{\mathrm{g}}+4 \mathrm{a}_{1}\right)}{2\left(\mathrm{a}_{\mathrm{g}}-2 \mathrm{a}_{1}\right)}\right]+\frac{1}{4} \mathrm{a}_{3} \sin \left(\frac{\pi \mathrm{a}_{\mathrm{g}}}{4 \mathrm{a}_{1}}\right) \\
& \mathrm{B}_{\text {fill, to }, 0}(\mathrm{x})=\frac{\pi}{2 \mathrm{a}_{2}} \\
& \mathrm{C}_{\text {fill, top }, 0}(\mathrm{x})=0
\end{aligned}
$$




$$
\begin{aligned}
\mathrm{D}_{\text {fill, top }, 0}(\mathrm{x})= & -\frac{1}{4} \mathrm{a}_{3} \sin \left(\frac{\pi \mathrm{x}}{2 \mathrm{a}_{1}}\right)+\frac{\mathrm{a}_{3}}{4} \sin \left[\frac{\pi\left(2 \mathrm{x}-\mathrm{a}_{\mathrm{g}}+4 \mathrm{a}_{1}\right)}{2\left(\mathrm{a}_{\mathrm{g}}-2 \mathrm{a}_{1}\right)}\right] \sin \left(\frac{\pi \mathrm{a}_{\mathrm{g}}}{4 \mathrm{a}_{1}}\right) \\
& -\frac{\mathrm{a}_{3}}{4} \sin \left[\frac{\pi\left(2 \mathrm{x}-\mathrm{a}_{\mathrm{g}}+4 \mathrm{a}_{1}\right)}{2\left(\mathrm{a}_{\mathrm{g}}-2 \mathrm{a}_{1}\right)}\right]-\frac{1}{4} \mathrm{a}_{3} \sin \left(\frac{\pi \mathrm{a}_{\mathrm{g}}}{4 \mathrm{a}_{1}}\right)
\end{aligned} .
$$

These four terms are then inserted into Equation (4.10) in order to plot the surface function that maps the upper portion of the top fill yarn in the 0 degree direction, as seen in Figure 4.9. This same procedure can be done for the bottom portion of the top fill yarn in the zero degree direction, along with the other 3 yarns, respectively. The result of finding the coefficients and plotting the surfaces for all of the fiber/matrix tow systems is plotted in Figure 4.1.

\subsubsection{CERL geometry}

The steps that were taken to resolve the surface functions for the bounds of the fiber/matrix tow system can be implemented for any plain weave system. For the fabric analyzed by CERL, all of the faces of the E-GLASS/epoxy composite were plotted, the results of which are presented in Figures 4.10 through 4.13. Therefore, there exists no simple relationship between the front and rear faces in both the 0 and 90 degree directions. The reality of measuring and analyzing all of the separate faces produces a range of values for the curve fitting function parameters. These parameters were averaged and normalized from the measurement of 5 separate specimens in order to allow for the surface function generation. The values of the parameters are summarized in 
Table 4.1 and Table 4.2, and the functions are plotted in Figures 4.14 through 4.17. The general shape of the warp tow on each face was fit to a sinusoidal function according to Equation (4.1), and the upper and lower boundaries were found by translating the curve such that the difference between the upper and lower bounds was the measured height of the warp tow, denoted as $b_{0}$ or $b_{90}$, respectively. From these boundary functions, the surfaces are generated in the same manner as Section 4.1.2.

\subsection{Evaluating the g-integral}

When the eigenstrain is assumed to be an average value of the inclusion, the

effective stiffness $\underline{\underline{\mathrm{C}}}$ can be determined from Equation (3.66) for a single inclusion and Equation (3.74) for multiple inclusions. In order to solve the equations, there are three terms that need to be evaluated: $\operatorname{FS}^{\mathrm{P}}(\xi), \mathrm{g}(\xi)$, and $\mathrm{S}^{\mathrm{P}}$. The g-integral will be discussed in this section.

Recall from Chapter 3 that the g-integral for a single inclusion was expressed according to Equation (3.61) as

$$
\mathrm{g}(-\underline{\xi})=\frac{1}{\Omega} \int_{\Omega} \exp (-\mathrm{i} \underline{\underline{\xi}} \cdot \underline{\mathrm{y}}) \mathrm{d} \mathrm{V}_{\mathrm{y}}
$$

in which $\Omega$ is the volume of the inclusion. Generation of the surface functions to describe the bounds of the 0 and 90 degree tows was necessary for the evaluation of the g-integral. It requires, first, the volume of the inclusion $\Omega$. Looking at the geometry of 
Ito and Chou, the volume of the tow that starts at the top on the 0 degree face is evaluated as follows

$$
\mathrm{V}_{\mathrm{tf} 0}=\int_{-\mathrm{a}_{2}}^{\mathrm{a}_{2}} \int_{-\mathrm{a}_{\mathrm{x}}}^{\mathrm{a}_{\mathrm{g}}} \int_{\mathrm{F}_{\mathrm{tfl} 0}(\mathrm{x}, \mathrm{y})}^{\mathrm{F}_{\mathrm{tfu} 0}(\mathrm{x}, \mathrm{y})} \mathrm{dzdxdy}
$$

The notation is important. $\mathrm{V}_{\mathrm{tfo}}$ stands for the volume of the top fill tow that starts from the $\underline{\mathbf{0}}$ degree front face and is swept to the 0 degree rear face. $\mathrm{F}_{\mathrm{tfl} 0}$ stands for the surface function that defines the top fill lower surface that is swept from the front face in the 0 degree direction. Similarly, $\mathrm{F}_{\mathrm{tfu} 0}$ stands for the surface function that defines the top fill upper surface that is swept from the front face in the $\underline{\mathbf{0}}$ degree direction. All of the functions swept from the front and rear 0 degree faces will be "F", and for the functions swept through the 90 degree faces will be "G". Equation (4.15) is used to find the respective volumes of all the tows. The limits of integration are defined by the surface functions, and these can also be used for expressing the g-integral. Substituting Equation (4.15) into Equation (3.61) and rewriting yields

$$
\mathrm{g}_{\mathrm{tf} 0}(-\underline{\xi})=\frac{1}{\mathrm{~V}_{\mathrm{tf} 0}} \int_{-\mathrm{a}_{2}}^{\mathrm{a}_{2}} \int_{-\mathrm{a}_{\mathrm{x}}}^{\mathrm{a}_{\mathrm{g}}} \int_{\mathrm{F}_{\mathrm{tfl} 0}(\mathrm{x}, \mathrm{y})}^{\mathrm{F}_{\mathrm{tfu} 0}(\mathrm{x}, \mathrm{y})} \exp (-\mathrm{i} \underline{\underline{\xi}} \cdot \underline{\mathrm{y}}) \mathrm{dzd} \mathrm{dxdy}
$$

In Equation (4.16), the term $\xi$ is defined by Equation (3.13) and $y$ is a position vector. The dot product of the vectors $\xi$ and $y$ can be expanded in the following way 


$$
\begin{aligned}
\underline{\xi} \cdot \underline{y} & =\pi\left[\begin{array}{lll}
\frac{\mathrm{n}_{1}}{\mathrm{a}_{1}} & \frac{\mathrm{n}_{2}}{\mathrm{a}_{2}} & \frac{\mathrm{n}_{3}}{\mathrm{a}_{3}}
\end{array}\right] \cdot\left[\begin{array}{lll}
\mathrm{x} & \mathrm{y} & \mathrm{z}
\end{array}\right] \\
& =\pi\left(\frac{\mathrm{n}_{1} \mathrm{x}}{\mathrm{a}_{1}}+\frac{\mathrm{n}_{2} \mathrm{y}}{\mathrm{a}_{2}}+\frac{\mathrm{n}_{3} \mathrm{z}}{\mathrm{a}_{3}}\right)
\end{aligned}
$$

where the "a" terms are the dimensions of the RVE and the " $\mathrm{n}$ " terms are indexes according to

$$
\mathrm{n}_{\mathrm{i}}=0, \pm 1, \pm 2, \ldots \pm \infty
$$

Substituting the results of Equation (4.17) into (4.16) yields

$$
\mathrm{g}_{\mathrm{tf} 0}(-\underline{\xi})=\frac{1}{\mathrm{~V}_{\mathrm{tf} 0}} \int_{-\mathrm{a}_{2}}^{\mathrm{a}_{2}} \int_{-\mathrm{a}_{\mathrm{x}}}^{\mathrm{a}_{\mathrm{g}}} \int_{\mathrm{F}_{\mathrm{tfl} 0}(\mathrm{x}, \mathrm{y})}^{\mathrm{F}_{\mathrm{tfu} 0}(\mathrm{x}, \mathrm{y})} \exp \left(-\mathrm{i} \pi\left(\frac{\mathrm{n}_{1} \mathrm{x}}{\mathrm{a}_{1}}+\frac{\mathrm{n}_{2} \mathrm{y}}{\mathrm{a}_{2}}+\frac{\mathrm{n}_{3} \mathrm{z}}{\mathrm{a}_{3}}\right)\right) \mathrm{dzdxdy}
$$

The $g$ integral, as expressed in Equation (4.19), is now a function of $\mathrm{n}_{1}, \mathrm{n}_{2}$, and $\mathrm{n}_{3}$. As the values of the " $\mathrm{n}$ " terms increases, the shape of the exponential term becomes highly oscillatory, and therefore the integral becomes more difficult to evaluate. For small values of $n(-5<n<5)$, Mathcad is an acceptable tool for calculating the g-integral.

\subsection{Evaluating $\operatorname{FS}^{\mathrm{P}}(\xi)$}

If it is assumed that the matrix surrounding the tows is isotropic, then $\mathrm{FS}^{\mathrm{P}}$ can be written according to the following equation: 


$$
\begin{aligned}
\mathrm{FS}^{\mathrm{P}}(\underline{\xi})_{\text {iso }}= & 2 \operatorname{sym}\left(\underline{\bar{\xi}} \otimes 1^{(2)} \otimes \underline{\bar{\xi}}\right)-\frac{1}{1-v}(\underline{\bar{\xi}} \otimes \underline{\bar{\xi}} \otimes \underline{\bar{\xi}} \otimes \underline{\bar{\xi}})+ \\
& +\frac{v}{1-v}\left(\underline{\bar{\xi}} \otimes \bar{\xi} \otimes 1^{(2)}\right)
\end{aligned}
$$

in which $v$ is Poisson's ratio for the matrix. This equation can be rewritten in indicial notation in the following form [37]

$$
\begin{aligned}
\operatorname{FS}^{\mathrm{P}} \mathrm{ijk}(\underline{\xi})_{\mathrm{iso}}= & \frac{1}{2}\left[\bar{\xi}_{\mathrm{j}}\left(\delta_{\mathrm{il}} \bar{\xi}_{\mathrm{k}}+\delta_{\mathrm{ik}} \bar{\xi}_{\mathrm{l}}\right)+\bar{\xi}_{\mathrm{i}}\left(\delta_{\mathrm{jl}} \bar{\xi}_{\mathrm{k}}+\delta_{\mathrm{jk}} \bar{\xi}_{\mathrm{l}}\right)\right] \\
& -\frac{1}{1-v}\left(\bar{\xi}_{\mathrm{i}} \bar{\xi}_{\mathrm{j}} \bar{\xi}_{\mathrm{k}} \bar{\xi}_{\mathrm{l}}\right)+\bar{\xi}_{\mathrm{i}} \bar{\xi}_{\mathrm{j}} \delta_{\mathrm{kl}}
\end{aligned}
$$

in which $\bar{\xi}$ has the following form

$$
\bar{\xi}=\frac{\underline{\xi}}{|\underline{\xi}|}
$$

and $\delta$ is the Dirac delta function. With $\mathrm{FS}^{\mathrm{P}}$ expressed in the form of Equation (4.21), it can now be easily programmed into any language or commercial mathematics software (such as Mathcad) for evaluation. A simple routine was written in Mathcad to not only evaluate Equation (4.21) as a function of $\xi$, but to also output the results in contracted notation. The result of evaluating the expression is a $6 \times 6$ matrix.

\subsection{Evaluating $S^{P}$}


The g-integral and $\mathrm{FS}^{\mathrm{P}}$ were defined in the previous sections, and are needed to evaluate $\mathrm{S}^{\mathrm{P}}$ according to Equation (3.63), which is written below as

$$
\sum_{\xi} \mathrm{f} \cdot g(-\underline{\xi}) g(\underline{\xi}) \mathrm{FS}^{\mathrm{P}}(\underline{\underline{\xi}}) .
$$

All of the terms in Equation (4.23) can be evaluated, and the volume fraction of the inclusion to the RVE is found by

$$
f=\frac{V_{t f 0}}{V_{R V E}}
$$

and the volume of the RVE is expressed as

$$
\mathrm{V}_{\mathrm{RVE}}=8 \cdot \mathrm{a}_{1} \cdot \mathrm{a}_{2} \cdot \mathrm{a}_{3}
$$

The summation is done for all $\xi$ terms from $-\infty$ to $\infty$. From Section 4.3, the g-integral was expressed as a function of $\mathrm{n}_{1}, \mathrm{n}_{2}$, and $\mathrm{n}_{3}$. Equation (4.23) can also be rewritten in the same manner as

$$
\mathrm{S}^{\mathrm{P}}=\sum_{\mathrm{n}_{1}} \sum_{\mathrm{n}_{2}} \sum_{\mathrm{n}_{3}} \mathrm{f}^{\prime} \cdot \mathrm{g}_{\mathrm{m}}\left(\mathrm{n}_{1}, \mathrm{n}_{2}, \mathrm{n}_{3}\right) \mathrm{g}_{\mathrm{p}}\left(\mathrm{n}_{1}, \mathrm{n}_{2}, \mathrm{n}_{3}\right) \mathrm{FS}^{\mathrm{P}}\left(\mathrm{n}_{1}, \mathrm{n}_{2}, \mathrm{n}_{3}\right)
$$


in which the $g_{p}$ and $g_{m}$ are the g-integrals that correspond to a positive or negative exponential term, respectively. The 'in front of summation denotes an exclusion of the term when $\mathrm{n}_{1}, \mathrm{n}_{2}$, and $\mathrm{n}_{3}$ all are equal to zero. This equation can also be programmed into Mathcad, and for a single inclusion the result is a 6 × 6 matrix. For multiple inclusions, the modification of $\mathrm{S}^{\mathrm{P}}$ would look like this

$$
\mathrm{S}^{\mathrm{P}}\left(\Omega_{\alpha}, \Omega_{\beta}\right)=\sum_{\mathrm{n}_{1}} \sum_{\mathrm{n}_{2}} \sum_{\mathrm{n}_{3}} \mathrm{f}^{\prime} \cdot \mathrm{g}_{\mathrm{m}, \alpha}\left(\mathrm{n}_{1}, \mathrm{n}_{2}, \mathrm{n}_{3}\right) \mathrm{g}_{\mathrm{p}, \beta}\left(\mathrm{n}_{1}, \mathrm{n}_{2}, \mathrm{n}_{3}\right) \mathrm{FS}^{\mathrm{P}}\left(\mathrm{n}_{1}, \mathrm{n}_{2}, \mathrm{n}_{3}\right)
$$

in which the determination of the g-integrals depend on the set of inclusion combinations. $\mathrm{S}^{\mathrm{P}}$ for multiple inclusions results in a $6^{*} \mathrm{~m} \times 6^{*} \mathrm{~m}$ matrix where $\mathrm{m}$ is the number of inclusions.

\subsection{Determination of material and global tow properties}

The final step in determining the effective stiffness of a plain weave fabric composite is the resolution of the material properties of the undulating tows in the warp and fill directions, respectively. This resolution is done in two steps: Finding the global material properties with respect to the direction of undulation and then transforming them into the global RVE coordinate system. For the tows that traverse from the front to the rear 0 degree face, the global coordinates of the local tow and the RVE are identical. For the two tows that sweep from the front to the rear 90 degree face, there needs an additional transformation to go from the local tow to the RVE. Since a given tow only undulates in one plane (either the $x-z$ plane for the 90 degree tows or the $y-z$ plane for the 
0 degree tows), at any given point along the local longitudinal axis the tow is transversely isotropic to a coordinate system in which the abscissa is along its slope. In order to transform the properties into the global RVE coordinates, the following steps must be followed:

1. Determine the compliance matrix $[\mathrm{S}]$ of each tow assuming that it is a unidirectional composite.

2. Transform the $[\mathrm{S}]$ matrix from the unprimed (material) coordinate system to the primed (global) coordinate system.

3. Average the point-wise global compliance matrix values over the length of each tow.

4. Invert the average global compliance matrix to obtain the average global stiffness matrix $[\mathrm{C}]$ for each tow.

Step 1 of the process, determining the compliance matrix assuming it was a unidirectional composite is equivalent to saying that the tow has the same material properties with respect to a coordinate system in which the abscissa is coincident to the slope of the tow. This step can be done using a variety of available micromechanical models for unidirectional composites [33]. For purposes of consistency, the micromechanical modeling developed by Luciano and Barbero in [34] employed periodic microstructure, so this was the modeling technique used to determine the local compliance matrix for each respective tow. A property that is necessary for this computation is the fiber volume fraction of the tows, denoted as $\mathrm{V}_{\mathrm{f}, \text { tow }}$. This value is considerably more than the overall fiber volume fraction because of the regions of pure matrix that surround the woven structure. From experimental techniques such as the resin burn out test, the overall fiber volume fraction can be found, which is denoted as $\mathrm{V}_{\mathrm{f}, \mathrm{o}} . \mathrm{V}_{\mathrm{f}, \mathrm{tow}}$ can be computed from the overall fiber volume fraction and the volume fraction of the tows to the total RVE, 
$\mathrm{V}_{\mathrm{f} \text {,meso. }}$. From these properties, the value of $\mathrm{V}_{\mathrm{f} \text {,tow }}$ can be calculated according the following equation

$$
\mathrm{V}_{\mathrm{f}, \text { tow }}=\frac{\mathrm{V}_{\mathrm{f}, \mathrm{o}} \mathrm{V}_{\mathrm{RVE}}}{\mathrm{V}_{\text {meso }}}
$$

Step 2 of the tow material property resolution is the transformation of the local compliance matrix to the global coordinate system. The transformation of the compliance matrix requires the calculation of the direction cosines matrix, denoted as [a], and the transformation matrix, denoted as $[\mathrm{T}]$. The [a] matrix for transformation from the local to global tow coordinate systems is

$$
a(\theta)=\left[\begin{array}{ccc}
\cos (\theta) & 0 & \sin (\theta) \\
0 & 1 & 0 \\
-\sin (\theta) & 0 & \cos (\theta)
\end{array}\right]
$$

in which $\theta$ is the approximated slope of the tow undulation. The transformation matrix [T] is a function of the [a] matrix, and its form is listed in Appendix A of this dissertation as well as in the Mathcad files of Appendix B. Once the transformation matrix is calculated at a given point in the tow, the transformed compliance matrix [S'] is calculated in the following manner

$$
\left[\mathrm{S}^{\prime}\right]=[\mathrm{T}]^{\mathrm{T}}[\mathrm{S}][\mathrm{T}] .
$$

The value of $\left[\mathrm{S}^{\prime}\right]$ can be calculated for any point through the length of the tow. For averaging purposes in atep 3, a number of points equally spaced throughout the length of 
the tow were selected, and values of [S'] were calculated at each incremental value. These calculated values were divided by the number of selected points to obtain an average tow compliance across the undulation. Finally, for the tows that traverse the 90 degree faces the averaged compliances were then transformed again to conform to the controlling 0 degree direction. This process necessitates a unique set of [a] and [S] terms, and they are presented below:

$$
\begin{gathered}
\mathrm{a}_{2}=\left[\begin{array}{lll}
0 & 1 & 0 \\
1 & 0 & 0 \\
0 & 0 & 1
\end{array}\right] \\
{\left[\mathrm{S}_{2}\right]=\left[\mathrm{T}_{2}\right]\left[\mathrm{S}^{\prime}\right]\left[\mathrm{T}_{2}\right]^{\mathrm{T}}}
\end{gathered}
$$

in which the transformations are simply a rotation by 90 degrees in the $x-y$ plane. These details are also available in Appendices A and B. The calculation of the averaged stiffness matrix $[\mathrm{C}]$ is determined by matrix inversion of Equation (4.32).

\subsection{Evaluating $\underline{\underline{\underline{C}}}$}

The steps outlined in Sections 4.2 through 4.5 outline a building block approach in which the next step is dependant upon the previous one. It was seen that evaluating the g-integral was dependant upon the surface functions that bound the tows, and resolving $S^{P}$ was dependant upon the evaluation of both the g-integral and $\mathrm{FS}^{\mathrm{P}}$. The same is true 
for evaluating the effective stiffness matrix $\underline{\underline{\mathrm{C}}}$. The evaluation of $\overline{\underline{\mathrm{C}}}$ is dependant upon the determination of $\mathrm{S}^{\mathrm{P}}$, as well as the material property definitions of the matrix and the inclusion, respectively. For a single inclusion, $\overline{\underline{C}}$ was written according to Equation (3.66) as

$$
\underline{\underline{\mathrm{C}}}=\mathrm{C}:\left\{1^{(4 \mathrm{~s})}-\mathrm{f}\left[\left(\left(\underline{\underline{\mathrm{C}}}-\underline{\underline{\mathrm{C}}}^{\Omega}\right)^{-1}: \underline{\underline{\mathrm{C}}}-\underline{\mathrm{S}}^{\mathrm{P}}\right)^{-1}\right]\right\} .
$$

and for multiple inclusions as (Equation (3.74)

$$
\underline{\underline{\mathrm{C}}}=\underline{\underline{C}}:\left\{\mathrm{I}^{(4 \mathrm{~s})}-\sum_{\alpha=1}^{\mathrm{n}} \mathrm{f}_{\alpha}\left[\sum_{\beta=1}^{\mathrm{n}} \mathrm{A}_{\alpha \beta}^{-1}:\left(\underline{\underline{C}}^{\alpha}-\underline{\underline{C}}\right): \mathrm{I}^{(4 \mathrm{~s})}\right]\right\} .
$$

These relationships were applied to two distinct geometric forms: The purely analytical form develop by Ito and Chou in [13] and the experimentally determined parameter developed at CERL. The results of the analyses are presented in subsequent section.

\subsection{Ito and Chou geometry results}

From the execution of the average eigenstrain periodic microstructure model, the geometry and material characteristics of the RVE of Ito and Chou were determined, and the results are summarized in Table 4.3 through Table 4.5., and a full text of the program is listed in Appendix B. The model showed excellent agreement with the experimental 
result, as well as the authors' classical lamination theory model when looking at the longitudinal modulus of elasticity, $\mathrm{E}_{1}$. From their results, this was the only material property listed. If it is assumed that the plain weave fabric is effectively orthotropic, that leaves 8 other material characteristics that need to be defined. As you can see from the comparison with the work in [13], the periodic microstructure model returns all of the material properties, not just $E_{1}$. A complete set of experimental data and numerical predictions are found in Scida et al. [17], who applied their model to an E-glass/vinyl ester plain weave fabric composite. As an example of the versatility of the periodic microstructure model, the original Ito and Chou geometry and material properties were modified to reflect the material properties of an E-glass/vinyl ester plain weave composite. This new model was calculated, and the results are reported in Table 4.8. From the table, it is seen that the periodic microstructure model accurately predicted all of the material properties either within or close to the listed tolerances.

\subsection{CERL geometry results}

The results of the model for the geometry of CERL are summarized in Table 4.11 and Appendix B. The results are compared with the finite element analysis of Kollegal and Sridharan [25] and they show a favorable comparison for the limited data reported. The finite element data of [25] only report values of $E_{1}, G_{12}$, and $v_{12}$. For all of those values, the model showed good agreement, further validating the procedures developed and adapted herein. 


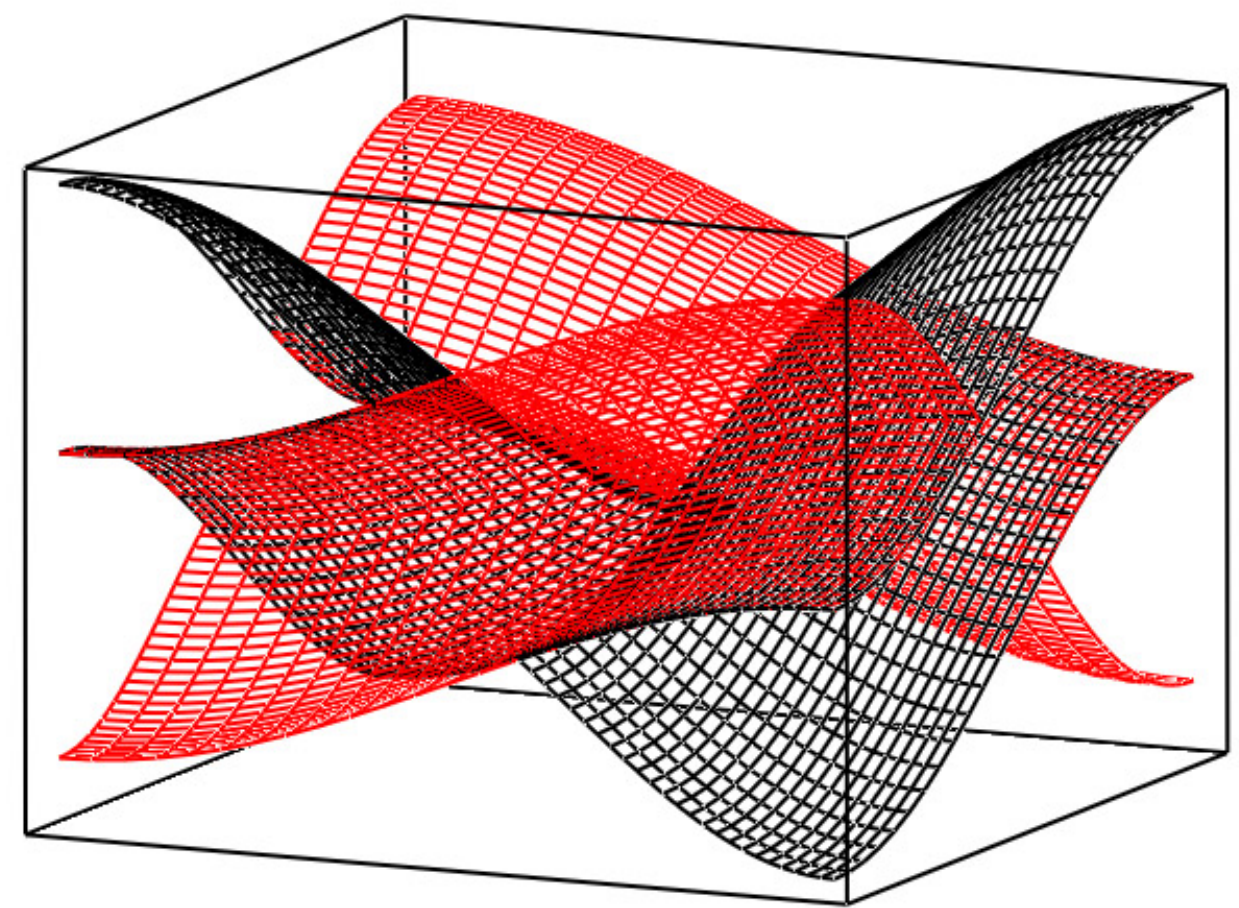

Figure 4.1: Illustration of the plain weave fabric representative volume element. 


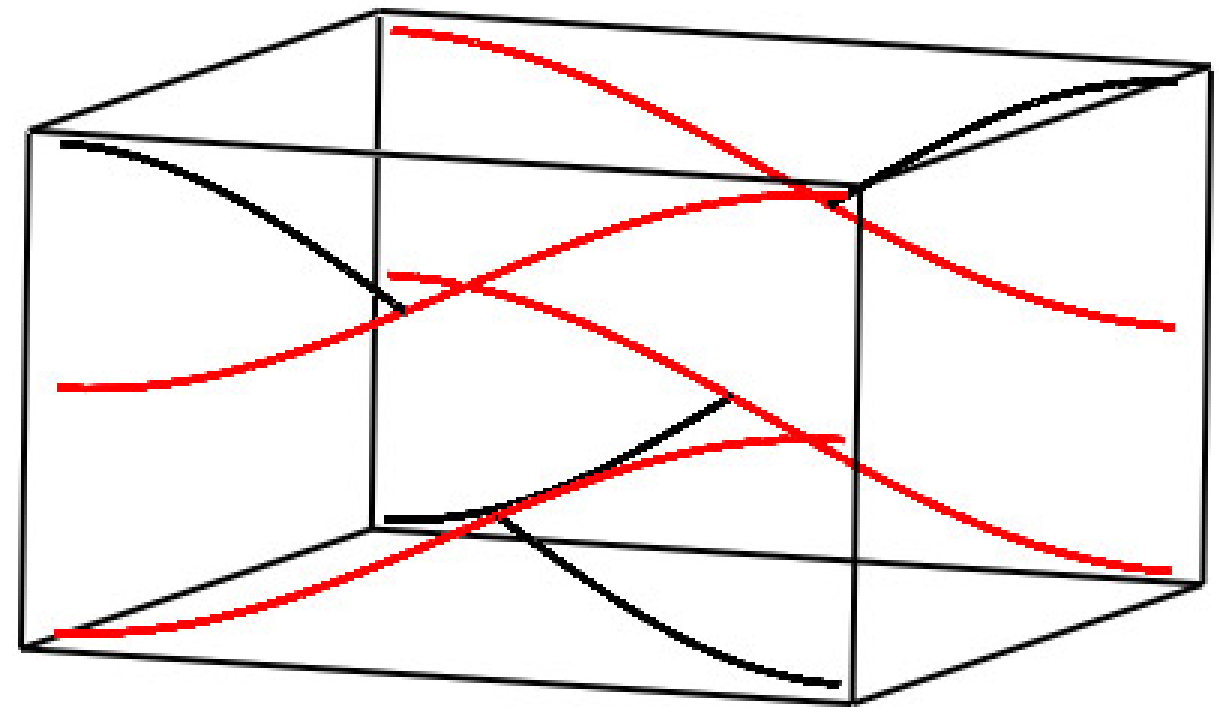

Figure 4.2: Two dimensional plot of the 0 degree front and rear faces of a plain weave fabric RVE. 


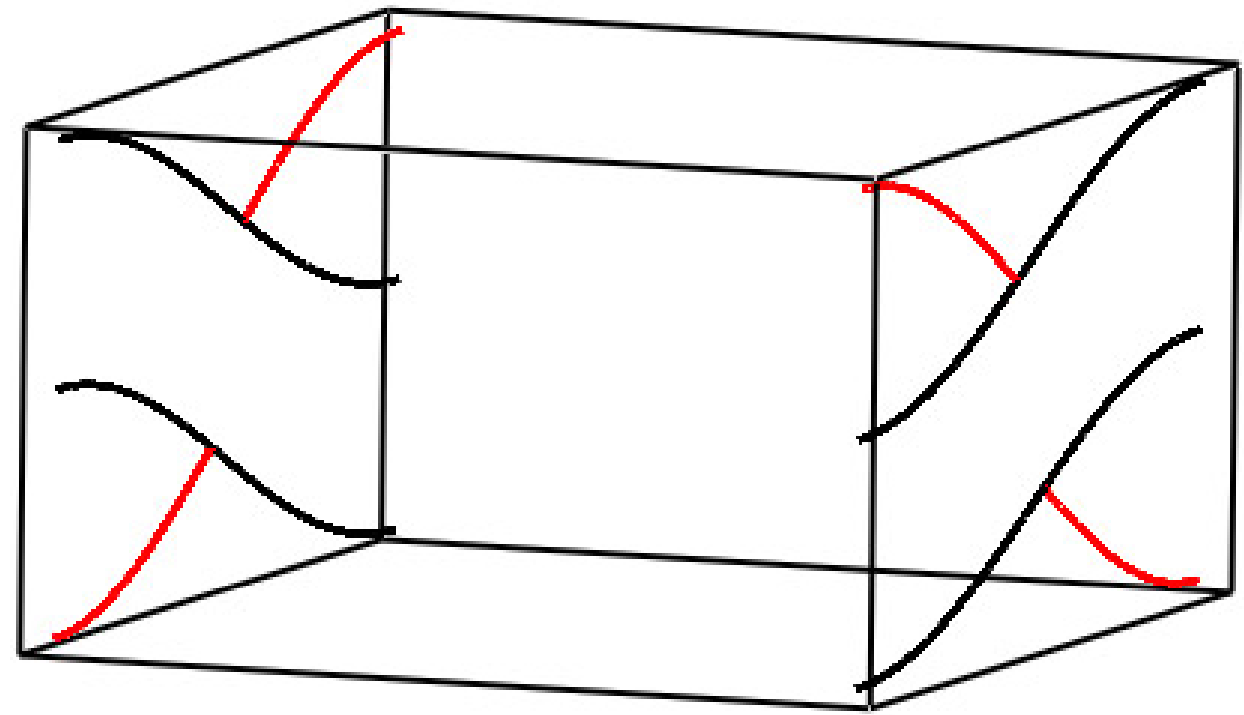

Figure 4.3: Two dimensional plot of the 90 degree front and rear faces of a plain weave fabric RVE. 


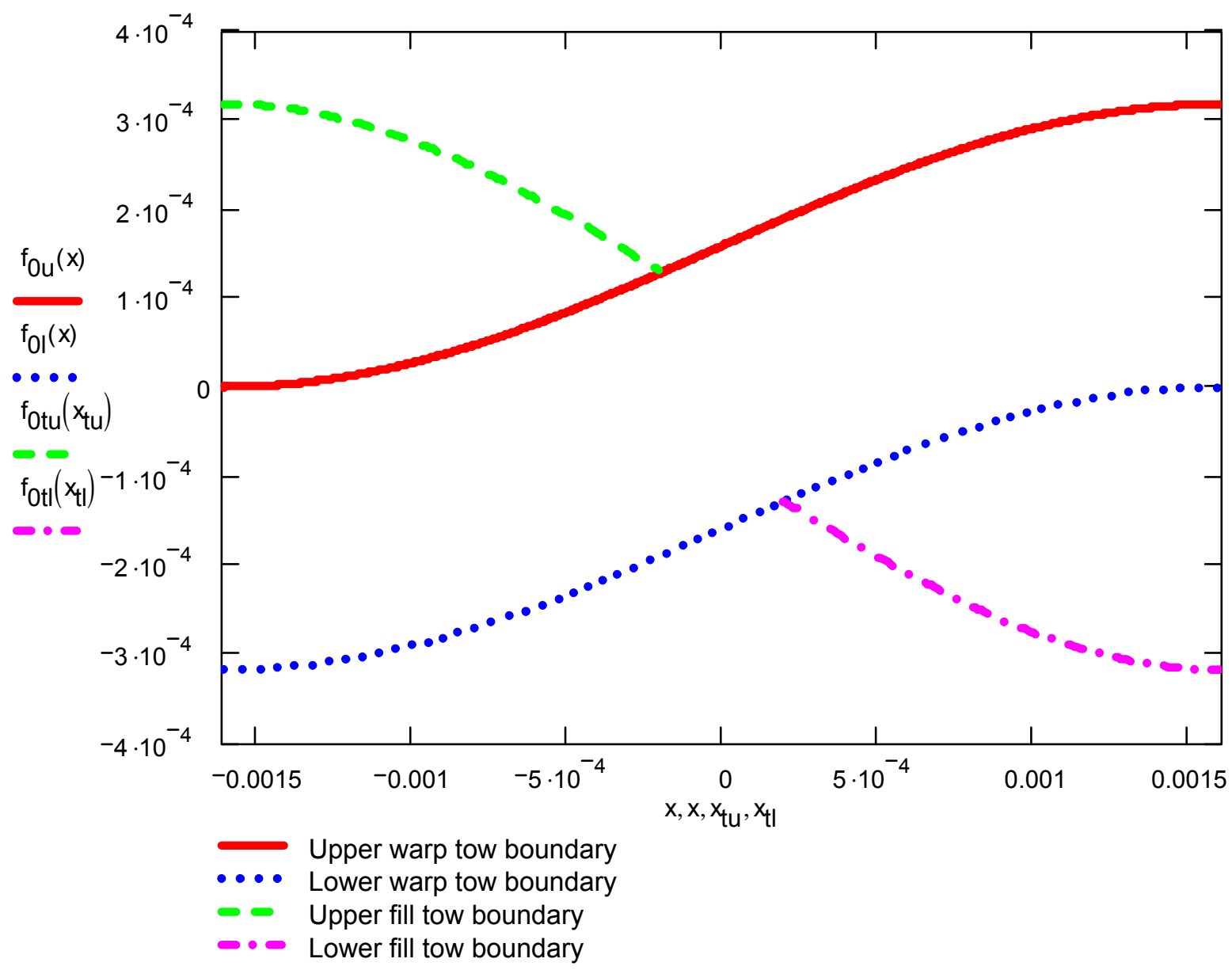

Figure 4.4: Plot of the 0 degree front face of the RVE of Ito and Chou [13]. 


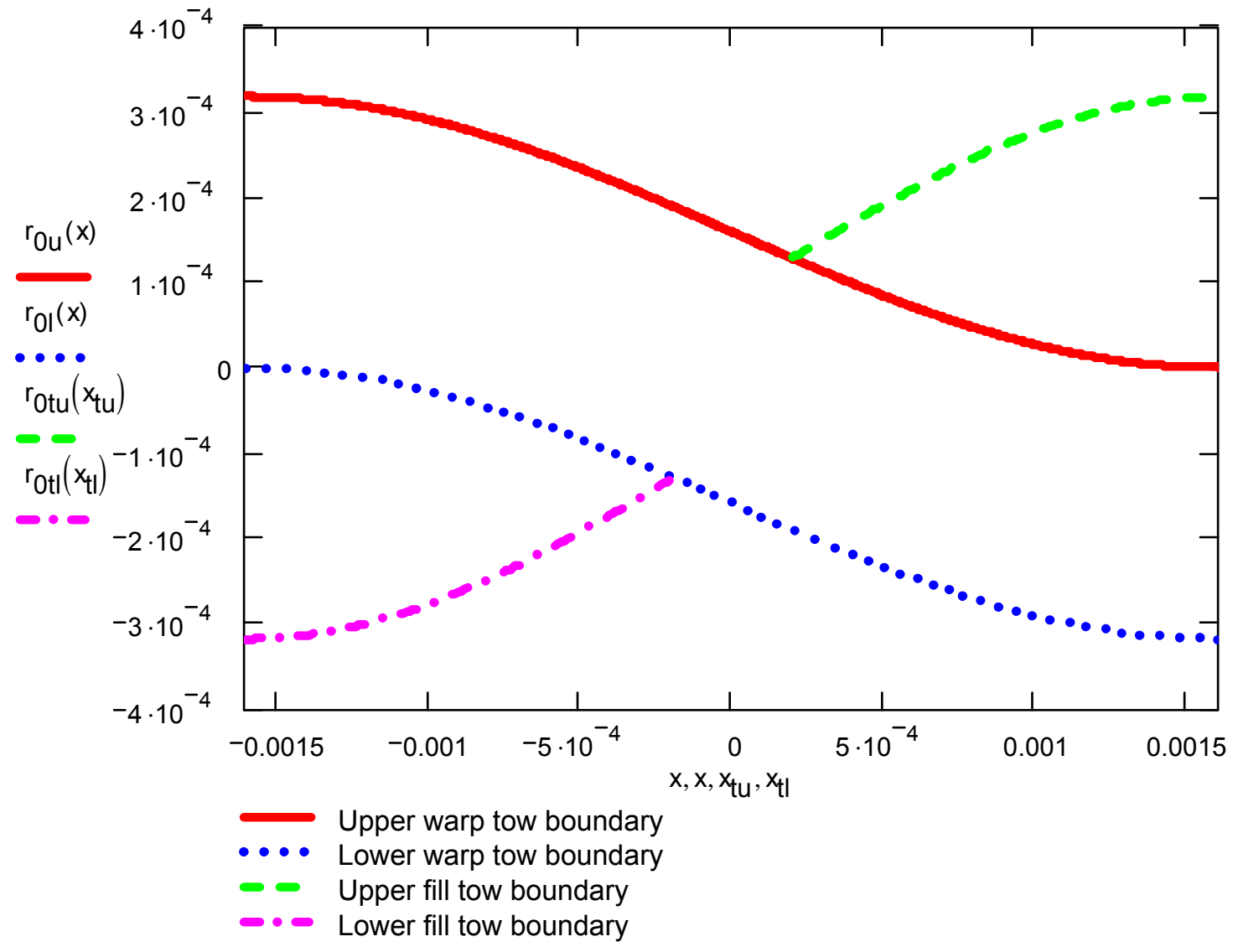

Figure 4.5: Plot of the 0 degree rear face of the RVE of Ito and Chou [13]. 


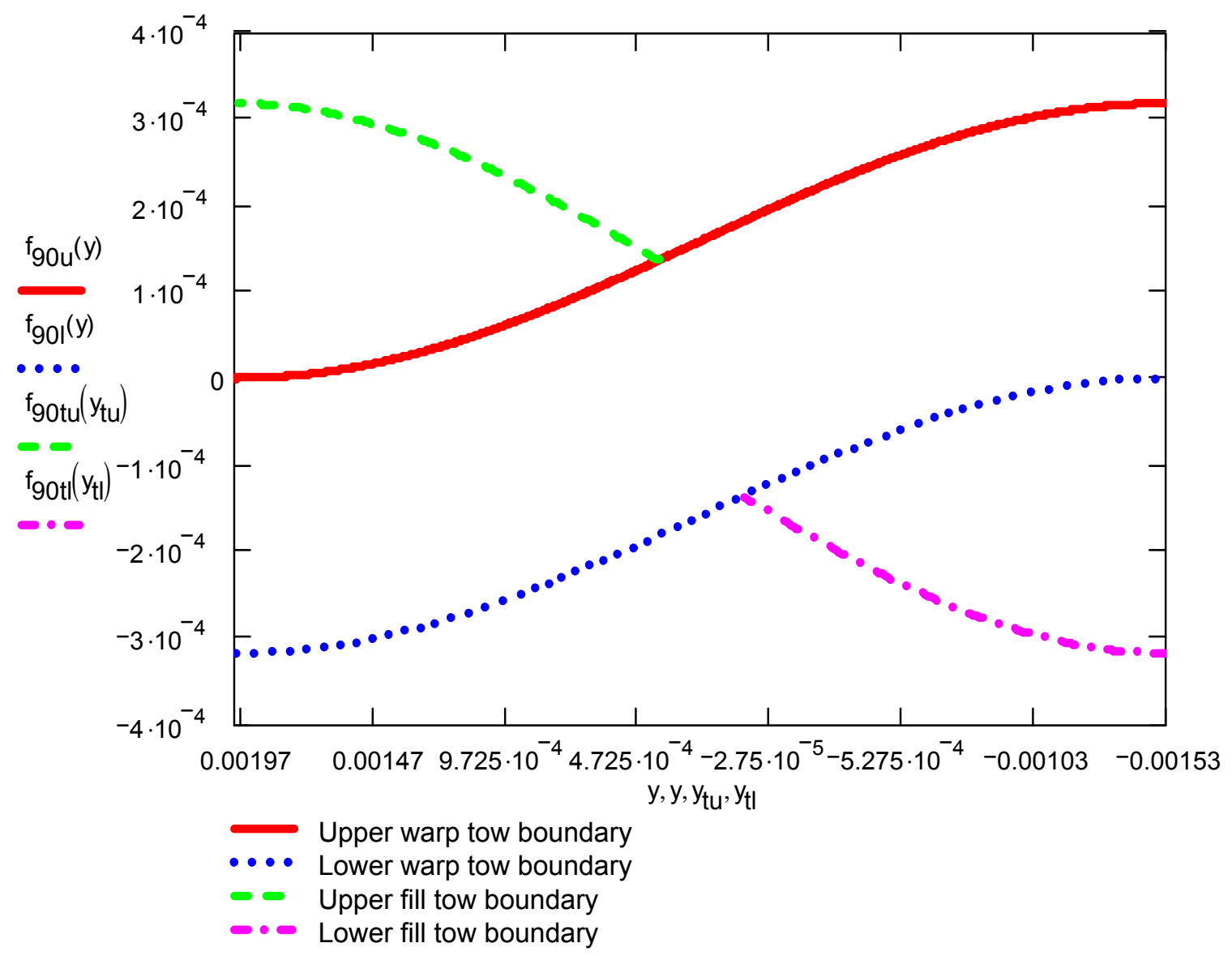

Figure 4.6: 90 degree front face of the RVE of Ito and Chou [13]. 


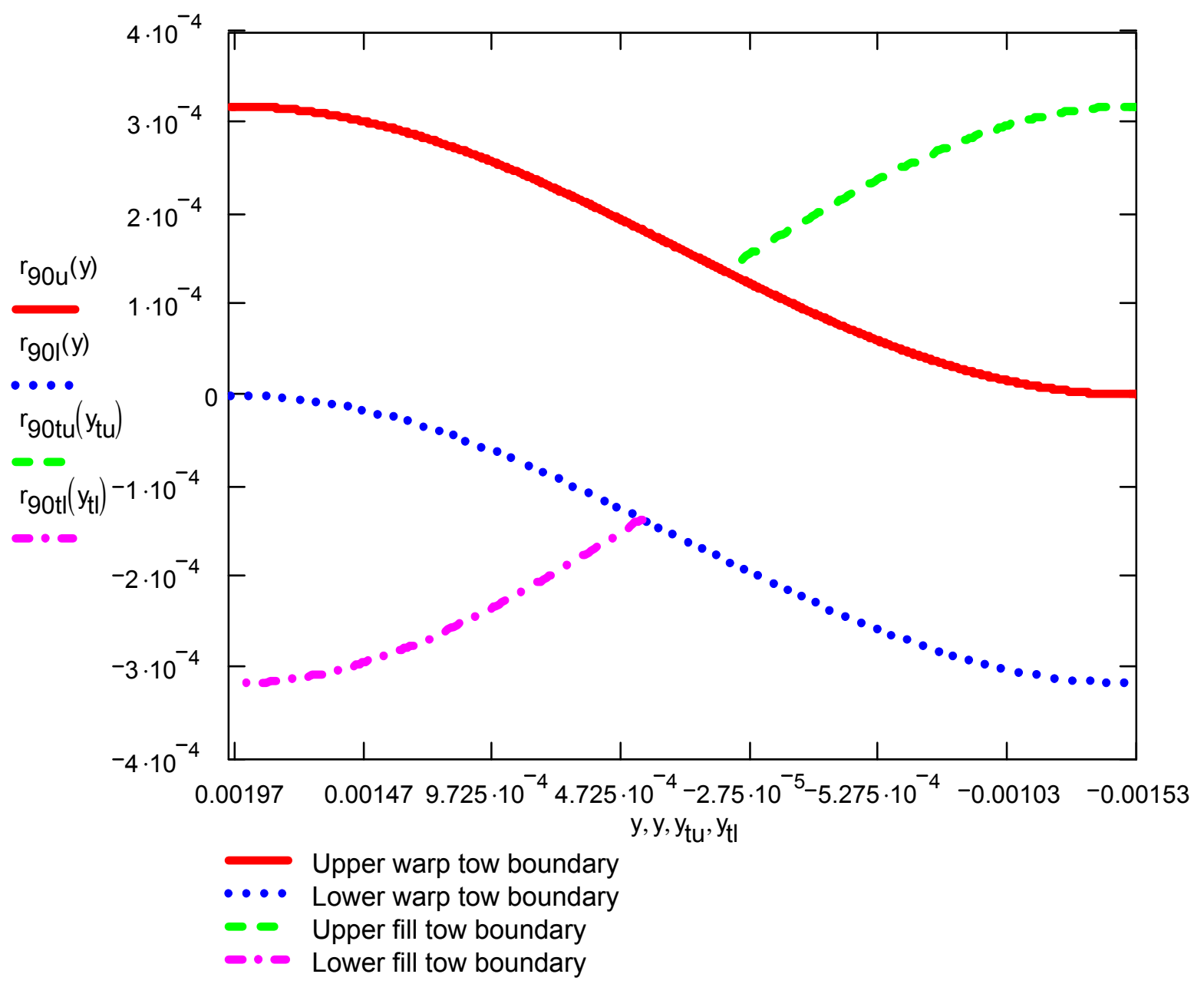

Figure 4.7: Plot of the 90 degree rear face for the RVE of Ito and Chou [13]. 


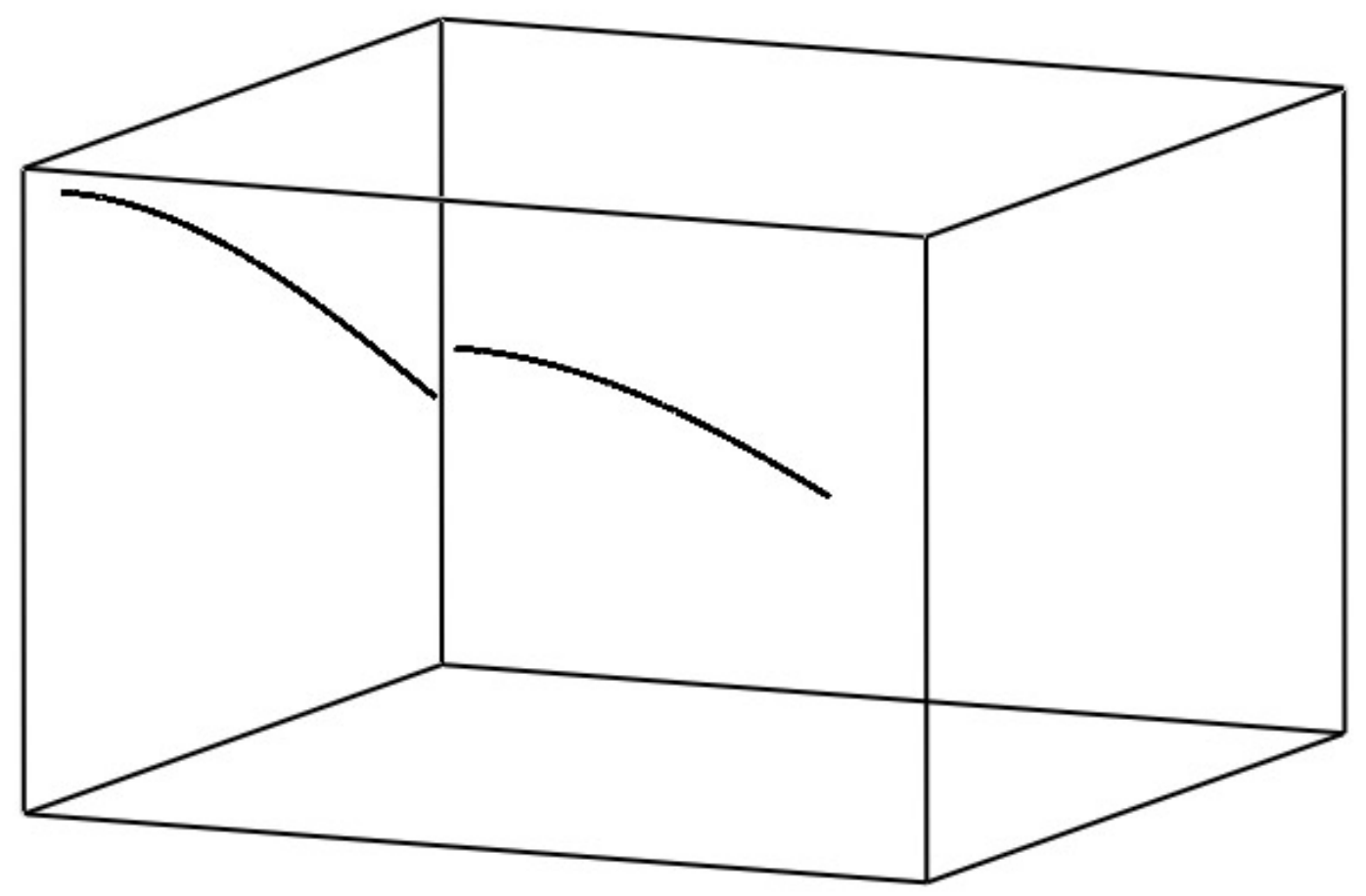

Figure 4.8: Plot of the top fill boundary that exists for the front and rear faces of the 0 degree direction in [13]. 


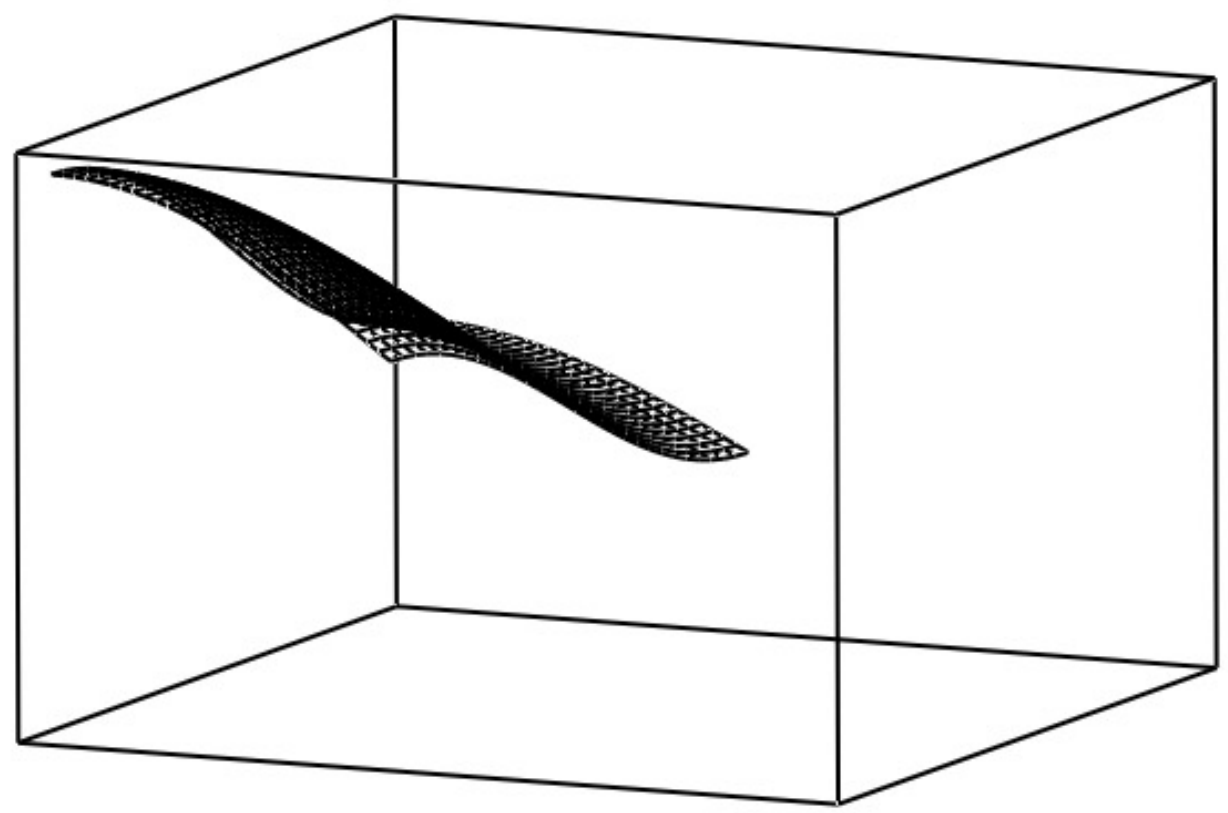

Figure 4.9: Plot of the surface function generated by Equation (4.10) for the upper portion of the top fill yarn in [13]. 


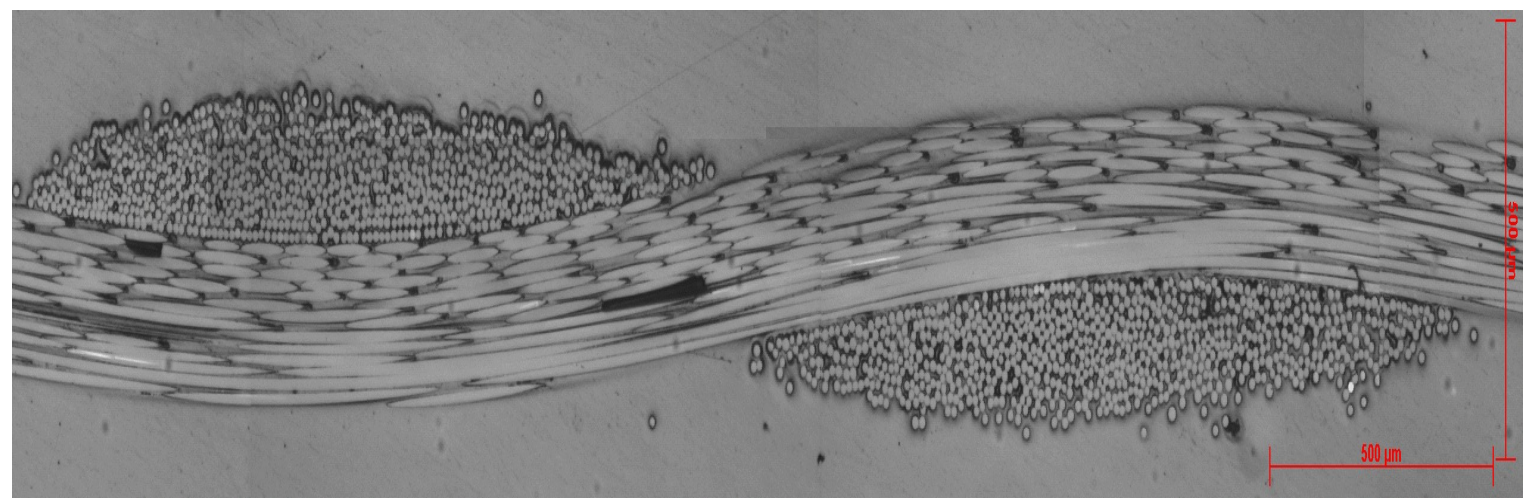

Figure 4.10: 0 degree front face for the fabric geometry of CERL. 


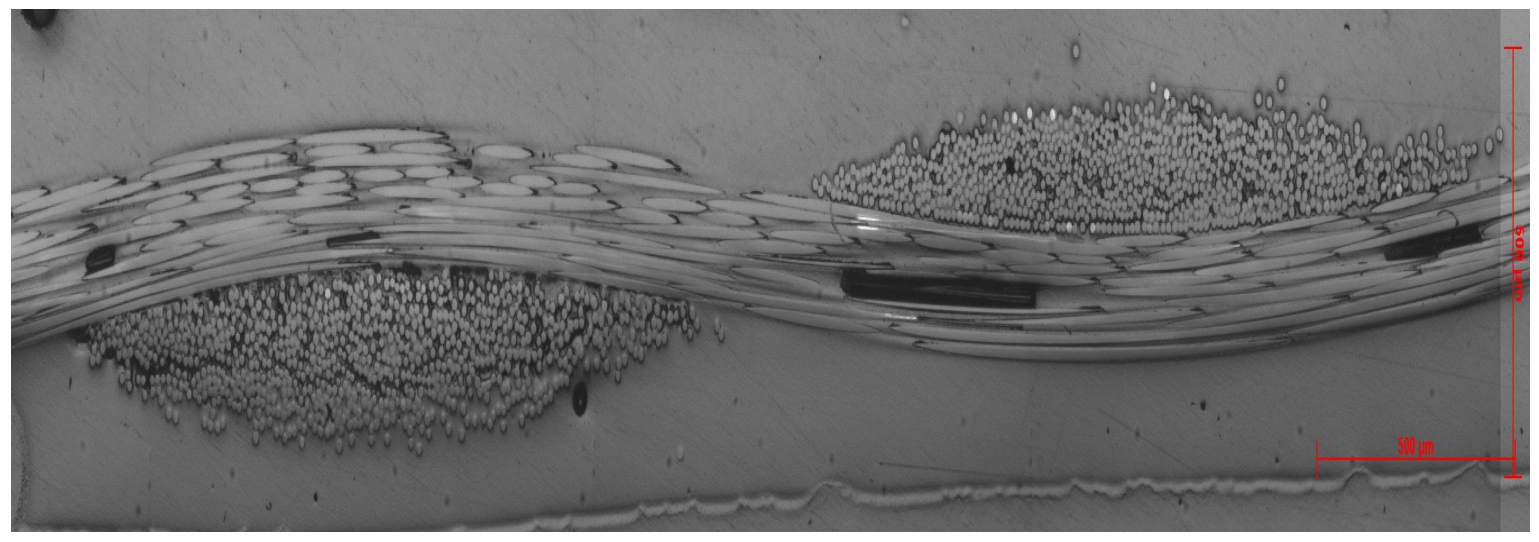

Figure 4.11: 0 degree rear face for the fabric geometry of CERL. 


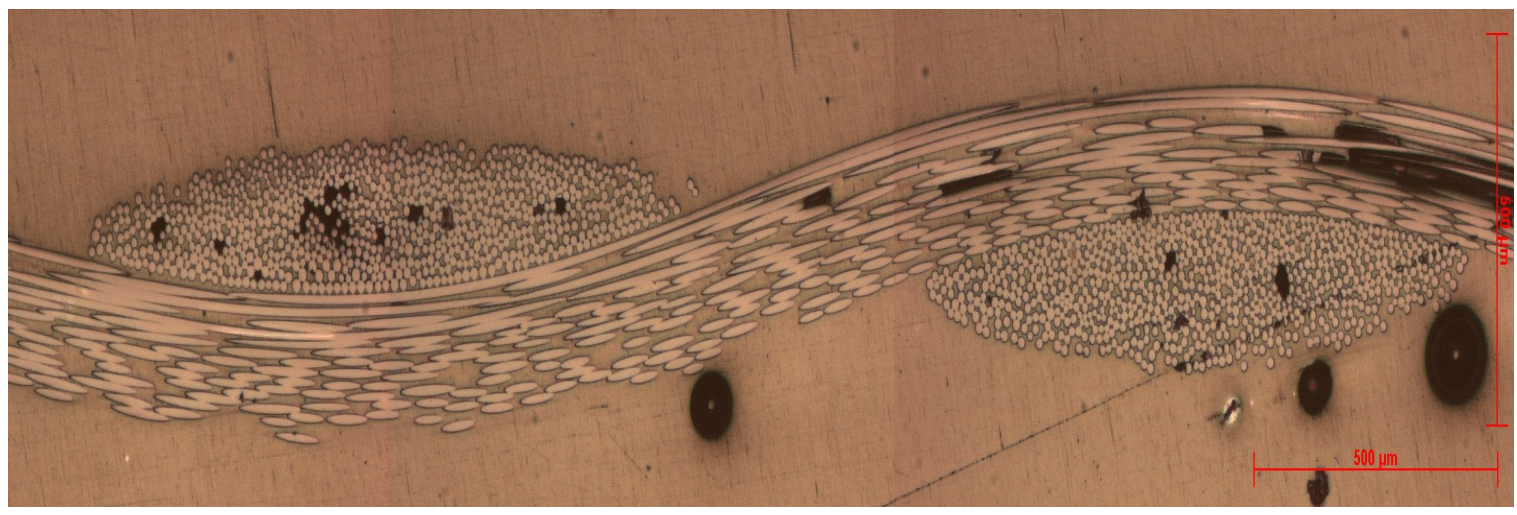

Figure 4.12: 90 degree front face of the fabric geometry of CERL. 


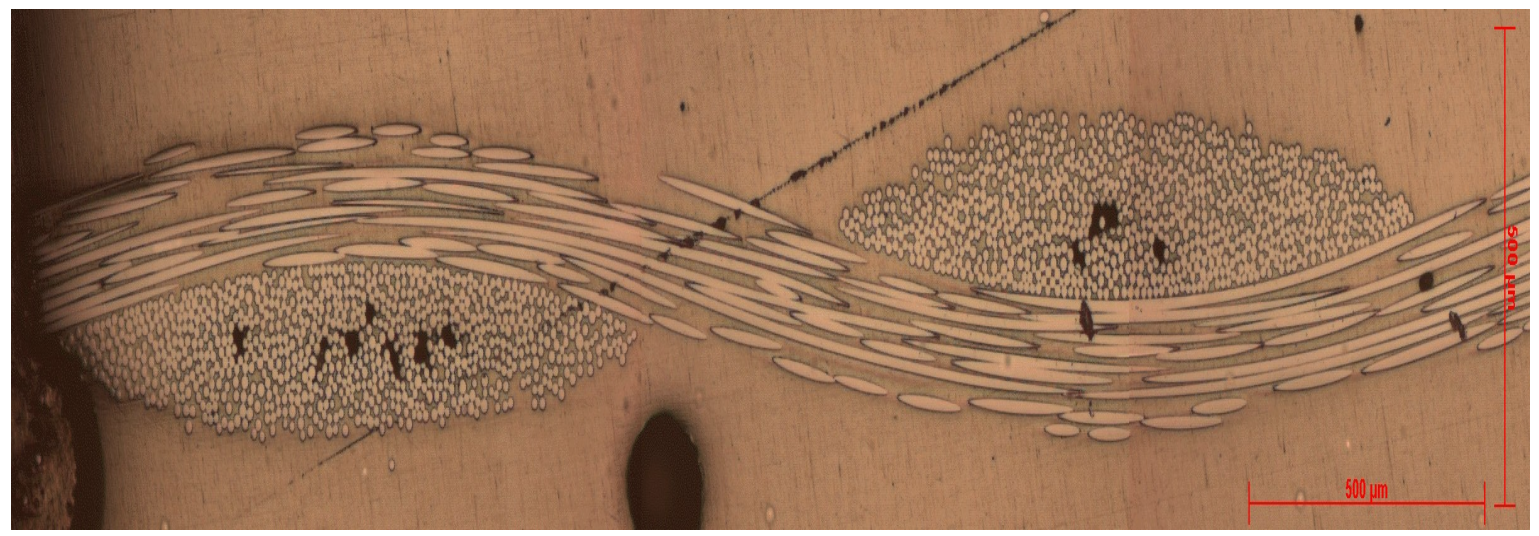

Figure 4.13: 90 degree rear face of the fabric geometry of CERL 


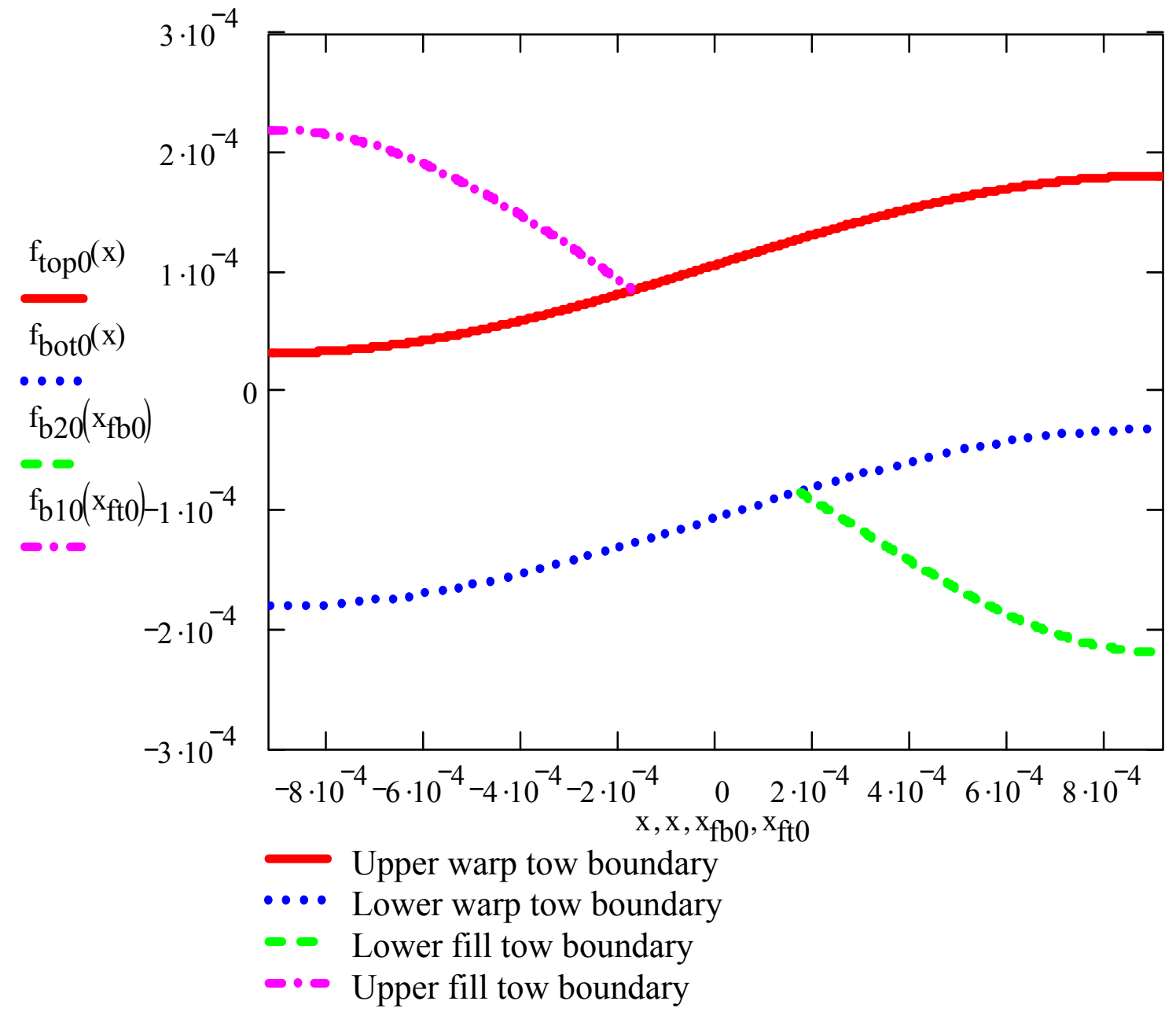

Figure 4.14: 0 degree front face for the CERL geometry 


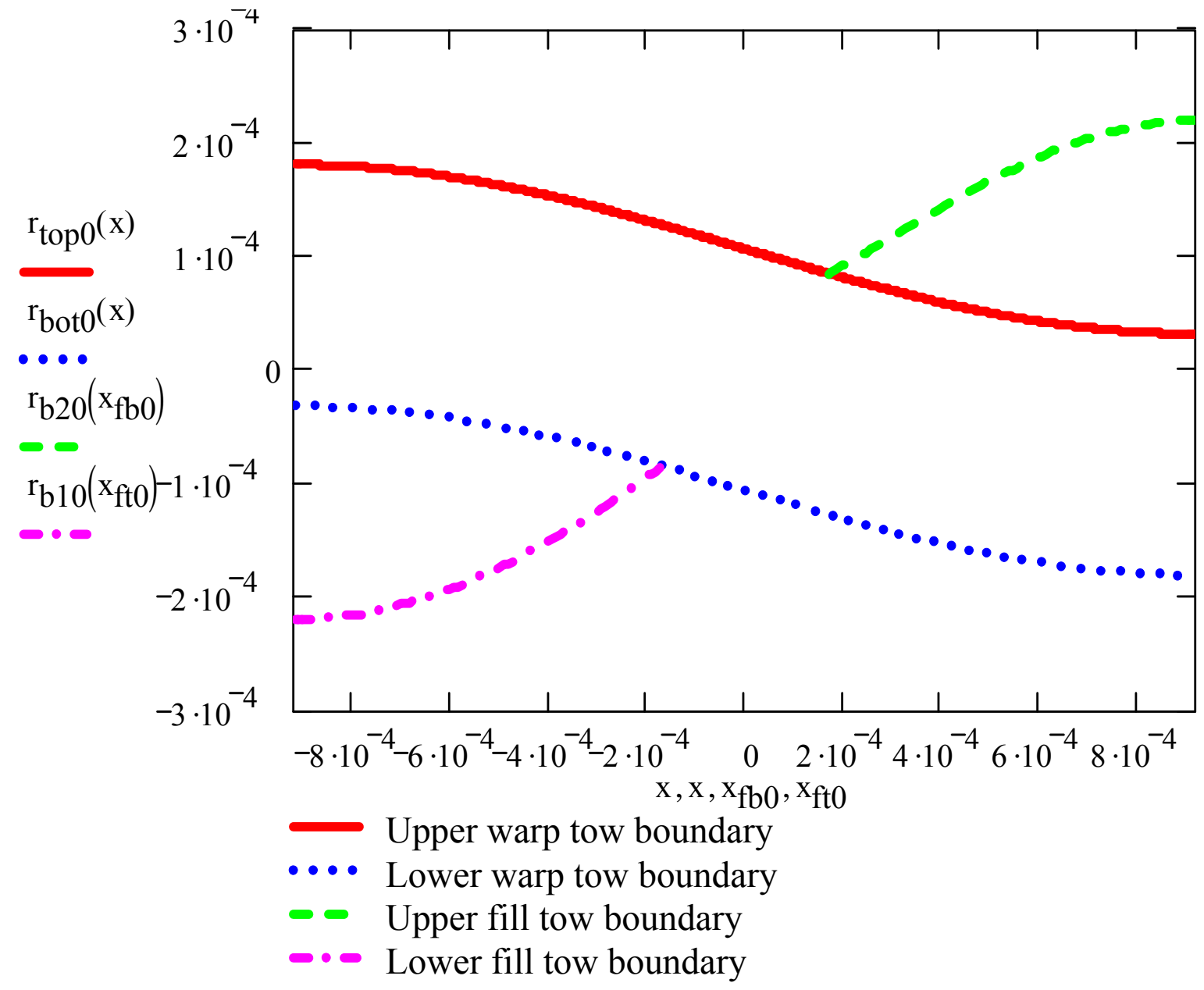

Figure 4.15: 0 degree rear face for the CERL geometry 


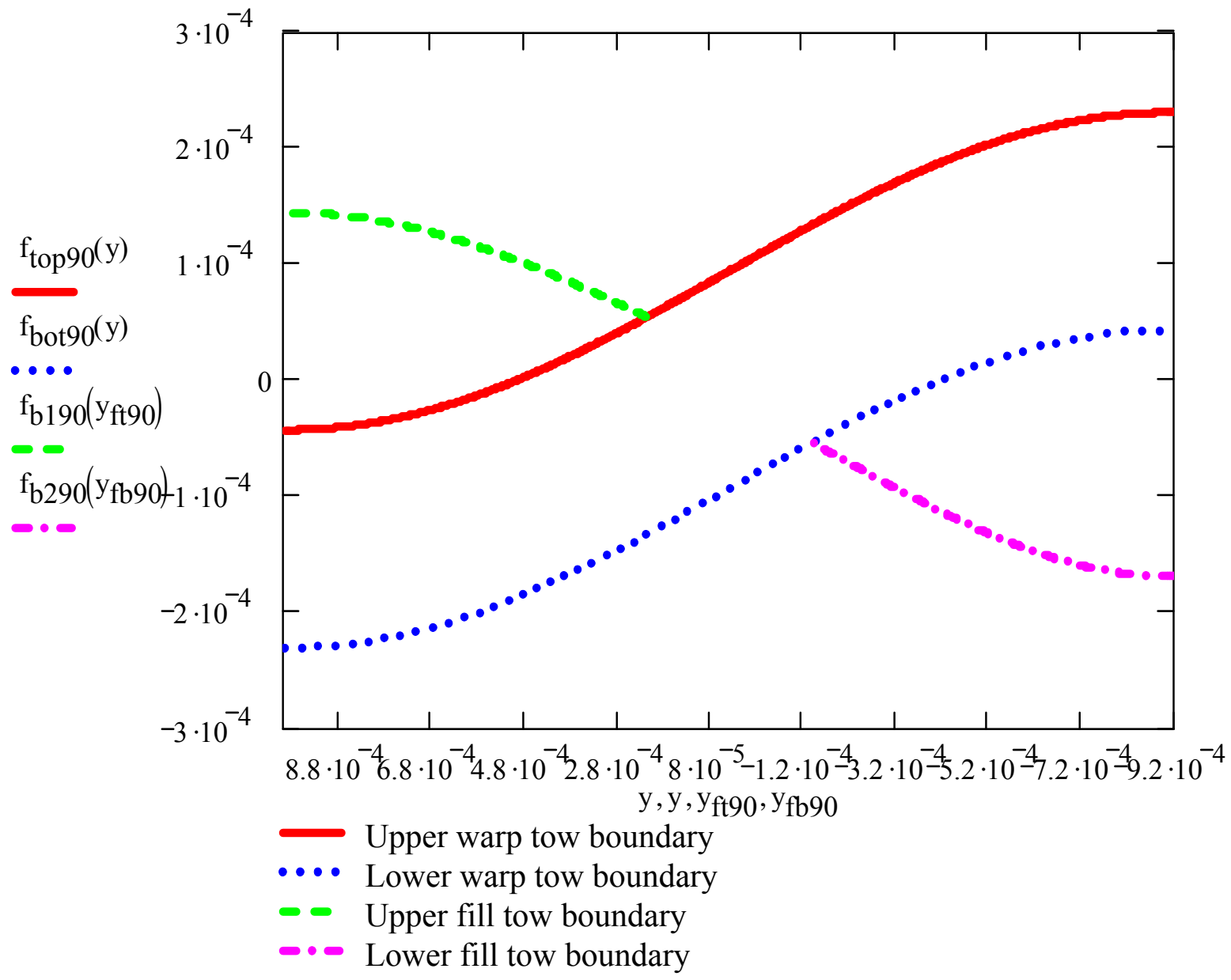

Figure 4.16: 90 degree front face for the CERL geometry 


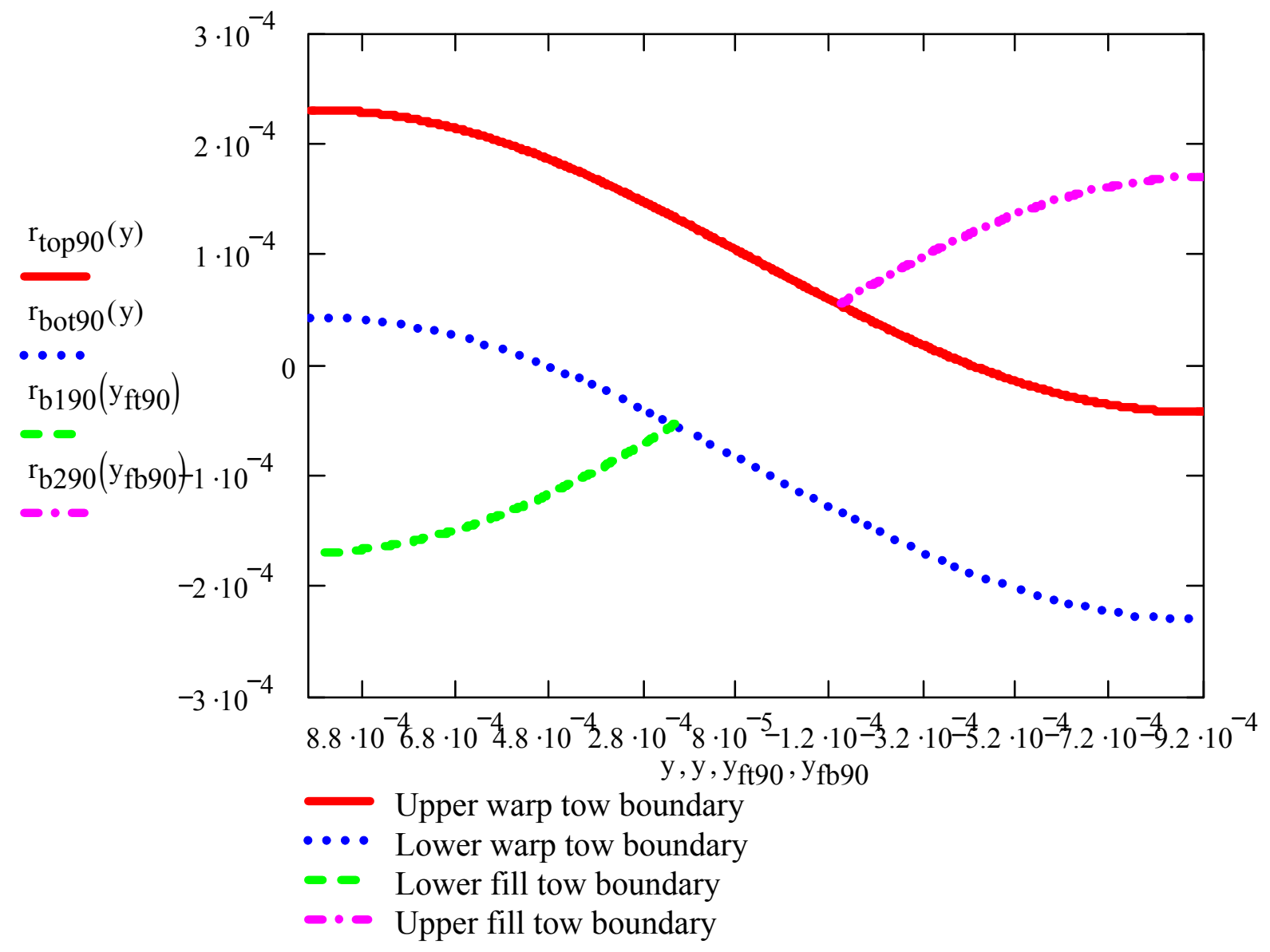

Figure 4.17: 90 degree rear face for the CERL geometry. 


\begin{tabular}{|c|c|c|c|c|}
\hline & \multicolumn{4}{|c|}{ o degree } \\
\hline & Top fill front & Bottom fill rear & $\begin{array}{l}\text { Bottom fill } \\
\text { front }\end{array}$ & Top fill rear \\
\hline $\mathbf{A}(\mathrm{m})$ & $1.29 \mathrm{E}-4$ & $-2.01 \mathrm{E}-4$ & $1.01 \mathrm{E}-4$ & $1.04 \mathrm{E}-4$ \\
\hline B (1/m) & -2153.1 & 1646.0 & -2554.6 & 2499.8 \\
\hline $\mathbf{C}$ & -0.4100 & 3.08514 & 0.7794 & -0.7290 \\
\hline D (m) & $9.10 \mathrm{E}-5$ & $-1.9 \mathrm{E}-5$ & $-1.19 \mathrm{E}-4$ & $1.16 \mathrm{E}-4$ \\
\hline \multicolumn{2}{|c|}{ Warp tow parameters } & & \multicolumn{2}{|c|}{ Height of 0 degree fill tow } \\
\hline $\mathbf{P}_{1,0}$ & $7.4 \mathrm{E}-5 \mathrm{~m}$ & & $\mathrm{~b}_{0}$ & $187.6 \mu \mathrm{m}$ \\
\hline $\mathbf{P}_{2,0}$ & $17101 / \mathrm{m}$ & & & \\
\hline \multicolumn{2}{|c|}{ RVE dimensions } & & & \\
\hline $\mathbf{a}_{1}$ & $920 \mu \mathrm{m}$ & & & \\
\hline $\mathbf{a}_{2}$ & $920 \mu \mathrm{m}$ & & & \\
\hline $\mathbf{a}_{3}$ & $250 \mu \mathrm{m}$ & & & \\
\hline
\end{tabular}

Table 4.1: 0 degree face parameters for the CERL geometry. 


\begin{tabular}{|c|c|c|c|c|}
\hline & \multicolumn{4}{|c|}{90 degree } \\
\hline & Top fill front & Bottom fill rear & $\begin{array}{l}\text { Bottom fill } \\
\text { front }\end{array}$ & Top fill rear \\
\hline $\mathbf{A}(\mathbf{m})$ & $1.00 \mathrm{E}-4$ & $-2.251 \mathrm{E}-4$ & $9.37 \mathrm{E}-5$ & $-1.889 \mathrm{E}-4$ \\
\hline B (1/m) & 1965.7 & 1415.5 & 2405.7 & 1561.4 \\
\hline $\mathrm{C}$ & -0.2376 & 0.2685 & 0.64245 & -0.13432 \\
\hline D (m) & $4.459 \mathrm{E}-5$ & $5.547 \mathrm{E}-5$ & $-7.592 \mathrm{E}-5$ & $-1.927 \mathrm{E}-5$ \\
\hline \multicolumn{2}{|c|}{ Warp tow parameters } & & \multicolumn{2}{|c|}{ Height of 0 degree fill tow } \\
\hline$P_{1,90}$ & $1.37 \mathrm{E}-4 \mathrm{~m}$ & & $\mathrm{~b}_{90}$ & $212.5 \mu \mathrm{m}$ \\
\hline$P_{2,90}$ & $17261 / \mathrm{m}$ & & & \\
\hline \multicolumn{2}{|c|}{ RVE dimensions } & & & \\
\hline$a_{1}$ & $920 \mu \mathrm{m}$ & & & \\
\hline $\mathbf{a}_{2}$ & $920 \mu \mathrm{m}$ & & & \\
\hline $\mathbf{a}_{3}$ & $250 \mu \mathrm{m}$ & & & \\
\hline
\end{tabular}

Table 4.2: Averaged values of the 90 degree face parameters for the CERL geometry 


\begin{tabular}{|c|c|}
\hline & $\begin{array}{c}\text { AS4/ } \\
\text { Vinyl Ester (Ito and } \\
\text { Chou) }\end{array}$ \\
\hline $\mathbf{E}_{\mathbf{f}}$ & $\mathbf{2 2 1 \mathrm { GPa }}$ \\
\hline $\mathbf{E}_{\mathbf{m}}$ & $\mathbf{3 . 4} \mathrm{GPa}$ \\
\hline$v_{\mathbf{f}}$ & $\mathbf{0 . 2 2}$ \\
\hline$v_{\mathbf{m}}$ & $\mathbf{0 . 3 0}$ \\
\hline $\mathbf{v}_{\mathbf{f}}$ & $\mathbf{0 . 7 5 3 6}$ \\
\hline
\end{tabular}

Table 4.3: Micro-scale properties of the fiber matrix tow system for the geometry of Ito and Chou. 


\begin{tabular}{|c|c|}
\hline & $\begin{array}{c}\text { AS4/ } \\
\text { Vinyl Ester (Ito and } \\
\text { Chou) }\end{array}$ \\
\hline $\mathbf{E}_{\mathbf{x}}$ & $171.7 \mathrm{GPa}$ \\
\hline $\mathbf{E}_{\mathbf{y}}$ & $\mathbf{2 3 . 0 9 \mathrm { GPa }}$ \\
\hline $\mathbf{G}_{\mathbf{x y}}$ & $9.370 \mathrm{GPa}$ \\
\hline $\mathbf{G}_{\mathbf{y z}}$ & $\mathbf{7 . 9 8 8 ~ G P a}$ \\
\hline $\mathbf{V}_{\mathbf{x y}}$ & $\mathbf{0 . 2 9 0 0 7}$ \\
\hline $\mathbf{V}_{\mathbf{y z}}$ & $\mathbf{0 . 4 4 5 2 3}$ \\
\hline
\end{tabular}

Table 4.4: Meso-scale averaged properties over the undulations for the fiber/matrix tow system for the geometry of Ito and Chou. 


\begin{tabular}{|c|c|c|}
\hline & \multicolumn{2}{|c|}{ Effective Material Properties } \\
\hline & $\begin{array}{c}\text { Periodic } \\
\text { Microstructure }\end{array}$ & $\begin{array}{l}\text { Ito and Chou } \\
\text { (experimental) }\end{array}$ \\
\hline $\mathbf{E}_{1}$ & 43.11 GPa & $\sim 43.5 \mathrm{GPa}$ \\
\hline $\mathbf{E}_{2}$ & $42.89 \mathrm{GPa}$ & - \\
\hline $\mathbf{E}_{3}$ & $8.429 \mathrm{GPa}$ & - \\
\hline $\mathbf{G}_{23}$ & $4.750 \mathrm{GPa}$ & - \\
\hline $\mathbf{G}_{13}$ & $4.740 \mathrm{GPa}$ & - \\
\hline $\mathbf{G}_{12}$ & $6.721 \mathrm{GPa}$ & - \\
\hline$v_{23}$ & 0.224 & - \\
\hline$v_{13}$ & 0.211 & - \\
\hline$v_{12}$ & 0.228 & - \\
\hline
\end{tabular}

Table 4.5: Effective material property comparison for the AS4/vinyl ester composite from [13]. 


\begin{tabular}{|c|c|}
\hline & $\begin{array}{c}\text { E Glass/ } \\
\text { Vinyl Ester (Scida et al.) }\end{array}$ \\
\hline $\mathbf{E}_{\mathbf{f}}$ & $\mathbf{7 2 . 4 5 \mathrm { GPa }}$ \\
\hline $\mathbf{E}_{\mathbf{m}}$ & $\mathbf{3 . 4 \mathrm { GPa }}$ \\
\hline$v_{\mathbf{f}}$ & 0.22 \\
\hline$v_{\mathbf{m}}$ & 0.38 \\
\hline $\mathrm{V}_{\mathbf{f}}$ & $\mathbf{0 . 8}$ \\
\hline
\end{tabular}

Table 4.6: Micro-scale properties of the fiber matrix tow system for the geometry of Ito and Chou and the material properties of Scida et al. [17]. 


\begin{tabular}{|c|c|}
\hline & $\begin{array}{c}\text { E Glass/ } \\
\text { Vinyl Ester (Scida et al.) }\end{array}$ \\
\hline $\mathbf{E}_{\mathbf{x}}$ & $59.58 \mathrm{GPa}$ \\
\hline $\mathbf{E}_{\mathbf{y}}$ & 21.51 GPa \\
\hline$G_{x y}$ & 8.770 GPa \\
\hline$G_{y z}$ & $7.591 \mathrm{GPa}$ \\
\hline$v_{x y}$ & 0.2916 \\
\hline$v_{y z}$ & 0.4171 \\
\hline
\end{tabular}

Table 4.7: Meso-scale properties over the undulations for the fiber/matrix tow system for the geometry of Ito and Chou and material properties of Scida et al. [17]. 


\begin{tabular}{|c|c|c|}
\hline & \multicolumn{2}{|c|}{ Effective Material Properties } \\
\hline & $\begin{array}{c}\text { Periodic } \\
\text { Microstructure }\end{array}$ & $\begin{array}{c}\text { Scida et al. } \\
\text { (experimental) }\end{array}$ \\
\hline $\mathbf{E}_{1}$ & 22.10 GPa & $24.8 \pm 1.1 \mathrm{GPa}$ \\
\hline $\mathbf{E}_{2}$ & 21.85 GPa & $24.8 \pm 1.1 \mathrm{GPa}$ \\
\hline $\mathbf{E}_{3}$ & $8.98 \mathrm{GPa}$ & $8.5 \pm 2.6 \mathrm{GPa}$ \\
\hline $\mathbf{G}_{\mathbf{2 3}}$ & 4.37 GPa & $4.2 \pm 0.7 \mathrm{GPa}$ \\
\hline $\mathbf{G}_{13}$ & $4.35 \mathrm{GPa}$ & $4.2 \pm 0.7 \mathrm{GPa}$ \\
\hline $\mathbf{G}_{12}$ & 6.37 GPa & $6.5 \pm 0.8 \mathrm{GPa}$ \\
\hline$v_{23}$ & 0.229 & $0.28 \pm 0.07$ \\
\hline$v_{13}$ & 0.224 & $0.28 \pm 0.07$ \\
\hline$v_{12}$ & 0.247 & $0.1 \pm 0.01$ \\
\hline
\end{tabular}

Table 4.8: Comparison of periodic microstructure vs. the experimental results from Scida et al. [17] for an E glass/vinyl ester plain weave fabric composite. 


\begin{tabular}{|c|c|}
\hline & $\begin{array}{c}\text { E Glass/Epoxy (Kollegal } \\
\text { and Sridharan) }\end{array}$ \\
\hline $\mathbf{E}_{\mathbf{f}}$ & $\mathbf{7 2 . 4 5 \mathrm { GPa }}$ \\
\hline $\mathbf{E}_{\mathbf{m}}$ & $3.5 \mathrm{GPa}$ \\
\hline $\mathbf{v}_{\mathbf{f}}$ & $\mathbf{0 . 2 2}$ \\
\hline$v_{\mathbf{m}}$ & $\mathbf{0 . 3 5}$ \\
\hline $\mathbf{V}_{\mathbf{f}}$ & $\mathbf{0 . 7}$ \\
\hline
\end{tabular}

Table 4.9: Micro-scale properties of the fiber matrix tow system for the CERL geometry and the material properties of $[25]$. 


\begin{tabular}{|c|c|}
\hline & $\begin{array}{c}\text { E Glass/Epoxy (Kollegal } \\
\text { and Sridharan) }\end{array}$ \\
\hline $\mathbf{E}_{\mathbf{x}}$ & $\mathbf{5 2 . 6 3 \mathrm { GPa }}$ \\
\hline $\mathbf{E}_{\mathbf{y}}$ & $16.69 \mathrm{GPa}$ \\
\hline $\mathbf{G}_{\mathbf{x y}}$ & $5.90 \mathrm{GPa}$ \\
\hline $\mathbf{G}_{\mathbf{y z}}$ & $\mathbf{5 . 5 8} \mathrm{GPa}$ \\
\hline $\mathbf{V}_{\mathbf{x y}}$ & $\mathbf{0 . 3 2 3 4 1}$ \\
\hline $\mathbf{V}_{\mathbf{y z}}$ & $\mathbf{0 . 4 9 5 3 5}$ \\
\hline
\end{tabular}

Table 4.10: Meso-scale properties over the undulations for the fiber/matrix tow system for the geometry of CERL and material properties of [25]. 


\begin{tabular}{|c|c|c|}
\hline & \multicolumn{2}{|c|}{ Effective Material Properties } \\
\hline & $\begin{array}{c}\text { Periodic } \\
\text { Microstructure }\end{array}$ & $\begin{array}{c}\text { Kollegal and } \\
\text { Sridharan } \\
\text { (experimental) }\end{array}$ \\
\hline $\mathbf{E}_{1}$ & 19.251 GPa & 19.29 GPa \\
\hline $\mathbf{E}_{2}$ & 16.489 GPa & - \\
\hline $\mathbf{E}_{\mathbf{3}}$ & $7.243 \mathrm{GPa}$ & - \\
\hline $\mathbf{G}_{23}$ & $2.952 \mathrm{GPa}$ & - \\
\hline $\mathbf{G}_{13}$ & $2.950 \mathrm{GPa}$ & - \\
\hline $\mathbf{G}_{12}$ & $4.656 \mathrm{GPa}$ & $3.18 \mathrm{GPa}$ \\
\hline$v_{23}$ & 0.261 & - \\
\hline$v_{13}$ & 0.233 & - \\
\hline$v_{12}$ & 0.265 & 0.2 \\
\hline
\end{tabular}

Table 4.11: Comparison of periodic microstructure vs. the experimental results from Kollegal and Sridharan [25] for an E glass/epoxy plain weave fabric composite. 


\section{Chapter 5}

\section{Exact Eigenstrain Analysis}

\subsection{Evaluation procedures for point-wise RVE stresses}

From the periodic microstructure derivations of Chapter 3, the assumption that the eigenstrain was an average value enabled the formation of Equations (3.58) through (3.74) in Section 3.4. The implementation of those relationships to the geometries of Ito and Chou and CERL produced a complete set of material properties. In this Chapter, the implementation of Equations (3.1) through (3.57) will be presented for the purpose of determining the point-wise stresses at any give location within the RVE. The solution of Equation (3.57) is the starting point for a sequence of Fourier coefficient and equation evaluations that will enable the resolution of stress at any give point inside of the RVE. All calculations were done in Mathcad 2001, and the equation formations and program results are listed in Appendix C.

\subsubsection{Solution of the Linear System of Equation (3.57)}

Recall from Sub-sections 3.2 through 3.3 that all of the field variables, consistency, and equilibrium conditions were expanded by means of three-dimensional 
Fourier series. These expanded terms were then substituted into the consistency conditions and the result was the following linear system

$$
\begin{aligned}
& \mathrm{FC}^{\Omega}(\underline{\xi}): \underline{\varepsilon}^{\mathrm{o}}+\left[\sum_{\zeta} \mathrm{F}^{\mathrm{C}} \underline{\underline{ }}^{\Omega}(\underline{\xi}-\underline{\zeta}): \underline{\mathrm{FS}}^{\mathrm{P}}(\underline{\zeta}): \mathrm{F} \underline{\varepsilon}^{*}(\underline{\zeta})\right] \\
& =\mathrm{C}:\left[\varepsilon^{\mathrm{o}}+\mathrm{FS}^{\mathrm{P}}(\underline{\xi}): \mathrm{F} \underline{\varepsilon}^{*}(\underline{\xi})-\mathrm{F} \underline{\varepsilon}^{*}(\underline{\xi})\right]
\end{aligned}
$$

which is Equation (3.57). The size of the linear system is dependant upon the number of $\mathrm{N}$ terms $\left(\mathrm{n}_{1}, \mathrm{n}_{2}\right.$, and $\mathrm{n}_{3}$ combinations) that were taken in order to evaluate the Fourier coefficients. In order to solve the system, one assumption was made: The Fourier coefficient of the tow stiffness matrix, represented as

$$
\underline{\underline{\mathrm{FC}}}(\underline{\xi})=\frac{1}{\mathrm{U}} \int_{\mathrm{U}} \underline{\mathrm{C}}(\underline{\mathrm{x}}) \exp (-\mathrm{i} \underline{\mathrm{x}} \cdot \underline{\xi}) \mathrm{dV}
$$

was approximated by assuming that the stiffness term, $\underline{\underline{\mathrm{C}}}(\underline{\mathrm{x}})$, was not a function of position. The average values of tow stiffnesses outlined in Section 4.5 were inserted for purposes of calculating $\underline{\underline{\mathrm{FC}}}(\underline{\xi})$. For this research, the resolution of the linear system was only solved for $\mathrm{N}=1$. The number of equations in the linear system grows exponentially when the value of $\mathrm{N}$ increases. This increase results in longer run times for the Mathcad shell, which is slower than a program written with a computer language.

\subsubsection{Evaluation of $\underline{\varepsilon}^{*}(\underline{\mathrm{x}})$}

According to the following consistency equation derived in Section 3.3: 


$$
\underline{\underline{C}}^{\Omega}(\underline{x}):\left(\varepsilon^{\mathrm{o}}+\varepsilon^{\mathrm{p}}(\underline{\mathrm{x}})\right)=\underline{\underline{\mathrm{C}}}:\left(\varepsilon^{\mathrm{o}}+\varepsilon^{\mathrm{p}}(\underline{\mathrm{x}})-\varepsilon^{*}(\underline{\mathrm{x}})\right)
$$

the terms that require evaluation are the periodic disturbance strain, $\varepsilon^{\mathrm{p}}(\underline{\mathrm{x}})$, and the eigenstrain, $\varepsilon^{*}(\underline{\mathrm{x}})$. Once the Fourier coefficients of the eigenstrain, $\mathrm{F} \underline{\varepsilon}^{*}(\underline{\xi})$, have been calculated the next step is to evaluate the expanded eigenstrain equation according to

$$
\underline{\varepsilon}^{*}(\underline{\mathrm{x}})=\sum_{\xi}{ }^{\prime} \mathrm{F} \underline{\varepsilon}^{*}(\underline{\xi}) \exp (\mathrm{ix} \cdot \underline{\xi})
$$

for a given point in the cross section. Since the evaluation of the Fourier coefficient is not dependant upon the position inside of the RVE, the eigenstrain can be easily calculated at any point within the RVE for any desired N.

\subsubsection{Evaluation of $\varepsilon^{\mathrm{P}}(\underline{\mathrm{x}})$}

Evaluation of $\varepsilon^{*}(\underline{\mathrm{x}})$ must be done first because resolving the periodic disturbance strain is a function of the eigenstrain. The relationship has been listed in Equation (3.55) and is as follows

$$
\underline{\varepsilon}^{\mathrm{P}}(\underline{\mathrm{x}})=\sum_{\xi}{ }^{\prime} \underline{\underline{S}}^{\mathrm{P}}(\underline{\xi}):\left[\frac{1}{\mathrm{U}} \int_{\mathrm{U}} \underline{\varepsilon}^{*}(\underline{\mathrm{y}}) \cdot \exp (\mathrm{i} \underline{\xi} \cdot(\underline{\mathrm{x}}-\underline{\mathrm{y}})) \mathrm{dV_{ \textrm {y } }}\right]
$$


in which the $\mathrm{x}$ vector is the same point to which the eigenstrain was calculated in Equation (3.20). From the resolution of $\underline{\varepsilon}^{*}(\underline{\mathrm{x}})$ and $\varepsilon^{\mathrm{P}}(\underline{\mathrm{x}})$ the stress values can now be determined at the pre-determined point.

\subsection{Selection of the consistency conditions for stress calculation}

The consistency equations listed in Sections 3.1 and 3.3 are relationships that equate stress terms at a given point. The homogenization of the tows to the matrix surrounding the tows produced the following consistency condition:

$$
\underline{\underline{C}}^{\Omega}(\underline{\mathrm{x}}):\left(\varepsilon^{\mathrm{o}}+\varepsilon^{\mathrm{p}}(\underline{\mathrm{x}})\right)=\underline{\underline{\mathrm{C}}}:\left(\varepsilon^{\mathrm{o}}+\varepsilon^{\mathrm{p}}(\underline{\mathrm{x}})-\varepsilon^{*}(\underline{\mathrm{x}})\right) .
$$

From the evaluations of $\underline{\varepsilon}^{*}(\underline{x})$ and $\varepsilon^{\mathrm{P}}(\underline{\mathrm{x}})$ in Section 5.1, the right side of Equation (3.53) can be evaluated provided that the selected point is within one of the four fiber/matrix tows. If the selected point lies outside of the tows and in the pure matrix region, then Equation (3.53) will not work because the tows were homogenized to the matrix due to the isotropic nature of composite resins. Therefore, the point wise stresses for locations outside of the tows can be computed using

$$
\sigma(\underline{\mathrm{x}})=\underline{\underline{C}}:\left(\varepsilon^{0}+\varepsilon^{\mathrm{p}}(\underline{\mathrm{x}})\right)
$$


From the geometric modeling of Section 4.1, bounds for each of the tows are described according to surface functions and the boundaries of the RVE. A simple routine was written in Mathcad to distinguish the location of a given point so that the appropriate stresses can be calculated, and subsequently use the correct consistency condition with which to calculate the point wise stresses.

\subsection{Comparison of Ito and Chou geometry with Finite Element Data}

The availability of internal or point wise stress data has been limited to only finite element analyses of plain weave fabric composites. Therefore, the idealized geometry of Ito and Chou was use to determine point wise stresses under a given longitudinally applied strain, normally in the range of 0.1 to $1.0 \%$ and for a convergence value of $\mathrm{N}=$

1. Point wise stresses were calculated for internal points corresponding to each of the four tows. The results are listed in. No suitable data has been found or generated to date that could be compared to the data produced with the periodic microstructure model. That effort is ongoing. However, from the procedures outlined in this chapter, along with the Mathcad program listed in Appendix C, this research has verified that the procedure can be applied in this application. The data used in the preliminary comparison was from a finite element analysis done of the Ito and Chou geometry for a separate project at West Virginia University. 


\begin{tabular}{|c|c|c|}
\hline & \multicolumn{2}{|c|}{ Point wise stress calculations } \\
\hline & $\begin{array}{c}\text { Periodic microstructure } \\
\text { AS4/Vinyl Ester }\end{array}$ & $\begin{array}{c}\text { Finite Element Model } \\
\text { AS4/Vinyl Ester }\end{array}$ \\
\hline$\sigma_{\mathbf{x}}$ & $193 \mathrm{MPa}$ & $660 \mathrm{MPa}$ \\
\hline$\sigma_{\mathbf{y}}$ & $-157 \mathrm{MPa}$ & $-117 \mathrm{MPa}$ \\
\hline$\sigma_{\mathbf{z}}$ & $4.054 \mathrm{MPa}$ & $-7.097 \mathrm{MPa}$ \\
\hline$\tau_{\mathbf{x y}}$ & $-4.69 \mathrm{MPa}$ & $-6.224 \mathrm{MPa}$ \\
\hline$\tau_{\mathbf{x z}}$ & $-3.49 \mathrm{MPa}$ & $-5.887 \mathrm{MPa}$ \\
\hline$\tau_{\mathbf{y z}}$ & $-7.51 \mathrm{MPa}$ & $-8.249 \mathrm{MPa}$ \\
\hline
\end{tabular}

Table 5.1: Comparison of point wise stress calculations with finite element analysis of the geometry of Ito and Chou. 


\section{Chapter 6}

\section{Summary and Conclusions}

\subsection{Summary}

The research that produced this dissertation came about from a combination of military demand, previous work of the principal investigator, and a review of current literature on woven fabric composites. Periodic microstructure was used by Luciano and Barbero [34] in the development of micromechanical models for the property prediction of unidirectional fiber reinforced composite lamina. The literature review, as written in Chapter 2, outlined the previous research on woven fabric composites, and from that it was determined that a new analytical model could be developed through the use of periodic microstructure that would combine the advantages of classical lamination theory and the finite element method. The derivation of all the relevant equations and relationships was done in Chapter 3, with an emphasis on application to a plain weave fabric geometry. In Chapter 4, the fiber/matrix tows inside of the RVE were mathematically characterized from both existing two dimensional yarn equations as well as photomicrographs of the fabric cross-section, resulting in the derivation of three dimensional surface functions that describe the bounds of the tows. From the equation derivations and the tow descriptions, a Mathcad program was written to evaluate both the 
effective stiffness of the plain weave fabric as well as point wise stresses throughout the RVE. These results were compared with published experimental, analytical, and finite element data from a variety of sources.

\subsection{Conclusions}

Based on comparisons of the periodic microstructure model with experimental data for both effective material property and point wise stress prediction, the objectives stated in Section 1.3 have been successfully fulfilled. This novel technique produces a full set of effective material properties for given constituent values and fiber volume fractions, the results of which compared very well with experimental data, as seen in Table 4.3 through Table 4.11. This is a significant extension of classical lamination theory, which is capable of only predicting the in plane properties. In addition, the solution of the linear system and subsequent calculations defined in Chapter 5 enable this analytical model to calculate point wise stresses anywhere through the volume of the cross section. This capability is entirely unique to the periodic microstructure model. However, further verification of the point wise stress model is necessary to validate the process of internal stress calculation. For the simplest case, $\mathrm{N}=1$, it required 5 hours of calculation time on a $1.33 \mathrm{GHz}$ windows based computer. This time constraint grows exponentially for increase $\mathrm{N}$ values, and the result is only the stress value at one point. These issues limited our ability to comprehensively examine the results from the model. Even with the limited validation, we were able to effectively demonstrate the procedures 
necessary to extract the internal point wise stresses without the need of a finite element model. 


\section{Chapter 7}

\section{Recommendations}

There are several areas in which the work done in this research could be extended and/or expanded. The application of this model to other geometries and material properties is limited only by the geometric modeling of the inclusion in a given RVE. The same Mathcad program was used in the effective material property prediction for both geometric models, as well as the point wise stress calculations. The differences are only the tow geometries and meso-scale tow properties. A further extension of the effective material property prediction would be to apply this technique to a different fabric geometry, such as a twill weave or a satin weave. In such cases, the RVE would be considerably more complex. However, once the tows were geometrically defined, the model could be easily modified to accommodate the new weaving pattern. The model is not limited to any specific type of material. The application in this research was for woven fabric composites. In actuality, this program could be applied to any heterogeneous system with a pseudo-periodic structure, as long as the heterogeneities can be geometrically defined.

With regard to the point wise stress model, there are still many areas that need to be investigated in order to verify the procedure. A more complete convergence study would be necessary, in light of the fact that the model required five hours for the simplest 
calculation. Also, a detailed finite element model developed specifically for the purpose of comparison with the periodic microstructure model would provide a dependable benchmark with which to compare. The finite element models in the literature are difficult to compare because even if stress distributions are published, it is usually on the free edges and not internal stresses.

These are a few recommendations that would help in acquiring a better understanding of this novel technique, with the hope that continued research and development would reinforce the work done herein. 


\section{Bibliography}

[1] Pan, N., "Analysis of Woven Fabric Strengths: Prediction of Fabric Strength Under Uniaxial and Biaxial Extensions," Composites Science and Technology, No. 56 (1996) pp. 311-327.

[2] Pierce, F. T., "The Geometry of Cloth Structure," Journal of the Textile Institute, No. 28 (1937) T45.

[3] Painter, E. V., "Mechanics of Elastic Performance of Textile Materials: Part VIII: Grapical Analysis of Fabric Geometry," Textile Research Journal, No. 22 (1952) p. 153.

[4] Love, L., "Graphical Relationships in Cloth Geometry for Plain, Twill, and Sateen Weaves," Textile Research Journal, No. 24 (1954) p. 1073.

[5] Hearle, J. W. S., Grosber, P., and Backer, S., Structural Mechanics of Yarns and Fabrics, Vol. 1. Wiley Interscience, New York, 1969.

[6] Taylor, H. M., "Tensile and Tearing Strength of Cotton Cloths," Journal of the Textile Institute, No. 50 (1959) T161.

[7] Postle, R., Carnaby, G. A., and de Jong, S., The Mechanics of Wool Structures. Ellis Horwood, UK 1988, p. 207.

[8] Scelzo, W. A., Backer, S., and Boyce, M. C., "Mechanistic Role of Yarn and Fabric Structure in Determining Tear Resistance of Woven Cloth: 1. Understanding Tongue Tear," Textile Research Journal, No. 64 (1994) p. 291.

[9] Scelzo, W. A., Backer, S., and Boyce, M. C., "Mechanistic Role of Yarn and Fabric Structure in Determining Tear Resistance of Woven Cloth: 2. Modeling Tongue Tear,” Textile Research Journal, No. 64 (1994) p. 321.

[10] Kilby, W. F., "Planar Stress-Strain Relationship in Woven Fabrics," Journal of the Textile Institute, No. 54, (1963) T9.

[11] Ishikawa, T., and Chou, T. W., "Stiffness and Strength Behaviour of Woven Fabric Composites," Journal of Materials Science, No. 17 (1982) pp. 3211-3220.

[12] Hahn, H. T. and Pandey, R., "A Micromechanics Model for Thermoelastic Properties of Plain Weave Fabric Composites," Journal of Engineering Materials and Technology, Vol. 116, (1994) pp. 517-523. 
[13] Ito, M. and Chou, T. W., "An Analytical and Experimental Study of Strength and Failure Behavior of Plain Weave Composites," Journal of Composite Materials, Vol. 32, No. 1 (1998) pp. 2-30.

[14] Ito, M. and Chou, T. W., "Elastic Moduli and Stress Field of Plain-Weave Composites Under Tensile Loading," Composites Science and Technology, No. 57 (1997) pp. 787-800.

[15] Naik, N. K. and Ganesh, V. K., "Failure Behaviour of Plain Weave Fabric Laminates under On-Axis Uniaxial Tensile Loading II - Analyytical Predictions," Journal of Composite Materials, Vol. 30, No. 6 (1996) pp. 1779-1821.

[16] Aboudi, J., Mechanics of Composite Materials: A Unified Micromechanical Approach, Elsevier Science, Netherlands (1991).

[17] Scida, D., Aboura, Z., Benzeggagh, M. L., and Bocherens, E., "A Micromechanics Model for 3D Elasticity and Failure of Woven-Fibre Composite Materials," Composites Science and Technology, No. 59 (1999) pp. 505-517.

[18] Vandeurzen, Ph., Ivens, J., and Verpoest, I., "A Three-Dimensional Micromechanical Analysis of Woven-Fabric Composites: I. Geometric Analysis," Composites Science and Technology, No. 56 (1996) pp. 1303-1315.

[19] Vandeurzen, Ph., Ivens, J., and Verpoest, I., "A Three-Dimensional Micromechanical Analysis of Woven-Fabric Composites: II. Elastic Analysis," Composites Science and Technology, No. 56 (1996) pp. 1317-1327.

[20] Zhang, Y. C. and Harding, J., "A Numerical Micromechanics Analysis of the Mechanical Properties of a Plain Weave Composite," Composites and Structures, Vol. 36, No. 5 (1990) pp. 839-844.

[21] Zhong, S. and Van Hoa, S., "Three Dimensional Micro-Mechanical Modeling of Woven Fabric Composites," Journal of Composite Materials, Vol. 35, No. 19 (2001) pp. 1701-1729.

[22] Dasgupta, A., Agarwal, R. K., and Bhandarkar, S. M., "Three-Dimensional Modeling of Woven-Fabric Composites for Effective Thermo-Mechanical and Thermal Properties," Composites Science and Technology, No. 56 (1996) pp. 209-223.

[23] Dasgupta, A. and Bhandarkar, S. M., "Effective Thermomechanical Behavior of PlainWeave Fabric-Reinforced Composites Using Homogenization Theory," Journal of Engineering Materials and Technology, Vol. 116 (1994) pp. 99-105.

[24] Kollegal, M. G. and Sridharan, S., "Strength Prediction of Plain Woven Fabrics," Journal of Composite Materials, Vol. 34, No. 3 (2000) pp. 240-257.

[25] Kollegal, M. G. and Sridharan, S., "A Simplified Model for Plain Woven Fabrics," Journal of Composite Materials, Vol. 34, No. 20 (2000) pp. 1756-1786. 
[26] Kollegal, M. G. and Sridharan, S., "Compressive Behavior of Plain Weave Lamina," Journal of Composite Materials, Vol. 32, No. 15 (1998) pp. 1334-1355.

[27] Kuhn, J. L. and Charalambides, P. G., "Elastic Response of Porous Matrix Plain Weave Fabric Composites: Part I: Modeling," Journal of Composite Materials, Vol. 32, No. 16 (1998) pp. 1426-1471.

[28] Kuhn, J. L. and Charalambides, P. G., "Elastic Response of Porous Matrix Plain Weave Fabric Composites: Part II: Results," Journal of Composite Materials, Vol. 32, No. 16 (1998) pp. 1472-1507.

[29] Aitharaju, V. R. and Averill, R. C., "Three-Dimensional Properties of Woven-Fabric Composites," Composites Science and Technology, No. 59 (1999) pp. 19011911.

[30] Kuhn, J. L. and Charalambides, P. G., "Modeling of Plain Weave Fabric Composite Geometry," Journal of Composite Materials, Vol. 33, No. 3 (1999) pp. 188-220.

[31] Blackketter, D. M., Walrath, D. E., and Hansen, A. C., "Modeling Damage in a Plain Weave Fabric-Reinforced Composite Material," Journal of Composites Technology and Research, Vol. 15, No. 2 (1993) pp. 136-142.

[32] Nemat-Nasser, S. and Hori, M., Micromechanics: Overall Properties of Heterogeneous Materials, Elsevier Science, 1993.

[33] Barbero, E. J., Introduction to Composite Materials Design, Taylor and Francis, 1998

[34] Luciano, R. and Barbero. E. J., "Formulas for the stiffness of composites with periodic microstructure,” International Journal of Solids and Structures, No. 31 (1994), pp. 2933-2944.

[35] Eshelby, J. D., "The determination of the elastic field of an ellipsoidal inclusion, and related problems," Proc. R. Soc. London, Ser. A., Vol. 241, 376-396.।

[36] Thom, H., "Finite Element Modeling of Plain Weave Composites," Journal of Composite Materials, Vol. 33, No. 16 (1999) pp. 1491-1510.

[37] Iwakuma, T. and Nemat-Nasser, S., "Composites With Periodic Microstructure," Computers and Structures, Vol. 16, No. 1-4 (1983) pp. 13-19. 


\section{Appendix A}

\section{Matrix Representation of $4^{\text {th }}$ Order Symmetric Tensors and Coordinate Transformations}

The stresses $(\sigma)$, strains $(\varepsilon)$, and material property terms (stiffness C or compliance S) that comprise the generalized constitutive equations are generally expressed in tensor notation. The stress and strain terms are second order tensors and the material properties are $4^{\text {th }}$ order symmetric tensors. The tensor representation of the constitutive equation, similar to that of Equation (3.2), would be

$$
\sigma_{\mathrm{ij}}=\mathrm{C}_{\mathrm{ijkl}} \varepsilon_{\mathrm{kl}}
$$

in which $\mathrm{i}, \mathrm{j}, \mathrm{k}, 1$ are indices that run from 1 to 3, respectively. In general, Equation (A.1) could be expanded into a system of nine equations because there are nine possible combinations of the $\mathrm{i}$ and $\mathrm{j}$ indices for $\sigma$ and $\varepsilon$. This general system of nine equations results in $\mathrm{C}$ having 81 terms. Because of symmetry, $\sigma_{\mathrm{ij}}=\sigma_{\mathrm{ji}}$ and $\varepsilon_{\mathrm{ij}}=\varepsilon_{\mathrm{ji}}$ and the system is reduced to six equations, resulting in the stiffness $\mathrm{C}$ having 36 terms. This representation is equivalent to the notation of Equation (3.2). The tensor notation can be further reduced, due to the symmetry of the system, to matrix notation through the used of contracted notation. The contraction is done according to the following system: 


$$
\begin{array}{ll}
\alpha=\mathrm{i} & \text { if } \mathrm{i}=\mathrm{j} \\
\alpha-9-\mathrm{i}-\mathrm{j} & \text { if } \mathrm{i} \neq \mathrm{j}
\end{array}
$$

For a second order tensor such as the stress, the contraction is as follows

$$
\sigma_{\mathrm{ij}}=\left[\begin{array}{c}
\sigma_{11} \\
\sigma_{22} \\
\sigma_{33} \\
\sigma_{23} \\
\sigma_{13} \\
\sigma_{12}
\end{array}\right] \quad \rightarrow \quad \sigma_{\alpha}=\left[\begin{array}{c}
\sigma_{1} \\
\sigma_{2} \\
\sigma_{3} \\
\sigma_{4} \\
\sigma_{5} \\
\sigma_{6}
\end{array}\right]
$$

the result of which is a first order tensor, which is a column vector. The same contraction can be performed on the stiffness or compliance tensors, but in this case there are two sets of terms to be contracted, the $\mathrm{i}, \mathrm{j}$ and $\mathrm{k}, 1$ terms, respectively. This is referred to as double contraction, and the result reduces the $4^{\text {th }}$ order tensor to a $6 \times 6$ matrix. The contraction is illustrated below

$$
\begin{gathered}
\mathrm{C}_{\mathrm{ijk} \mathrm{kl}}=\left[\begin{array}{llllll}
\mathrm{C}_{1111} & \mathrm{C}_{1122} & \mathrm{C}_{1133} & \mathrm{C}_{1123} & \mathrm{C}_{1113} & \mathrm{C}_{1112} \\
\mathrm{C}_{2211} & \mathrm{C}_{2222} & \mathrm{C}_{2233} & \mathrm{C}_{2223} & \mathrm{C}_{2213} & \mathrm{C}_{2212} \\
\mathrm{C}_{3311} & \mathrm{C}_{3322} & \mathrm{C}_{3333} & \mathrm{C}_{3323} & \mathrm{C}_{3313} & \mathrm{C}_{3312} \\
\mathrm{C}_{2311} & \mathrm{C}_{2322} & \mathrm{C}_{2333} & \mathrm{C}_{2323} & \mathrm{C}_{2313} & \mathrm{C}_{2312} \\
\mathrm{C}_{1311} & \mathrm{C}_{1322} & \mathrm{C}_{1333} & \mathrm{C}_{1323} & \mathrm{C}_{1313} & \mathrm{C}_{1312} \\
\mathrm{C}_{1211} & \mathrm{C}_{1222} & \mathrm{C}_{1233} & \mathrm{C}_{1223} & \mathrm{C}_{1213} & \mathrm{C}_{1212}
\end{array}\right] \\
\mathrm{C}_{\alpha \beta}=\left[\begin{array}{lllllll}
\mathrm{C}_{11} & \mathrm{C}_{12} & \mathrm{C}_{13} & \mathrm{C}_{14} & \mathrm{C}_{15} & \mathrm{C}_{16} \\
\mathrm{C}_{21} & \mathrm{C}_{22} & \mathrm{C}_{23} & \mathrm{C}_{24} & \mathrm{C}_{25} & \mathrm{C}_{26} \\
\mathrm{C}_{31} & \mathrm{C}_{32} & \mathrm{C}_{33} & \mathrm{C}_{34} & \mathrm{C}_{35} & \mathrm{C}_{36} \\
\mathrm{C}_{41} & \mathrm{C}_{42} & \mathrm{C}_{43} & \mathrm{C}_{44} & \mathrm{C}_{45} & \mathrm{C}_{46} \\
\mathrm{C}_{51} & \mathrm{C}_{52} & \mathrm{C}_{53} & \mathrm{C}_{54} & \mathrm{C}_{55} & \mathrm{C}_{56} \\
\mathrm{C}_{61} & \mathrm{C}_{62} & \mathrm{C}_{63} & \mathrm{C}_{64} & \mathrm{C}_{65} & \mathrm{C}_{66}
\end{array}\right] .
\end{gathered}
$$


Now that the $2^{\text {nd }}$ and $4^{\text {th }}$ order tensors are contracted, there is an additional modification necessary to equivalently express the tensor and matrix equations for the constitutive relationship. The double contraction of $\mathrm{C}$ and $\varepsilon$, which is expressed in Equation (3.2), is written in matrix form as

$$
\left[\sigma_{\alpha}\right]=\left[\mathrm{C}_{\alpha \beta}\right]\left[\mathrm{W}_{\beta \gamma}\right]\left[\varepsilon_{\gamma}\right]
$$

in which $\mathrm{W}_{\beta \gamma}$ is referred to as the Reuter matrix, and is expressed as

$$
[\mathrm{W}]=\left[\begin{array}{llllll}
1 & 0 & 0 & 0 & 0 & 0 \\
0 & 1 & 0 & 0 & 0 & 0 \\
0 & 0 & 1 & 0 & 0 & 0 \\
0 & 0 & 0 & 2 & 0 & 0 \\
0 & 0 & 0 & 0 & 2 & 0 \\
0 & 0 & 0 & 0 & 0 & 2
\end{array}\right]
$$

Writing these terms in matrix form allowed for the equations derived in the body of this dissertation to be programmed into Mathcad 2001, and any required matrix manipulations or operations could be easily done using its built-in functions.

The determination of the average stiffnesses in each of the fiber tows required the use of coordinate transformations for the stiffness and compliance terms in the material coordinate system. These terms are generally written as fourth order tensors, but because of symmetry the terms can be reduced to matrix form by means of contracting the notation. The general form of the constitutive equation for an anisotropic material in a general coordinate system is

$$
\sigma_{\mathrm{ij}}=\mathrm{C}_{\mathrm{ijkl}} \varepsilon_{\mathrm{kl}}
$$

and for a different coordinate system is 


$$
\sigma_{\mathrm{ij}}^{\prime}=\mathrm{C}_{\mathrm{ijkl}}^{\prime} \varepsilon_{\mathrm{kl}}^{\prime}
$$

The relationship between the stiffness tensors is expressed in terms of the [a] matrices of Equations (4.29) and (4.31), respectively, as

$$
\mathrm{C}_{\mathrm{ijkl}}^{\prime}=\mathrm{a}_{\mathrm{ip}} \mathrm{a}_{\mathrm{jq}} \mathrm{a}_{\mathrm{kr}} \mathrm{a}_{\mathrm{ls}} \mathrm{C}_{\mathrm{pqrs}}
$$

which can also be expressed as

$$
\mathrm{C}_{\mathrm{ijkl}}^{\prime}=\mathrm{T}_{\mathrm{ipjq}} \mathrm{T}_{\mathrm{krls}} \mathrm{C}_{\mathrm{pqrs}}
$$

in which the $\mathrm{T}$ terms constitute the transformation from the unprimed to the primed coordinate system. Rewriting Equation (A.10) in matrix form results in the following

$$
\left[\mathrm{C}^{\prime}\right]=[\mathrm{T}][\mathrm{C}][\mathrm{T}]^{\mathrm{T}}
$$

when going from the unprimed to the primed coordinate system. To go in the opposite direction, the matrix form is

$$
[\mathrm{C}]=[\mathrm{T}]^{\mathrm{T}}\left[\mathrm{C}^{\prime}\right][\mathrm{T}]
$$

The [a] matrix is often written in the following form 


$$
[a]=\left[\begin{array}{lll}
l_{1} & m_{1} & n_{1} \\
l_{2} & m_{2} & n_{2} \\
l_{3} & m_{3} & n_{3}
\end{array}\right]
$$

in which the $1, \mathrm{~m}$, and $\mathrm{n}$ values are the direction cosines. Using this notation, the transformation matrix can be written as

$$
[\mathrm{T}]=\left(\begin{array}{cccccc}
\mathrm{I}_{1}^{2} & \mathrm{~m}_{1}{ }^{2} & \mathrm{n}_{1}{ }^{2} & 2 \cdot \mathrm{m}_{1} \cdot \mathrm{n}_{1} & 2 \cdot \mathrm{I}_{1} \cdot \mathrm{n}_{1} & 2 \cdot \mathrm{I}_{1} \cdot \mathrm{m}_{1} \\
\mathrm{I}_{2}{ }^{2} & \mathrm{~m}_{2}{ }^{2} & \mathrm{n}_{2}{ }^{2} & 2 \cdot \mathrm{m}_{2} \cdot \mathrm{n}, 2 & 2 \cdot \mathrm{I}_{2} \cdot \mathrm{n}_{2} & 2 \cdot \mathrm{I}_{1} \cdot \mathrm{m}_{1} \\
\mathrm{I}_{3}{ }^{2} & \mathrm{~m}_{3}{ }^{2} & \mathrm{n}_{3}{ }^{2} & 2 \cdot \mathrm{m}_{3} \cdot \mathrm{n}_{3} & 2 \cdot \mathrm{I}_{3} \cdot \mathrm{n}_{3} & 2 \cdot \mathrm{I}_{1} \cdot \mathrm{m}_{1} \\
2 \cdot \mathrm{I}_{2} \cdot \mathrm{I}_{3} & 2 \cdot \mathrm{m}_{2} \cdot \mathrm{m}_{3} & 2 \cdot \mathrm{n}_{2} \cdot \mathrm{n}_{3} & \mathrm{~m}_{2} \cdot \mathrm{n}_{3}+\mathrm{n}_{2} \cdot \mathrm{m}_{3} & \mathrm{I}_{2} \cdot \mathrm{n}_{3}+\mathrm{n}_{2} \cdot \mathrm{I}_{3} & \mathrm{I}_{2} \cdot \mathrm{m}_{3}+\mathrm{m}_{2} \cdot \mathrm{I}_{3} \\
2 \cdot \mathrm{I}_{1} \cdot \mathrm{I}_{3} & 2 \cdot \mathrm{m}_{1} \cdot \mathrm{m}_{3} & 2 \cdot \mathrm{n}_{1} \cdot \mathrm{n}_{3} & \mathrm{~m}_{1} \cdot \mathrm{n}_{3}+\mathrm{n}_{1} \cdot \mathrm{m}_{3} & \mathrm{I}_{1} \cdot \mathrm{n}_{3}+\mathrm{n}_{1} \cdot \mathrm{I}_{3} & \mathrm{I}_{1} \cdot \mathrm{m}_{3}+\mathrm{m}_{1} \cdot \mathrm{I}_{3} \\
2 \cdot \mathrm{I}_{1} \cdot \mathrm{I}_{2} & 2 \cdot \mathrm{m}_{1} \cdot \mathrm{m}_{2} & 2 \cdot \mathrm{I}_{1} \cdot \mathrm{I}_{2} & \mathrm{~m}_{1} \cdot \mathrm{n}_{2}+\mathrm{n}_{1} \cdot \mathrm{m}_{2} \mathrm{I}_{1} \cdot \mathrm{n}_{2}+\mathrm{n}_{1} \cdot \mathrm{I}_{2} & \mathrm{I}_{1} \cdot \mathrm{m}_{2}+\mathrm{m}_{1} \cdot \mathrm{I}_{2}
\end{array}\right)
$$

These terms were used in the Mathcad files to do all of the necessary transformations. 


\section{Appendix B}

\section{Computation of the Effective Material Properties of a Plain Weave Woven Fabric Composite}

This is the text of a Mathcad file written to compute the effective material properties of a plain weave fabric composite using periodic microstructure. All of the effective material property data generated in this research was computed in a file of this general form. The only differences are the RVE and weave geometry, the material properties and fiber volume fractions of the constituent materials, and the convergence value $\mathrm{N}$ used to calculate the matrix $\mathrm{S}^{\mathrm{P}}$.

This file contains geometric descriptions determined by the Construction Engineering Research laboratory of the US Army Corps of Engineers.

\section{Part 1: Geometric description, function derivation, and 3-D plotting}

The basis of the RVE from the respect of the $2 \mathrm{D}$ view is to start from the fill tows, as represented by a series of sine curves

The dimension of the RVE is $2 \mathrm{a}_{\mathrm{x}}$ by $2 \mathrm{a}_{\mathrm{y}}$ by $2 \mathrm{a}_{\mathrm{z}}$, and the dimensions are as follows:

$$
\begin{aligned}
& \mu \mathrm{m}:=10^{-6} \cdot \mathrm{m} \quad \mathrm{a}_{\mathrm{x}}:=920 \cdot \mu \mathrm{m} \quad \mathrm{a}_{\mathrm{y}}:=920 \cdot \mu \mathrm{m} \quad \mathrm{a}_{\mathrm{z}}:=250 \cdot \mu \mathrm{m} \\
& \mathrm{m}_{\text {inc }}:=4 \\
& \alpha:=1 . . \mathrm{m}_{\text {inc }} \quad \beta:=1 . . \mathrm{m}_{\text {inc }}
\end{aligned}
$$

Data from CERL for the equations that represent the geometry for the 0 degree direction 
$\mathrm{n}:=5 \quad \mathrm{i}:=1 \ldots \mathrm{n}$

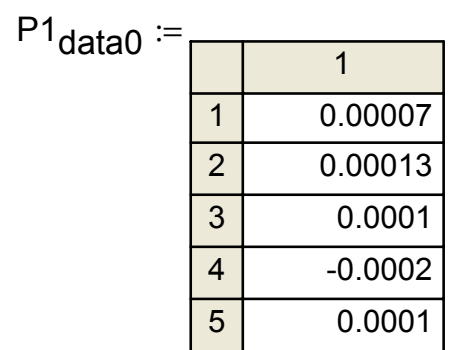

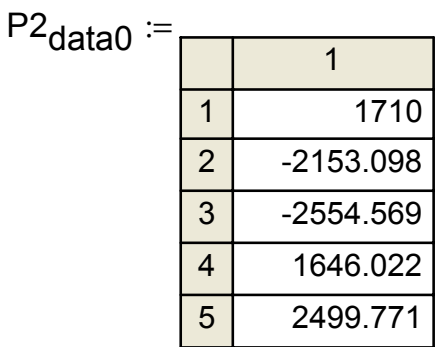

$\mathrm{P} 3_{\text {data0 }}:=$

\begin{tabular}{|r|r|}
\hline & 1 \\
\hline 1 & -0.41005 \\
\hline 2 & 0.77941 \\
\hline 3 & 3.08514 \\
\hline 4 & -0.72899 \\
\hline
\end{tabular}

$\mathrm{P}_{\text {data0 }}:=$

\begin{tabular}{|l|r|}
\hline & \multicolumn{1}{|c|}{1} \\
\hline 1 & 0.00009 \\
\hline 2 & -0.00012 \\
\hline 3 & -0.00002 \\
\hline 4 & 0.00012 \\
\hline
\end{tabular}

$\mathrm{x}_{\text {data0 }}:=$\begin{tabular}{|r|r|}
\hline & \multicolumn{1}{|c|}{1} \\
\hline 1 & -0.00017 \\
\hline 2 & 0.00017 \\
\hline 3 & -0.00017 \\
\hline 4 & 0.00017 \\
\hline
\end{tabular}

$\mathrm{b}_{0}:=$

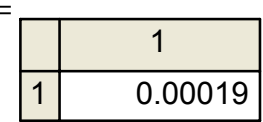

$\mathrm{b}_{0}:=\mathrm{b}_{0} \cdot \mathrm{m}$

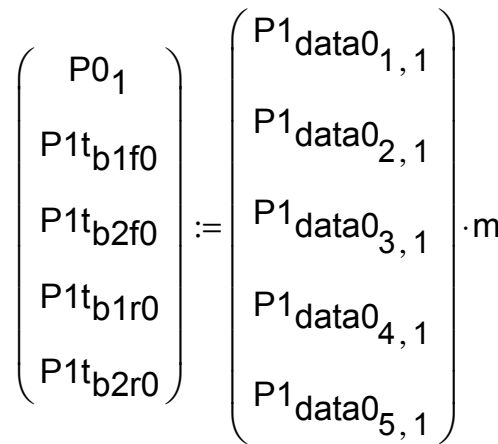

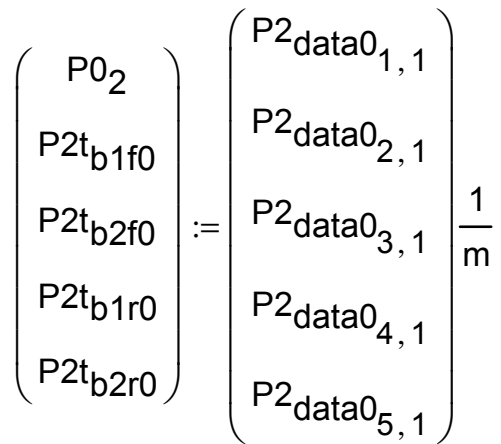

$\left(\begin{array}{l}\mathrm{P} 3 t_{b 1 f 0} \\ P 3 t_{b 2 f 0} \\ P 3 t_{b 1 r 0} \\ P 3 t_{b 2 r 0}\end{array}\right):=\left(\begin{array}{l}P^{3} \text { data0 }_{1,1} \\ \mathrm{P} \text { data0 }_{2,1} \\ \mathrm{P}_{\text {dataO }_{3,1}} \\ \mathrm{P}_{\text {data0 }_{4,1}}\end{array}\right)$

$\left(\begin{array}{l}x_{\text {cb1f0 }} \\ x_{\text {cb2f0 }} \\ x_{\text {cb1r0 }} \\ x_{\text {cb2r0 }}\end{array}\right):=\left(\begin{array}{l}x_{\text {data0 }_{1,1}} \\ x_{\text {data0 }_{2,1}} \\ x_{\text {data0 }_{3,1}} \\ x_{\text {data0 }_{4,1}}\end{array}\right) \cdot m$

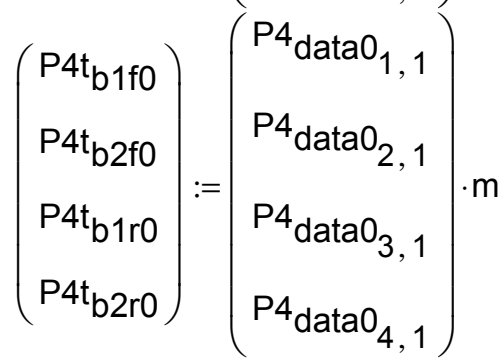

Data from Army Corps for the equations that represent the geometry for the 90 degree direction 
$\mathrm{P} 1_{\text {data90 }}:=$

\begin{tabular}{|l|l|}
\hline & 1 \\
\hline 1 & 0.00014 \\
\hline 2 & 0.00016 \\
\hline 3 & 0.00008 \\
\hline 4 & 0.00027 \\
\hline 5 & -0.0002 \\
\hline
\end{tabular}

$\mathrm{P}_{\text {data90 }}:=$

\begin{tabular}{|r|r|}
\hline & \multicolumn{1}{c|}{1} \\
\hline 1 & -0.0967683 \\
\hline 2 & 1.003615 \\
\hline 3 & 3.481002 \\
\hline 4 & -0.1294923 \\
\hline
\end{tabular}

$\mathrm{y}_{\text {data90 }}:=$

\begin{tabular}{|r|r|}
\hline & \multicolumn{1}{|c|}{1} \\
\hline 1 & 0.00017 \\
\hline 2 & -0.00017 \\
\hline 3 & 0.00017 \\
\hline 4 & -0.00017 \\
\hline
\end{tabular}

$b_{90}:=b_{90} \cdot m$

$\left(\begin{array}{c}\mathrm{P} 0_{1} \\ \mathrm{P} 1 \mathrm{t}_{\mathrm{b} 1 \mathrm{f} 90} \\ \mathrm{P} 1 \mathrm{t}_{\mathrm{b} 2 \mathrm{f} 90} \\ \mathrm{P} 1 \mathrm{t}_{\mathrm{b} 1 \mathrm{r} 90} \\ \mathrm{P} 1 \mathrm{t}_{\mathrm{b} 2 \mathrm{r} 90}\end{array}\right):=\left(\begin{array}{l}\mathrm{P}^{\text {data90 }_{1,1}} \\ \mathrm{P}_{\text {data90 }_{2,1}} \\ \mathrm{P} \text { data90 }_{3,1} \\ \mathrm{P} \text { data90 }_{4,1} \\ \mathrm{P} \text { data90 }_{5,1}\end{array}\right) \cdot \mathrm{m}$

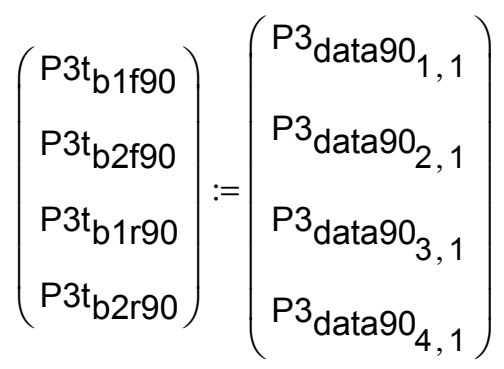

$\mathrm{P} 2$ data90 :=

\begin{tabular}{|c|c|}
\hline & 1 \\
\hline 1 & 1726.67 \\
\hline 2 & 1812.57 \\
\hline 3 & 2798.27 \\
\hline 4 & 1338.46 \\
\hline 5 & 1566.63 \\
\hline
\end{tabular}

$\mathrm{P}_{\text {data90 }}:=$

\begin{tabular}{|l|r|}
\hline & \multicolumn{1}{|c|}{1} \\
\hline 1 & 0.000025 \\
\hline 2 & -0.000099 \\
\hline 3 & 0.000085 \\
\hline 4 & -0.000019 \\
\hline
\end{tabular}

$\mathrm{b}_{90}:=$

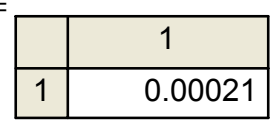

$\left(\begin{array}{c}\mathrm{P}_{2} \\ \mathrm{P}^{2} \mathrm{t}_{\mathrm{b} 1 \mathrm{f} 90} \\ \mathrm{P} 2 \mathrm{t}_{\mathrm{b} 2 \mathrm{f} 90} \\ \mathrm{P} 2 \mathrm{t}_{\mathrm{b} 1 \mathrm{r} 90} \\ \mathrm{P} 2 \mathrm{t}_{\mathrm{b} 2 \mathrm{r} 90}\end{array}\right):=\left(\begin{array}{l}\mathrm{P} \text { data90 }_{1,1} \\ \mathrm{P} \text { data90 }_{2,1} \\ \mathrm{P} \text { data90 }_{3,1} \\ \mathrm{P}{ }_{\text {data90 }_{4,1}} \\ \mathrm{P} \text { data90 }_{5,1}\end{array}\right) \frac{1}{\mathrm{~m}}$

$\left(\begin{array}{l}\mathrm{P} \mathrm{t}_{\mathrm{b} 1 \mathrm{f} 90} \\ \mathrm{P} 4 \mathrm{t}_{\mathrm{b} 2 \mathrm{f} 90} \\ \mathrm{P} 4 \mathrm{t}_{\mathrm{b} 1 \mathrm{r} 90} \\ \mathrm{P} 4 \mathrm{t}_{\mathrm{b} 2 \mathrm{r} 90}\end{array}\right):=\left(\begin{array}{l}\mathrm{P} \text { data90 }_{1,1} \\ \mathrm{P} \mathrm{data90}_{2,1} \\ \mathrm{P}_{\text {data90 }_{3,1}} \\ \mathrm{P}_{\text {data90 }} \\ 4,1\end{array}\right) \cdot \mathrm{m}$ 


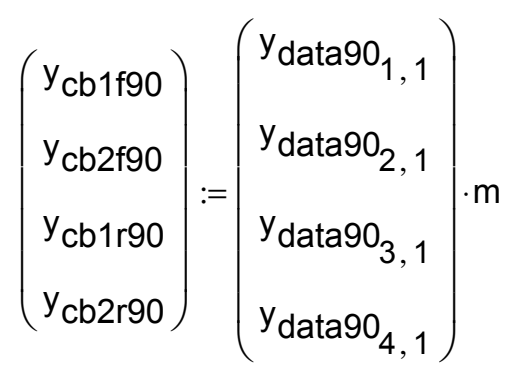

$\left(\begin{array}{c}\mathrm{P}_{1} \\ \mathrm{P} 1 \mathrm{t}_{\mathrm{b} 1 \mathrm{f0}} \\ \mathrm{P} 1 \mathrm{t}_{\mathrm{b} 2 \mathrm{f0}} \\ \mathrm{P} 1 \mathrm{t}_{\mathrm{b} 1 \mathrm{r} 0} \\ \mathrm{P} 1 \mathrm{t}_{\mathrm{b} 2 \mathrm{r} 0}\end{array}\right)=\left(\begin{array}{c}74.42109 \\ 128.8584 \\ 100.5215 \\ -200.7841 \\ 103.5348\end{array}\right) \mu \mathrm{m}$

$\left(\begin{array}{c}\mathrm{P}_{2} \\ \mathrm{P}_{2} \mathrm{t}_{\mathrm{b} 1 \mathrm{f} 0} \\ \mathrm{P}_{2} \mathrm{t}_{\mathrm{b} 2 \mathrm{f} 0} \\ \mathrm{P} 2 \mathrm{t}_{\mathrm{b} 1 \mathrm{r} 0} \\ \mathrm{P} 2 \mathrm{t}_{\mathrm{b} 2 \mathrm{r} 0}\end{array}\right)=\left(\begin{array}{c}0.00171 \\ -0.00215 \\ -0.00255 \\ 0.00165 \\ 0.0025\end{array}\right) \frac{1}{\mu \mathrm{m}}$

$\left(\begin{array}{l}\mathrm{P}^{2} t_{b 1 f 0} \\ \mathrm{P} t_{b 2 f 0} \\ P 3 t_{b 1 r 0} \\ P 3 t_{b 2 r 0}\end{array}\right)=\left(\begin{array}{c}-0.41005 \\ 0.77941 \\ 3.08514 \\ -0.72899\end{array}\right)$

$\left(\begin{array}{l}\mathrm{P} t_{b 1 f 0} \\ \mathrm{P} t_{b 2 f 0} \\ \mathrm{P} 3 t_{b 1 r 0} \\ \mathrm{P} t_{b 2 r 0}\end{array}\right)=\left(\begin{array}{c}-0.41005 \\ 0.77941 \\ 3.08514 \\ -0.72899\end{array}\right)$

$\left(\begin{array}{c}\mathrm{P} 0_{1} \\ \mathrm{P} 1 \mathrm{t}_{\mathrm{b} 1 \mathrm{f} 90} \\ \mathrm{P} 1 \mathrm{t}_{\mathrm{b} 2 \mathrm{f} 90} \\ \mathrm{P} 1 \mathrm{t}_{\mathrm{b} 1 \mathrm{r} 90} \\ \mathrm{P} 1 \mathrm{t}_{\mathrm{b} 2 \mathrm{r} 90}\end{array}\right)=\left(\begin{array}{c}0.00014 \\ 0.00016 \\ 8.16908 \times 10^{-5} \\ 0.00027 \\ -0.0002\end{array}\right) \mathrm{m}$

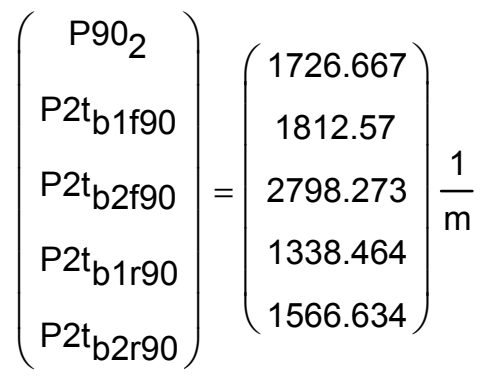

$\left(\begin{array}{l}P 3 t_{b 1 f 90} \\ P 3 t_{b 2 f 90} \\ P 3 t_{b 1 r 90} \\ P 3 t_{b 2 r 90}\end{array}\right)=\left(\begin{array}{c}-0.09677 \\ 1.00361 \\ 3.481 \\ -0.12949\end{array}\right)$

$\left(\begin{array}{l}{\mathrm{P} 4 \mathrm{t}_{\mathrm{b} 1 \mathrm{f} 90}}_{\mathrm{P} 4 \mathrm{t}_{\mathrm{b} 2 \mathrm{f} 90}} \\ \mathrm{P} 4 \mathrm{t}_{\mathrm{b} 1 \mathrm{r} 90} \\ \mathrm{P} 4 \mathrm{t}_{\mathrm{b} 2 \mathrm{r} 90}\end{array}\right)=\left(\begin{array}{c}2.52333 \times 10^{-5} \\ -9.89974 \times 10^{-5} \\ 8.46611 \times 10^{-5} \\ -1.92365 \times 10^{-5}\end{array}\right) \mathrm{m}$

\section{Equations that form the 2 tows in the 0 degree direction}

For each tow, there are 2 surface functions that define the top and bottom faces of the tow, receptively. These equations were developed using the symbolic solve block function, with properties of the tows in at the front and rear faces as boundary conditions. 


\section{Tow 1}

\section{Top Equation}

$$
\begin{aligned}
& \mathrm{A}_{1 \text { top }}(\mathrm{x}):=\frac{1}{2} \cdot \mathrm{P0} 0_{1} \cdot \sin \left(\mathrm{PO}_{2} \cdot \mathrm{x}+\pi\right)-\frac{1}{2} \cdot \frac{\mathrm{b}_{90}}{2}-\frac{1}{2} \cdot \mathrm{P} 1 \mathrm{t}_{\mathrm{b} 1 \mathrm{fo}} \cdot \sin \left(\mathrm{P} 2 \mathrm{t}_{\mathrm{b} 1 \mathrm{f0}} \cdot \mathrm{x}+\mathrm{P} 3 \mathrm{t}_{\mathrm{b} 1 \mathrm{fo}}\right)-\frac{1}{2} \cdot \mathrm{P} 4 \mathrm{t}_{\mathrm{b} 1 \mathrm{fC}} \\
& \mathrm{B}_{1 \text { top }}:=\frac{12500}{23} \cdot \frac{\pi}{\mathrm{m}} \\
& \mathrm{C}_{1 \text { top }}:=0 \\
& \mathrm{D}_{1 \text { top }}(\mathrm{x}):=\frac{1}{2} \cdot \mathrm{P0} 0_{1} \cdot \sin \left(\mathrm{PO}_{2} \cdot \mathrm{x}+\pi\right)-\frac{1}{2} \cdot \frac{\mathrm{b}_{90}}{2}+\frac{1}{2} \cdot \mathrm{P} 1 \mathrm{t}_{\mathrm{b} 1 \mathrm{f0}} \cdot \sin \left(\mathrm{P} 2 \mathrm{t}_{\mathrm{b} 1 \mathrm{fo}} \cdot \mathrm{x}+\mathrm{P} 3 \mathrm{t}_{\mathrm{b} 1 \mathrm{fo}}\right)+\frac{1}{2} \cdot \mathrm{P} 4 \mathrm{t}_{\mathrm{b} 1 \mathrm{fC}} \\
& \mathrm{F}_{1 \text { top }}(\mathrm{x}, \mathrm{y}):=\mathrm{A}_{1 \text { top }}(\mathrm{x}) \cdot \sin \left(\mathrm{B}_{1 \text { top }} \cdot \mathrm{y}+\mathrm{C}_{1 \text { top }}\right)+\mathrm{D}_{1 \text { top }}(\mathrm{x})
\end{aligned}
$$

\section{Bottom Equation}

$$
\begin{aligned}
& \mathrm{A}_{1 \mathrm{bot}}(\mathrm{x}):=\frac{1}{2} \cdot \mathrm{P} 4 \mathrm{t}_{\mathrm{b} 1 \mathrm{rO}}-\frac{1}{2} \cdot \mathrm{P} 0_{1} \cdot \sin \left(\mathrm{PO} \mathrm{C}_{2} \cdot \mathrm{x}\right)-\frac{1}{2} \cdot \frac{\mathrm{b}_{90}}{2}+\frac{1}{2} \cdot \mathrm{P} 1 \mathrm{t}_{\mathrm{b} 1 \mathrm{r} 0} \cdot \sin \left(\mathrm{P} 2 \mathrm{t}_{\mathrm{b} 1 \mathrm{r} 0} \cdot \mathrm{x}+\mathrm{P} 3 \mathrm{t}_{\mathrm{b} 1 \mathrm{r} 0}\right) \\
& \mathrm{PO}_{2}=1710 \frac{1}{\mathrm{~m}} \\
& B_{1 \text { bot }}:=\frac{12500}{23} \cdot \frac{\pi}{m} \\
& C_{1 \text { bot }}:=0 \\
& \mathrm{D}_{1 \mathrm{bot}}(\mathrm{x}):=\frac{1}{2} \cdot \mathrm{P} 4 \mathrm{t}_{\mathrm{b} 1 \mathrm{rO}}+\frac{1}{2} \cdot \mathrm{P} 0_{1} \cdot \sin \left(\mathrm{PO}_{2} \cdot \mathrm{x}\right)+\frac{1}{2} \cdot \frac{\mathrm{b}_{90}}{2}+\frac{1}{2} \cdot \mathrm{P} 1 \mathrm{t}_{\mathrm{b} 1 \mathrm{r} 0} \cdot \sin \left(\mathrm{P} \mathrm{t}_{\mathrm{b} 1 \mathrm{r} 0} \cdot \mathrm{x}+\mathrm{P} 3 \mathrm{t}_{\mathrm{b} 1 \mathrm{ro}}\right) \\
& F_{1 \text { bot }}(x, y):=A_{1 \text { bot }}(x) \cdot \sin \left(B_{1 \text { bot }} \cdot y+C_{1 \text { bot }}\right)+D_{1 \text { bot }}(x)
\end{aligned}
$$




\section{Tow 2}

\section{Top Equation}

$$
\begin{aligned}
& A_{2 t o p}(x):=\frac{-1}{2} \cdot P 0_{1} \cdot \sin \left(P_{2} \cdot x\right)+\frac{1}{2} \cdot \frac{b_{90}}{2}+\frac{1}{2} \cdot P 1 t_{b 2 r o} \cdot \sin \left(P 2 t_{b 2 r 0} \cdot x+P 3 t_{b 2 r o}\right)+\frac{1}{2} \cdot P 4 t_{b 2 r C} \\
& \mathrm{~B}_{2 \mathrm{top}}:=\frac{12500}{23} \cdot \frac{\pi}{\mathrm{m}} \\
& \mathrm{P} 3 \mathrm{t}_{\mathrm{b} 2 \mathrm{r} 0}=-0.72899 \\
& C_{2 \text { top }}:=0 \\
& \mathrm{D}_{2 \mathrm{top}}(\mathrm{x}):=\frac{1}{2} \cdot \mathrm{PO}_{1} \cdot \sin \left(\mathrm{PO}_{2} \cdot \mathrm{x}\right)-\frac{1}{2} \cdot \frac{\mathrm{b}_{90}}{2}+\frac{1}{2} \cdot \mathrm{P} 1 \mathrm{t}_{\mathrm{b} 2 \mathrm{r} 0} \cdot \sin \left(\mathrm{P}_{2} \mathrm{t}_{\mathrm{b} 2 \mathrm{rO}} \mathrm{x}+\mathrm{P} 3 \mathrm{t}_{\mathrm{b} 2 \mathrm{rO}}\right)+\frac{1}{2} \cdot \mathrm{P} 4 \mathrm{t}_{\mathrm{b} 2 \mathrm{rC}} \\
& F_{2 \text { top }}(x, y):=A_{2 \text { top }}(x) \cdot \sin \left(B_{2 \text { top }} \cdot y+C_{2 \text { top }}\right)+D_{2 \text { top }}(x)
\end{aligned}
$$

\section{Bottom Equation}

$$
\begin{aligned}
& \mathrm{A}_{2 \mathrm{bot}}(\mathrm{x}):=\frac{-1}{2} \cdot \mathrm{P} \mathrm{t}_{\mathrm{b} 2 \mathrm{fO}}+\frac{1}{2} \cdot \mathrm{P} 0_{1} \cdot \sin \left(\mathrm{PO}_{2} \cdot \mathrm{x}+\pi\right)+\frac{1}{2} \cdot \frac{\mathrm{b}_{90}}{2}-\frac{1}{2} \cdot \mathrm{P} 1 \mathrm{t}_{\mathrm{b} 2 \mathrm{ff}} \cdot \sin \left(\mathrm{P} 2 \mathrm{t}_{\mathrm{b} 2 \mathrm{fO}} \cdot \mathrm{x}+\mathrm{P} 3 \mathrm{t}_{\mathrm{b} 2 \mathrm{fO}}\right) \\
& B_{2 b o t}:=\frac{12500}{23} \cdot \frac{\pi}{m} \\
& C_{2 b o t}:=0 \\
& \mathrm{D}_{2 \mathrm{bot}}(\mathrm{x}):=\frac{1}{2} \cdot \mathrm{P} 4 \mathrm{t}_{\mathrm{b} 2 \mathrm{fO}}+\frac{1}{2} \cdot \mathrm{PO}_{1} \cdot \sin \left(\mathrm{PO}_{2} \cdot \mathrm{x}+\pi\right)+\frac{1}{2} \cdot \frac{\mathrm{b}_{90}}{2}+\frac{1}{2} \cdot \mathrm{P} 1 \mathrm{t}_{\mathrm{b} 2 \mathrm{fO}} \cdot \sin \left(\mathrm{P} \mathrm{t}_{\mathrm{b} 2 \mathrm{fO}} \cdot \mathrm{x}+\mathrm{P} 3 \mathrm{t}_{\mathrm{b} 2 \mathrm{fO}}\right) \\
& F_{2 b o t}(x, y):=A_{2 b o t}(x) \cdot \sin \left(B_{2 b o t} \cdot y+C_{2 b o t}\right)+D_{2 b o t}(x)
\end{aligned}
$$




\section{Equations that form the tows (labeled 3 and 4) in the 90 degree direction}

\section{Tow 3}

\section{Top Equation}

$$
\begin{aligned}
& A_{3 t o p}(y):=\frac{1}{2} \cdot F_{2 b o t}\left(a_{x}, y\right)-\frac{1}{2} \cdot P 1 t_{b 1 f 90} \cdot \sin \left(P 2 t_{b 1 f 90} \cdot y+P 3 t_{b 1 f 90}\right)-\frac{1}{2} \cdot P 4 t_{b 1 f 9 C} \\
& B_{3 \text { top }}:=\frac{12500}{23} \cdot \frac{\pi}{m} \\
& C_{3 \text { top }}:=0 \\
& D_{3 t o p}(y):=\frac{1}{2} \cdot F_{2 b o t}\left(a_{x}, y\right)+\frac{1}{2} \cdot P 1 t_{b 1 f 90} \cdot \sin \left(P 2 t_{b 1 f 90} \cdot y+P 3 t_{b 1 f 90}\right)+\frac{1}{2} \cdot P 4 t_{b 1 f 9 C} \\
& F_{3 \text { top }}(x, y):=A_{3 \text { top }}(y) \cdot \sin \left(B_{3 \text { top }} \cdot x\right)+D_{3 \text { top }}(y)
\end{aligned}
$$

\section{Bottom Equation}

$$
\begin{aligned}
& A_{3 \text { bot }}(y):=\frac{-1}{2} \cdot F_{1 \text { top }}\left(-a_{x}, y\right)+\frac{1}{2} \cdot P 1 t_{b 1 r 90} \cdot \sin \left(P 2 t_{b 1 r 90} \cdot y+P 3 t_{b 1 r 90}\right)+\frac{1}{2} \cdot P 4 t_{b 1 r 9 C} \\
& B_{3 b o t}:=\frac{12500}{23} \cdot \frac{\pi}{m} \\
& C_{3 b o t}:=0 \\
& D_{3 b o t}(y):=\frac{1}{2} \cdot F_{1 \text { top }}\left(-a_{x}, y\right)+\frac{1}{2} \cdot P 1 t_{b 1 r 90} \cdot \sin \left(P 2 t_{b 1 r 90} \cdot y+P 3 t_{b 1 r 90}\right)+\frac{1}{2} \cdot P 4 t_{b 1 r 9 C} \\
& F_{3 b o t}(x, y):=A_{3 b o t}(y) \cdot \sin \left(B_{3 b o t} \cdot x\right)+D_{3 b o t}(y)
\end{aligned}
$$

\section{Tow 4}

\section{Top Equation}

$A_{4 t_{o p}}(y):=\frac{1}{2} \cdot P 4 t_{b 2 r 90}-\frac{1}{2} \cdot F_{1 b o t}\left(-a_{x}, y\right)+\frac{1}{2} \cdot P 1 t_{b 2 r 90} \cdot \sin \left(P 2 t_{b 2 r 90} \cdot y+P 3 t_{b 2 r 90}\right)$ 


$$
\begin{aligned}
& B_{4 \text { top }}:=\frac{12500}{23} \cdot \frac{\pi}{m} \\
& C_{4 \text { top }}:=0 \\
& D_{4 \text { top }}(y):=\frac{1}{2} \cdot P 4 t_{b 2 r 90}+\frac{1}{2} \cdot F_{1 b o t}\left(-a_{x}, y\right)+\frac{1}{2} \cdot P 1 t_{b 2 r 90} \cdot \sin \left(P 2 t_{b 2 r 90} \cdot y+P 3 t_{b 2 r 90}\right) \\
& F_{4 \text { top }}(x, y):=A_{4 \text { top }}(y) \cdot \sin \left(B_{4 \text { top }} \cdot x\right)+D_{4 t o p}(y)
\end{aligned}
$$

\section{Bottom Equation}

$$
\begin{aligned}
& A_{4 b o t}(y):=\frac{-1}{2} \cdot P 4 t_{b 2 f 90}+\frac{1}{2} \cdot F_{2 t o p}\left(a_{x}, y\right)-\frac{1}{2} \cdot P 1 t_{b 2 f 90} \cdot \sin \left(P 2 t_{b 2 f 90} \cdot y+P 3 t_{b 2 f 90}\right) \\
& B_{4 b o t}:=\frac{12500}{23} \cdot \frac{\pi}{m} \\
& C_{4 b o t}:=0 \\
& D_{4 b o t}(y):=\frac{1}{2} \cdot P 4 t_{b 2 f 90}+\frac{1}{2} \cdot F_{2 t o p}\left(a_{x}, y\right)+\frac{1}{2} \cdot P 1 t_{b 2 f 90} \cdot \sin \left(P 2 t_{b 2 f 90} \cdot y+P 3 t_{b 2 f 90}\right) \\
& F_{4 b o t}(x, y):=A_{4 b o t}(y) \cdot \sin \left(B_{4 b o t} \cdot x\right)+D_{4 b o t}(y)
\end{aligned}
$$

\section{D Representation}

Once the respective top and bottom surface functions are generated, the RVE is plotted in order to visually inspect and verify the overall weaving shape of the tows.

$$
\begin{aligned}
& x_{b 10}:=-a_{x} \quad x_{b 1 f}:=x_{c b 1 f C} \quad x_{b 20}:=x_{c b 2 f C} \quad x_{b 2 f}:=a_{x} \quad x_{c b 1 f 0}=-0.00017 m \\
& y_{b 10}:=-a_{y} \quad y_{b 1 f}:=a_{y} \quad y_{b 20}:=-a_{y} \quad y_{b 2 f}:=a_{y} \quad x_{b 1900}:=-a_{x} \\
& \text { mesh := } 25 \\
& F_{1 t}:=\operatorname{CreateMesh}\left(F_{1 \text { top }}, x_{b 10}, x_{b 1 f}, y_{b 10}, y_{b 1 f}, \text { mesh }\right) \\
& F_{1 b}:=\operatorname{CreateMesh}\left(F_{1 b o t}, x_{b 10}, x_{b 1 f}, y_{b 10}, y_{b 1 f}, \text { mesh }\right) \\
& F_{2 t}:=\text { CreateMesh }\left(F_{2 t o p}, x_{b 20}, x_{b 2 f}, y_{b 20}, y_{b 2 f}, \text { mesh }\right) \\
& F_{2 b}:=\text { CreateMesh }\left(F_{2 b o t}, x_{b 20}, x_{b 2 f}, y_{b 20}, y_{b 2 f}, \text { mesh }\right)
\end{aligned}
$$




$$
\begin{aligned}
& x_{b 190 f}:=a_{x} \quad x_{b 2900}:=-a_{x} \quad x_{b 290 f}:=a_{x} \quad y_{b 1900}:=y_{c b 1 r 90} \\
& y_{b 190 f}:=a_{y} \quad y_{b 2900}:=-a_{y} \quad y_{b 290 f}:=y_{c b 2 r 90} \\
& F_{3 t}:=\text { CreateMesh }\left(F_{3 t o p}, x_{b 1900}, x_{b 190 f}, y_{b 1900}, y_{b 190 f}, \text { mesh }\right) \\
& F_{3 b}:=\text { CreateMesh }\left(F_{3 b o t}, x_{b 1900}, x_{b 190 f}, y_{b 1900}, y_{b 190 f}, \text { mesh }\right) \\
& F_{4 t}:=\text { CreateMesh }\left(F_{4 t o p}, x_{b 2900}, x_{b 290 f}, y_{b 2900}, y_{b 290 f}, \text { mesh }\right) \\
& F_{4 b}:=\text { CreateMesh }\left(F_{4 b o t}, x_{b 2900}, x_{b 290 f}, y_{b 2900}, y_{b 290 f}, \text { mesh }\right)
\end{aligned}
$$

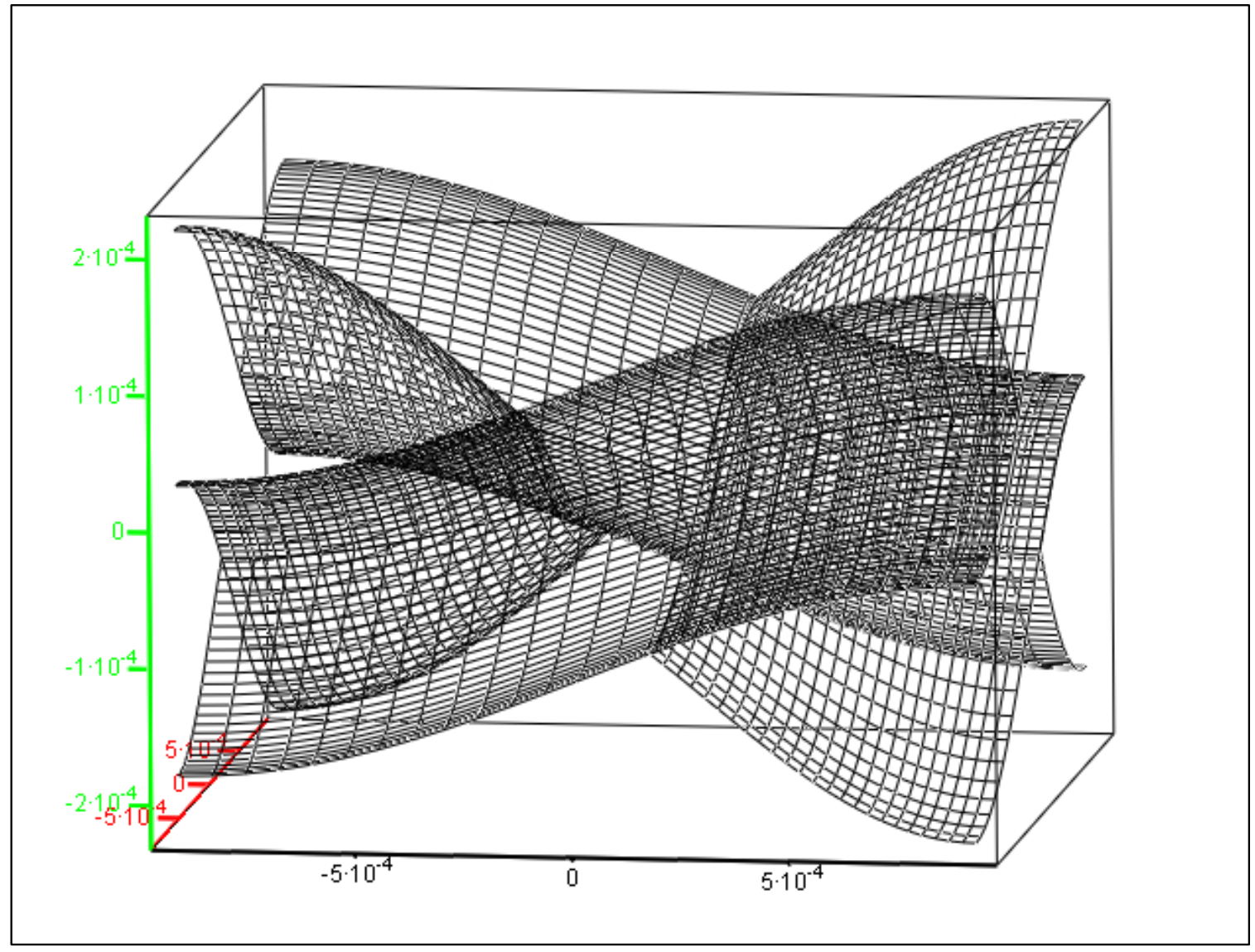

$F_{1 t}, F_{1 b}, F_{2 t}, F_{2 b}, F_{3 t}, F_{3 b}, F_{4 t}, F_{4 b}$

Location of tow 1 ( 0 degree minus):

$\mathrm{x}$ from -ax to -.00017

$\mathrm{y}$ from -ay to ay

Location of tow 3 (90 degree plus):

$x$ from -ax to ax

$\mathrm{y}$ from .00017 to ay
Location of tow 2 ( 0 degree plus):

$\mathrm{x}$ from .00017 to ax

$\mathrm{y}$ from -ay to ay

Location of tow 4 (90 degree minus):

$\mathrm{x}$ from -ax to ax

$\mathrm{y}$ from -ay to -.00017 
The 3D surface functions are simplified for future calculations by means of indexing.

$\mathrm{i}:=1 . . \mathrm{m}_{\text {inc }}$

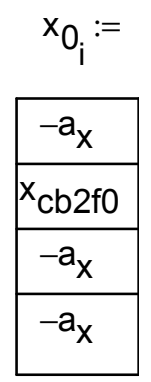

\begin{tabular}{c}
$\mathrm{x}_{\mathrm{f}_{\mathrm{i}}}:=$ \\
$\mathrm{x}_{\mathrm{cb} 1 \mathrm{f0}}$ \\
\hline $\mathrm{a}_{\mathrm{x}}$ \\
\hline $\mathrm{a}_{\mathrm{x}}$ \\
\hline $\mathrm{a}_{\mathrm{x}}$ \\
\hline
\end{tabular}

\begin{tabular}{c}
$\mathrm{y}_{0_{i}}:=$ \\
\hline$-a_{y}$ \\
\hline$-a_{y}$ \\
\hline$y_{c b 1 f 90}$ \\
\hline$-a_{y}$ \\
\hline
\end{tabular}

\begin{tabular}{c}
$\mathrm{y}_{\mathrm{f}_{\mathrm{i}}}:=$ \\
\hline $\mathrm{a}_{\mathrm{y}}$ \\
\hline $\mathrm{a}_{\mathrm{y}}$ \\
\hline $\mathrm{a}_{\mathrm{y}}$ \\
\hline $\mathrm{y}_{\mathrm{cb} 2 \mathrm{f} 90}$ \\
\hline
\end{tabular}

$$
F_{\text {top }}(x, y, i):=\mid \begin{array}{lll}
F_{1 \text { top }}(x, y) & \text { if } & i=1 \\
F_{2 \text { top }}(x, y) & \text { if } & i=2 \\
F_{3 \text { top }}(x, y) & \text { if } & i=3 \\
F_{4 t o p}(x, y) & \text { if } & i=4
\end{array}
$$

$F_{\text {bot }}(x, y, i):=\mid \begin{array}{lll}F_{1 b o t}(x, y) & \text { if } & i=1 \\ F_{2 b o t}(x, y) & \text { if } & i=2 \\ F_{3 b o t}(x, y) & \text { if } & i=3 \\ F_{4 b o t}(x, y) & \text { if } & i=4\end{array}$

\section{Determination of the tow volumes}

$$
v_{i}:=\int_{y_{0_{i}}}^{y_{f_{i}}} \int_{x_{0_{i}}}^{x_{f_{i}}} \int_{F_{\text {bot }}(x, y, i)}^{F_{\text {top }}(x, y, i)} 1 d z d x d y
$$

\section{Determination of the RVE volume and fiber volume fractions}

$$
\mathrm{V}_{\mathrm{RVE}}:=8 \cdot \mathrm{a}_{\mathrm{x}} \cdot \mathrm{a}_{\mathrm{y}} \cdot \mathrm{b}_{90}
$$

Volume of the total RVE

$$
\begin{aligned}
& \mathrm{V}_{\text {RVE }}=1.43911 \mathrm{~mm}^{3} \\
& \mathrm{~V}_{\text {meso }}:=\sum_{\mathrm{i}} \mathrm{V}_{\mathrm{i}}
\end{aligned}
$$

Total volume of all of the 4 tows

$$
\mathrm{V}_{\text {meso }}=7.06515 \times 10^{-10} \mathrm{~m}^{3}
$$




$$
\begin{aligned}
& f_{\text {meso }}:=\frac{V_{\text {meso }}}{V_{\text {RVE }}} \\
& f_{\text {meso }}=0.49094
\end{aligned}
$$

Volume fraction of the tows to the RVE

$v_{f_{0}}:=0.37 \quad$ overall fiber volume fraction of the RVE

$v_{\text {fmeso }}:=1-\frac{\left(1-v_{f o}\right) \cdot V_{R V E}-\left(V_{R V E}-v_{\text {meso }}\right)}{V_{\text {meso }}} \quad$ Meso-scale fiber volume fraction of an inclusion

$v_{\text {fmeso }}=0.75366$

$f_{i}:=\frac{V_{i}}{V_{R V E}}$

$\mathrm{f}_{\mathrm{i}}=$

\begin{tabular}{|l|}
\hline 0.11578 \\
\hline 0.11309 \\
\hline 0.13223 \\
\hline 0.12984 \\
\hline
\end{tabular}

\section{Part 2: $\xi$ vector definition}

The vector $\xi$ is a terms that is used in the construction of the Fourier series expansion of all field variables, such as stresses and strains.

$$
\begin{array}{ll}
\xi(r, s, t):=\pi\left(\frac{r}{a_{x}} \frac{s}{a_{y}} \frac{t}{a_{z}}\right)^{\top} & \xi_{a b s}(r, s, t):=\sqrt{\xi(r, s, t) \cdot \xi(r, s, t)} \\
\xi_{\text {bar }}(r, s, t):=\frac{\xi(r, s, t)}{\xi_{\text {abs }}(r, s, t)} & x(x, y, z):=\left(\begin{array}{lll}
x & y & z
\end{array}\right)^{\top}
\end{array}
$$




\section{Part 3: The G-integral}

$$
\begin{aligned}
& g_{p}(r, s, t, i):=\frac{1}{V_{i}} \cdot \int_{y_{0_{i}}}^{y_{f_{i}}} \int_{x_{0_{i}}}^{x_{f_{i}}} \int_{F_{\text {bot }}(x, y, i)}^{F_{\text {top }}(x, y, i)} e^{i \cdot(\xi(r, s, t) \cdot X(x, y, z))} d z d x d y \\
& g_{m}(r, s, t, i):=\frac{1}{V_{i}} \cdot \int_{y_{0_{i}}}^{y_{f_{i}}} \int_{x_{0_{i}}}^{x_{f_{i}}} \int_{F_{b o t}(x, y, i)}^{F_{\text {top }}(x, y, i)} e^{-i \cdot(\xi(r, s, t) \cdot X(x, y, z))} d z d x d y
\end{aligned}
$$

\section{Part 4: Material properties of the constituent materials}

In order to homogenize the the properties of the inclusions (tows) to that of the surrounding matrix, the constituent materials, i.e. the matrix and the tow (meso scale), must be determined. The results for the CERL geometry and an E Glass/Epoxy composite are reported here.

\section{Material Properties of the matrix}

$$
\begin{aligned}
& \mathrm{GPa}:=10^{9} \cdot \mathrm{Pa} \\
& \mathrm{E}_{\mathrm{m}}:=3.4 \cdot \mathrm{GPa} \quad \mathrm{v}_{\mathrm{m}}:=0.38 \\
& \mathrm{C}_{\mathrm{m}}:=\frac{\mathrm{E}_{\mathrm{m}}}{\left(1+v_{\mathrm{m}}\right) \cdot\left(1-2 \cdot v_{\mathrm{m}}\right)} \cdot\left[\begin{array}{cccccc}
1-v_{\mathrm{m}} & v_{\mathrm{m}} & v_{\mathrm{m}} & 0 & 0 & 0 \\
v_{\mathrm{m}} & 1-v_{\mathrm{m}} & v_{\mathrm{m}} & 0 & 0 & 0 \\
v_{\mathrm{m}} & v_{\mathrm{m}} & 1-v_{\mathrm{m}} & 0 & 0 & 0 \\
0 & 0 & 0 & \frac{1}{2}\left(1-2 \cdot v_{\mathrm{m}}\right) & 0 & 0 \\
0 & 0 & 0 & 0 & \frac{1}{2}\left(1-2 \cdot v_{\mathrm{m}}\right) & 0 \\
0 & 0 & 0 & 0 & 0 & \frac{1}{2}\left(1-2 \cdot v_{\mathrm{m}}\right)
\end{array}\right]
\end{aligned}
$$




\section{Material Properties of the Inclusions}

$\mathrm{C}_{\mathrm{avg}_{\alpha}}$ are the stiffness matrices of the $\alpha$ number of inclusions. In this example, all of the inclusions are orthotropic in the direction of the undulation of the fibers in the inclusion. The material coordinate stiffnesses of each tow is determined by assuming transverse isotropy with respect to a coordinate system in which the abscissa corresponds to the slope of the tow. Those transformed properties are averaged over the length of the inclusion. The data for the tow constituent properties were taken from Table 1.1 of Barbero, E. J. "Introduction to Composite Materials Design" for E-Glass/Epoxy. The accompanying software, CADEC, was used to determine the transversely isotropic properties as if the tow were unidirectional. In addition, the value of the fiber volume fraction inside of the tows was determined above for given overall fiber volume fraction and the volume fraction of the tows.

$$
\begin{array}{lll}
\mathrm{E}_{\alpha}:=59.58 \cdot \mathrm{GPa} & \mathrm{E}_{\alpha}:=21.51 \cdot \mathrm{GPa} & \mathrm{E}_{\mathrm{z}_{\alpha}}:=\mathrm{E}_{\alpha} \\
\mathrm{G}_{\mathrm{xy}}:=8.770 \cdot \mathrm{GPa} & \mathrm{G}_{\mathrm{yz}}:=7.591 \cdot \mathrm{GPa} & \mathrm{G}_{\mathrm{xz}}:=\mathrm{G}_{\mathrm{xy}} \\
\mathrm{v}_{\mathrm{xy}}:=0.29155 & \mathrm{v}_{\mathrm{yz}}:=0.41706 & v_{\mathrm{xz}}:=v_{\mathrm{xy}}
\end{array}
$$

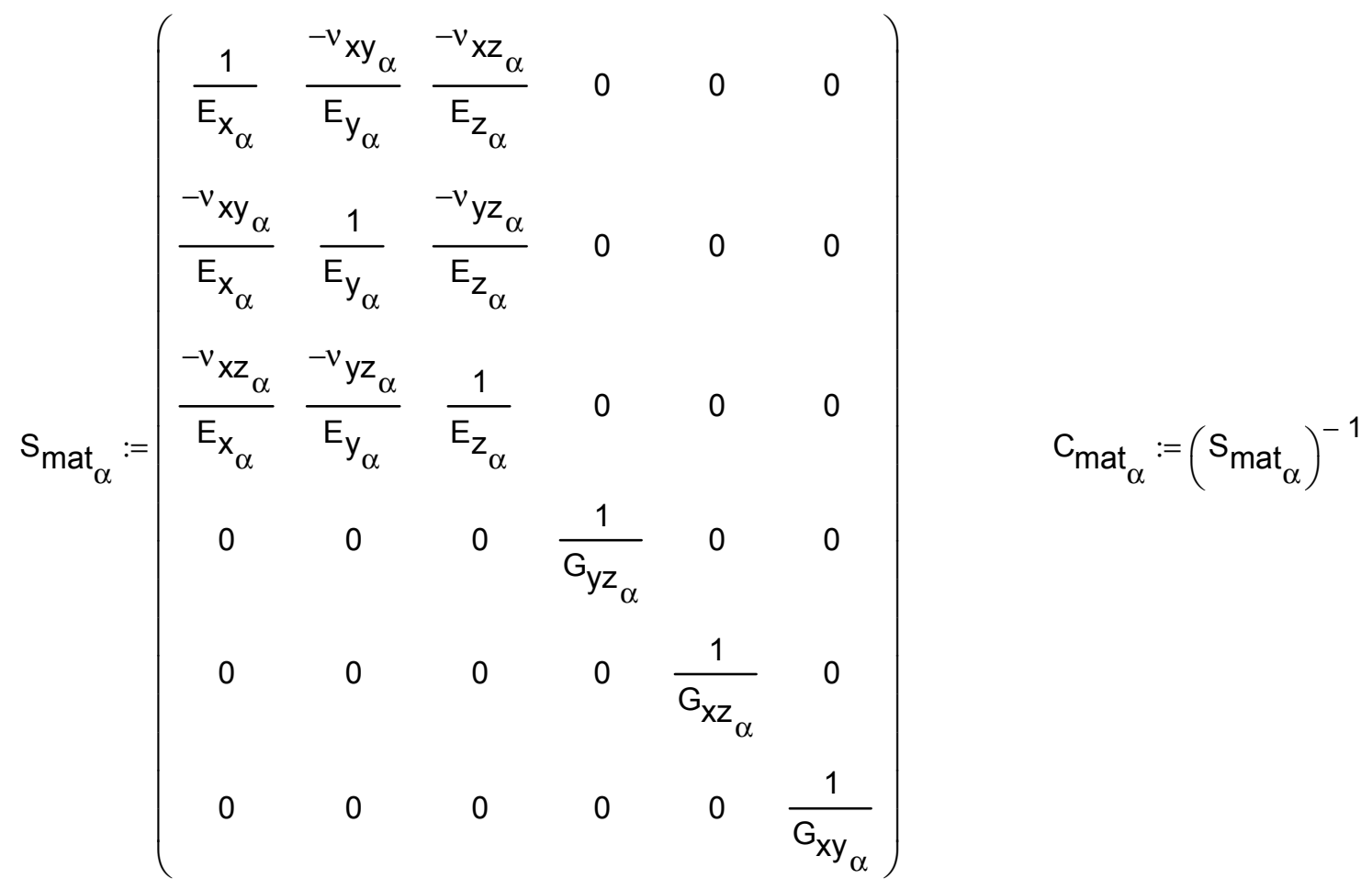

Coordinate Transformation for contracted stiffness notation 


$$
\begin{aligned}
& F_{x}(\alpha, x):=\mid \begin{array}{l}
F_{3 t o p}\left(x, a_{y}\right) \text { if } \alpha=3 \vee \alpha=1 \\
F_{4 \text { top }}\left(x,-a_{y}\right) \text { if } \alpha=4 \vee \alpha=2
\end{array} \\
& \mathrm{~F}_{\mathrm{X}}^{\prime}(\alpha, \mathrm{x}):=\frac{\partial}{\partial \mathrm{x}} \mathrm{F}_{\mathrm{X}}(\alpha, \mathrm{x}) \quad \theta_{\mathrm{X}}(\alpha, \mathrm{x}):=\operatorname{atan}\left(\mathrm{F}_{\mathrm{X}}^{\prime}(\alpha, \mathrm{x})\right) \\
& a(\alpha, \theta):=\left(\begin{array}{ccc}
\cos (\theta) & 0 & \sin (\theta) \\
0 & 1 & 0 \\
-\sin (\theta) & 0 & \cos (\theta)
\end{array}\right) \\
& T(\alpha, \theta):=\mid \begin{aligned}
& \text { for } i \in 1 . .6 \\
& \text { for } j \in 1 . .6
\end{aligned} \\
& \mathrm{~T}_{\mathrm{i}, \mathrm{j}} \leftarrow\left(\mathrm{a}(\alpha, \theta)_{\mathrm{i}, \mathrm{j}}\right)^{2} \text { if } \mathrm{i} \leq 3 \wedge \mathrm{j} \leq 3 \\
& \text { for } i i \in 1 . .3 \quad \text { if } i \leq 3 \wedge j>3 \\
& \text { for } \mathrm{jj} \in \mathrm{ii} . .3 \\
& \text { if } \quad \mathrm{ii} \neq \mathrm{jj} \\
& \mid \begin{array}{l}
\gamma \leftarrow 9-\mathrm{ii}-\mathrm{jj} \\
\mathrm{T}_{\mathrm{i}, \mathrm{j}} \leftarrow\left(2 \mathrm{a}(\alpha, \theta)_{\mathrm{i}, \mathrm{ii}} \cdot \mathrm{a}(\alpha, \theta)_{\mathrm{i}, \mathrm{j}}\right) \text { if } \gamma=\mathrm{j}
\end{array} \\
& \text { for } i i \in 1 . .3 \quad \text { if } i>3 \wedge j \leq 3 \\
& \text { for } \mathrm{jj} \in \mathrm{ii} . .3 \\
& \text { if } \quad \mathrm{ii} \neq \mathrm{jj} \\
& \mid \begin{array}{l}
\beta \leftarrow 9-\mathrm{ii}-\mathrm{jj} \\
\mathrm{T}_{\mathrm{i}, \mathrm{j}} \leftarrow\left(\mathrm{a}(\alpha, \theta)_{\mathrm{ii}, \mathrm{j}} \cdot \mathrm{a}(\alpha, \theta)_{\mathrm{jj}, \mathrm{j}}\right) \text { if } \beta=\mathrm{i}
\end{array} \\
& \text { for } i i \in 1 . .3 \quad \text { if } i>3 \wedge j>3 \\
& \text { for } \mathrm{jj} \in \mathrm{ii} . .3 \\
& \text { if } \quad \mathrm{i} \neq \mathrm{jj} \\
& \mid \begin{array}{l}
\chi \leftarrow 9-\mathrm{ii}-\mathrm{jj} \\
\text { for } k \mathrm{kk} \in 1 . .3
\end{array} \\
& \text { for } \| \in k k . .3 \\
& \text { if } k \mathrm{k} \neq \mathrm{II}
\end{aligned}
$$

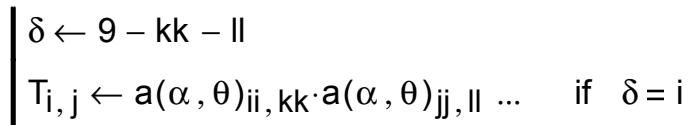

$$
\begin{aligned}
& +\mathrm{a}(\alpha, \theta)_{\mathrm{ii}, \mathrm{ll}} \cdot \mathrm{a}(\alpha, \theta)_{\mathrm{jj}, \mathrm{kk}} \\
& \mathrm{T}_{\mathrm{X}}(\alpha, \theta):=\mathrm{T}(\alpha, \theta)
\end{aligned}
$$




$$
\begin{aligned}
& \mathrm{S}_{\text {mat }}^{\prime}(\alpha, \mathrm{x}):=\left(\left(\mathrm{T}_{\mathbf{X}}\left(\alpha, \theta_{\mathrm{X}}(\alpha, \mathrm{x})\right)\right)^{\mathrm{T}} \cdot \mathrm{S}_{\text {mat }_{\alpha}} \cdot \mathrm{T}_{\mathbf{X}}\left(\alpha, \theta_{\mathrm{X}}(\alpha, \mathrm{x})\right)\right) \\
& \text { mstep }:=100 \quad \text { nstep }:=1 \ldots(\text { mstep }+1) \\
& x_{\text {nstep }}:=-a_{x}+(\text { nstep }-1) \cdot \frac{2 \cdot a_{x}}{m s t e p} \quad y_{n s t e p}:=-a_{y}+(\text { nstep }-1) \cdot \frac{2 \cdot a_{y}}{m s t e p} \\
& S_{\text {avg }_{\alpha}}:=\mid \begin{array}{cc}
\text { for } i \in 1 . .6 & C_{\text {avg }_{\alpha}}:=\left(S_{\text {avg }_{\alpha}}\right)^{-1} \\
\text { for } j \in 1 . .6 &
\end{array} \\
& \mid \begin{array}{l}
s_{i, j} \leftarrow \frac{1}{\text { mstep }} \cdot \sum_{n=1}^{\text {mstep +1 }} S_{\text {mat }}^{\prime}\left(\alpha, x_{n}\right)_{i, j} \text { if } \alpha \leq 2 \\
s_{i, j} \leftarrow \frac{1}{\text { mstep }} \cdot \sum_{n=1}^{\text {mstep }+1} S_{\text {mat }}^{\prime}\left(\alpha, y_{n}\right)_{i, j} \text { if } \alpha>2
\end{array}
\end{aligned}
$$$$
a(\alpha):=\left(\begin{array}{lll}
0 & 1 & 0 \\
1 & 0 & 0 \\
0 & 0 & 1
\end{array}\right)
$$ 


$$
\begin{aligned}
& T 1(\alpha):=\mid \begin{array}{r}
\text { for } i \in 1 . .6 \\
\text { for } j \in 1 . .6
\end{array} \\
& \mid \begin{array}{ll}
T_{i, j} \leftarrow\left(a(\alpha)_{i, j}\right)^{2} \text { if } i \leq 3 \wedge j \leq 3 & \\
\text { for } i i \in 1 . .3 & \text { if } i \leq 3 \wedge j>3
\end{array} \\
& \text { for } \mathrm{jj} \in \mathrm{ii} . .3 \\
& \text { if } \quad \mathrm{ii} \neq \mathrm{jj} \\
& \mid \begin{array}{l}
\gamma \leftarrow 9-\mathrm{ii}-\mathrm{jj} \\
\mathrm{T}_{\mathrm{i}, \mathrm{j}} \leftarrow\left(2 \mathrm{a}(\alpha)_{\mathrm{i}, \mathrm{ii}} \cdot \mathrm{a}(\alpha)_{\mathrm{i}, \mathrm{jj}}\right) \text { if } \gamma=\mathrm{j}
\end{array} \\
& \text { for } \quad i i \in 1 . .3 \quad \text { if } i>3 \wedge j \leq 3 \\
& \text { for } \mathrm{jj} \in \mathrm{ii} . .3 \\
& \text { if } \quad \mathrm{ii} \neq \mathrm{jj} \\
& \mid \begin{array}{l}
\beta \leftarrow 9-\mathrm{ii}-\mathrm{jj} \\
\mathrm{T}_{\mathrm{i}, \mathrm{j}} \leftarrow\left(\mathrm{a}(\alpha)_{\mathrm{ii}, \mathrm{j}} \cdot \mathrm{a}(\alpha)_{\mathrm{jj}, \mathrm{j}}\right) \text { if } \beta=\mathrm{i}
\end{array} \\
& \text { for } i i \in 1 . .3 \quad \text { if } i>3 \wedge j>3 \\
& \text { for } \mathrm{jj} \in \mathrm{ii} . .3 \\
& \text { if } \quad \mathrm{ii} \neq \mathrm{jj} \\
& \chi \leftarrow 9-\mathrm{ii}-\mathrm{jj} \\
& \text { for } k k \in 1 . .3 \quad \text { if } \chi=\mathrm{j} \\
& \text { for } \| \in k k \text {.. } 3 \\
& \text { if } k \mathrm{k} \neq \| \\
& \delta \leftarrow 9-\mathrm{kk}-\|
\end{aligned}
$$

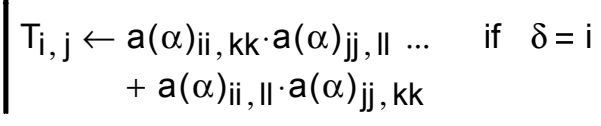

$$
\begin{aligned}
& \mathrm{S}_{\mathrm{avg}_{\alpha}}:=\mid \begin{array}{l}
\mathrm{T} 1(\alpha) \cdot \mathrm{S}_{\mathrm{avg}_{\alpha}} \cdot \mathrm{T} 1(\alpha)^{\top} \text { if } \quad \alpha<3 \quad \mathrm{C}_{\mathrm{avg}_{\alpha}}:=\left(\mathrm{S}_{\mathrm{avg}_{\alpha}}\right)^{-1} \\
\mathrm{~S}_{\mathrm{avg}_{\alpha}}^{\prime} \text { otherwise }
\end{array} \\
& \mathrm{C}_{\text {meso }}:=\frac{1}{4} \cdot \sum_{\alpha} \mathrm{C}_{\mathrm{avg}_{\alpha}}
\end{aligned}
$$




\section{Part 5: FSP calculation}

$\mathrm{n}:=3$

$$
\begin{aligned}
& \operatorname{FSP}(r, s, t):=\mid \text { for } i \in 1 . . n \\
& \text { for } \mathrm{j} \in \mathrm{i} . . \mathrm{n} \\
& \mid \begin{array}{l}
\alpha \leftarrow i \text { if } i=j \\
\alpha \leftarrow 9-i-j \text { if } i \neq j \\
\text { for } k \in 1 . . n
\end{array} \\
& \text { for } I \in \mathrm{k} . . \mathrm{n} \\
& \beta \leftarrow \mathrm{k} \text { if } \mathrm{k}=\mathrm{l} \\
& \beta \leftarrow 9-k-1 \text { if } k \neq 1 \\
& \mathrm{~F}_{\alpha, \beta} \leftarrow \frac{1}{2} \cdot\left[\begin{array}{c}
\xi_{\mathrm{bar}}(\mathrm{r}, \mathrm{s}, \mathrm{t})_{\mathrm{j}} \cdot\left(\begin{array}{l}
\delta(\mathrm{i}, \mathrm{l}) \cdot \xi_{\mathrm{bar}}(\mathrm{r}, \mathrm{s}, \mathrm{t})_{\mathrm{k}} \cdots \\
+\delta(\mathrm{i}, \mathrm{k}) \cdot \xi_{\mathrm{bar}}(\mathrm{r}, \mathrm{s}, \mathrm{t})_{\mid}
\end{array}\right) \cdots \\
+\xi_{\mathrm{bar}}(\mathrm{r}, \mathrm{s}, \mathrm{t})_{\mathrm{i}} \cdot\left(\begin{array}{l}
\delta(\mathrm{j}, \mathrm{l}) \cdot \xi_{\mathrm{bar}}(\mathrm{r}, \mathrm{s}, \mathrm{t})_{\mathrm{k}} \cdots \\
+\delta(\mathrm{j}, \mathrm{k}) \cdot \xi_{\mathrm{bar}}(\mathrm{r}, \mathrm{s}, \mathrm{t})_{\mid}
\end{array}\right)
\end{array}\right] \cdots \\
& +\frac{1}{v_{m}-1} \cdot \xi_{\text {bar }}(r, s, t)_{i} \cdot \xi_{\text {bar }}(r, s, t)_{j} \cdot \xi_{\text {bar }}(r, s, t)_{k} \cdot \xi_{\text {bar }}(r, s, t)_{1} \ldots \\
& +\frac{v_{m}}{1-v_{m}} \cdot \xi_{\text {bar }}(r, s, t)_{i} \cdot \xi_{\text {bar }}(r, s, t) j \cdot \delta(k, l)
\end{aligned}
$$

\section{Part 6: SP tensor formulation}

The $\mathrm{S}^{\mathrm{P}}$ tensor is the key computational aspect of the periodic microstructure micro mechanical model. Evaluation of this term for all possible combinations of inclusions is where the model becomes computationally expensive. An alternate program to compute $\mathrm{S}^{\mathrm{P}}$ that encompasses all of the previous calculations has been written in Fortran. It is a more efficient way of determining $\mathrm{S}^{\mathrm{P}}$, and the values can be entered into this program with for the continuation of the model computation. 
Calculation of the SP tensor as a function of $\mathrm{N}$

$\operatorname{SP}(N, \alpha, \beta):=\mid \begin{aligned} & \text { Sold } \leftarrow 0 \\ & \text { for } r \in-N . . N \\ & \text { for } s \in-N . . N \\ & \text { for } t \in-N . . N \\ & \mid \begin{array}{l}\text { continue if } \quad(r=0) \wedge(s=0) \wedge(t=0) \\ S \leftarrow f_{\beta} \cdot g_{p}(r, s, t, \alpha) \cdot g_{m}(r, s, t, \beta) \cdot F S P(r, s, t) \\ \text { Snew } \leftarrow S+\text { Sold } \\ \text { Sold } \leftarrow \text { Snew }\end{array}\end{aligned}$

Matrix representation of SP for all possible combinations of inclusions

$\mathrm{SP}_{\alpha, \beta}:=\mathrm{SP}(1, \alpha, \beta)$

SPtotal is the construction of the $6 * \mathrm{~m}_{\mathrm{inc}}$ by $6 * \mathrm{~m}_{\mathrm{inc}}$ matrix using the computed value of SP above.

$$
\mathrm{SP}_{\text {total }}:=\mid \begin{aligned}
& \text { for } \quad \alpha \in 1 . . \mathrm{m}_{\text {inc }} \\
& \mid \begin{array}{l}
\text { for } \beta \in 1 . . \mathrm{m}_{\text {inc }} \\
\text { Sold } \leftarrow \mathrm{SP}_{\alpha, 1} \text { if } \beta=1 \\
\text { otherwise } \\
\mid \begin{array}{l}
\text { Saug } \leftarrow \text { augment }\left(\text { Sold }, \mathrm{SP}_{\alpha, \beta}\right) \\
\text { Sold } \leftarrow \text { Saug }
\end{array} \\
\text { Soldstack } \leftarrow \text { Saug if } \alpha=1 \\
\text { otherwise } \\
\text { Sstack } \quad \text { Sstack } \leftarrow \text { stack (Soldstack, Saug) }
\end{array}
\end{aligned}
$$


SPdata is an input variable for externally computed values of $\mathrm{S}^{\mathrm{P}}$ for $\mathrm{N}:=3$

SPdata : $=$
\begin{tabular}{r|r|r|r|r|r|r|}
\hline & 1 & \multicolumn{1}{c|}{2} & \multicolumn{1}{c|}{3} & \multicolumn{1}{c|}{4} & \multicolumn{1}{c|}{5} & \multicolumn{1}{c|}{6} \\
\cline { 2 - 8 } & 0.18721 & 0.07201 & 0.05628 & -0.00221 & 0.00016 & -0.000021 \\
\hline 2 & 0.00585 & 0.03623 & -0.01325 & 0.03879 & 0.0000045 & -0.000021 \\
\hline 3 & 0.11897 & 0.11559 & 0.35259 & -0.01209 & -0.0000611 & 0.0000288 \\
\hline 4 & 0.01615 & 0.05715 & 0.00627 & 0.14594 & 0.0000172 & 0.0000907 \\
\hline 5 & 0.00023 & 0.0000784 & 0.0000128 & 0.0000172 & 0.22649 & 0.01921 \\
\hline 6 & -0.000031 & -0.000031 & 0.0000189 & 0.0000907 & 0.01921 & 0.0919 \\
\hline
\end{tabular}

Because of the imported data, the $\mathrm{S}^{\mathrm{P}}$ terms need to be separated into the sub-matrices, as given in the Mathcad computation of $\mathrm{S}^{\mathrm{P}}$

$$
\begin{aligned}
& \alpha \operatorname{step}(\alpha):=\alpha+5 \cdot(\alpha-1) \quad \beta \operatorname{step}(\beta):=\beta+5 \cdot(\beta-1) \\
& \mathrm{SP}:=\mid \begin{array}{l}
\text { for } \alpha \in 1 . . \mathrm{m}_{\text {inc }} \\
\text { for } \beta \in 1 . . \mathrm{m}_{\text {inc }} \\
\quad \mathrm{S}_{\alpha, \beta} \leftarrow \operatorname{submatrix}(\operatorname{SPdata}, \alpha \operatorname{step}(\alpha), \alpha \operatorname{step}(\alpha)+5, \beta \operatorname{step}(\beta), \beta \operatorname{step}(\beta)+5) \\
\mathrm{S}
\end{array}
\end{aligned}
$$$$
W:=\left(\begin{array}{llllll}
1 & 0 & 0 & 0 & 0 & 0 \\
0 & 1 & 0 & 0 & 0 & 0 \\
0 & 0 & 1 & 0 & 0 & 0 \\
0 & 0 & 0 & 2 & 0 & 0 \\
0 & 0 & 0 & 0 & 2 & 0 \\
0 & 0 & 0 & 0 & 0 & 2
\end{array}\right)
$$

$\mathrm{W}$ is the Reuter matrix, which is used to resolve the double contraction of two tensors represented by matrices.

\section{Part 7: Determining the A matrix and its inverse}

$$
A:=\mid \begin{aligned}
& \text { for } \quad \alpha \in 1 . . m_{\text {inc }} \\
& \text { for } \beta \in 1 . . m_{\text {inc }} \\
& \quad A_{\alpha, \beta} \leftarrow\left[C_{m} \cdot W \cdot\left(\mathrm{SP}_{\alpha, \beta}-\delta(\alpha, \beta) \cdot W^{-1}\right)-C_{a_{\alpha g}} \cdot W \cdot S P_{\alpha, \beta}\right] \cdot W \\
& \text { AA }
\end{aligned}
$$


$\mathrm{A}_{\text {final }}$ is the combination of all possible interactions of inclusions

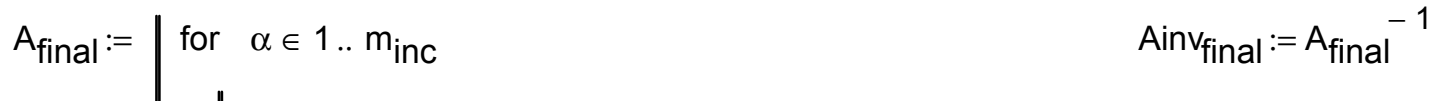

$$
\begin{aligned}
& \text { for } \beta \in 1 . . \mathrm{m}_{\text {inc }} \\
& \mid \begin{array}{l}
A_{\text {old }} \leftarrow A_{\alpha, 1} \text { if } \beta=1 \\
\text { otherwise }
\end{array} \\
& \text { otherwise } \\
& \begin{array}{l}
\mathrm{A}_{\text {aug }} \leftarrow \operatorname{augment}\left(\mathrm{A}_{\text {old }}, \mathrm{A}_{\alpha, \beta}\right) \\
\mathrm{A}_{\text {old }} \leftarrow \mathrm{A}_{\text {aug }}
\end{array} \\
& A_{\text {oldstack }} \leftarrow A_{\text {aug }} \text { if } \alpha=1 \\
& \text { otherwise } \\
& \mid \begin{array}{l}
A_{\text {stack }} \leftarrow \operatorname{stack}\left(A_{\text {oldstack }}, A_{\text {aug }}\right) \\
A_{\text {oldstack }} \leftarrow A_{\text {stack }}
\end{array} \\
& A_{\text {stack }}
\end{aligned}
$$

Calculation of the inverse of $A_{\text {final }}$

$$
\begin{aligned}
& \alpha \text { step }(\alpha):=\alpha+5 \cdot(\alpha-1) \quad \beta \operatorname{step}(\beta):=\beta+5 \cdot(\beta-1) \\
& \text { Ainv }:=\mid \begin{array}{l}
\text { for } \alpha \in 1 . .4 \\
\text { for } \beta \in 1 . .4 \\
A_{\alpha, \beta} \leftarrow \operatorname{submatrix}\left(\operatorname{Ainv}_{\text {final }}, \alpha \operatorname{\alpha step}(\alpha), \alpha \operatorname{step}(\alpha)+5, \beta \operatorname{step}(\beta), \beta \operatorname{step}(\beta)+5\right) \\
\text { A }
\end{array}
\end{aligned}
$$

$\mathrm{C}_{\mathrm{bar}}$ is the effective stiffness of the homogenized RVE

$C_{b a r}:=C_{m} \cdot W \cdot\left[W^{-1}-\sum_{\alpha=1}^{4} f_{\alpha} \sum_{\beta=1}^{4} \operatorname{Ainv}_{\alpha, \beta} \cdot W \cdot\left[\left(C_{\text {avg }_{\alpha}}-C_{m}\right) \cdot W \cdot W^{-1}\right]\right]$

$$
C_{\text {bar }}=\left(\begin{array}{cccccc}
30.684876 & 12.538234 & 9.222006 & 0.006812 & 0.000551 & 0.000698 \\
12.343095 & 26.955036 & 9.067244 & -0.012031 & 0.00164 & -0.000183 \\
9.653916 & 9.190744 & 12.196127 & -0.001284 & 0.000174 & 0.000001 \\
-0.005143 & -0.01238 & -0.002963 & 3.399771 & 0.00006 & 0.00069 \\
-0.011013 & -0.006405 & -0.005154 & -0.00002 & 3.335631 & 0.003261 \\
0.000399 & 0.000184 & 0.000082 & 0.00069 & 0.002892 & 5.360821
\end{array}\right) G P a
$$




$$
\begin{aligned}
& \mathrm{s}_{\mathrm{bar}}:=\mathrm{C}_{\mathrm{bar}}{ }^{-1} \\
& \mathrm{E}_{1}:=\frac{1}{\mathrm{~S}_{\mathrm{bar}_{1,1}}} \quad \mathrm{E}_{1}=21.95038 \mathrm{GPa} \quad \mathrm{G}_{23}:=\frac{1}{\mathrm{~S}_{\mathrm{bar}_{4,4}}} \quad \mathrm{G}_{23}=3.39977 \mathrm{GPa} \\
& E_{2}:=\frac{1}{S_{\text {bar }_{2,2}}} \quad E_{2}=18.88755 G P a \quad G_{13}:=\frac{1}{S_{\text {bar }_{5,5}}} \quad G_{13}=3.33563 G P a \\
& \mathrm{E}_{3}:=\frac{1}{\mathrm{~S}_{\mathrm{bar}_{3,3}}} \quad \mathrm{E}_{3}=8.01202 \mathrm{GPa} \quad \mathrm{G}_{12}:=\frac{1}{\mathrm{~S}_{\mathrm{bar}_{6,6}}} \quad \mathrm{G}_{12}=5.36082 \mathrm{GPa} \\
& v_{12}:=-\mathrm{S}_{\mathrm{bar}_{1,2}} \cdot \mathrm{E}_{2} \quad v_{12}=0.23899 \\
& v_{13}:=-S_{\text {bar }_{1,3}} \cdot E_{3} \quad v_{13}=0.20063 \\
& v_{23}:=-S_{\text {bar }_{2,3}} \cdot E_{3} \quad v_{23}=0.24451
\end{aligned}
$$




\section{Appendix C}

\section{Computation of Point-wise Stresses in the RVE of a Plain Weave Fabric Composite}

This is the text of a Mathcad file written to compute the point-wise stresses throughout the RVE of a plain weave fabric composite using periodic microstructure. All of the stress data generated in this research was computed in a file of this general form. The only differences between different files are the RVE and weave geometry, the material properties and fiber volume fractions of the constituent materials, and the convergence value $\mathrm{N}$ used to calculate the matrix $\mathrm{S}^{\mathrm{P}}$.

This file contains geometric descriptions determined by the research of Ito and Chou.

\section{Part 1: Geometric description, function derivation, and 3-D plotting}

The basis of the RVE from the respect of the 2D view is to start from the fill tows, as represented by a series of sine curves

The dimension of the RVE is $2 \mathrm{a}_{\mathrm{x}}$ by $2 \mathrm{a}_{\mathrm{y}}$ by $2 \mathrm{a}_{\mathrm{z}}$, and the dimensions are as follows:

$$
\begin{aligned}
& \mu \mathrm{m}:=10^{-6} \cdot \mathrm{m} \\
& \mathrm{i}:=1 . .3 \quad \mathrm{j}:=1 . .2
\end{aligned}
$$

\begin{tabular}{cc}
$\mathrm{a}_{\mathrm{i}}:=$ & $\mathrm{a}_{\mathrm{g}_{\mathrm{j}}}:=$ \\
\hline $1608 \cdot \mu \mathrm{m}$ & $\quad \mathrm{a}_{\mathrm{y}}:=\mathrm{a}_{2} \quad \mathrm{a}_{\mathrm{z}}:=\mathrm{a}_{3}$ \\
\hline $1527.5 \cdot \mu \mathrm{m}$ & \\
\hline $318 \cdot \mu \mathrm{m} \cdot \mu \mathrm{m}$ \\
$\mathrm{a}_{\mathrm{x}}:=\mathrm{a}_{1} \quad$
\end{tabular}

$a_{g}$ is the gap width between the tows 


$$
\begin{aligned}
& \mathrm{m}_{\text {inc }}:=4 \\
& \mathrm{~h}_{\mathrm{C}_{\mathrm{j}}}:=\frac{\mathrm{a}_{3}}{2} \cdot\left(\sin \left(\frac{\pi \cdot \mathrm{a}_{\mathrm{g}_{\mathrm{j}}}}{4 \mathrm{a}_{\mathrm{j}}}\right)+1\right)
\end{aligned}
$$

Distance between the top of the transverse tow and the contact point with the longitudinal tow

Equations for the front side of the 0 degree direction of the RVE (x-z plane)

$$
f_{0}(x):=\frac{a_{3}}{2} \cdot \sin \left(\frac{2 \cdot \pi \cdot x}{4 \cdot a_{1}}\right) \quad f_{0 u}(x):=f_{0}(x)+\frac{a_{3}}{2} \quad f_{01}(x):=f_{0}(x)-\frac{a_{3}}{2}
$$

Assuming as sinusoidal shape for the transverse tows, the two equations below represent the bounds for the transverse fill tows in the 0 degree direction

$$
\begin{aligned}
& f_{0 t u}(x):=\left(\frac{-1}{2} \cdot a_{3} \cdot \sin \left(\frac{1}{4} \cdot \pi \cdot \frac{a_{g_{1}}}{a_{1}}\right)-\frac{1}{2} \cdot a_{3}\right) \cdot \sin \left[\frac{\pi}{\left(a_{g_{1}}-2 \cdot a_{1}\right)} \cdot x+\frac{-1}{2} \cdot \pi \cdot \frac{\left(a_{g_{1}}-4 \cdot a_{1}\right)}{\left(a_{g_{1}}-2 \cdot a_{1}\right)}\right] \ldots \\
& +\frac{-1}{2} \cdot a_{3} \cdot \sin \left(\frac{1}{4} \cdot \pi \cdot \frac{a_{g_{1}}}{a_{1}}\right)+\frac{1}{2} \cdot a_{3} \\
& f_{0 t l}(x):=\left(\frac{-1}{2} \cdot a_{3}-\frac{1}{2} \cdot a_{3} \cdot \sin \left(\frac{1}{4} \cdot \pi \cdot \frac{a_{g_{1}}}{a_{1}}\right)\right) \cdot \sin \left[\frac{\pi}{\left(a_{g_{1}}-2 \cdot a_{1}\right)} \cdot x+\frac{1}{2} \cdot \pi \cdot \frac{\left(a_{g_{1}}-4 \cdot a_{1}\right)}{\left(a_{g_{1}}-2 \cdot a_{1}\right)}\right] \ldots \\
& +\frac{-1}{2} \cdot a_{3}+\frac{1}{2} \cdot a_{3} \cdot \sin \left(\frac{1}{4} \cdot \pi \cdot \frac{a_{g_{1}}}{a_{1}}\right) \\
& x_{\text {tu }}:=-a_{1},-a_{1}+10 \cdot \mu m . . \frac{-a_{g_{1}}}{2} \quad x_{t l}:=\frac{a_{g_{1}}}{2}, \frac{a_{g_{1}}}{2}+10 \cdot \mu m . . a_{1}
\end{aligned}
$$




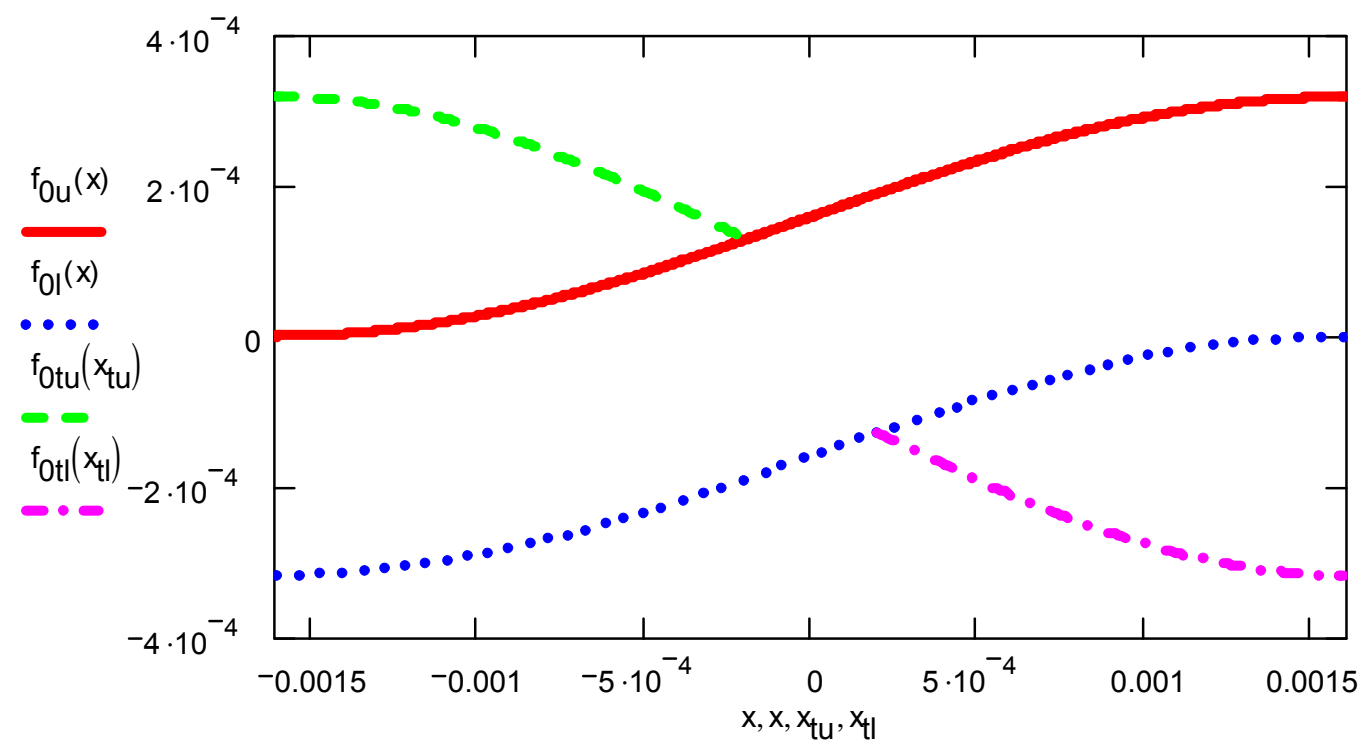

Equations for the rear side of the 0 degree direction of the RVE (x-z plane)

$$
\begin{aligned}
& r_{0}(x):=-\frac{a_{3}}{2} \cdot \sin \left(\frac{2 \cdot \pi \cdot x}{4 \cdot a_{1}}\right) \quad r_{0 u}(x):=r_{0}(x)+\frac{a_{3}}{2} \quad r_{01}(x):=r_{0}(x)-\frac{a_{3}}{2} \\
& \mathrm{r}_{\mathrm{Otl}}(\mathrm{x}):=-\mathrm{f}_{\mathrm{Otu}}(\mathrm{x}) \quad \mathrm{r}_{\mathrm{Otu}}(\mathrm{x}):=-\mathrm{f}_{\mathrm{Otl}}(\mathrm{x}) \\
& x_{t l}:=-a_{1},-a_{1}+10 \cdot \mu m . . \frac{-a_{g_{1}}}{2} \quad x_{t u}:=\frac{a_{g_{1}}}{2}, \frac{{ }^{a} g_{1}}{2}+10 \cdot \mu m . . a_{1}
\end{aligned}
$$

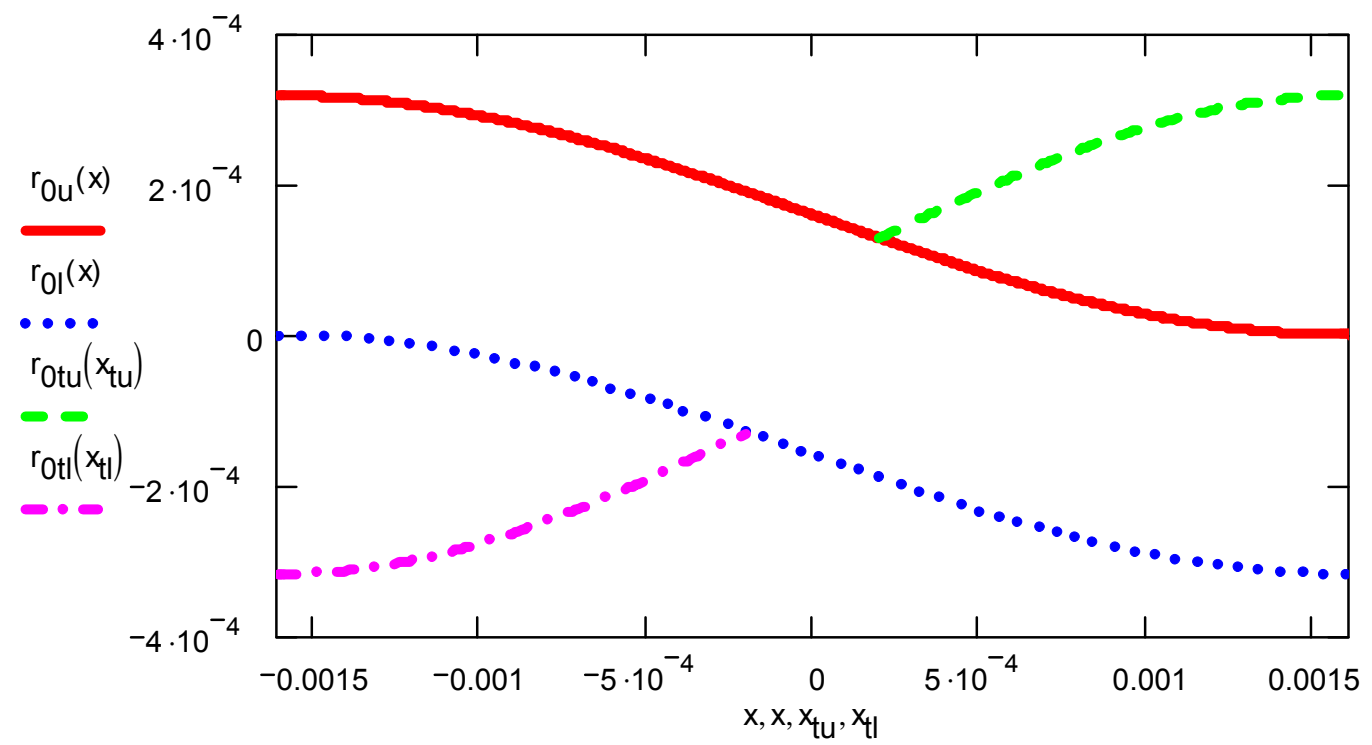




$$
\begin{aligned}
f_{90}(y):= & -\frac{a_{3}}{2} \cdot \sin \left(\frac{2 \cdot \pi \cdot y}{4 \cdot a_{2}}\right) \quad f_{90 u}(y):=f_{90}(y)+\frac{a_{3}}{2} \quad f_{901}(y):=f_{90}(y)-\frac{a_{3}}{2} \\
f_{90 t l}(y):= & \left(\frac{1}{2} \cdot a_{3} \cdot \sin \left(\frac{1}{4} \cdot \pi \cdot \frac{a_{g_{2}}}{a_{2}}\right)+\frac{1}{2} \cdot a_{3}\right) \cdot \sin \left[\frac{\pi}{\left(a_{g_{2}}-2 \cdot a_{2}\right)} \cdot y+\frac{-1}{2} \cdot \pi \cdot \frac{\left(a_{g_{2}}-4 \cdot a_{2}\right)}{\left(a_{g_{2}}-2 \cdot a_{2}\right)}\right] \ldots \\
& +\frac{1}{2} \cdot a_{3} \cdot \sin \left(\frac{1}{4} \cdot \pi \cdot \frac{a_{g_{2}}}{a_{2}}\right)-\frac{1}{2} \cdot a_{3} \\
f_{90 t u}(y):= & \left(\frac{1}{2} \cdot a_{3}+\frac{1}{2} \cdot a_{3} \cdot \sin \left(\frac{1}{4} \cdot \pi \cdot \frac{a_{g_{2}}}{a_{2}}\right)\right) \cdot \sin \left[\frac{\pi}{\left(a_{g_{2}}-2 \cdot a_{2}\right)} \cdot y+\frac{1}{2} \cdot \pi \cdot \frac{\left(a_{g_{2}}-4 \cdot a_{2}\right)}{\left(a_{g_{2}}-2 \cdot a_{2}\right)}\right] \ldots \\
& +\frac{1}{2} \cdot a_{3}-\frac{1}{2} \cdot a_{3} \cdot \sin \left(\frac{1}{4} \cdot \pi \cdot \frac{a_{g_{2}}}{a_{2}}\right) \\
y_{t l}:=-a_{2}, & -a_{2}+10 \cdot \mu m . . \frac{-a_{g_{2}}}{2}
\end{aligned}
$$

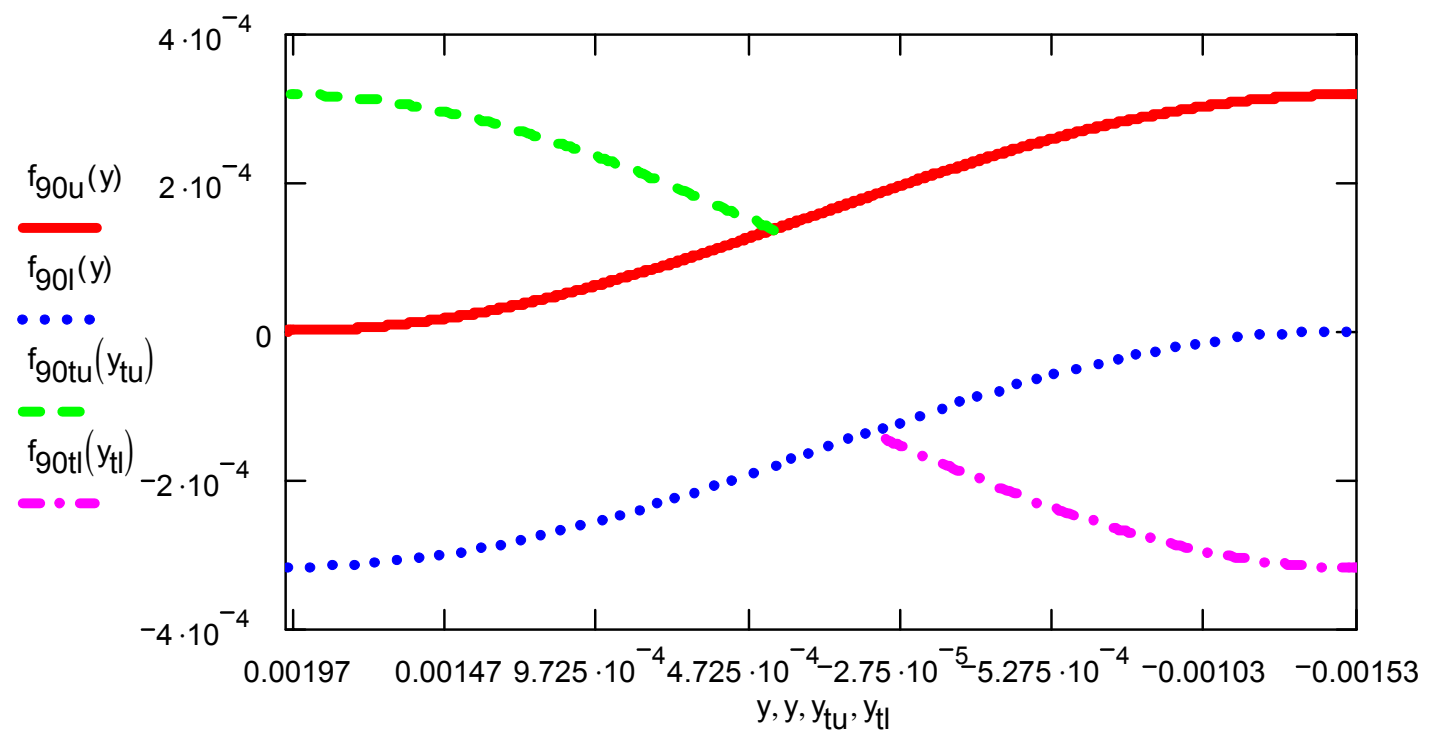

$$
r_{90}(y):=\frac{a_{3}}{2} \cdot \sin \left(\frac{2 \cdot \pi \cdot y}{4 \cdot a_{2}}\right) \quad r_{90 u}(y):=r_{90}(y)+\frac{a_{3}}{2} \quad r_{901}(y):=r_{90}(y)-\frac{a_{3}}{2}
$$




$$
\begin{aligned}
& r_{90 t u}(y):=-f_{90 t l}(y) \quad r_{90 t l}(y):=-f_{90 t u}(y) \\
& y_{t u}:=-a_{2},-a_{2}+10 \cdot \mu m . . \frac{-a_{g_{2}}}{2} \quad y_{t l}:=\frac{a_{g_{2}}}{2}, \frac{a_{g_{2}}}{2}+10 \cdot \mu m . . a_{2}
\end{aligned}
$$

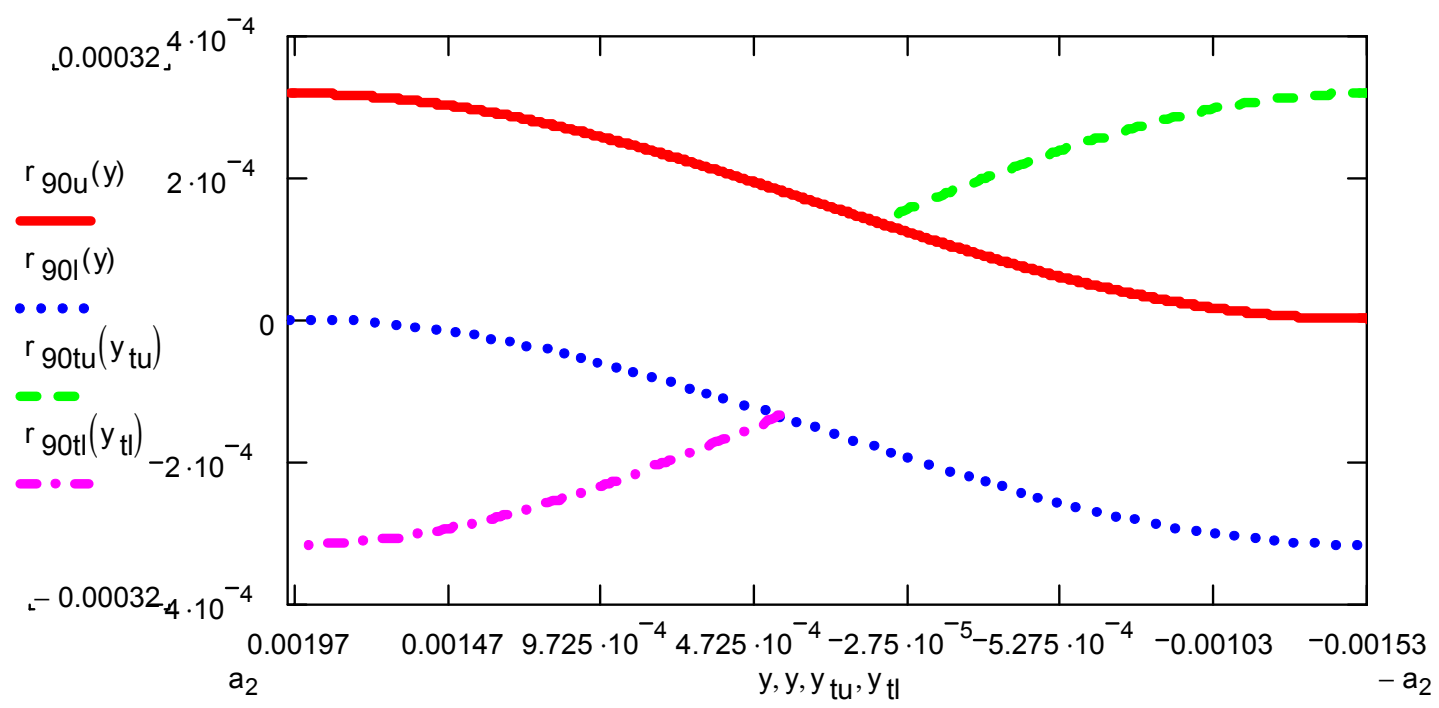

\section{Equations that form the 2 tows ( 1 and 2$)$ in the 0 degree direction}

For each tow, there are 2 surface functions that define the top and bottom faces of the tow, repectively.

\section{Tow 1}

\section{Top Equation}

$$
\begin{aligned}
& A_{1 \text { top }}(x): \frac{-1}{4} \cdot a_{3} \cdot \sin \left(\frac{1}{2} \cdot \pi \cdot \frac{x}{a_{1}}\right)+\frac{1}{4} \cdot a_{3} \cdot \sin \left[\frac{1}{2} \cdot \pi \cdot \frac{\left(2 \cdot x-a_{g_{1}}+4 \cdot a_{1}\right)}{\left(a_{g_{1}}-2 \cdot a_{1}\right)}\right] \cdot\left(\sin \left(\frac{1}{4} \cdot \pi \cdot \frac{a_{g_{1}}}{a_{1}}\right)+1\right) \ldots \\
&+\left(\frac{1}{4} \cdot a_{3} \cdot \sin \left(\frac{1}{4} \cdot \pi \cdot \frac{a_{g_{1}}}{a_{1}}\right)-\frac{1}{2} \cdot a_{3}\right) \\
& B_{1 \text { top }}:=\frac{1}{2} \cdot \frac{\pi}{a_{2}} \quad C_{1 \text { top }}:=0
\end{aligned}
$$




$$
\begin{aligned}
\mathrm{D}_{1 \text { top }}(\mathrm{x}):= & \frac{-1}{4} \cdot \mathrm{a}_{3} \cdot \sin \left(\frac{1}{2} \cdot \pi \cdot \frac{\mathrm{x}}{\mathrm{a}_{1}}\right)-\frac{1}{4} \cdot \sin \left[\frac{1}{2} \cdot \pi \cdot \frac{\left(2 \cdot \mathrm{x}-\mathrm{a}_{\mathrm{g}_{1}}+4 \cdot \mathrm{a}_{1}\right)}{\left(\mathrm{a}_{\mathrm{g}_{1}}-2 \cdot \mathrm{a}_{1}\right)}\right] \cdot \mathrm{a}_{3} \cdot \sin \left(\frac{1}{4} \cdot \pi \cdot \frac{\mathrm{a}_{\mathrm{g}_{1}}}{\mathrm{a}_{1}}\right) \ldots \\
& +-\left[\frac{1}{4} \cdot \sin \left[\frac{1}{2} \cdot \pi \cdot \frac{\left(2 \cdot \mathrm{x}-\mathrm{a}_{\mathrm{g}_{1}}+4 \cdot \mathrm{a}_{1}\right)}{\left(\mathrm{ag}_{1}-2 \cdot \mathrm{a}_{1}\right)}\right] \cdot \mathrm{a}_{3}+\frac{1}{4} \cdot \mathrm{a}_{3} \cdot \sin \left(\frac{1}{4} \cdot \pi \cdot \frac{\mathrm{a}_{\mathrm{g}_{1}}}{\mathrm{a}_{1}}\right)\right]
\end{aligned}
$$

$F_{1 \text { top }}(x, y):=A_{1 \text { top }}(x) \cdot \sin \left(B_{1 \text { top }} \cdot y+C_{1 \text { top }}\right)+D_{1 \text { top }}(x)$

\section{Bottom Equation}

$$
\begin{aligned}
A_{1 b o t}(x):= & \frac{1}{4} \cdot \sin \left[\frac{1}{2} \cdot \pi \cdot \frac{\left(2 \cdot x-a_{g_{1}}+4 \cdot a_{1}\right)}{\left(a_{g_{1}}-2 \cdot a_{1}\right)}\right] \cdot a_{3}-\frac{1}{4} \cdot a_{3} \cdot \sin \left(\frac{1}{2} \cdot \pi \cdot \frac{x}{a_{1}}\right)-\frac{1}{2} \cdot a_{3} \ldots \\
& +\frac{1}{4} \cdot \sin \left[\frac{1}{2} \cdot \pi \cdot \frac{\left(2 \cdot x-a_{g_{1}}+4 \cdot a_{1}\right)}{\left(a_{g_{1}}-2 \cdot a_{1}\right)}\right] \cdot a_{3} \cdot \sin \left(\frac{1}{4} \cdot \pi \cdot \frac{a_{g_{1}}}{a_{1}}\right)+\frac{1}{4} \cdot a_{3} \cdot \sin \left(\frac{1}{4} \cdot \pi \cdot \frac{a_{g_{1}}}{a_{1}}\right)
\end{aligned}
$$

$\mathrm{B}_{1 \mathrm{bot}}:=\frac{1}{2} \cdot \frac{\pi}{\mathrm{a}_{2}} \quad \mathrm{C}_{1 \text { bot }}:=0$

$$
\begin{aligned}
D_{1 b o t}(x):= & \frac{1}{4} \cdot \sin \left[\frac{1}{2} \cdot \pi \cdot \frac{\left(2 \cdot x-a_{g_{1}}+4 \cdot a_{1}\right)}{\left(a_{g_{1}}-2 \cdot a_{1}\right)}\right] \cdot a_{3}+\frac{1}{4} \cdot a_{3} \cdot \sin \left(\frac{1}{2} \cdot \pi \cdot \frac{x}{a_{1}}\right) \ldots \\
& +\frac{1}{4} \cdot \sin \left[\frac{1}{2} \cdot \pi \cdot \frac{\left(2 \cdot x-a_{g_{1}}+4 \cdot a_{1}\right)}{\left(a_{g_{1}}-2 \cdot a_{1}\right)}\right] \cdot a_{3} \cdot \sin \left(\frac{1}{4} \cdot \pi \cdot \frac{a_{g_{1}}}{a_{1}}\right)+\frac{1}{4} \cdot a_{3} \cdot \sin \left(\frac{1}{4} \cdot \pi \cdot \frac{a_{g_{1}}}{a_{1}}\right)
\end{aligned}
$$

$F_{1 \text { bot }}(x, y):=A_{1 \text { bot }}(x) \cdot \sin \left(B_{1 \text { bot }} \cdot y+C_{1 \text { bot }}\right)+D_{1 \text { bot }}(x)$

\section{Tow 2}

\section{Top Equation}

$$
\begin{aligned}
A_{2 t o p}(x):= & \frac{1}{4} \cdot \sin \left[\frac{1}{2} \cdot \pi \cdot \frac{\left(2 \cdot x+a_{g_{1}}-4 \cdot a_{1}\right)}{\left(a_{g_{1}}-2 \cdot a_{1}\right)}\right] \cdot a_{3} \cdot \sin \left(\frac{1}{4} \cdot \pi \cdot \frac{a_{g_{1}}}{a_{1}}\right)-\frac{1}{4} \cdot a_{3} \cdot \sin \left(\frac{1}{2} \cdot \pi \cdot \frac{x}{a_{1}}\right)+\frac{1}{2} \cdot a_{3} \ldots \\
& +\frac{1}{4} \cdot \sin \left[\frac{1}{2} \cdot \pi \cdot \frac{\left(2 \cdot x+a_{g_{1}}-4 \cdot a_{1}\right)}{\left(a_{g_{1}}-2 \cdot a_{1}\right)}\right] \cdot a_{3}-\frac{1}{4} \cdot a_{3} \cdot \sin \left(\frac{1}{4} \cdot \pi \cdot \frac{a_{g_{1}}}{a_{1}}\right)
\end{aligned}
$$


$\mathrm{B}_{2 \mathrm{top}}:=\frac{1}{2} \cdot \frac{\pi}{\mathrm{a}_{2}} \quad \mathrm{C}_{2 \text { top }}:=0$

$$
\begin{aligned}
D_{2 \text { top }}(x):= & \frac{1}{4} \cdot \sin \left[\frac{1}{2} \cdot \pi \cdot \frac{\left(2 \cdot x+a_{g_{1}}-4 \cdot a_{1}\right)}{\left(a_{g_{1}}-2 \cdot a_{1}\right)}\right] \cdot a_{3} \cdot \sin \left(\frac{1}{4} \cdot \pi \cdot \frac{a_{g_{1}}}{a_{1}}\right)+\frac{1}{4} \cdot a_{3} \cdot \sin \left(\frac{1}{2} \cdot \pi \cdot \frac{x}{a_{1}}\right) \ldots \\
& +\frac{1}{4} \cdot \sin \left[\frac{1}{2} \cdot \pi \cdot \frac{\left(2 \cdot x+a_{g_{1}}-4 \cdot a_{1}\right)}{\left(a_{g_{1}}-2 \cdot a_{1}\right)}\right] \cdot a_{3}-\frac{1}{4} \cdot a_{3} \cdot \sin \left(\frac{1}{4} \cdot \pi \cdot \frac{a_{g_{1}}}{a_{1}}\right)
\end{aligned}
$$

$F_{2 \text { top }}(x, y):=A_{2 \text { top }}(x) \cdot \sin \left(B_{2 \text { top }} \cdot y+C_{2 \text { top }}\right)+D_{2 \text { top }}(x)$

\section{Bottom Equation}

$$
\begin{aligned}
& A_{2 b o t}(x):=\frac{-1}{4} \cdot a_{3} \cdot \sin \left(\frac{1}{2} \cdot \pi \cdot \frac{x}{a_{1}}\right)+\frac{1}{2} \cdot a_{3}+\frac{1}{4} \cdot \sin \left[\frac{1}{2} \cdot \pi \cdot \frac{\left(2 \cdot x+a_{g_{1}}-4 \cdot a_{1}\right)}{\left(a_{g_{1}}-2 \cdot a_{1}\right)}\right] \cdot a_{3} \ldots \\
& +\frac{1}{4} \cdot \sin \left[\frac{1}{2} \cdot \pi \cdot \frac{\left(2 \cdot x+a_{g_{1}}-4 \cdot a_{1}\right)}{\left(a_{g_{1}}-2 \cdot a_{1}\right)}\right] \cdot a_{3} \cdot \sin \left(\frac{1}{4} \cdot \pi \cdot \frac{a_{g_{1}}}{a_{1}}\right)-\frac{1}{4} \cdot a_{3} \cdot \sin \left(\frac{1}{4} \cdot \pi \cdot \frac{a_{g_{1}}}{a_{1}}\right) \\
& \mathrm{B}_{2 \mathrm{bot}}:=\frac{1}{2} \cdot \frac{\pi}{\mathrm{a}_{2}} \quad \mathrm{C}_{2 \mathrm{bot}}:=0 \\
& \mathrm{D}_{2 \mathrm{bot}}(\mathrm{x}):=\frac{-1}{4} \cdot \mathrm{a}_{3} \cdot \sin \left(\frac{1}{2} \cdot \pi \cdot \frac{\mathrm{x}}{\mathrm{a}_{1}}\right)-\frac{1}{4} \cdot \sin \left[\frac{1}{2} \cdot \pi \cdot \frac{\left(2 \cdot \mathrm{x}+\mathrm{a}_{\mathrm{g}_{1}}-4 \cdot \mathrm{a}_{1}\right)}{\left(\mathrm{a}_{\mathrm{g}_{1}}-2 \cdot \mathrm{a}_{1}\right)}\right] \cdot \mathrm{a}_{3} \ldots \\
& +-\frac{1}{4} \cdot \sin \left[\frac{1}{2} \cdot \pi \cdot \frac{\left(2 \cdot x+a_{g_{1}}-4 \cdot a_{1}\right)}{\left(a_{g_{1}}-2 \cdot a_{1}\right)}\right] \cdot a_{3} \cdot \sin \left(\frac{1}{4} \cdot \pi \cdot \frac{a_{g_{1}}}{a_{1}}\right)+\frac{1}{4} \cdot a_{3} \cdot \sin \left(\frac{1}{4} \cdot \pi \cdot \frac{a_{g_{1}}}{a_{1}}\right)
\end{aligned}
$$

$F_{2 b o t}(x, y):=A_{2 b o t}(x) \cdot \sin \left(B_{2 b o t} \cdot y+C_{2 b o t}\right)+D_{2 b o t}(x)$ 
Equations that form the 2 tows (3 and 4) in the 90 degree direction

\section{Tow 3}

\section{Top Equation}

$$
\begin{aligned}
A_{3 t o p}(y):= & \frac{1}{4} \cdot a_{3} \cdot \sin \left(\frac{1}{2} \cdot \pi \cdot \frac{y}{a_{2}}\right)-\frac{1}{2} \cdot a_{3}-\frac{1}{4} \cdot \sin \left[\frac{1}{2} \cdot \pi \cdot \frac{\left(2 \cdot y+a_{g_{2}}-4 \cdot a_{2}\right)}{\left(a_{g_{2}}-2 \cdot a_{2}\right)}\right] \cdot a_{3} \ldots \\
& +-\frac{1}{4} \cdot \sin \left[\frac{1}{2} \cdot \pi \cdot \frac{\left(2 \cdot y+a_{g_{2}}-4 \cdot a_{2}\right)}{\left(a_{g_{2}}-2 \cdot a_{2}\right)}\right] \cdot a_{3} \cdot \sin \left(\frac{1}{4} \cdot \pi \cdot \frac{a_{g_{2}}}{a_{2}}\right)+\frac{1}{4} \cdot a_{3} \cdot \sin \left(\frac{1}{4} \cdot \pi \cdot \frac{a_{g_{2}}}{a_{2}}\right)
\end{aligned}
$$

$\mathrm{B}_{3 \text { top }}:=\frac{1}{2} \cdot \frac{\pi}{\mathrm{a}_{1}} \quad \mathrm{C}_{3 \text { top }}:=0$

$$
\begin{aligned}
\mathrm{D}_{3 \text { top }}(\mathrm{y}):= & \frac{1}{4} \cdot \mathrm{a}_{3} \cdot \sin \left(\frac{1}{2} \cdot \pi \cdot \frac{\mathrm{y}}{\mathrm{a}_{2}}\right)+\frac{1}{4} \cdot \sin \left[\frac{1}{2} \cdot \pi \cdot \frac{\left(2 \cdot \mathrm{y}+\mathrm{a}_{\mathrm{g}_{2}}-4 \cdot \mathrm{a}_{2}\right)}{\left(\mathrm{ag}_{2}-2 \cdot \mathrm{a}_{2}\right)}\right] \cdot \mathrm{a}_{3} \ldots \\
& +\frac{1}{4} \cdot \sin \left[\frac{1}{2} \cdot \pi \cdot \frac{\left(2 \cdot y+\mathrm{ag}_{2}-4 \cdot \mathrm{a}_{2}\right)}{\left(\mathrm{ag}_{2}-2 \cdot \mathrm{a}_{2}\right)}\right] \cdot \mathrm{a}_{3} \cdot \sin \left(\frac{1}{4} \cdot \pi \cdot \frac{\mathrm{ag}_{2}}{\mathrm{a}_{2}}\right)-\frac{1}{4} \cdot \mathrm{a}_{3} \cdot \sin \left(\frac{1}{4} \cdot \pi \cdot \frac{\mathrm{ag}_{2}}{\mathrm{a}_{2}}\right)
\end{aligned}
$$

$F_{3 \text { top }}(x, y):=A_{3 \text { top }}(y) \cdot \sin \left(B_{3 \text { top }} \cdot x\right)+D_{3 \text { top }}(y)$

\section{Bottom Equation}

$$
\begin{aligned}
& A_{3 b o t}(y):= \frac{-1}{4} \cdot \sin \left[\frac{1}{2} \cdot \pi \cdot \frac{\left(2 \cdot y+a_{g_{2}}-4 \cdot a_{2}\right)}{\left(a_{g_{2}}-2 \cdot a_{2}\right)}\right] \cdot a_{3} \cdot \sin \left(\frac{1}{4} \cdot \pi \cdot \frac{a_{g_{2}}}{a_{2}}\right)+\frac{1}{4} \cdot a_{3} \cdot \sin \left(\frac{1}{2} \cdot \pi \cdot \frac{y}{a_{2}}\right)-\frac{1}{2} \cdot a_{3} \ldots \\
&+-\frac{1}{4} \cdot \sin \left[\frac{1}{2} \cdot \pi \cdot \frac{\left(2 \cdot y+a_{g_{2}}-4 \cdot a_{2}\right)}{\left(a_{g_{2}}-2 \cdot a_{2}\right)}\right] \cdot a_{3}+\frac{1}{4} \cdot a_{3} \cdot \sin \left(\frac{1}{4} \cdot \pi \cdot \frac{a_{g_{2}}}{a_{2}}\right) \\
& B_{3 \text { bot }}:=\frac{1}{2} \cdot \frac{\pi}{a_{1}} \quad \quad C_{3 b o t}:=0
\end{aligned}
$$




$$
\begin{aligned}
\mathrm{D}_{3 b o t}(\mathrm{y}):= & \frac{-1}{4} \cdot \sin \left[\frac{1}{2} \cdot \pi \cdot \frac{\left(2 \cdot y+a_{g_{2}}-4 \cdot a_{2}\right)}{\left(a_{g_{2}}-2 \cdot a_{2}\right)}\right] \cdot a_{3} \cdot \sin \left(\frac{1}{4} \cdot \pi \cdot \frac{a_{g_{2}}}{a_{2}}\right)-\frac{1}{4} \cdot a_{3} \cdot \sin \left(\frac{1}{2} \cdot \pi \cdot \frac{y}{a_{2}}\right) \ldots \\
& +-\frac{1}{4} \cdot \sin \left[\frac{1}{2} \cdot \pi \cdot \frac{\left(2 \cdot y+a_{g_{2}}-4 \cdot a_{2}\right)}{\left(a_{g_{2}}-2 \cdot a_{2}\right)}\right] \cdot a_{3}+\frac{1}{4} \cdot a_{3} \cdot \sin \left(\frac{1}{4} \cdot \pi \cdot \frac{a_{g_{2}}}{a_{2}}\right)
\end{aligned}
$$

$F_{3 b o t}(x, y):=A_{3 b o t}(y) \cdot \sin \left(B_{3 b o t} \cdot x\right)+D_{3 b o t}(y)$

\section{Tow 4}

\section{Top Equation}

$$
\begin{aligned}
A_{4 t o p}(y):= & \frac{-1}{4} \cdot \sin \left[\frac{1}{2} \cdot \pi \cdot \frac{\left(2 \cdot y-a_{g_{2}}+4 \cdot a_{2}\right)}{\left(a_{g_{2}}-2 \cdot a_{2}\right)}\right] \cdot a_{3}+\frac{1}{4} \cdot a_{3} \cdot \sin \left(\frac{1}{2} \cdot \pi \cdot \frac{y}{a_{2}}\right)+\frac{1}{2} \cdot a_{3} \ldots \\
& +-\frac{1}{4} \cdot \sin \left[\frac{1}{2} \cdot \pi \cdot \frac{\left(2 \cdot y-a_{g_{2}}+4 \cdot a_{2}\right)}{\left(a_{g_{2}}-2 \cdot a_{2}\right)}\right] \cdot a_{3} \cdot \sin \left(\frac{1}{4} \cdot \pi \cdot \frac{a_{g_{2}}}{a_{2}}\right)-\frac{1}{4} \cdot a_{3} \cdot \sin \left(\frac{1}{4} \cdot \pi \cdot \frac{a_{g_{2}}}{a_{2}}\right)
\end{aligned}
$$

$\mathrm{B}_{4 \text { top }}:=\frac{1}{2} \cdot \frac{\pi}{\mathrm{a}_{1}} \quad \mathrm{C}_{4 \text { top }}:=0$

$$
\begin{aligned}
\mathrm{D}_{4 \text { top }}(\mathrm{y}):= & \frac{-1}{4} \cdot \sin \left[\frac{1}{2} \cdot \pi \cdot \frac{\left(2 \cdot y-\mathrm{ag}_{2}+4 \cdot \mathrm{a}_{2}\right)}{\left(\mathrm{ag}_{2}-2 \cdot \mathrm{a}_{2}\right)}\right] \cdot \mathrm{a}_{3}-\frac{1}{4} \cdot \mathrm{a}_{3} \cdot \sin \left(\frac{1}{2} \cdot \pi \cdot \frac{\mathrm{y}}{\mathrm{a}_{2}}\right) \ldots \\
& +-\frac{1}{4} \cdot \sin \left[\frac{1}{2} \cdot \pi \cdot \frac{\left(2 \cdot y-\mathrm{a}_{\mathrm{g}_{2}}+4 \cdot \mathrm{a}_{2}\right)}{\left(\mathrm{ag}_{2}-2 \cdot \mathrm{a}_{2}\right)}\right] \cdot \mathrm{a}_{3} \cdot \sin \left(\frac{1}{4} \cdot \pi \cdot \frac{\mathrm{ag}_{2}}{\mathrm{a}_{2}}\right)-\frac{1}{4} \cdot \mathrm{a}_{3} \cdot \sin \left(\frac{1}{4} \cdot \pi \cdot \frac{\mathrm{a}_{2}}{\mathrm{a}_{2}}\right)
\end{aligned}
$$

$F_{4 \text { top }}(x, y):=A_{4 t o p}(y) \cdot \sin \left(B_{4 t o p} \cdot x\right)+D_{4 t o p}(y)$

\section{Bottom Equation}

$$
\begin{aligned}
A_{4 b o t}(y):= & \frac{1}{4} \cdot a_{3} \cdot \sin \left(\frac{1}{2} \cdot \pi \cdot \frac{y}{a_{2}}\right)+\frac{1}{2} \cdot a_{3}-\frac{1}{4} \cdot \sin \left[\frac{1}{2} \cdot \pi \cdot \frac{\left(2 \cdot y-a_{g_{2}}+4 \cdot a_{2}\right)}{\left(a_{g_{2}}-2 \cdot a_{2}\right)}\right] \cdot a_{3} \cdot \sin \left(\frac{1}{4} \cdot \pi \cdot \frac{a_{g_{2}}}{a_{2}}\right) \ldots \\
& +-\frac{1}{4} \cdot \sin \left[\frac{1}{2} \cdot \pi \cdot \frac{\left(2 \cdot y-a_{g_{2}}+4 \cdot a_{2}\right)}{\left(a_{g_{2}}-2 \cdot a_{2}\right)}\right] \cdot a_{3}-\frac{1}{4} \cdot a_{3} \cdot \sin \left(\frac{1}{4} \cdot \pi \cdot \frac{a_{g_{2}}}{a_{2}}\right)
\end{aligned}
$$




$$
\begin{aligned}
& \mathrm{B}_{4 b o t}:=\frac{1}{2} \cdot \frac{\pi}{\mathrm{a}_{1}} \quad \mathrm{C}_{4 \mathrm{bot}}:=0 \\
& \mathrm{D}_{4 \text { bot }}(\mathrm{y}):=\frac{1}{4} \cdot \mathrm{a}_{3} \cdot \sin \left(\frac{1}{2} \cdot \pi \cdot \frac{\mathrm{y}}{\mathrm{a}_{2}}\right)+\frac{1}{4} \cdot \sin \left[\frac{1}{2} \cdot \pi \cdot \frac{\left(2 \cdot \mathrm{y}-\mathrm{a}_{\mathrm{g}_{2}}+4 \cdot \mathrm{a}_{2}\right)}{\left(\mathrm{ag}_{2}-2 \cdot \mathrm{a}_{2}\right)}\right] \cdot \mathrm{a}_{3} \cdot \sin \left(\frac{1}{4} \cdot \pi \cdot \frac{\mathrm{a}_{2}}{\mathrm{a}_{2}}\right) \ldots \\
&+ {\left[\frac{1}{4} \cdot \sin \left[\frac{1}{2} \cdot \pi \cdot \frac{\left(2 \cdot \mathrm{y}-\mathrm{a}_{\mathrm{g}_{2}}+4 \cdot \mathrm{a}_{2}\right)}{\left(\mathrm{a}_{\mathrm{g}_{2}}-2 \cdot \mathrm{a}_{2}\right)}\right] \cdot \mathrm{a}_{3}+\frac{1}{4} \cdot \mathrm{a}_{3} \cdot \sin \left(\frac{1}{4} \cdot \pi \cdot \frac{\mathrm{a}_{2}}{\mathrm{a}_{2}}\right)\right] }
\end{aligned}
$$

$F_{4 b o t}(x, y):=A_{4 b o t}(y) \cdot \sin \left(B_{4 b o t} \cdot x\right)+D_{4 b o t}(y)$

\section{D Representation}

$$
\begin{aligned}
& x_{b 10}:=-a_{1} \quad x_{b 1 f}:=\frac{-a_{g_{1}}}{2} \quad x_{b 20}:=\frac{a_{1}}{2} \quad x_{b 2 f}:=a_{1} \\
& \mathrm{y}_{\mathrm{b} 10}:=-\mathrm{a}_{2} \quad \mathrm{y}_{\mathrm{b} 1 \mathrm{f}}:=\mathrm{a}_{2} \quad \mathrm{y}_{\mathrm{b} 20}:=-\mathrm{a}_{2} \quad \mathrm{y}_{\mathrm{b} 2 \mathrm{f}}:=\mathrm{a}_{2} \\
& \text { mesh }:=25 \\
& F_{1 t}:=\text { CreateMesh }\left(F_{1 \text { top }}, x_{b 10}, x_{b 1 f}, y_{b 10}, y_{b 1 f}, \text { mesh }\right) \\
& F_{1 b}:=\text { CreateMesh }\left(F_{1 b o t}, x_{b 10}, x_{b 1 f}, y_{b 10}, y_{b 1 f}, \text { mesh }\right) \\
& F_{2 t}:=\operatorname{CreateMesh}\left(F_{2 t o p}, x_{b 20}, x_{b 2 f}, y_{b 20}, y_{b 2 f}, \text { mesh }\right) \\
& F_{2 b}:=\text { CreateMesh }\left(F_{2 b o t}, x_{b 20}, x_{b 2 f}, y_{b 20}, y_{b 2 f}, \text { mesh }\right) \\
& x_{b 1900}:=-a_{1} \quad x_{b 190 f}:=a_{1} \quad x_{b 2900}:=-a_{1} \quad x_{b 290 f}:=a_{1} \\
& y_{b 1900}:=\frac{a_{g_{2}}}{2} \quad y_{b 190 f}:=a_{2} \quad y_{b 2900}:=-a_{2} \quad y_{b 290 f}:=\frac{-a_{g_{2}}}{2} \\
& F_{3 t}:=\text { CreateMesh }\left(F_{3 t o p}, x_{b 1900}, x_{b 190 f}, y_{b 1900}, y_{b 190 f}, \text { mesh }\right) \\
& F_{3 b}:=\text { CreateMesh }\left(F_{3 b o t}, x_{b 1900}, x_{b 190 f}, y_{b 1900}, y_{b 190 f}, \text { mesh }\right) \\
& F_{4 t}:=\text { CreateMesh }\left(F_{4 t o p}, x_{b 2900}, x_{b 290 f}, y_{b 2900}, y_{b 290 f}, \text { mesh }\right) \\
& F_{4 b}:=\text { CreateMesh }\left(F_{4 b o t}, x_{b 2900}, x_{b 290 f}, y_{b 2900}, y_{b 290 f}, \text { mesh }\right)
\end{aligned}
$$




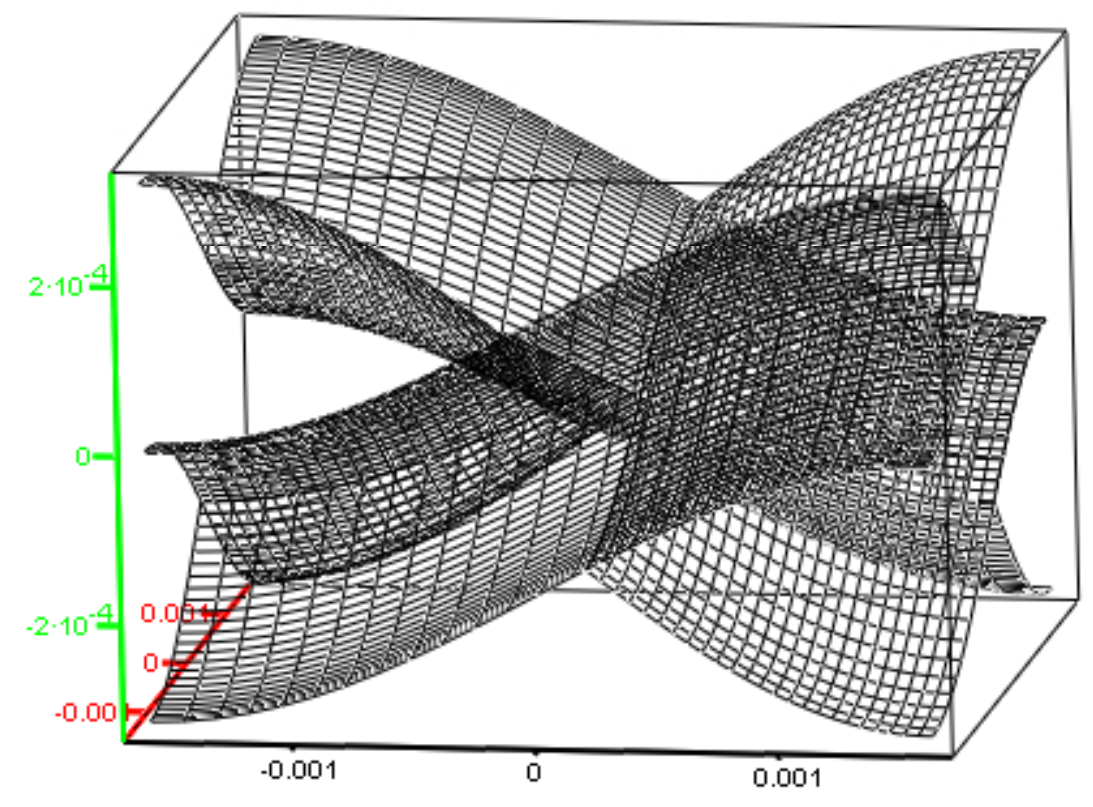

$F_{1 t}, F_{1 b}, F_{2 t}, F_{2 b}, F_{3 t}, F_{3 b}, F_{4 t}, F_{4 b}$

Location of tow 1 ( 0 degree minus): $\mathrm{x}$ from -ax to $-0.5 \mathrm{a}_{\mathrm{g}}$ $\mathrm{y}$ from -ay to ay

Location of tow 3 (90 degree plus): $x$ from -ax to ax $\mathrm{y}$ from $0.5 \mathrm{a}_{\mathrm{g}}$ to ay
Location of tow 2 ( 0 degree plus):

$\mathrm{x}$ from $0.5 \mathrm{a}_{\mathrm{g}}$ to ax $\mathrm{y}$ from -ay to ay

Location of tow 4 (90 degree minus):

$\mathrm{x}$ from -ax to ax

$\mathrm{y}$ from -ay to $-0.5 \mathrm{a}_{\mathrm{g}}$

$i:=1 . .4$

\begin{tabular}{|c|c|c|c|}
\hline$x_{0_{i}}:=$ & $\mathrm{x}_{\mathrm{f}_{\mathrm{i}}}:=$ & $\mathrm{y}_{0_{i}}:=$ & $\mathrm{y}_{\mathrm{f}_{\mathrm{i}}}:=$ \\
\hline$-a_{x}$ & $0.5 \cdot \mathrm{a}_{\mathrm{g}_{1}}$ & $-a_{y}$ & $a_{y}$ \\
\hline$-0.5 \cdot a_{g_{1}}$ & $a_{x}$ & $-a_{y}$ & $a_{y}$ \\
\hline$-a_{x}$ & $a_{x}$ & $0.5 \cdot \mathrm{a}_{\mathrm{g}_{2}}$ & $a_{y}$ \\
\hline$-a_{x}$ & $a_{x}$ & $-a_{y}$ & $a_{g_{2}}$ \\
\hline
\end{tabular}




$$
F_{\text {top }}(x, y, i):=\left|\begin{array}{ll}
F_{1 \text { top }}(x, y) \text { if } i=1 \\
F_{2 \text { top }}(x, y) \text { if } i=2 \\
F_{3 \text { top }}(x, y) \text { if } i=3 \\
F_{4 \text { top }}(x, y) \text { if } i=4
\end{array} \quad F_{\text {bot }}(x, y, i):=\right| \begin{array}{lll}
F_{1 \text { bot }}(x, y) \text { if } & i=1 \\
F_{2 b o t}(x, y) & \text { if } & i=2 \\
F_{3 b o t}(x, y) & \text { if } & i=3 \\
F_{4 b o t}(x, y) & \text { if } & i=4
\end{array}
$$

\section{Determination of the tow volumes}

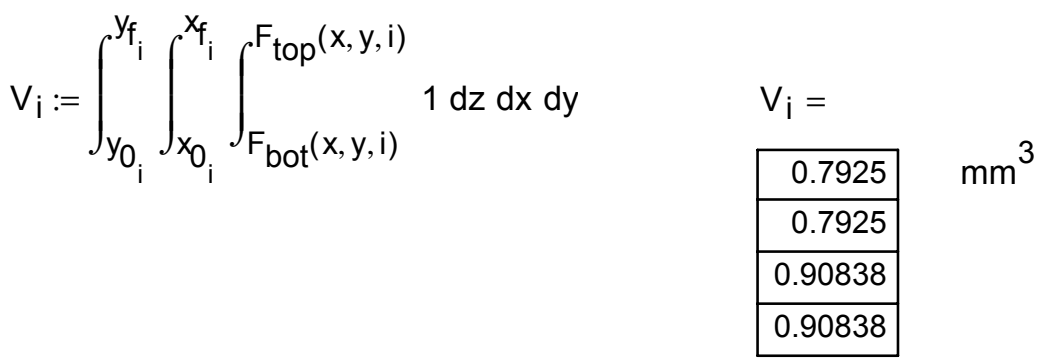

\section{Determination of the RVE volume}

$$
\begin{array}{ll}
V_{R V E}:=8 \cdot a_{x} \cdot a_{y} \cdot a_{z} & \text { Volume of the total RVE } \\
V_{R V E}=6.24862 m^{3} & \text { Total volume of all of the } 4 \text { tows } \\
V_{\text {meso }}:=\sum_{i} v_{i} & \text { Volume fraction of the tows to the RVE } \\
f_{\text {meso }}:=\frac{V_{\text {meso }}}{V_{R V E}} & \\
f_{\text {meso }}=0.5444 & \text { overall fiber volume fraction of the RVE } \\
v_{f o}:=0.37 &
\end{array}
$$

Meso-scale fiber volume fraction of an inclusion

$v_{\text {fmeso }}=0.67965$ 


$$
\begin{aligned}
& f_{i}:=\frac{V_{i}}{V_{R V E}} \\
& f_{i}= \\
& \hline 0.12683 \\
& \hline 0.12683 \\
& \hline 0.14537 \\
& \hline 0.14537 \\
& \hline
\end{aligned}
$$

\section{Part 2: $\xi$ vector definition}

The vector $\xi$ is a terms that is used in the construction of the Fourier series expansion of all field variables, such as stresses and strains.

$$
\begin{array}{ll}
\xi(r, s, t):=\pi\left(\frac{r}{a_{x}} \frac{s}{a_{y}} \frac{t}{a_{z}}\right)^{\top} & \xi_{a b s}(r, s, t):=\sqrt{\xi(r, s, t) \cdot \xi(r, s, t)} \\
\xi_{\text {bar }}(r, s, t):=\frac{\xi(r, s, t)}{\xi_{\text {abs }}(r, s, t)} & X(x, y, z):=\left(\begin{array}{lll}
x & y & z
\end{array}\right)^{\top}
\end{array}
$$

\section{Part 3: The G-integral}

$$
\begin{aligned}
& g_{p}(r, s, t, i):=\frac{1}{V_{i}} \cdot \int_{y_{0_{i}}}^{y_{f_{i}}} \int_{x_{0_{i}}}^{x_{f_{i}}} \int_{F_{\text {bot }}(x, y, i)}^{F_{\text {top }}(x, y, i)} e^{i \cdot(\xi(r, s, t) \cdot x(x, y, z))} d z d x d y \\
& g_{m}(r, s, t, i):=\frac{1}{v_{i}} \cdot \int_{y_{0_{i}}}^{y_{f_{i}}} \int_{x_{0_{i}}}^{x_{f_{i}}} \int_{F_{b o t}(x, y, i)}^{F_{\text {top }}(x, y, i)} e^{-i \cdot(\xi(r, s, t) \cdot X(x, y, z))} d z d x d y
\end{aligned}
$$

\section{Part 4: Material properties of the constituent materials}

In order to homogenize the the properties of the inclusions (tows) to that of the surrounding matrix, the constituent materials, i.e. the matrix and the tow (meso scale), must be determined. The results for the Ito and Chou geometry and an E Glass/Epoxy composite are reported here.

\section{Material Properties of the matrix}




$$
\begin{aligned}
& \mathrm{GPa}:=10^{9} \cdot \mathrm{Pa} \\
& \mathrm{E}_{\mathrm{m}}:=3.12 \cdot \mathrm{GPa} \quad v_{\mathrm{m}}:=0.30 \\
& \mathrm{C}_{\mathrm{m}}:=\frac{\mathrm{E}_{\mathrm{m}}}{\left(1+v_{\mathrm{m}}\right) \cdot\left(1-2 \cdot v_{\mathrm{m}}\right)} \cdot\left[\begin{array}{cccccc}
1-v_{\mathrm{m}} & v_{\mathrm{m}} & v_{\mathrm{m}} & 0 & 0 & 0 \\
v_{\mathrm{m}} & 1-v_{\mathrm{m}} & v_{\mathrm{m}} & 0 & 0 & 0 \\
v_{\mathrm{m}} & v_{\mathrm{m}} & 1-v_{\mathrm{m}} & 0 & 0 & 0 \\
0 & 0 & 0 & \frac{1}{2}\left(1-2 \cdot v_{\mathrm{m}}\right) & 0 & 0 \\
0 & 0 & 0 & 0 & \frac{1}{2}\left(1-2 \cdot v_{\mathrm{m}}\right) & 0 \\
0 & 0 & 0 & 0 & 0 & \frac{1}{2}\left(1-2 \cdot v_{\mathrm{m}}\right)
\end{array}\right]
\end{aligned}
$$

\section{Material Properties of the Inclusions}

$$
\mathrm{C}_{\mathrm{avg}} \text { are the stiffness matrices of the } \alpha \text { number of inclusions. In this example, all of the }
$$

inclusions are orthotropic in the direction of the undulation of the fibers in the inclusion. The material coordinate stiffnesses of each tow is determined by assuming transverse isotropy with respect to a coordinate system in which the abscissa corresponds to the slope of the tow. Those transformed properties are averaged over the length of the inclusion. The data for the tow constituent properties were taken from Table 1.1 of Barbero, E. J. "Introduction to Composite Materials Design" for E-Glass/Epoxy. The accompanying software, CADEC, was used to determine the transversely isotropic properties as if the tow were unidirectional. In addition, the value of the fiber volume fraction inside of the tows was determined above for given overall fiber volume fraction and the volume fraction of the tows.

$$
\begin{array}{lll}
\alpha:=1 . . \mathrm{m}_{\mathrm{inc}} & \\
\mathrm{E}_{\mathrm{x}_{\alpha}}:=56.52 \cdot \mathrm{GPa} & \mathrm{E}_{\mathrm{y}_{\alpha}}:=19.90 \cdot \mathrm{GPa} & \mathrm{E}_{\mathrm{z}_{\alpha}}:=\mathrm{E}_{\mathrm{y}_{\alpha}} \\
\mathrm{G}_{\mathrm{xy}}:=6.983 \cdot \mathrm{GPa} & \mathrm{G}_{\mathrm{yz}}:=6.553 \cdot \mathrm{GPa} & \mathrm{G}_{\mathrm{xz}}:=\mathrm{G}_{\mathrm{xy}} \\
v_{\mathrm{xy}}:=0.31844 & v_{\mathrm{yz}}:=0.51802 & v_{\mathrm{xz}}:=v_{\mathrm{xy}}
\end{array}
$$




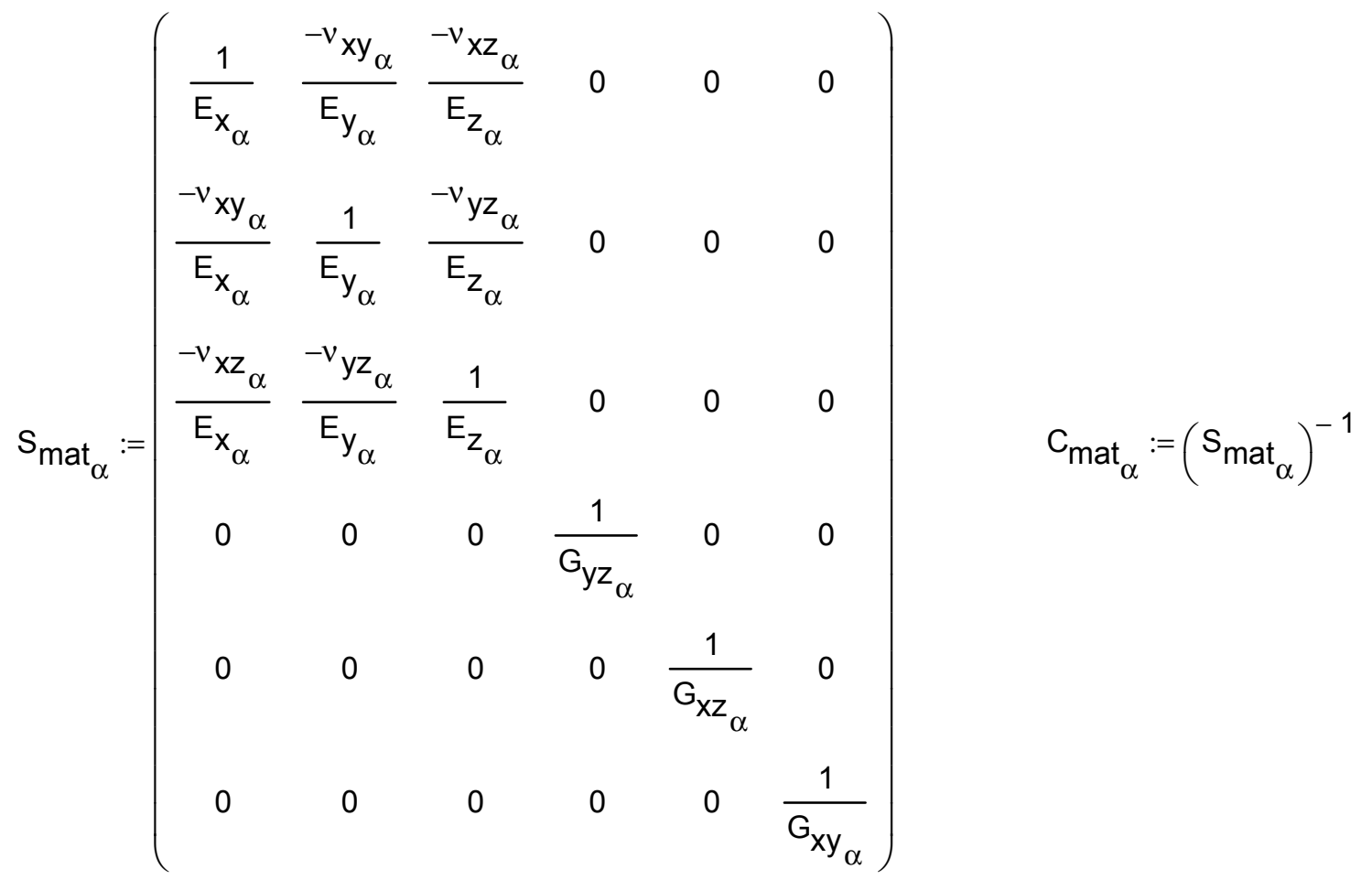

Coordinate Transformation for contracted stiffness notation

$$
\begin{aligned}
& F_{x}(\alpha, x):=\mid \begin{array}{l}
F_{3 \text { top }}\left(x, a_{y}\right) \text { if } \alpha=3 \vee \alpha=1 \\
F_{4 \text { top }}\left(x,-a_{y}\right) \text { if } \alpha=4 \vee \alpha=2
\end{array} \\
& \mathrm{~F}_{\mathrm{X}}^{\prime}(\alpha, \mathrm{x}):=\frac{\partial}{\partial \mathrm{x}} \mathrm{F}_{\mathrm{X}}(\alpha, \mathrm{x}) \quad \theta_{\mathrm{X}}(\alpha, \mathrm{x}):=\operatorname{atan}\left(\mathrm{F}_{\mathrm{X}}^{\prime}(\alpha, \mathrm{x})\right) \\
& a(\alpha, \theta):=\left(\begin{array}{ccc}
\cos (\theta) & 0 & \sin (\theta) \\
0 & 1 & 0 \\
-\sin (\theta) & 0 & \cos (\theta)
\end{array}\right)
\end{aligned}
$$




$$
\begin{aligned}
& T(\alpha, \theta):=\mid \begin{array}{l}
\text { for } i \in 1 . .6 \\
\text { for } j \in 1 . .6
\end{array} \\
& \mathrm{~T}_{\mathrm{i}, \mathrm{j}} \leftarrow\left(\mathrm{a}(\alpha, \theta)_{\mathrm{i}, \mathrm{j}}\right)^{2} \text { if } \mathrm{i} \leq 3 \wedge \mathrm{j} \leq 3 \\
& \text { for } i i \in 1 . .3 \quad \text { if } i \leq 3 \wedge j>3 \\
& \text { for } \mathrm{jj} \in \mathrm{ii} . .3 \\
& \text { if } \mathrm{ii} \neq \mathrm{jj} \\
& \mid \begin{array}{l}
\gamma \leftarrow 9-\mathrm{ii}-\mathrm{jj} \\
\mathrm{T}_{\mathrm{i}, \mathrm{j}} \leftarrow\left(2 \mathrm{a}(\alpha, \theta)_{\mathrm{i}, \mathrm{ii}} \cdot \mathrm{a}(\alpha, \theta)_{\mathrm{i}, \mathrm{jj}}\right) \text { if } \gamma=\mathrm{j}
\end{array} \\
& \text { for } i i \in 1 . .3 \quad \text { if } i>3 \wedge j \leq 3 \\
& \text { for } \mathrm{jj} \in \mathrm{ii} . .3 \\
& \text { if } \quad \mathrm{ii} \neq \mathrm{jj} \\
& \mid \begin{array}{l}
\beta \leftarrow 9-i i-j j \\
T_{i, j} \leftarrow\left(a(\alpha, \theta)_{i i, j} \cdot a(\alpha, \theta)_{j j}, j\right) \text { if } \beta=i
\end{array} \\
& \text { for } i i \in 1 . .3 \quad \text { if } i>3 \wedge j>3 \\
& \text { for } \mathrm{jj} \in \mathrm{ii} . .3 \\
& \text { if } \quad \text { ii } \neq \mathrm{jj} \\
& \mid \begin{array}{l}
\chi \leftarrow 9-\mathrm{ii}-\mathrm{jj} \\
\text { for } k \mathrm{kk} \in 1 . .3
\end{array} \\
& \text { for } \| \mathrm{k} \in \mathrm{kk} . .3 \\
& \text { if } \mathrm{kk} \neq \| \\
& \delta \leftarrow 9-\mathrm{kk}-\|
\end{aligned}
$$

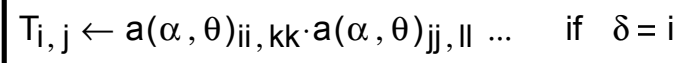

$$
\begin{aligned}
& +\mathrm{a}(\alpha, \theta)_{\mathrm{ii}, \mathrm{ll}} \cdot \mathrm{a}(\alpha, \theta)_{\mathrm{jj}, \mathrm{kk}} \\
& \mathrm{T}_{\mathrm{X}}(\alpha, \theta):=\mathrm{T}(\alpha, \theta) \\
& \mathrm{S}_{\text {mat }}^{\prime}(\alpha, \mathrm{x}):=\left(\left(\mathrm{T}_{\mathrm{X}}\left(\alpha, \theta_{\mathrm{X}}(\alpha, \mathrm{x})\right)\right)^{\mathrm{T}} \cdot \mathrm{S}_{\text {mat }_{\alpha}} \cdot \mathrm{T}_{\mathrm{X}}\left(\alpha, \theta_{\mathrm{X}}(\alpha, \mathrm{x})\right)\right) \\
& \text { mstep }:=100 \\
& \text { nstep }:=1 . .(\text { mstep }+1) \quad x_{\text {nstep }}:=-a_{x}+(\text { nstep }-1) \cdot \frac{2 \cdot a_{x}}{m s t e p} \\
& y_{\text {nstep }}:=-a_{y}+(\text { nstep }-1) \cdot \frac{2 \cdot a_{y}}{m s t e p}
\end{aligned}
$$




$$
\begin{aligned}
& S_{\operatorname{avg}_{\alpha}}^{\prime}:=\mid \begin{array}{l}
\text { for } \quad i \in 1 . .6 \\
\text { for } j \in 1 . .6
\end{array} \\
& \mid \begin{array}{l|l}
S_{i, j} \leftarrow \frac{1}{m s t e p} \cdot \sum_{n=1}^{\text {mstep }+1} S_{\text {mat }}^{\prime}\left(\alpha, x_{n}\right)_{i, j} \text { if } \alpha \leq 2 \\
S_{i, j} \leftarrow \frac{1}{m s t e p} \cdot \sum_{n=1}^{m s t e p+1} S_{\text {mat }}^{\prime}\left(\alpha, y_{n}\right)_{i, j} \text { if } \alpha>2
\end{array} \\
& \mid \begin{array}{l|l}
S_{i, j} \leftarrow \frac{1}{\text { mstep }} \cdot \sum_{n=1}^{\text {mstep }+1} S_{\text {mat }}^{\prime}\left(\alpha, x_{n}\right)_{i, j} \text { if } \alpha \leq 2 \\
S_{i, j} \leftarrow \frac{1}{\text { mstep }} \cdot \sum_{n=1}^{\text {mstep }+1} S_{\text {mat }}^{\prime}\left(\alpha, y_{n}\right)_{i, j} \text { if } \alpha>2
\end{array} \\
& a(\alpha):=\left(\begin{array}{lll}
0 & 1 & 0 \\
1 & 0 & 0 \\
0 & 0 & 1
\end{array}\right) \\
& \mathrm{C}_{\mathrm{avg}_{\alpha}}:=\left(\mathrm{S}_{\mathrm{avg}_{\alpha}}\right)^{-1}
\end{aligned}
$$




$$
\begin{aligned}
& T 1(\alpha):=\mid \begin{array}{c}
\text { for } i \in 1 . .6 \\
\text { for } j \in 1 . .6
\end{array} \\
& \mathrm{~T}_{\mathrm{i}, \mathrm{j}} \leftarrow\left(\mathrm{a}(\alpha)_{\mathrm{i}, \mathrm{j}}\right)^{2} \text { if } \mathrm{i} \leq 3 \wedge \mathrm{j} \leq 3 \\
& \text { for } i i \in 1 . .3 \quad \text { if } i \leq 3 \wedge j>3 \\
& \text { for } \mathrm{jj} \in \mathrm{ii} . .3 \\
& \text { if } \quad \mathrm{i} \neq \mathrm{jj} \\
& \mid \begin{array}{l}
\gamma \leftarrow 9-\mathrm{ii}-\mathrm{jj} \\
\mathrm{T}_{\mathrm{i}, \mathrm{j}} \leftarrow\left(2 \mathrm{a}(\alpha)_{\mathrm{i}, \mathrm{ii}} \cdot \mathrm{a}(\alpha)_{\mathrm{i}, \mathrm{jj}}\right) \text { if } \gamma=\mathrm{j}
\end{array} \\
& \text { for } i i \in 1 . .3 \quad \text { if } i>3 \wedge j \leq 3 \\
& \text { for } \mathrm{jj} \in \mathrm{ii} . .3 \\
& \text { if } \quad \mathrm{ii} \neq \mathrm{jj} \\
& \mid \begin{array}{l}
\beta \leftarrow 9-\mathrm{ii}-\mathrm{jj} \\
\mathrm{T}_{\mathrm{i}, \mathrm{j}} \leftarrow\left(\mathrm{a}(\alpha)_{\mathrm{ii}, \mathrm{j}} \cdot \mathrm{a}(\alpha)_{\mathrm{jj}, \mathrm{j}}\right) \text { if } \beta=\mathrm{i}
\end{array} \\
& \text { for } i i \in 1 . .3 \quad \text { if } i>3 \wedge j>3 \\
& \text { for } \mathrm{jj} \in \mathrm{ii} . .3 \\
& \text { if } \quad \mathrm{i} \neq \mathrm{jj} \\
& \mid \begin{array}{l}
\chi \leftarrow 9-\mathrm{i}-\mathrm{jj} \\
\text { for } k \mathrm{kk} \in 1 . .3
\end{array} \\
& \text { for } \| \mathrm{kkk} . .3 \\
& \text { if } \mathrm{kk} \neq \| \mathrm{I} \\
& \delta \leftarrow 9-\mathrm{kk}-\|
\end{aligned}
$$

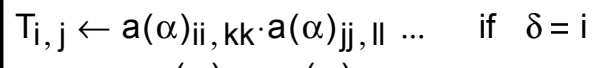

$$
\begin{aligned}
& +\mathrm{a}(\alpha)_{\mathrm{ii}, \|} \cdot \mathrm{a}(\alpha)_{\mathrm{jj}, \mathrm{kk}} \\
& \mathrm{S}_{\mathrm{avg}_{\alpha}}:=\mid \begin{array}{l}
\mathrm{T} 1(\alpha) \cdot \mathrm{S}_{\mathrm{avg}_{\alpha}}^{\prime} \cdot \mathrm{T} 1(\alpha)^{\top} \\
\mathrm{S}_{\mathrm{avg}_{\alpha}}^{\prime} \text { if } \quad \text { otherwise }
\end{array} \\
& \mathrm{C}_{\mathrm{avg}_{\alpha}}:=\left(\mathrm{s}_{\mathrm{avg}_{\alpha}}\right)^{-1} \\
& \mathrm{C}_{\text {meso }}:=\frac{1}{4} \cdot \sum_{\alpha} \mathrm{C}_{\text {avg }_{\alpha}}
\end{aligned}
$$

Part 5: FSP formulation for an isotropic reference elasticity tensor 


$$
\begin{aligned}
& \mathrm{n}:=3 \\
& \operatorname{FSP}(r, s, t):=\mid \text { for } i \in 1 . . n \\
& \text { for } j \in i . . n \\
& \alpha \leftarrow \mathrm{i} \text { if } \mathrm{i}=\mathrm{j} \\
& \alpha \leftarrow 9-\mathrm{i}-\mathrm{j} \text { if } \mathrm{i} \neq \mathrm{j} \\
& \text { for } k \in 1 . . n \\
& \text { for } I \in k . . n \\
& \beta \leftarrow \mathrm{k} \text { if } \mathrm{k}=\mathrm{I} \\
& \beta \leftarrow 9-k-1 \text { if } k \neq 1 \\
& \mathrm{~F}_{\alpha, \beta} \leftarrow \frac{1}{2} \cdot\left[\begin{array}{c}
\xi_{\mathrm{bar}}(\mathrm{r}, \mathrm{s}, \mathrm{t})_{\mathrm{j}} \cdot\left(\begin{array}{l}
\delta(\mathrm{i}, \mathrm{l}) \cdot \xi_{\mathrm{bar}}(\mathrm{r}, \mathrm{s}, \mathrm{t})_{\mathrm{k}} \ldots \\
+\delta(\mathrm{i}, \mathrm{k}) \cdot \xi_{\mathrm{bar}}(\mathrm{r}, \mathrm{s}, \mathrm{t})_{\mathrm{l}}
\end{array}\right) \ldots \\
+\xi_{\mathrm{bar}}(\mathrm{r}, \mathrm{s}, \mathrm{t})_{\mathrm{i}} \cdot\left(\begin{array}{l}
\delta(\mathrm{j}, \mathrm{l}) \cdot \xi_{\mathrm{bar}}(\mathrm{r}, \mathrm{s}, \mathrm{t})_{\mathrm{k}} \ldots \\
+\delta(\mathrm{j}, \mathrm{k}) \cdot \xi_{\mathrm{bar}}(\mathrm{r}, \mathrm{s}, \mathrm{t})_{l}
\end{array}\right)
\end{array}\right] \cdots \\
& +\frac{1}{v_{m}-1} \cdot \xi_{\text {bar }}(r, s, t)_{i} \cdot \xi_{\text {bar }}(r, s, t)_{j} \cdot \xi_{\text {bar }}(r, s, t)_{k} \cdot \xi_{\text {bar }}(r, s, t)_{\mid} \ldots \\
& +\frac{v_{\mathrm{m}}}{1-v_{\mathrm{m}}} \cdot \xi_{\mathrm{bar}}(\mathrm{r}, \mathrm{s}, \mathrm{t})_{\mathrm{i}} \cdot \xi_{\mathrm{bar}}(\mathrm{r}, \mathrm{s}, \mathrm{t})_{\mathrm{j}} \cdot \delta(\mathrm{k}, \mathrm{l})
\end{aligned}
$$

\section{Part 6: SP tensor formulation}

The $\mathrm{S}^{\mathrm{P}}$ tensor is the key computational aspect of the periodic microstructure micromechanical model. Evaluation of this term for all possible combinations of inclusions is where the model becomes computationally expensive. An alternate program to compute $\mathrm{S}^{\mathrm{P}}$ that encompasses all of the previous calculations has been written in Fortran. It is a more efficient way of determining SP, and the values can be entered into this program with for the continuation of the model computation 


$$
\begin{aligned}
& \operatorname{SP}(N, \alpha, \beta):=\mid \text { Sold } \leftarrow 0 \\
& \text { for } r \in-N \text {.. N } \\
& \text { for } s \in-N \text {.. N } \\
& \text { for } t \in-N \text {.. N } \\
& \mid \begin{array}{l}
\text { continue if } \quad(r=0) \wedge(s=0) \wedge(t=0) \\
S \leftarrow f_{\beta} \cdot g_{p}(r, s, t, \alpha) \cdot g_{m}(r, s, t, \beta) \cdot F S P(r, s, t) \\
\text { Snew } \leftarrow S+\text { Sold } \\
\text { Sold } \leftarrow \text { Snew }
\end{array} \\
& \alpha:=1 . . \mathrm{m}_{\text {inc }} \quad \beta:=1 . . \mathrm{m}_{\text {inc }} \\
& \mathrm{SP}_{\alpha, \beta}:=\operatorname{SP}(1,2, \alpha, \beta)
\end{aligned}
$$

Matrix representation of SP for all possible combinations of inclusions

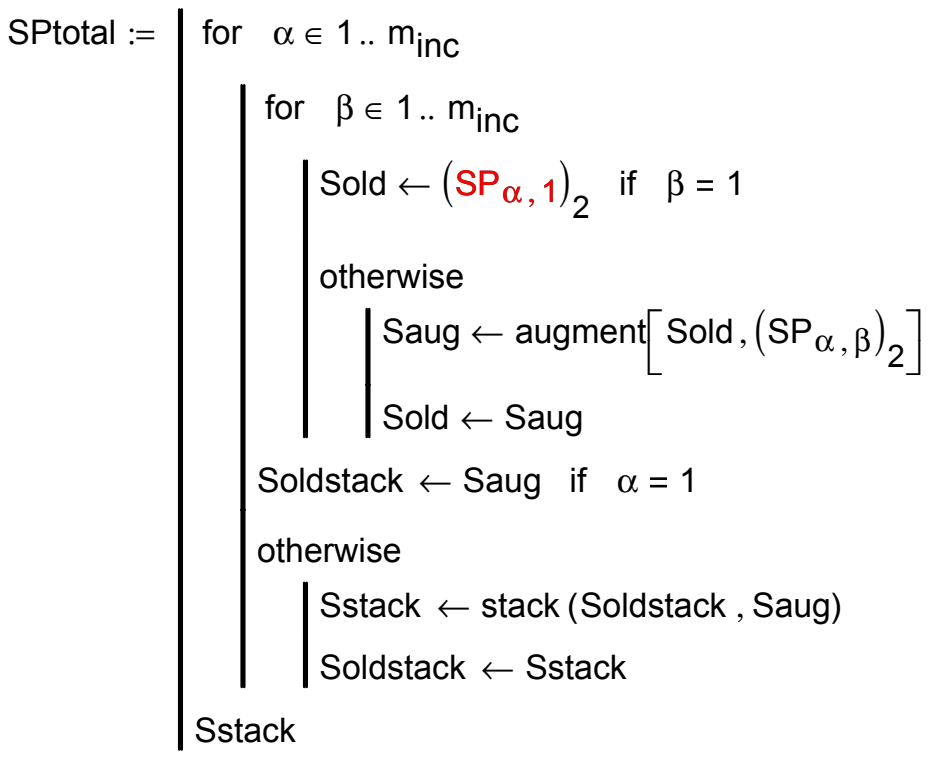

SPtotal is the construction of the $6^{*} \mathrm{~m}_{\mathrm{inc}}$ by $6^{*} \mathrm{~m}_{\mathrm{inc}}$ matrix using the computed value of $\mathrm{S}$ above.

SPdata is an input variable for externally computed values of $\mathrm{S}^{\mathrm{P}}$ for $\mathrm{N}:=3$ 


SPdata :
\begin{tabular}{|r|r|r|r|r|r|r|}
\hline & 1 & 2 & 3 & 4 & \multicolumn{1}{l|}{5} & 6 \\
\hline 1 & 0.2774 & 0.1147 & 0.0793 & -0.005 & 0.0005 & -0 \\
\hline 2 & 0.0122 & 0.0677 & -0.0217 & 0.0659 & -0 & 0 \\
\hline 3 & 0.2358 & 0.2373 & 0.629 & -0.0248 & -0.0002 & -0 \\
\hline 4 & 0.03 & 0.1009 & 0.0102 & 0.2561 & -0 & 0.0003 \\
\hline 5 & 0.0009 & 0.0003 & 0.0002 & -0 & 0.3587 & 0.0305 \\
\hline 6 & 0 & 0 & -0 & 0.0003 & 0.0305 & 0.1312 \\
\hline
\end{tabular}

Because of the imported data, the $\mathrm{S}^{\mathrm{P}}$ terms need to be separated into the sub-matrices, as given in the Mathcad computation of $\mathrm{S}^{\mathrm{P}}$

$$
\begin{aligned}
& \alpha \operatorname{step}(\alpha):=\alpha+5 \cdot(\alpha-1) \quad \beta \operatorname{step}(\beta):=\beta+5 \cdot(\beta-1) \\
& \mathrm{SP}:=\mid \begin{array}{l}
\text { for } \alpha \in 1 . . \mathrm{m}_{\text {inc }} \\
\text { for } \beta \in 1 . . \mathrm{m}_{\text {inc }} \\
\quad \mathrm{S}_{\alpha, \beta} \leftarrow \operatorname{submatrix}(\operatorname{SPdata}, \alpha \operatorname{step}(\alpha), \alpha \operatorname{step}(\alpha)+5, \beta \operatorname{step}(\beta), \beta \operatorname{step}(\beta)+5) \\
\mathrm{S}
\end{array}
\end{aligned}
$$$$
W:=\left(\begin{array}{llllll}
1 & 0 & 0 & 0 & 0 & 0 \\
0 & 1 & 0 & 0 & 0 & 0 \\
0 & 0 & 1 & 0 & 0 & 0 \\
0 & 0 & 0 & 2 & 0 & 0 \\
0 & 0 & 0 & 0 & 2 & 0 \\
0 & 0 & 0 & 0 & 0 & 2
\end{array}\right)
$$

W is the Reuter matrix, which is used to resolve the double contraction of two tensors represented by matrices.

\section{Part 7: Resolution of $\xi$ and $\zeta$ vectors for solution of the linear system to produce the coefficients of the eigenstrain, $F \varepsilon^{*}$}
$\mathrm{N}:=1$
$M:=N$
$\mathrm{N}_{\text {zero }}:=\frac{(2 \cdot \mathrm{N}+1)^{3}}{2}+\frac{1}{2}$
$\mathrm{N}_{\text {zero }}=14$
$\zeta(\mathrm{r}, \mathrm{s}, \mathrm{t}):=\xi(\mathrm{r}, \mathrm{s}, \mathrm{t})$
$\mathrm{N}_{\text {total }}:=(2 \cdot \mathrm{N}+1)^{3}$
$N_{\text {total }}=27$ 
$\xi c:=\mid \begin{aligned} & i \leftarrow 0 \\ & \text { for } r \in-N . . N \\ & \text { for } s \in-N . . N \\ & \text { for } t \in-N . . N \\ & \quad \begin{array}{llll}i \leftarrow i+1 \\ x_{i} \leftarrow\left(\begin{array}{llll}i & r & s & t\end{array}\right)\end{array}\end{aligned}$

$r(x):=\left(\xi c_{x}\right)_{1,2}$

$u(z):=\left(\zeta c_{z}\right)_{1,2}$

$v(z):=\left(\zeta C_{z}\right)_{1,3}$

$$
\zeta c:=\mid \begin{aligned}
& i \leftarrow 0 \\
& \text { for } u \in-M . . M \\
& \text { for } \quad v \in-M . . M \\
& \text { for } w \in-M . . M \\
& \qquad \begin{array}{l}
i \leftarrow i+1 \\
z_{i} \leftarrow\left(\begin{array}{llll}
i & u & v & w
\end{array}\right)
\end{array}
\end{aligned}
$$

$s(x):=\left(\xi c_{x}\right)_{1,3}$

$w(z):=\left(\zeta c_{z}\right){ }_{1,4}$

Evaluation of the integral form for each tow geometry

$I_{\text {tow }}(a, i):=\frac{1}{V_{R V E}} \cdot \int_{y_{O_{i}}}^{y_{f_{i}}} \int_{x_{O_{i}}}^{x_{f_{i}}} \int_{F_{b o t}(x, y, i)}^{F_{\text {top }}(x, y, i)} e^{-i \cdot(a \cdot X(x, y, z))} d z d x d y$

Evaluation of the Fourier coefficient of the tow stiffness matrices, $\mathrm{FC}(\xi)$

$$
\mathrm{FC}(\mathrm{a}, \mathrm{i}):=\mid \begin{aligned}
& \text { expint } \leftarrow \mathrm{I}_{\text {tow }}[(\xi(\mathrm{r}(\mathrm{a}), \mathrm{s}(\mathrm{a}), \mathrm{t}(\mathrm{a}))), \mathrm{i}] \\
& \text { for } \mathrm{ii} \in 1 . .6 \\
& \text { for } \mathrm{jj} \in 1 . .6 \\
& \quad \mathrm{C}_{\mathrm{ii}, \mathrm{jj}} \leftarrow\left(\mathrm{C}_{\mathrm{avg}}\right)_{\mathrm{ii}, \mathrm{jj}} \cdot \text { expint } \\
& \mathrm{CC}_{\mathrm{a}} \leftarrow \mathrm{C}
\end{aligned}
$$

\section{Applied strain field}

$\varepsilon_{0}:=\left(\begin{array}{llllll}0.001 & 0 & 0 & 0 & 0 & 0\end{array}\right)^{\top}$

$\varepsilon_{0}$ is the tensorial strain field that is applied to the RVE

Evaluation of the Fourier terms for $(\xi-\zeta)$ 


$$
\mathrm{FC}_{\text {diff }}(\mathrm{a}, \mathrm{b}, \mathrm{i}):=\mid \begin{aligned}
& \text { expint } \leftarrow \mathrm{I}_{\text {tow }}[(\xi(\mathrm{r}(\mathrm{a}), \mathrm{s}(\mathrm{a}), \mathrm{t}(\mathrm{a}))-\zeta(\mathrm{u}(\mathrm{b}), \mathrm{v}(\mathrm{b}), \mathrm{w}(\mathrm{b}))), \mathrm{i}] \\
& \text { for } \mathrm{ii} \in 1 . .6 \\
& \text { for } \mathrm{jj} \in 1 . .6 \\
& \quad \mathrm{C}_{\mathrm{ii}, \mathrm{jj}} \leftarrow\left(\mathrm{C}_{\mathrm{avg}}\right)_{\mathrm{ii}, \mathrm{jj}} \cdot \text { expint } \\
& \mathrm{CC}_{\mathrm{a}} \leftarrow \mathrm{C}
\end{aligned}
$$

$\operatorname{FSP}_{\xi}(\mathrm{a}):=\operatorname{FSP}(r(a), s(a), t(a))$

zero $:=\left(\begin{array}{cccccc}0 & 0 & 0 & 0 & 0 & 0 \\ 0 & 0 & 0 & 0 & 0 & 0 \\ 0 & 0 & 0 & 0 & 0 & 0 \\ 0 & 0 & 0 & 0 & 0 & 0 \\ 0 & 0 & 0 & 0 & 0 & 0 \\ 0 & 0 & 0 & 0 & 0 & 0\end{array}\right) \cdot P a$

$\mathrm{FSP}_{\zeta}(\mathrm{b}):=\mathrm{FSP}(\mathrm{u}(\mathrm{b}), \mathrm{v}(\mathrm{b}), \mathrm{w}(\mathrm{b}))$

Evaluation of the Left side of the linear system of Equation (3.57) for a given tow

$$
\begin{aligned}
& \operatorname{Left}(a, i):=\text { for } b \in 1 \text {... } N_{\text {total }}
\end{aligned}
$$

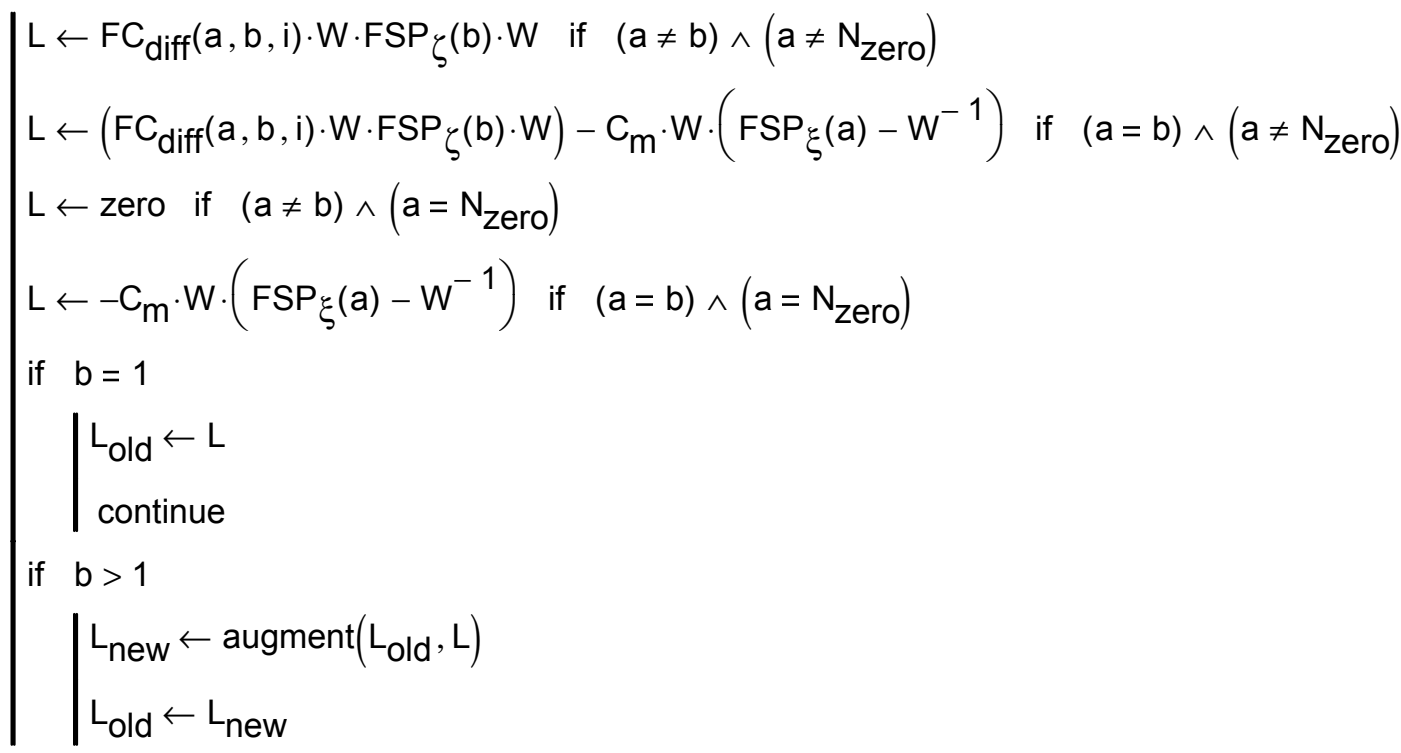


Evaluation of the right side of Equation (3.57)

$\operatorname{Right}(\mathrm{a}, \mathrm{i}):=\left(\mathrm{C}_{\mathrm{m}}-\mathrm{FC}(\mathrm{a}, \mathrm{i})\right) \cdot \mathrm{W} \cdot \varepsilon_{0}$

The terms AA and $\mathrm{b}$ are the routines that assemble each Left and Right calculation into a matrix form.
$A A_{i}:=$

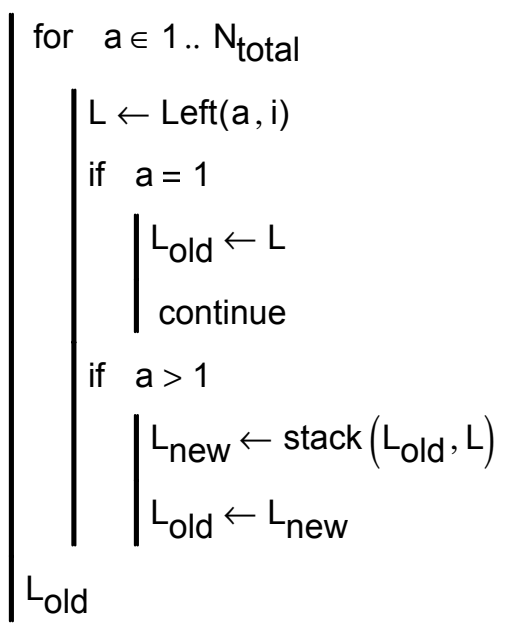
$b_{i}:=\mid \begin{aligned} & \text { for } \quad a \in 1 . . N_{\text {total }} \\ & \left|\begin{array}{ll}R \leftarrow \operatorname{Right}(a, i) \\ \text { if } \quad a=1 \\ \mid \begin{array}{l}R_{\text {old }} \leftarrow R \\ \text { continue }\end{array} \\ \text { if } \quad a>1 \\ R_{\text {old }}\end{array}\right| \begin{array}{l}R_{\text {new }} \leftarrow \text { stack }\left(R_{\text {old }}, R\right) \\ R_{\text {old }} \leftarrow R_{\text {new }}\end{array}\end{aligned}$

The Fourier coefficients of the eigenstrain are determined for a given $\mathrm{N}$ value by solving the linear system: $[\mathrm{AA}]\left[\mathrm{F \varepsilon}^{*}\right]=[\mathrm{b}]$

$$
\begin{aligned}
& \text { Festar }_{i}:=\operatorname{Isolve}\left(A A_{i}, b_{i}\right) \\
& F \varepsilon(i):=\left\{\begin{array}{l}
\text { for } \beta \in 1 \ldots N_{\text {total }} \\
\text { eigen } \beta \leftarrow \operatorname{submatrix}\left(\operatorname{Festar}_{i}, \beta \operatorname{step}(\beta), \beta \operatorname{step}(\beta)+5,1,1\right) \\
\text { eigen }
\end{array}\right.
\end{aligned}
$$

$\varepsilon_{\text {star }}$ is the equation representing the addition of the coefficient terms for all values of $\mathrm{n}_{1}, \mathrm{n}_{2}$, and $\mathrm{n}_{3}$ and a given point in the RVE

$$
\begin{aligned}
& \operatorname{sstar}(x, y, z, i):=\sum_{a=1}^{N_{\text {total }}} F_{\varepsilon}(i)_{a} \cdot e^{i \cdot(\xi(r(a), s(a), t(a)) \cdot x(x, y, z))} \\
& \text { estar }\left(-.001 \cdot \mathrm{m},-\mathrm{a}_{\mathrm{y}}, \mathrm{F}_{\mathrm{bot}}\left(-.001 \cdot \mathrm{m},-\mathrm{a}_{\mathrm{y}}, 4\right), 4\right)=\mathbf{\square} \quad \text { estardata }:=\left(\begin{array}{c}
-0.00435 \\
-0.0003 \\
-0.00084 \\
-0.00291 \\
-0.00147 \\
0.00192
\end{array}\right)
\end{aligned}
$$


Bounds on the RVE:

$$
-a_{x} \geq x \leq a_{x} \quad-a_{y} \geq y \leq a_{y} \quad-a_{z} \geq z \leq a_{z}
$$

Determining if a given point in the RVE is in a given tow, or the matrix

$$
w(x, y, z):=\mid \begin{aligned}
& i \leftarrow 1 \text { if }\left(-a_{x} \leq x \leq \frac{-a_{1}}{2}\right) \wedge\left(-a_{y} \leq y \leq a_{y}\right) \wedge\left(z \geq F_{\text {bot }}(x, y, 1)\right) \wedge\left(z \leq F_{\text {top }}(x, y, 1)\right) \\
& i \leftarrow 2 \text { if }\left(a_{x} \geq x \geq \frac{a_{g_{1}}}{2}\right) \wedge\left(-a_{y} \leq y \leq a_{y}\right) \wedge\left(z \geq F_{\text {bot }}(x, y, 2)\right) \wedge\left(z \leq F_{\text {top }}(x, y, 2)\right) \\
& i \leftarrow 3 \text { if }\left(a_{y} \geq y \geq \frac{a_{2}}{2}\right) \wedge\left(-a_{x} \leq x \leq a_{x}\right) \wedge\left(z \geq F_{\text {bot }}(x, y, 3)\right) \wedge\left(z \leq F_{\text {top }}(x, y, 3)\right) \\
& i \leftarrow 4 \text { if }\left(-a_{y} \leq y \leq \frac{-a_{g_{2}}}{2}\right) \wedge\left(-a_{x} \leq x \leq a_{x}\right) \wedge\left(z \geq F_{\text {bot }}(x, y, 4)\right) \wedge\left(z \leq F_{\text {top }}(x, y, 4)\right) \\
& i \leftarrow 5 \text { otherwise } \\
& i
\end{aligned}
$$

$$
\begin{aligned}
& \varepsilon_{\text {psum }}(x, y, z, a):=\mid \begin{array}{l}
i \leftarrow w(x, y, z) \\
\text { for } j \in 1 . .6
\end{array} \\
& A_{j} \leftarrow \int_{y_{O_{i}}}^{y_{f_{i}}} \int_{x_{0_{i}}}^{x_{f_{i}}} \int_{F_{b_{\text {bot }}}(u, v, i)}^{F_{\text {top }}(u, v, i)} \operatorname{star}(u, v, w, i)_{j} \cdot e^{i \cdot[\xi(r(a), s(a), t(a)) \cdot(X(x, y, z)-X(u, v, w))]} d w d u d v \\
& \text { for } j \in 1 . .6 \text { if } i=5 \\
& A_{j} \leftarrow 0 \\
& \text { A } \\
& \text { epsumn } 1:=\mid \begin{array}{l}
\text { for } \quad a \in 1 . . N_{\text {total }} \\
A_{a} \leftarrow \varepsilon_{\text {psum }}\left(-.001 \cdot m,-a_{y}, F_{\text {bot }}\left(-.001 \cdot m,-a_{y}, 4\right), a\right) \\
A
\end{array}
\end{aligned}
$$

Evaluation of the disturbance strain at a given point 
Evaluation of the disturbance strain by means of Equation (3.55)

$\varepsilon_{p}(x, y, z):=\frac{1}{V_{R V E}} \cdot \sum_{a=1}^{N_{\text {total }}} \operatorname{FSP}_{\xi}(a) \cdot W \cdot\left(\right.$ cpsumn $\left._{a}\right)$

epdata $:=\varepsilon_{\mathrm{p}}\left(-.001 \cdot \mathrm{m},-\mathrm{a}_{\mathrm{y}}, \mathrm{F}_{\text {bot }}\left(-.001 \cdot \mathrm{m},-\mathrm{a}_{\mathrm{y}}, 4\right)\right) \quad$ epdata $:=\left(\begin{array}{c}0.0001 \\ -0.00024 \\ 7.02796 \times 10^{-5} \\ 2.69811 \times 10^{-5} \\ 0.00045 \\ 0.00018\end{array}\right)$

$\sigma_{\text {effdata }}:=C_{m} \cdot W \cdot\left(\varepsilon_{0}+\right.$ epdata - estardata $)$

$\sigma_{\text {effdata }}=$\begin{tabular}{|l|r|}
\hline & 1 \\
\hline 1 & $2.46365 \cdot 10^{7}$ \\
\hline 2 & $1.17005 \cdot 10^{7}$ \\
\hline 3 & $1.37412 \cdot 10^{7}$ \\
\cline { 2 - 3 } 4 & $7.04875 \cdot 106$ \\
\hline 5 & $4.608 \cdot 106$ \\
\hline 6 & $-4.176 \cdot 106$ \\
\hline
\end{tabular}




\title{
Curriculum Vitae
}

133 Sun Valley Dr.

Morgantown, WV 26508
Phone (304) 594-9219

E-mail: tmdamiani@mail.wvu.edu

\section{Thomas M. Damiani}

\author{
Education \\ 2000 - present \\ West Virginia University \\ Morgantown, WV \\ Doctor of Philosophy - Mechanical Engineering \\ - Discipline - Solids, Mechanics, and Materials \\ - Research emphasis: Micromechanical modeling of fabric reinforced composites \\ - $\mathrm{GPA}-3.80$ \\ 1997 - $2000 \quad$ West Virginia University Morgantown, WV \\ Master of Science - Mechanical Engineering \\ - Discipline - Solids, Mechanics, and Materials \\ - Research emphasis: Long-term strength prediction of fiber reinforced composites \\ - $\mathrm{GPA}-3.70$ \\ 1993 - $1997 \quad$ West Virginia Wesleyan College Buckhannon, WV

\section{Bachelor of Science - Engineering/Physics} \\ - Minored in Mathematics and Economics \\ - $\mathrm{GPA}-3.43$ \\ Professional \\ experience \\ 1997 - present \\ West Virginia University \\ Graduate Research Assistant \\ - Research responsibilities \\ - $\quad$ Developing novel extensions of existing research in composite materials analysis \\ and property prediction \\ - $\quad$ Writing monthly progress reports to and preparing presentations for the funding \\ organizations. \\ - Writing, editing, and presenting papers to technical journals, conferences, and \\ contract sponsors \\ - Teaching responsibilities \\ - $\quad$ Led study sessions and graded homework and exams for undergraduate strength of \\ materials and statics courses.
}

\section{Teaching Experiences}

West Virginia University

\section{Undergraduate Courses Taught}

- MAE 243 - Strength of Materials (Summer II session 2002)

- MAE 243 - Strength of Materials (Fall semester 2002) 
Patents and

publications
Damiani, T.M., "Mesomechanics of Fabric Reinforced Composites," Proceedings of the Fourteenth U.S. National Congress of Theoretical and Applied Mechanics, Blacksburg, VA, June 2002.

Barbero, E.J. and Damiani, T.M., "Phenomenological Prediction of Tensile Strength of EGlass Composites from Available Aging and Stress Corrosion Data," Journal of Reinforced Plastic Composites, xxx $2003 \mathrm{xxx}-\mathrm{xxx}$

Barbero, E.J. and Damiani, T.M., "Interaction Between Static Fatigue and Zero-Stress Aging in E-glass Fiber Composites," ASCE Journal of Composites for Construction, Vol. 7, No. 1, Feb. 2003, pp. 3-9.

Damiani, T.M., "A Model to Predict the Long-Term Strength of E-Glass Fiber Composites Subjected to Environmental Exposure," M.S. thesis, West Virginia University, July 2000.

\section{Abstracts}

\section{SAMPE National Symposium, Long Beach, CA}

Damiani, T.M., "Mesomechanics of Fabric Reinforced Composites"

\section{Fourteenth U.S. National Congress of Theoretical and Applied Mechanics, Blacksburg, VA}

Damiani, T.M., "Mesomechanics of Fabric Reinforced Composites"
- Supplemental teaching fellowship recipient (2002-2003)

- $1^{\text {st }}$ Place Award - SAMPE 2002 Regional Student Symposium

- $4^{\text {th }}$ Place Award - SAMPE 2002 National Student Symposium

- National Collegiate Engineering Award winner (1997)

- Joseph E. Wiest Engineering/Physics Award winner (1997)

- Selected as captain of the men's track team (1995-1997)

- WVIAC Academic All-Conference Award (1995)

- Three-time WVIAC champion in the discus throw (1994-1996)

Society for the Advancement of Materials and Process Engineering (SAMPE)

American Society for Engineering Education (ASEE) 